

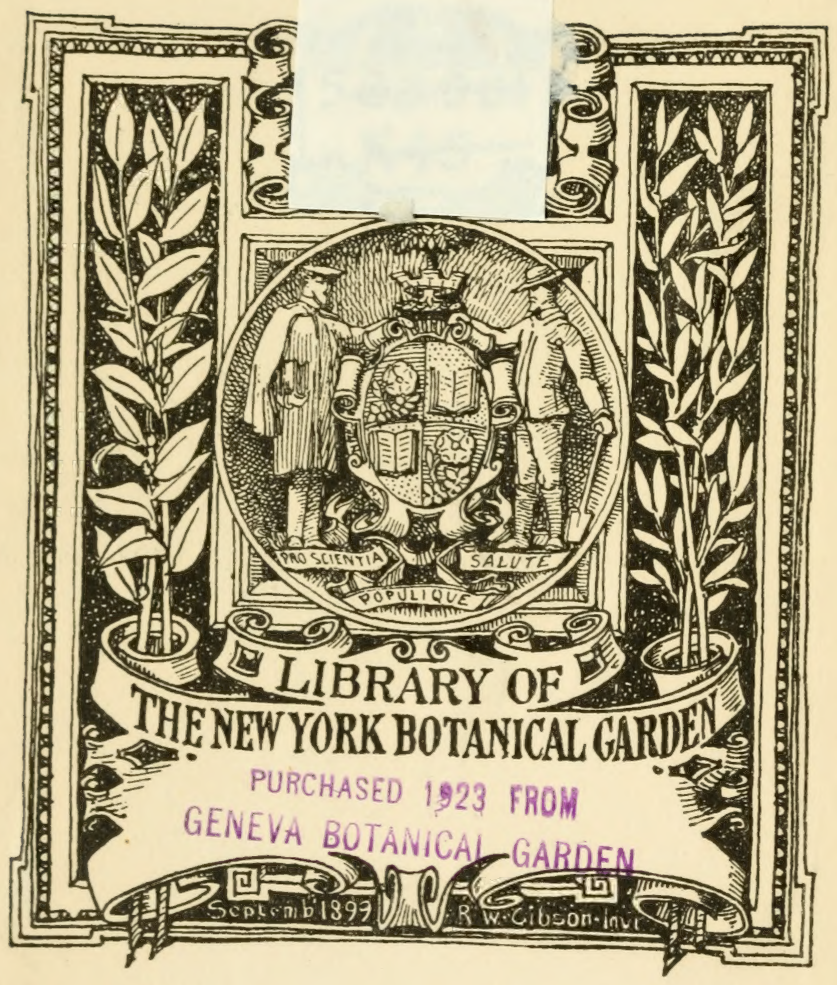


DUPLICATA DE LA BIBLIOTHÊQUE DU CONSFRVATOIRE BOTANIQUE DE GENEVE VENDU INT 1922 

Din or m, acy sinmioly $/ 913$

\title{
Niederösterreichische Weiden.
}

\author{
Von
}

\section{A. Kerner.}

Vorgelegt in der Sitzung: vom 3. August 1859.

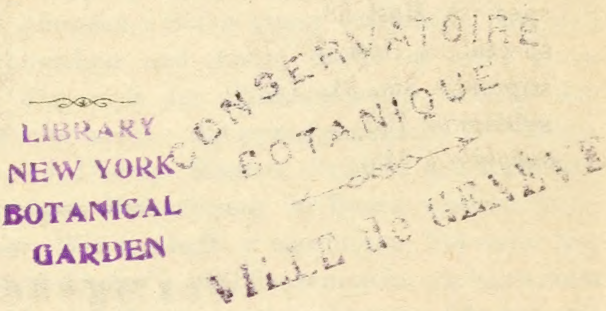

Separatabdruck aus den Verhandlungen der k. k. zool.-bot. Gesell:chaft in Wien, Jahroang 1860. I. Quartal.

$$
\begin{aligned}
& 10 ; 1.56,199.282 \\
& \text { DUPLICATA DE LA BIBLIOTHEQUE } \\
& \text { DU CONSERVATOIRE BOTANIQUE DE GENH } \\
& \text { VENDU TWN } 1822
\end{aligned}
$$

\section{Wien.}

Druek von Carl Ueberreuter.

1860. 


$$
\begin{aligned}
& \text { Q } 122 \\
& 53 \\
& \text { K4 }
\end{aligned}
$$




\title{
LABR A R : \\ NEW YORK \\ BOTAIHCAL \\ GARDEN
}

\begin{abstract}
"In temperatis et frigidiusculis hemisphaerae borea'is utrius. que continentis innumerce Salicis mira formarum inconstantia luxuriant botanicorum crux et scandalum."
\end{abstract}

Endlicher Enchir. bot. p. 178.

Die Ansicht, dass Planzen - Blendlinge in der freien Natur vorkommen und sich dort durch zufällige Veranlassung ebensogut bilden können, wie sic in den Gärten durch absichtliche künstliche Befruchtung entstehen, hat sich gegenwärtig allerwärts Bahn gebrochen und kaum dürfte es mehr einen Widersacher der Ansicht geben, dass viele der Pflanzenformen, welche den vielgestaltigen durch das dioicische oder andro - und gynodynamische Verhältniss ihrer Blüthen ausgezeichneten Weiden, Disteln, Münzen, Primeln und Habichts kräutern angehören, einer zweiartigen Befruchtung ihr Dasein verdanken. Nachdem die vor dem Forum der Wissenschaft wiederholten Versuche der Gärtner die Möglichkeit der Bastartbildung*) im Pflanzenreiche nachgewiesen hatten, glaubte man auch alsbald eine Menge wildwachsender Pflanzen als Blendlinge zu erkennen und suchte gewisse Regeln festzustellen, um für eine fragliche Pflanze den Nachweis ihrer Bastartnatur geben zu können. Einerseits sollten die Verhältnisse des Vorkommens, anderseits die Form und endlich die Unfruchtbarkeit als Anhaltspunkte zu diesem Nachweise dienen. Diejenigen Mittelbildungen, bei denen man eine ungleichartige Befruchtung vermuthete, sollten nur dort vorkommen, wo auch die beiden Stammformen, zwischen denen sie die Mitte hielten, sich finden, die Stammältern sollten zu gleicher Zeit blühen, die Blendlinge sollten nur vereinzelt und zerstreut angetroffen werden, sie solllen unfruchtbar sein und es sollten entsprechend den zwei Kreuzungen, welche zwischen zwei Pflanzenarten möglich sind, zwei Bastarte sich bilden, welche in den Zeugungsorganen der pollengebenden Stammart, in den Ernährungsorganen der samentragenden mehr ähnlich sehen.

\%) Nach Grimm: Bastart, nicht Bastard. 
Alle, welche über Bastarte ihre Ansichten verüffentlichten, sprechen sich endlich auch noch dahin aus, dass zur Erkennung der Blendlinge ein gewisser Scharfblick nothwendig sei, welcher diesen Pflanzen „die so zu sagen ihre Entstehung an der Stirne tragen" ihre Bastartnatur ansieht. Sobald aber die individuelle Ansicht des Beobachters mit in's Spiel gezogen wird, so ist auch die Möglichkeit gegeben, dass irrige Ansichten über den Ursprung einer Pflanze verbreitet werden und nicht selten scheinen auch Uebergangsformen, welche zwei klimatische oder geognostische Parallelformen einer und derselben Art verbinden, als Blendlinge angesehen worden zu sein.

Spätere Entdeckungen haben an den oben aufgezählten Sätzen der Bastartkunde gewaltig gerüttelt, so dass gegenwärtig keiner derselben mehr in seinem ganzen Umfange Geltung finden kann.

Nicht immer werden die Bastarte nur in der Nähe der Stammältern gefunden, sondern oft kommen sie weit entfernt von diesen oder in Gegenden vor, wo nur die eine der Stammformen gleichzeitig angetroffen wird. So findet sich z. B. eine Mittelform zwischen Salix purpurea und $S$. nigricans bei Lilienthal nächst Breslau, obschon in der näheren Umgebung dort keine $S$. nigricans angetroffen wird; ebenso wächst ein Blendling aus S. pentandra und fragilis im Wienthale bei Penzing, obschon auf viele Meilen weit keine S. pentandra dort aufgefunden wurde. Solche Erscheinungen können aber nicht gegen die Bastartnatur einer Pflanze sprechen, indem S. nigricans früher in der Nähe des zuerst erwähnten Bastartes vorgekommen sein mag, ebenso wie es möglich ist, dass $S$. pentandra im Wienerwalde in der Nähe des Standortes des Blendlings aus $S$. pentandra und $S$. fragilis vorkam, ja vielleicht noch vorkommt. - Von diesem. Standpunkte aus dürften die Bastarte manchmal sogar interessante Anhaltspunkte geben, aus denen man auf Veränderungen.schliessen kann, welche die Pflanzenwelt im Laufe der Zeit erlitten hat. Uebrigens bedarf es bei Pflanzen, deren Samen, wie jene der Weiden und Disteln ein Spiel des Windes sind und durch den leisesten Luftstrom weithin über Berg und Thal geführt werden, kaum der Annahme des früheren Vorhandenseins einer Stammart an dem Standorte des Bastarts. Auch darf bei Betrachtung solcher Fälle nicht unberücksichtigt bleiben, dass Bastartbefruchtungen besonders häufig durch Insekten, insonderheit Bienen herbeigeführt werden, welche den Pollen aus weit entlegenen Bezirken von Art zu Art verschleppen und insbesonders wird in Beziehung der Weiden von Wichura ${ }^{*}$ ) aufme.ksam gemacht, dass bei ihnen der Pollen nicht wie bei den Haselnüssen und Kiefern vom Winde umhergetrieben, sondern n u r durch Insekten der weiblichen Blüthe zugeführt wird. Jedermann, der im Frühlinge, wo die Weiden den Reigen der Blüthen eröffnen helfen, die um hre Kätzchen summenden Schwärme der Immen gesehen hat, und beobachtete,

*) Wichura: Ueber hünstlıch erzeugte Weidenbastarte. 31. Jahresbericht der schles. Gesellschaft für viterland. Kultur. Seite 160. 
wie diese, mit blüthenstaubbedecktem Pelze von Strauch zu Strauch sich forttummeln, der wird die Möglichkeit einer Befruchtung weit entfernter verschiedenartiger Blüthen nicht weiter bezweifeln, ja es wird sich ihm sogar unwillkürlich die Frage aufdrängen, warum die Bastarte nicht noch viel häufiger angetroffen werden, als es wirklich der Fall ist.

Die gleiche Blüthezeit der Stammältern ist allerdings zur Sicherstellung der Bastartnatur unumgänglich nothwendig, nur muss man hier gleichfalls zulassen, dass die beiden in Blüthe stehenden Stammarten weit von einander getrennt vorkommen können. - Die Reihe des Aufblühens läuft bei den Weiden ebenso, wie bei allen andern Pflanzen in einer ganz bestimmten Folge ab, die Mannigfaltigkeit der Standorte aber bedingt die Möglichkeit, dass Arten, welche sonst unter gleichen äusseren Verhältnissen in sehr verschiedenen Zeiträumen blühen würden, an zwei durch ihre Lage, Erhebung und Beschattung verschiedenen Punkten derselben Gegend zu gleicher Zeit ihre Blüthen entfalten können. Die Insekten werden sich nicht scheuen, die im kühlen Schatten blühenden Weiden gerade so zu besuchen, wie jene, welche in sonnigen windgeschützten Lagen aufgeblühet sind, ebenso wie sie im raschen Fluge in wenigen Augenblicken einen Höhengürtel durchmessen, an dessen oberem und unterem Rande bedeutende Unterschiede in der Zeit der Blüthenentwicklung vorkommen. Vielleicht mag es sich auch hieraus erklären, dass in gebirgigen Gegenden, wo durch die Mannigfaltigkeit der Bodengestaltung auch eine grössere Abwechslung der auf die Entwicklung der Pflanzen einwirkenden Verhältnisse bedingt wird, die Bastarte sich viel häufiger, als anderswo finden. In NiederOesterreich, dessen Weiden in diesem Aufsatze ihre Besprechung finden werden, war insbesondere der Reichthum an Blendlingen in den tief eingeschnittenen Alpenthälern, wie z. B. den engen Thalschluchten bei Gaming und Lunz auffallend; eben dort aber sahen wir auch auf der einen Seite des Thales Salix glabra in voller Blüthe und $S$. grandifolia längst abgeblüht, während an der gegenüberliegenden gegen Mitternacht gerichteten Berglehne die Kätzchen von S. glabra eben die Kno-penschuppen durchbrachen und S. grandifolia in voller Blüthe stand.

Das zerstreute und sparsame Vorkommen scheint unter allen zur Feststellung der Blendlingsnatur benützten Merkmalen noch das zuverlässigste zu sein. Nur wenige Weidenbastarte, wie z. B. jene von Salix alba und $S$. fragilis machen eine Ausnahme und stehen mehreren Arten, welche nicht hybriden Ursprungs sind, in ihrer Häufigkeit nicht nach. Diese Erscheinung - welche auch verursacht haben mag, dass sich Floristen, die bei anderen Weiden die Bastartnatur anerkennen, nicht entschliessen konnten, auch für diese Mittelbildungen den hybriden Ursprung gelten zu lassen - steht übrigens ziemlich vereinzelt da und für die Mehrzahl derjenigen Formen, welche wir für Blendlinge halten, trifft das Merkmal des zerstreuten und sparsamen Vorkommens gegenwärtig allerdings vollkommen zu. - Ob diese Blendlinge 
für immer ein solches beschränktes Vorkommen zeigen werden, ist eine Frage, auf welche wir später nochmals zurückkommen werden.

Die Unfruchtbarkeit wurde in früherer Zeit für einen der wichtigsten und sichersten Anhaltspunkte zur Erkennung eines Blendlings gehalten. Die Gärtner bestritten zwar längst diese Ansicht und beuteten sogar die Fruchtbarkeit der Bastarte thatsächlich aus, indem sie durch künstliche ungleichartige Befruchtung von Bastarten mit Stammältern so wie von Bastarten untereinander neue Formen hervorriefen; - die Männer der Wissenschaft jedoeh sträubten sich lange gegen die Annahme der Möglichkeit einer solchen Befruchtung, weil damit eines der wichtigsten Merkmale, auf das sich der Unterschied ron Art und Bastart *) stützte, aufgegeben werden musste. - In einem Aufsatze Alex. Braun's **) finden wir zuerst ausdrücklich hervorgehoben: dass Unfruchtbarkeit nicht immer ein Kennzeichen der Bastarte sei, da sie oft durch die eine oder andere der Stammarten befruchtet, Früchte und Samen zur Reife bringen - und in letzterer Zeit spricht sich auch Wimmer***) dahin aus, dass die Blendlinge keimfähige Samen zu geben im Stande seien. Die höchst dankenswerthen Versuche von Wichura†) haben für die Weiden die Keimfähigkeit der von Bastarten erzeugten Samen, so wie ihre Befruchtungsfähigkeit in früher nicht geahnter Ausdehnung sichergestellt und nicht nur die Möglichkeit der Kreuzung einer Stammart mit einer anderen Stammart, sondern auch eines Bastartes mit einem andern Bastarte und endlich einer Stammart mit einem Bastarte in allen möglichen Versetzungen nachgewiesen. - Allerdings scheint die Fruchtbarkeit sich nicht auf alle Blendlinge auszudehnen und von Wimmer und Wichura werden einzelne Weidenbastarte, z. B. jene von $S$. viminalis mit $S$. amygdalina, so wie von $S$. viminalis mit $S$. cinerea als unfruchtbar hervorgehoben. Solche Fälle bilden aber, verglichen mit der weit überwiegenden Mehrheit der Fälle von Fruchtbarkeit, Ausnahmen von der Regel und beirren um so weniger, als auch andere Pflanzen, die allen Anzeichen nach keine Blendlinge sind, keimungsunfähige Samen hervorbringen, ohne dass dafür ein Grund an. gegeben werden könnte.

So wie die früher festgehaltene Ansicht, dass die Blendlinge der Fruchtbarkeit entbehren, sich nicht bestätigte, ebenso konnte die Regel, dass die beiden Bastarte - welche zwischen zwei Stammarten entstehen, je nachdem die eine und die andere die Rolle der Pollengevenden spielt - sich dadurch unterscheiden lassen: dass jede derselben in den Zeugungs-

*) Wimmer äusserte sich Flora 18\%6, Seite 148: Wenn Bastarte auch bis zur Ausbildung des Embryo gelangten und auf diese Weise fruchtbar würden und sich fortpflanzlen, so wären sie bis zum Range von Arten fortgeschritten, also auf diese Weise wirkliche und zwar neue Speciez entstanden.

*:*) Flora oder allgem. bot. Zeitung IV. Bd, I. Seite $\boldsymbol{k}$. Seite 11 i⿱⺈.

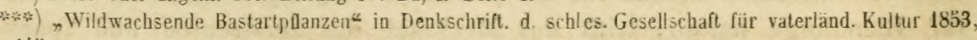

†) Wichura a. a. O. Seite 163 . 
organen der pollengebenden, in den Ernährungsorganen der samentragenden Stammart näher stehe, keine Geltung finden. Dass entsprechend der doppelten Polle, welche jede Stammart bei der Befruchtung spielen kann, auch zweierlei Erzeugnisse zwischen zwei Stammarten entstehen können, ist zwar nicht zu bezweifeln, die Form dieser Erzeugnisse aber im Vorhinein angeben - oder umgekehrt aus der Form auf die Rolle zurückschliessen zu wollen, welche die Stammältern bei der Erzeugung des Blendlings gespielt haben, sind wir auf Grundlage der bisherigen Erfahrungen nicht berechtigt und ein solches Verfahren ist daher zum wenigsten rerfrïht.

Die Zwischenbildungen, bei welchen wir in Berïcksichtigung ihrer Form und ihres Vorkommens einen zweiartigen Ursprung voraussetzen, halten en we de r genau die Mitte zwischen den muthmasslichen Stammältern oder sie neigen sich in ihrer Form mehr zu einer der erzeugenden Stammformen hin. Diese letzt ren, fir welche wir den Tamen goneiklinische *) Formen rorschlagen, haben in der Neuzeit eine doppelte Deutung erfahren. - Nachdem man sich wiederholt ïberzeugt hatte. dass die durch kïnstliche zweiartige Befruchtung erzielten Samen aus einem und demselben Blïthen-Köpfchen, ja selbst aus einer und derselben Kapsel gewöhnlich sehr rerschiedene Mittelbildungen liefern, ron denen einige dieser, andere jener Stammart näher stehen, tauchte die Ansicht auf, dass der Pollen auf die rerschiedenen Samenknospen eines und desselben Fruchtknotens mit ungleicher Befruchtungsliraft einwirken könne und dadurch ungleiche Erzeugnisse zu Tag bringe. Schon Gärtner hatte auf diesen ungleichen Einfluss hingewiesen, indem er sagte, dass häufig eine der Stammarten auf den Blendling einen ..typischen Einfluss" übt, so dass der Hlendling in seinen Merkmalen der einen Stammart dann viel näher stelit, als der zweiten. Versuche ron Grenier und Jordan bestätigten neuerlich diese Angabe, welche auch ganz allgemein ron den Gärtnern behauptet wird. Yon anderer Seite wurden jedoch diese goneiklinischen Blendlinge als Bastarte zweiter Ordnung angesehen, welche durch befruchtende Verbindung eines Bastartes erster Ordnung mit einer der Stammformen entstanden sind. Tamentlich scheint Schultz von dieser Toraussetzung ausgegangen zu sein. als er solche Formen mit einem Dreinamen (z B. Hieracium praealto - Pilosellu praealtum) bezeichnete. Diese Ansicht hat gleichfalls ihre Berechtigung und Begründung in den Ergebnis:en. welche die Versuche künstlicher Bastartirung zu Tage gefördert und die Möglichkeit, dass solche durch zweimalige Ǩreuzung entstandene Blendlinge auch in der freien Natur vorkommen. ist nicht in Abrede zu stellen. da dic Insekten die blïhenden Bastarte ebensogut besuchen werden, wie die Pflanzen, die keine Bastarte sind. - Aber auch für den Fall, dass die Befuchtung nicht immer durch Vermittiung der Insekten gedacht

*) Von goven's Erzenger und raivw himeigen. 
wird, ist bei den dioicischen Teiden die Fntstehung eines doppelt gekrenzten Blendlings in der freien Natur nichts weniger als unwahrscheinlich, weil nur selten Staub- und Fruchtblïthen tragende Sträncher eines und desselben Blendlings nebeneinanderstehen, sondern diese fast immer einzeln zwischen anderen verbreiteteren Arten angetroffen werden, so dass - wenn überhaupt cine befruchtende Verbindung der Blïthen untereinander wachsenden Teidenzweige ohne Uebertragung des Pollens durch Insekten stattfindet - sich ebensogut Stammart mit Stammart, wie Blendling mit Stammart verbinlen kann. - Jede dieser zwei Ansichten über die Bildung goneiklinischer Bastarte gründet sich auf Versuche, die keine Einwendung zulassen. Welchen Weg: .jedoch die Natur bei Bildung solcher Bastarte einschlägt, ob den in der ersten oder den in der zweiten Ansicht bezeichneten, ob rielleicht beide - muss vorläufig dahingestellt bleiben. Entschieden ist aber die Ansicht zurïckzuweisen, dass solche, einer der Stammformen sich nähernde Blendlinge als „Rückschläge" anzusehen seien. Man stellte sich nämlich ror, dass den durch zweiartige Befruchtung entstandenen Mittelformen, die gewissermassen als regclwidrige Bildungen zu betrachten seien, die Sucht innewohne, wieder in eine der Stammformen zurückzukehren und dass die Natur gezwungen sei, in den Artgrenzen zu bleiben, die sie sich einmal gezogen habe. - Obschon nun die Erfahrung lehrt, dass die Form einer Pflanze durch ä us sere Einflüsse wesentlich geändert werden könne, so müssen wir doch dic Möglichkeit, dass auch durch inneren Einfluss eine andere Formges'altung stattfinden könne, in Abrede stellen.

Jede Pflanze mu-s als ein Wesen aufgefasst werden, dem eine bestimmte Idee als Bildungsgesetz zu Grunde liegt, deren kürperliche Erscheinung eben die Pflanze selbst ist. Da die Idee der Form aber in einem nothwendigen Einklang: mit den äusseren Verhältnissen stehen muss, so werden sich bei Aenderung der örtlichen Einflüsse allerdings auch gewisse Merkmale der Pllanze ungestalten können, das Individuum aber als kürperliche Erscheinung der seiner Art zu Grunde liegenden Idee rermag auf diese sclbst nicht bestimmend einzuwirken und sie nicht zu ändern.

Dem ron zwei verschiedenen Pflanzenarten erzeugten neuem Keime muss in dem Augenblicke der Tereinigung gleichfalls ein bestimmtes Bildung'sgesetz eingepflanzt werden, das sich je nach der Stärke, nit welcher sich die beiden Stammältern betheiligten, bald mehr dem Vorbilde der einen Stammart, bald dem der andern anschmiegen wir.l. Das in dem Keim aber einmal gegebene Bildungsgesetz ist ron dem Augenblicke der Vereinigung ein bestimmtes und selbstständiges geworden und reımag. als Individuum körperlich in Erscheinung zu treten. Das Bastart-Individuum aber vermag auf seine eigene Gestaltung nicht einzuwirken, sondern folgt eben nothwendig dem ihm zu Grunde liegenden Gesetze. Der eimmal gebildete Blendling ist fortpflanzungsfähig, rermag sich also zu erhalten und muss gerade so als Art aufgefasst und ron dem Naturforscher a's solche 
beschrieben werden, wie eine andere selbstständige Form, die nicht im Verdachte eines zweiartigen Ursprunges steht, da derselbe uns von der Natur als bestimmte selbstständig gewordene Form geboten wird. - Der Begriff eines Blendlings ist von dem einer Stammform nicht anders, als durch den verschiedenen Ur:prung abzugrenzen - da aber der Ursprung bei den wildwachsenden Bastarten nur mit Rücksicht auf die Form gemuthmasst werden kann, da es überdiess denkbar ist, dass die Stammform selbst einst den Ursprung eines Blendlings gehabt hat und dass nur eines ihrer Stammältern ausgestorben sei, so ist a uch diese Grenze schwankend und unhaltbar.

Die Behauptung, dass die Bastarte nach einigen Generationen aussterben und dass, wie $K$ ant sagt: die Blendlingsart in mehr oder weniger Gliedern der Zeugung erlischt, kann nach den vorliegenden Erfahrungen eben so wenig bejaht, wie verneint werden. - Wenn wir die Pflanzenwelt nicht als ein Abyeschlossenes, sondern als ein in fortdauernder Veränderung, im steten Werden Begriffenes auffassen, so liegt es nahe, anzunehmen, dass die Natur auch den Weg der Bastartirung einschlage, um ihre Arten zu verrielfältigen, - oder wären die Blendlinge wirklich nur: „fruchtlose Versuche der Natur, sich mit ihren jetzigen Kräften zu neuen spezifischen Typen zu erheben".*) - Wir bezweifeln es. - Man hat zwar als auffallende Erscheinung hervorgehoben, dass die Bastarte gegenwärtig meistens nur in geringer Menge und in der Regel nur zwischen den Stammältcrn angetroffen werden und diese Erscheinungen als Beweise ang'esehen, dass der Erhaltung, Vermehrung und Verbreitung der Bastarte irgend welche noch unbekannte Hindernisse entgegenstehen müssen. Diese Erscheinungin sind aber eben die einzigen Anzeichen, durch welche wir gegenwärtig geleitet werden, eine im Freien vorkommende Mittelform als Bastart zu erklären. Sobald die Mittelform häufiger auftrilt und sich auch noch an Orten findet, wo die eine oder andere der verwandten zwei Arten fehlt, so nimmt man Anstand, sie als Blendling anzusehen und betrachtet sie als "gute Art". - Ist es nun aber nicht möglich, dass diejenigen Mittelformen, bei welchen man gegenwärtig aus dem sparsamen und zerstreuten Vorkommen auf cinen Blendling:-Ursprung schliesst, sich mit der Zeit weiter vorbreiten und rermehren? - Die Zeit, seit welcher man die Pflanzenbastarte rerfolgt, ist wohl viel zu kurz, als dass schon jetzt mit einiger Bestimmtheit hier eice Antwort gegeben werden könnte und es muss die Lösung dieser Frage der Zukunft vorbehalten bleiben.

Dass es übrigens eine gewisse Grenze der Bastart-Neubildung gebe, unterliegt wohl keinem Zweifel. Gewiss ist, dass nur verwandte Formen, die eine ,sexuelle Affinität" besitzen, durch ungleichartige Befruchtung Blend-

*) Nägeli: Die Cirsien der Schweiz. Neue Denkschriften der allem. Schweiz. Gesellschaft fir Naturw. Band 5. 
linge geben künnen. Aber auch unter diesen durch Verwandtschaft mit einander rerbundenen Pflanzengruppen, bei welchen bis jetzt Bastarte beobachtet wurden, scheint die Kreuzung nicht mit gleicher Leichtigkeit ein Ergebniss hervorzubringen. Die Grenze der Kreuzungsfähigkeit ist bis jetzt aber noch nicht genau festgestellt.

Durch die Versuche ron Wichura ist bewiesen, dass Blendlinge mit Blendlingen, ron denen jeder zwei anderen Arten seine Entstchung rerdankt, eine befruchtende Verbindung eingehen können und es wurden Pllanzen erzeugt, an welchen mittelbar vier rerschiedene Formen betheiligt waren. Die Erkennung solcher Bastarte iu der freien Natur dürfte übrigens selbst dem gewandtesten Beobachter eine unlösliche Aufgabe bleiben - und wenn wir den Gedanken der Möglichkeit, dass solche aus vier Stammformen herrorgegangene Bastarte selbst wicder unter einander sich kreuzen künıen, weiter spinnen, so sind wir an dem Punkte angelangt, wo es unmüglich wird, die Fornen durch Unterscheidungsmerkmale auseinander $\mathrm{zu}$ halten oder um mit Wimmer zu sprechen: die Formen fliessen dann chaotisch in einander und die Art rerschwindet. - Die Habichtskräuter scheinen uns allerdings ein Beispiel eines solchen Ineinanderfliessens zu geben und darauf hinzuweisen, dass bei gewissen Pflanzengattungen eine unendliche Reihe ron Blendlingen gebildet werden könne.

\section{Benennung der Bastarte.}

Entsprechend den rerschiedenen Ansichten über die Entstehung und die Bedeutung der Pflanzenbastarte waren auch die den Blendlingen gegebenen wissenschaftlichen Benennungen rerschieden. Die Mehrzahl der Botaniker hielt sich an die zuerst ron Schiede in Anwendung gebrachte Benennungsweise und bildete den Namen eines Bastartes durch Zusammensetzung aus den Namen der muthmasslichen Stammältern - Da man der Ansicht war, dass sich die pollengebende Stammart in den Zeugungsorganen, die samentragende in den Ernährungsorganen des Bastartes ausspreche, wollte man durch Vorsetzung des Namens der ersteren und Nachsetzung des. Namens der letzteren dieses Verhältniss ausdrücken und glaubte auf diese Weise die zwei Blendlinge $(a \vec{\sigma} b \subseteq)$ und $(b \vec{\sigma} a \subseteq)$ möglicht rollkommen bezeichnet zu haben. - Bald stellte sich aber auch das Bedürfniss heraus, diejenigen Bastarte, welche sich mehr der Form einer der Stammältern nähern, zu bezeichnen und ron der irrigen Ansicht geleitet, dass solche goneiklinische Blendlinge: „Rückschläge* zu den Stammarten seien, wurden sie unter dem Vorgange Nägelits auch fehlerliaft als ,formae recedentes" mit ( $a b)$ recedens ad $a$ u.s.f. bezeichnet; diejenigen Botaniker hingegen, welche in diesen goneiklinischen Bastarten das Ergebniss einer zweitmaligen Kreuzung eines schon rorhandenen Bastartes mit einer seiner Stammformen zu erkennen glaubten,

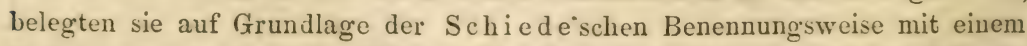
Dreinamen und so wurden Namen wie Hieracium Pilosella-praealto-Pilosellu u. dgl, gebildet. 
Da bei der Ermittlung der Stammältern einer in Freien gefundenen für einen Bastart gehaltenen Mittelform die, jedem Beobachter eigenthümliche Betrachtungsweise in's Spiel kommt, so ist natürlich auch die Möglichkeit gegeben, dass mit dem $\mathrm{Schiede}$ "schen Zweinamen eine irrige Ansicht über die Pflanze in die Welt geschleudert werden kann, deren spätere Berichtigung auch eine Aenderung des Namens nothwendig nach sich zieht. Auf diese Teise ist die Schiede"sche Benennung schon mehrfach die Ursache zur Entstehung eines sehr ülerflüssigen Synonymen-Ballastes geworden. Tenn schon bei den Bastarten einmaliger Kreuzung ein fehlerhafter Rückschluss auf die Stammältern und deren Rolle rorkommen kann, so wird ein solcher Schluss bei Bastarten, welche als das Ergebniss einer zweitmaligen Kreuzung eines schon rurhandẻnen Bastarts mit einer seiner Stammformen gedacht werden, um so leichter rorkommen künnen. - Wir bilden natürlich unser Urtheil über den Ursprung eines wildwachsenden Blendlings nur auf Grundlage der äusseren Merkmale, welche der vorliegenden fraglichen Pflanze eigen sind. Berücksichtigen wir aber die ganze Reihe ron verschiedenen Verbindungen, welche zwischen den beiden Stammarten $a$ und $b$ und den durch erstmalige Kreuzung entstandenen Bastarten ( $a \sigma^{\top} b \subseteq$ und $b \sigma^{*} a \mathbf{C}$ ) denkbar sind*). so müssten wir offen gestehen, das wir keinen, selbst nicht dem scharf.innigsten Beobachter zutrauen, aus der Form eines in der freien Natur aufgefundenen goneiklinischen Bastartes sich mit solcher Bcstimmtheit ein Lrtheil über die Entstehung zu bilden, dass er darnach im Stande wäre, der ạufgefundenen Pflanze auch mit Leberzeugung einen Platz in der unten angegebenen Reihe müglicher Terbindungs-Formeln anzuweisen. -- Der Nachtheil der S ch i ed éschen Benennungsweise: dass sich der Name zum Theil auf die individuelle und darum möglicherweise Irrungen unterworfene Ansicht des Beobachters stützt, ist hier fast unrermeidlich und es scheinen uns daher Namen, wie Hieracium piacalto-Pilosella-praealtum oder H. Pilosella-Pilosella-piaealtum u. dgl., abgesehen ron ihrer Hässlichkeit, ganz hergerichtet, um die Verwirung erst recht zu rermehren. - Dazu kommen noch folgende zwei Dinge zu berücksichtigen: Erstens, dass die Ansicht, es sei die pollengebende Stammart in den Zeugungsorganen, die samentragende in den Ernährung'sorganen des Lastartes ausgesprochen wie oben bereits erwähnt - keine hinreichende Begründung in der Erfahrung hat und zweitens, dass man bei den im Freien aufgefundenen groneiklinischen Blendlingen niemals wird entscheiden können, ob man es wirklich mit einern Erzeugniss der Kreuzung eines Bastartes mit einer seiner Stammältern zu

*) Den Bastart (
1. $4 \delta^{\top} a$
2. $A$ O
3. $A \sigma^{-1}, 0$
4. 1 웅
i. $I$ ठ
6. 1,00
7. $B O^{\top}, O$
S. $I$ O 1.5

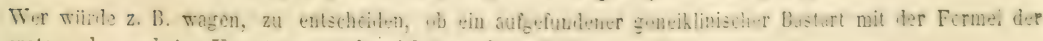
ersten oder sechsten Versetzung zu bezeiclinen sei. 
thun habe, oder ob die gefundene Pllanze nicht rielmehr durch ungleiche Betheiligung zweier Stammarten bei der Befruchtung entstanden sei. - Aus allen dem geht aber hervor: dass wir mit dem Namen, den wir einem wildwachsenden muthmasslichen Blendlinge geben, niemals ein bestimmtes Urtheil über den Ursprung des Blendlings verbinden dürfen. - Soll aber der Name auf den Ursprung der P'tlanze gar keinen Bezug haben und mit einem nach der $\mathrm{Sch}$ iedeschen Benennungsweise gebildeten Zwei- oder Dreinamen nichts weiter als das beiläufige Verhältniss der Form cines Bastartes zur Form der muthmasslichen Stammältern ausgedrückt werden, so künnte dort, wo nur ein, zwei, drei Zwischenformen in Mitte zweier Stammältern beobachtet werden, die Schiede sche Formel immerhin den der Pflanze gebührenden Art-Namen ersetzen; sobald aber eine ganze Kette ron Zwischenformen inmitten der Stammältern auftritt und jedes einzelne Glied dieser Kette entsprechend bezeichnet werden soll, ist die $\mathrm{Sch}$ iede'sche Benennungsweise durch Versetzung der Namen der Siammältern unzureichend, oder wenn sie rersucht wird, abgeschmackt und rerwirrend.

Neuere Systematiker, welche sich mit Bastarten beschäftigten und die der oben ausgesprochenen Ansicht sind, dass es bis jetzt nicht möglich sei, sich aus der form des Bastartes mit Sicherheit einen Rüickschluss auf die Rolle der Stammältern zu erlauben, legten auch der Vor- und Nachsetzung der Namen keine weitere Bedeutung bei und erkannten die Unzweckmässigkeit und Unzulänglichkeit einer Bezeichnung der goneiklinischen Bastarte durch blosse Verschiebung der Namen der Stammformen. - Um aber dennoch die Schiedesche Benennungsweise in Anwendung bringen zu können, fassten sie sämmtliche Glieder der Kette ron $Z$ wischenformen, welche inmitten $Z$ weier $S$ tammältern erscheinen, unter einem $Z$ weinamen zusammen und betrachtetendie einzelnen Glieder der Kette als Varietäten dieses Formeninbegriffes. So z. B. unterscheidet Wimmer ron Salix purpureaviminalis, welcher Name ihm gleichbedeutend mit Salix viminalis-purpurea ist, die Varietäten: b. Forlyana, c. sericea u. dgl. - Dieses Verfahren ist jedoch darum unzulässig, weil die einzelnen Glieder einer sulchen Kette nicht immer durch äussere Einflüsse bedingte Formabänderungen einer und derselben Art sind, sondern meistens selbst bestimmte selbstständig gewordene Formen darstellen, deren auch jeder dann ein Art-Name gebührt. *)

Neuerlich **) wurde von Grenier eine Bezeichnung der Bastarte auf Grundlage der Schiedeschen Benennungsweise in Anwendung gebracht, welche noch eine besondere Berücksichtigung verdient. Nachdem Gren ier in seiner Abhandlung anfänglich nachweist, dass die goneiklinischen Formen

*) Auf Varıetäten der Blendlingsarten werden wir später nochmals zurückkommen.

**) Annales des Sciences naturelles tom. XIX. Calier Nr. 3. 
sowohl das Ergebniss ciner Kreuzung eines Bastartes mit einer seiner Stammältern, als auch das Ergebniss einer ungleichen Befruchtungskraft (l'inégale action) des Pollens sein können und sich weiters dahin ausspricht, dass es schwierig, ja meistens unmöglich sei, die Rolle zu bezeichnen, welche die Aeltern bei der Befruchtung spielten, und so die pollengebende und samentragende Stammart herauszufinden, um nach der Vorschrift Schiede's den Zweinamen durch Vorsetzung des Vaternamens und Nachsetzung des Mutternamens zu bilden, so schlägt er vor, dass man in erster Linie immer den Namen jener Stammform stelle, welcher sich der Blendling am meisten nähert und dass man dort, wo wieder ein verschiedener Grad der Näherung rorkommt, diesen durch die Wörtchen super und sub ausdrücke. Gr enie r bringt hierauf seine Benennungsweise auf mehrere Fälle in Anwendung. Der letzte derselben, in welchem er eine ganze Reihe von Bastarten zwischen Cirsium rivulare und palustre zu benennen versucht, mag hier, da er alle anderen Fälle einschliesst, seinen Platz finden. Drei Blendlingsarten, welche dem C. palustie näher stehen, werden als C.palustri-rivulare bezeichnet und $z$ war nach dem Grade des Näherstehens als 1. C. superpalustirrivulare, 2. C. palustri-rivulare und 3. C. subpalustri-rivulare. Drei Formen, welche dem $C$. vivulare näher stehen, werden $C$. rivulave-palustie benannt und gleichfalls wieder nach dem Grade ihres Näherstehens als 1. C. superrivulare-palustre, 2. C. rivulare-palustre und 3. C. subrivulare-palustire unterschieden. Darnach entwickelt sich die ganze Reihe:

1. Cirsium superpalustri-rivulare,

2. $"$ palustri-rivulare,

3. $"$ subpalustri-rivulare,

4. " superrivulare-palustre,

5. $"$ rivulare-palustive,

6. $\gg$ subrivulare-palustre.

Grenier meint zum Schlusse, dass sich nur selten sechs Verbindungen hinreichend durch ̈̈ussere Merkmale unterschieden in der Natur vorfinden und dass man dieselben werde auf rier zurückführen können, indem die Verbindungen 3 und 4, so wie die Verbindungen 1 und 6 in ihrer Form häufig zusammenfallen. - Diese Anwendung der S c hied e schen Benennungsweise auf die goneiklinischen Formen hat jedenfalls ror den früher besprochenen ähnlichen Versuchen von $\mathrm{Nägeli}, \mathrm{Schultz}$ und Wimmer einige Tortheile. Sie erweckt in uns nicht eine irrige Ansicht über die Lebensgeschichte der Blendlinge, wi diess durch die Nägelïsche Bezeichnung nit "recedens" geschehen würde; sie schliesst auch kein falsches Urtheil über den Ursprung des Bastartes ein, wie das bei der Schultz schen Bezeichnungsweise möglich ist, da sie es dahingestellt sein lïsst, ob eine goneiklinische Form durch grössere od (r geringere Befruchtungskraft der cinen Stanmart entstanden oder aber das Ergebniss der Kreuzung eines Bastartes mit einer seiner Stammformen sei, -- sie hat endlich ror der Wimmer schen 
Bezeichnungsweise den Tortheil, dass sie den goneiklinischen Formen ihre Selbstständigkeit wahrt und nicht Anlass giebt, sie irrigerweise als Varietäten aufzufassen. - Demungeachtet ist auch diese Bezeichnungsweise unzureichend. - Wenn goneiklinische Formen durch ungleiche Einwirkung des Pollens entstanden gedacht werden, so müssen wir, um logisch zu sein, zwischen $a \sigma^{*}$ und $b \subseteq$ eine ganze Reihe ron Blendlingen zulassen, deren einzelne Glieder desto ähnlicher der Stammform $l$ sind, je schwächer die Einwirkung des Pollens von $a$ war und die desto älınlicher der Stammform $a$ sein werden, je gewaltiger der Eingriff ron a gewesen ist. Huldigen wir der zweiten Ansicht, der zu Folge ein goneiklinischer Bastart das Erzeugniss der befruchtenden Verbindung eines Blendlings mit einer seiner Stammältern ist, so müssen wir gleichfalls die Möglichkeit des Daseins ron mehr als zwei in ilırer Form rerschiedenen zu $a$ und ebenso rieler zu $b$ hinneigender Bastarte zulassen, wenn wir auch behaupten, dass es nicht möglich ist, nach der Form

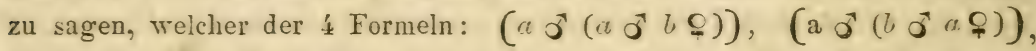

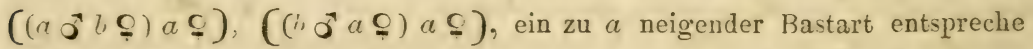
Nach der Grenier'schen Bezeichnungsweise müssten aber in allen jenen Fällen, wo mehr als sechs durch äussere Merkmale unterscheidbare Glieder der Blendlingskette zwischen $a$ und $b$ rorkommen, zwei und mehrere spezifische Formen unter einen Namen zusammengefasst werden, was rom naturhistorischen Standpunkte nicht zulässig ist. Wenn auch solche Fälle nur selten rorkommen dürften, so ist doch ihre Möglichkeit nicht in Abrede zu stellen und bereits durch die Erfahrung bestätigt. - Ebenso dürfen wir uns nicht rerhehlen, dass in jenen Fällen, wo nur eine einzelne goneiklinische Form rorliegt, diese Bezeichnungsweise nur sehr unsicher angewendet werden kann. Gesetzt, es würde ein einzelner Bastart zwischen Salie retusa und S. herlacea gefunden werden, welcher sich in seiner Form mehr zu der ersten Stammart hinneigt, so wüssteil wir im Vorhinein nicht anzugeben, ob derselbe als S. superretusa-herbaren, S. rehrst-herbarea oder S. subretusa-herbacea zu bezeichnen sei und es wäre müglich, dass, nachdem wir denselben als $S$. retusa-heibacea bezeichneten, nachträglich beim Bekanntwerden ron weiteren Gliedern der Reihe sein Name in S. superretusa-heibacea umgewandelt werden nüsste. - So wenig aber die Bezeichnung einer Pflanze in uns Vorstellungen über den Ursprung, die Bedeutung und die Lebensgeschichte erwecken darf, so lange diese nur in das Dunkel der Muthmassungen gehüllt sind, ebensowenig darf der Name einer Planze so formulirt sein, dass er durch spätere Entdeckungen zur Unwahrheit werden kann. Das ist aber immer der Fall, wenn mit einem Namen nach der Grenierschen Methode ein Glied aus einer Reihe bezeichnet werden soll, die wir noch nicht rollständig kennen.

Aus dem Allem geht herror, dass die Schiede"sche Benennungstreise in allen Abänderungen unzureichend ist. - Gestïtzt auf die früher Seite 8 
ausgesprochene Ansicht, dass den Blendlingsarten der Werth einer Art nicht abzusprechen ist und dass die Grenze zwischen denjenigen Arten, bei welchen wir, aus der äusseren Form und dern Torkommen muthmassen, dass sie eines zweiartigen Ursprungs seien und jenen, bei welchen keine der gegenwärtigen Erscheinungen auf einen solchen Ursprung hinweist, eine sehr schwankende sei, werden wir auch in der nachfolgen len Beschreibung der niederösterreichischen Weiden die muthmasslichen Blendlinge ebenso wie die als unzweifelhafte Arten allgemein anerkannten Formen mit Art-Namen bezeichnen. Bei den Arten mit wahrscheinlicher Bastartnatur, soll das Verhältniss der Form zu den muthmasslichen Stammältern durch eine nach der Grenier-Schiede'schen Bezeichnungsweise gebildete und der Beschreibung des Bastartes rorangeschickte Formel ausgedrückt und dem Artnamen das von Reichenbach zuerst für Blendlingsarten in Anwendung gebrachte Zeichen $\approx$ rorgesetzt werden. Dieses Verfahren ist nicht cine Neuerung, sondern wurde und wird ron ausgezeichneten Botanikern, welche auch das Torhandensein ron Pflanzenbastarten in der freien Natur durchaus nicht in Abrede stellen, mehrfach ausgeführt und ist nach unserer Ansicht das cinzige, durch welches wir einer sonst unvermeidlichen Verwirung der Nomenklatur rorbeugen künnen. Auch ron Wimmer wurde diese Art der Bezeichnung in dem Texte, der seinem Herb. Salic. beigeschlossen ist (siehe Fasc. VIII.) bereits in Anwendnng ge-

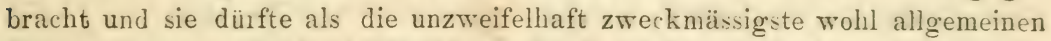
Eingang finden.- Bei den im Nachfolgenden beschrieb: nen niederösterreichischen Weiden stellte sich nur für wenige die Nothwendigkeit heraus, sie mit neuen Namen zu belegen. Die Mehrzahl fand sich bereits ron älteren Autoren mit Artnamen rerüffentlicht. Wenn es gestützt auf Originalexemplare möglich war, die Gleichheit einer der aufgefundenen Weiden der niederösterreichischen Flora mit jenen Formen, auf welche sich die älteren Artnamen bezogen, herzustellen, so wurden diese natürlich wieder in Anwendung gebracht und man wird daher mehrere halb verschollene Namen ron Tausch und Host wieder an ihren Platz gesetzt finden.

Die zurorkommende Güte, mit welcher mir Herr Direktor Fenzl die Schätze des kais. botan. Hofkabinetes, der Vorstand der k. k. zoolog-botan. Gesellschaft, dann Herr Oberlandesgerichtsrath Jeilreich und Herr Dr. Reichhardt ihre Herbarien zur Verfügung stellten, machte es müglich, die Weiden des Herb. nom. ron Fries, jene des Herb. salicum ron Wim mer, die Original-Exemplare zu Neilreichs Flora von Nielerösterreich, die Tauschischen Weiden, jene des Host'schen Gartens u. s. f. zu vergleichen. Es sei mir gestattet, den genannten Herren für ihre freundliche Unterstiitzung meinen besten Dank auszudrücken und ihre Namen im Nachfolgenden neu beschriebenen Weiden beilegen zu dürfen. 


\section{Begrenzung der Weidenarten.}

Bei Begrenzung jener Weidenarten, deren Form und Vorkommen keinen $z$ weiartigen Ursprung muthmassen lässt, bin ich im Allgemeinen Wim mern gefolgt, dem das grosse Verdienst zukommt, durch richtige Erkennung der in der freien Natur vorkommenden Blendlingsarten die Stammarten der Weiden auf eine rerhältnissmässig kleine Zahl zurückgeführt zu haben. Auch in Beziehung der Begrenzung der Varietäten schliesse ich mich an ihn an und huldige namentlich auch seinem Ausspruche, dass gewisse Formen als "Parallelformen" anzusehen seien - kann mir aber nicht versagen, im Nachstehenden meine Ansichten über Art und Varietät einzuschalten, da sie die Grundlage der im früheren ausgesprochenen Ansicht über den Werth und die Bedeutung der Blendlingsarten bilden.

Jede lebende Pflanzenart hat die Fähigheit, Stoffe, die ausser ihr liegen, in Form einfacher Verbindungen aufzunehmen und aus ihnen zusammengesetztere Verbindungen $\mathrm{zu}$ bilden. Das Vorbild dieses Bildens ist kein zufälliges, sondern ein nothwendiges, ein bestimmtes und die bestimmt gestaltende Kraft liegt in jedem kleinsten Theil der lebenden Pflanzenart.

Wir sthen, dass diese Kraft von Zelle auf Zelle fort und fort übertragen wird, so wie wir umgekehrt von Zelle auf Zelle, von Individuum zu Individuum diese gestaltende Kraft durch frühere Zeiträume zurückverfolgen können und sie uns bis zu einem Lranfang gleich bleibend denken müssen. Die Pflanze folgt bei dieser Bildung allerdings physikalischen und chemischen Kräften, und die ron ihr erzeugten Produkte hat man zum Theil sogar ziunstlich aus unorganischen Substanzen zu erzeugen rermocht, - dennoch lassen sich die Resultate, welche die lebende Pflanze erzielt, durch die physikalischen und chemischen Kräfte allein nicht erklären, namentlich ist es unmöglich anzugeben, warum jede Pflanzenart andere aber inmer b e st im m te V e r bind un ge n bildet. Der Grund dieser bestimmt gestaltenden Lebenskraft ist die für jede Pfianzenart bestimmte F orm-I d e e. Durch sie hat der Stoff seine bestimmte chemische Qualität, sie ist der Inbegriff aller Kräfte und Eigenschaften, die einer bestimmten Qualität des Stoffes zukommt und durch sie tritt dieser Stoff unter gegebenen $\ddot{a}$ usseren Umständen auch in seiner ihm eigenthümlichen Form nothwendig in Erscheinung. Da die Form-Idee im Stoffe sich nur unter gegebenen äusseren Umständen verwirklichen kann, so muss sie mit diesen äussern Umständen im Einklang stehen, und bei Betrachtung der rerwirklichten Form-Ideen, d. i. in unserem Falle der lebenden pflanzlichen Körper, müssen auch diese äusseren Umstände oder Lebensbedingungen in Betrachtung gezogen werden.

Dass jede Pflanze wirklich auch eine chemisch bestimmte sei und dass ihre chemische Eigenthümlichkeit die Form setzt, dürfte keinem Zweifel unterliegen und es findet diese Ansicht ilhre Stütze einerseits in den bezüglichen Verhältnissen der unorganischen Natur, andererseits in der Erfahrung an den Pflanzen selbst. - Die Gesetze der organischen Natur künnen dem Wesen 
nach keine anderen scin, als jene der unorganischen, nur sind sie bei den Erzeugnissen der letzteren klarer und erkennbarer, als bei den im exwigen Wechsel befindlichen pflanzlichen und thierischen Organismen. - Yan hat bei den unorganischen Körpern zuerst den Einklang der Form mit der chemischen Konstitution mehr gewïidigt und gefunden, dass es nichts chemisch Verschiedenes gebe, was nicht auch durch naturhistorische Merkmale unter schieden werden könnte. Auch der umgekehrte Satz: dass alles, was durch Merkmale der Form unterschieden werden kann, in seiner chemischen Grundlage rerschieden sei, ist mit Ausnahme der später noch zu besprechenden polymorphen Substanzen als Regel für die unorganischen Kürper anzusehen, und so rerschleiert auch noch Fieles in Beziehung auf diesen Zusammenhang ron Gestalt und chemischer Zusammensetzung sein mag, so scheint doch ihr wechselseitiges Bedingenen ganz ausser Zweifel zu sein. - Die Erfahrung giebt uns rielfache Anhaltspunkte, diesen für die unorganische Natur geltenden Zusammenhang auch auf die Pflanzenwelt anzuwenden. Die organische Chemie bereichert ron Tag zu Tag die Wissenschaft mit Ergebnissen, welche eine Bestätigung der Ansicht geben, dass die chemische Qualität jeder Pflanzenart eine bestimmte sei und dass die durch den Begriff der Familie ron den Systematikern ihrer Furmähnlichkeit halber rerbundenen Arten auch durch ähnliche chemische Verbindungen sich auszeichnen. Aber selbst dort, wo die organische Chemie uns noch keinen Aufschluss über den Zusammenhang der chemischen Konstitution verwandter Pflanzenformen gegeben hat, liefern uns anderweitige Erfahrungen wichtige Anhaltspunkte. - Bekannt ist, dass die meisten Insekten bestimmte Nahrungsstoffe haben, oftmals nähren sie sich nur ron einer einzigen Art, häufig aber auch ron mehreren, - im letzteren Falle aber sind es regelmässig rerwandte Pflanzenformen und um nur ein bekanntes Bei-piel zu erwähnen, sei hier der Lutta vesicatoria gedacht, welche als Nahrungspflanzen die rerschiedenen Eschen. und Fliederarten. so we den Liguster - also drei Pflanzengattungen aufsucht, welche auf den ersten Blick scheinbar unähnlich. sich erst bei näherer Betrachtung als formrerwandt herausstellen und sicherlich in ihrer stufflichen Grundlage ein entsprechendes Verwandtschafts-Verhältniss zeigen. - Auch das Gleichbleiben des Geschmackes und Geruches bei einer und derselben Pflanzenart ist ein schlagender Beweis, das; jede Pflanzenart immer nach derselben Schablone arbeitet, dass die in ihr sich bildenden Verbindungen für jede Art bestimmt sind, dass mit einem Tort ihre cheni-che Qualität immer eine und dieselbe ist. Wenn man für viele Pflanzenarten in botanischen Werken den Ausdruck ,.chemisch indifferent" in Anwendung bringt und damit bezelchnen will: dass die organische Chemie bis jetzt keine beronderen eigenthümlichen Verbindungen nachzuweisen rermochte und dass diesc Pflanzen auf unsern Geschmacks- und Geruchssinn niclit eigenthümlich einwirken, so beweist das noch nichts für das Fehlen solcher eigenthiumlichen Verbindungen - und wir zweifeln nicht. dass erneuerte chemische Unter- 
suchungen diesen Ausdruck mit der Zeit wohl voll-tändig zu rerbannen im Stande sein werden.

Wenn nach dem Obigen also jede Pflanzenart durch die Form-Idee eine bestimmte chemische Qualität hat und durch sie befähigt ist, die ausser dem pflanzlichen Organismus befindlichen einfacheren Verbindungen in sich aufzunehmen und zu einem sich Gleichartigen zu rerbinden und zu gestalten, so bedarf die Pflanze zu ihrer erneuernden Gestaltung zunächst der Materialien zur Neubildung, sie bedarf jener Elemente, welche sie zu zusammengesetzteren ihr eigen!hümlichen Verbindungen umbilden soll. - Bekanntlich sind diese Materialien zunächst die vicr Grundstoffe: Kohlenstoff, Sauerstoff, Wasserstoff, Stickstoff, welche in sehr einfachen Verbindungen so weit und noch weiter rerbreitet sind als die Ptlanzenwelt, und dann einige wenige unorganische in dem Boden befindliche Salze. Trotz der geringen Zahl dieser Baustoffe, ist bei dem Unstande, dass die chemische Konstitution der Verbindungen durch verschiedene Quantität der einzelnen in Verbindung eingehenden Grundstoffe eine rer chiedene wird, die Anzahl der denkbaren organischen Terbindungen eine unendliche, und die Anzahl der bis jetzt bekannten ist wohl erst ein Bruchtheil der noch aufzufindenden. - Die Anzahl der rerschiedenen ron der Natur gebotenen Pllanzenformen aber bleibt weit hinter der unendlichen Reihe denkbarer rerschiedener chemischer Qualitäten zurück und ist - wenigstens für jede Zeit - eine abgegrenzte.

Bei ungeänderten äusseren Bedingungen rerwirklicht sich die einmal gesetzte Form-Idee nothwendig fort und fort in glcicher Form. Findet die Pflanze die zu ihrer Fortbildung hinreichende Quantität und die ungeanderte Qualität der chemischen Baustoffe, so wie die entsprechenden Wärme- und Lichtrerhältnisse, so wird das Neugebildete dem Bildenden nothwendig gleichgestaltet sein. - Fine rermehrte Quantität dieser äusseren Bildungsbedingungen wird grössere Ueppigkeit, eine Ver minderung wird Zwerghaftigkeit bedingen. - Reich- und; armblüthige, breit- und schmalblättrige u. d. g. Formen können so aus einer und derselben Grundlage hervorgehen, ohne dass diese darum ihre chemische Qualität und ihre eigenthümliche Form aufzugeben brauchten.

Aendert sich jedoch die Qualität der Lebensbedingungen der Pflanze, so wird diese Aenderung entweder eine erneuerte Gestaltung ganz unmöglich machen oder eine Ungestaltung der Form zur Folge haben.

Eine Aenderung jencr Reihe ron chemischen Elementen, a us welchen die Pflanze die Hauptmasse ihres Körpers bildet, nämlich des Kohlenstoffes, Sauerstoffes, Wasserstofles und manchmal auch des Stickstoffes, die der Pflanze in der Kohlensäure, dem Wasser und dem Ammoniak geboten werden müssen, würde die Weiterentwiclielung gänzlich hemmen - nicht so aber auch eine Aenderung derjenigen Grundstoffe, welche ron der Pflanze als Salze aus dem Boden aufgenommen werden, urid wenn daher ron einem formändernden Einflusse, 
der von der Pflange aufgenommenen Nahrungsmittel die Rede ist, so kann sich das nur auf diese aus dem Boden aufgesogenen Salze beziehen.

Die Rolle, welche diese in Beziehung auf die chemische Qualitiit der Pflanze spielen, kann eine doppelte sein. Sie gehen entweder in die für die Pflanzenart eigenthümlichen Verbindungen ein und bilden einen wesentlichen Bestandtheil einer oder mehrerer dieser Verbindungen - oder sie sind nur unwesentliche Beimengungen, und es fragt sich nun weiter, welchen Einfluss sie je nach dieser doppelten Rolle auf die Form der Pflanze haben können. -

Die Betrachtung unorganischer Körper lehrt, dass die Grundstoffe und die chemischen Verbindungen selbst dann in bestimmten ihnen zukommenden Formen erscheinen, wenn andere nicht zur Qualität ihrer Substanz gehörige Stoffe beig emengt sind, wenn anders diese Beimengung eine gewisse Grenze. nicht ïberschreitet. Diese Grenze scheint für jeden Grundstoff und jede Verbindung eine bestimmte zu sein. Eines der auffallendsten Beispiele ist jedenfalls der kohlensaure Kalk, der selbst dann in seiner eigenthümlichen Kristallform erscheinen kann, wenn ihm 63\% Quarzsand beigemengt sind. Für die Mehrzahl der Verbindungen würde zwar eine solche bedeutende Beimengung eine Behinderung der Formung sein, - gewiss aber ist, dass alle ron der Vatur geformt gebotenen Grundstoffe und Terbindungen mehrerer Grundstoffe Beimengungen enthalten können, welche wie schon Linné meinte, in die der Hauptrerbindung eigenthümliche Form gleichsam eing'ezwängt werden. - Mehrfache Versuche haben gezeigt, dass solche Beimengungen zwar nicht die Bestimmtheit der Form ändern, dass die kristallografische Bestimmtheit der Substanz nicht gestört werde, dass aber verschiedene zu einer und derselben kristallografischen Einheit gehörige, demselben Kristallsystem und derselben Kristallreihe sich unterordnende Formen hervorgebracht werden. So z. B. kristallisirt Salmiak aus reiner Lösung in Oktaëdern, in Folge der Beimengung eines Kupfersalzes in Kombination ron Würfel und Oktaëder und nach Beimengung ron Harnstoff in Würfeln; - aus einer reinen Lösung des doppelapfelsauren Ammoniaks kristallisirt diese Verbindung in rhombischen holoëdrischen Kristallformen heraus, ist aber die Lösung durch Erhitzung etwas zersetzt und eine geringe Menge des Zersetzungsproduktes beigemengt, so erscheinen an den Kristallformen auch hemiëdrische Flächen; - Alaun kristallisirt aus neutralen Lüsungen in Oktaëdern, aus alkalischen Lüsungen in Würfeln. -

Ganz ähnlich wie bei den unorganischen Körpern findet man auch bei den pflanzlichen Organismen unwesentliche Beimengungen, welche ron den Pflanzen mit den anderen Materialien, die sie zur Neubildung ihrer Substanz nothwendig bedürfen, aufgenommen werden. Eine solche Beimengung wird jedoch hier ebensowenig wie in der unorganischen Natur im Stande scin, die Wesenheit der chemischen Qualität der Pflanze aufzuheben, sie wird die Form-Idee, nach welcher die Pflanze als bestimmte Art erscheint. nicht 
gründlich ändern, wohl aber werden durch sie geringe Modificationen in der erscheinenden Pllanze bedingt werden künnen, die sich so lange trhalten, als die Beimengung in die Pllanze gelangt. - Auf einem mit Kochsalz geschwängerten Boden bekommen Pflanzen, welche nicht halophil sind, fleischige Blätter, ohne dass darum die Grundform geändert würde. Ebenso modifizirt sich die Form vielsr Pflanzen, je nachdem sie auf kalkreichem oder kalkfreiem Boden wachsen. Sie werden sich auf den zweierlei Bodenunterlagen gewissermassen vertreten und ersetzen und künnen als Parallelformen aufgefasst werden. Ihre Verschiedenheit dauert so lange, als die Verschiedenheit der Beimengung andauert, - die eigenthümliche Grundform der Pflanze wird jedoch eben so wenig geändert, als die sie bedingende chemische Qualität in ihrer Wesenheit eine Aenderung erleidet.

Für manche Gewächse scheinen übrigens diese Elemente, welche aus dem Boden in Form von Salzen aufgenommen werden, nicht die Rolle von Beimengungen zu spielen, sondern einen wesentlichen Bestandtacil jener chemischen Verbindungen zu bilden, welche eben für die bestimmte Pflanzenart charakteristisch sind und ihre chenischo Qualität bilden. Das Fehlen eines solchen Elementes in einer Bodenart macht diese nicht immer untauglich, dass sich in ihr jener pflanzliche Organismus weiter bilde, in dessen eigenthümliche Verbindungen das fehlende Element eingehen sollte, indem das eine Element durch ein anderes, das der Boden liefert oder durch organische Radikale ersetzt zu werden scheint. Die so entstehenden Substitutionsprodukte werden natürlich denselben Zusammensetzungstypus, dieselbe Molekularanordnung haben, und so wenig der Charakter der Stammverbindung verloren geht, so wenig wird auch der Charakter der Form in dem pflanzlichen Organismus verloren gehen, in welchem die Substitution stattgefunden hat, obschon es wahrscheinlich ist, dass durch sie gewisse Aenderungen in den äusseren Merkmahlen bedingt werden. Es werden auf diese Weise gleichfalls Parallelformen einer und derselben Art entstehen kömnen.

Wir haben vorläufig keinen Anhaltspunkt um zu unterscheiden, ob bei vorliegenden Parallelformen, die durch andere Bodenverhältnisse bedingt sind, die Abweichung der einen Form von der anderen durch Substitution eines Elementes in der charakteristischen chemischen Verbindung oder nur durch Beimengung eines Stoffes bedingt werde, - gewiss ist aber, dass solche Parallelformen rielfach vorhanden sind. Schon $Z$ ahlbrukner*) hat auf dieselben aufmerk:am gemacht uud später ist durch Unger, Schnitzlein, $\mathrm{S}$ e $\mathrm{n} \mathrm{t} \mathrm{n}$ er und Andere auf den wichtigen Einfluss des Bodens auf die Pflanzen und die durch die chemische Eigenthümlichkeit der Unterlage bedingte Formverschiedenheit vielfach hingewiesen worden.

*) Darstellung der ffflanzengengraphischen Verhältnisse des Erzherzagthums Oesterreich unter der Euns in den Beiträgen zur Landeskunde Oesterreichs unter der Enns. I. Seite $2 * 2$. 
Nächst dem Boden vermag aber auch der Sonnenstrahl Parallelformen einer und derselben Art herrorzurufen. - Es ist unzweifelhaft, dass durch den Einfluss ron Licht und Wärme, insoferne durch sie die ron der Sonne ausgehende bewegende Kraft übertragen wird, die Anregung zur Zerlegung so wie zur Neubildung chemischer Verbindungen gegeben wird. Die Wärmestrahlen so wie die Lichtstrahlen, beide bedingen eine ganze Welt ron Erscheinungen in der organischen und unorganischen Natur und sind "die beiden hohen Dio kuren, durch deren Einfluss und Vermittlung ganz insbesondere das pflanzliche Leben gedeiht."

Indem die Wärme bewegende Kraft auf die Pflanze überträgt, regt sie diese fort und fort an, die ausser ihr befindlichen Elemente aufzunehmen und dieselben sich zu verähnlichen, - sie wird aber auch selbst in der Pflanze latent, "geht gewissermassen in die Verbindung der Molekular-Aggregate über, welche wir Körper nennen." - Die chemische Umbildung in der Pflanze, die der Hauptsache nach als Desoxydation aufgefasst werden muss, ist wie früher erwähnt wurde, für jede Art eine bestimmte, da aber Desoxydation immer eine Wärme-Absorption oder Kraftaufnahme zur nothwendigen Folge hat, so wird die Menge der aufgenommenen Wärme in einem Einklang mit der jeder Pflanze eigenthümlichen chemischen Umbildung stehen müssen und durch die in Verbindung eingehende bestimmte Quantität der Wärme wird die chemische Qualität der Verbindung auch eine physikalisch bestimmte. - Die periodische Entwicklung der Pflanzen über welche ron $\mathrm{De}$ Candolle in seiner Geographie botanique und neuerlich von Hermann Hoffmann in seinen Grundzügen der Pflanzenklimatologie eine Reihe der interessantesten Beobachtungen rorliegen, weisen alle darauf hin, dass jeder Pflanze ein bestimmtes Wärmemass zukomme. Eine Aenderung dieses Lebensbedürfnisses der Pflanze wird nicht immer ein Aufhüren des Organismus nothwendig nach sich ziehen, wohl aber eine Aenderung seiner physikalischen Qualität hervorrufen und in so ferne auch die Form so lange ändern können, als diese Verschiedenheit des Lebensbedürfnisses Wärme dauert, ohne dass darum die chemische Qualität eine andere geworden wäre. - Auch die unorganische Natur bietet hieher gehörige Verhältnisse in dem Dimorphismus oder Polymorphismus - wie man dieses Verhältniss in neuerer Zeit richtiger genannt hat, - und auch dort ist die Wärme die Ursache verschiedener Form einer und derselben chemischen Verbindung, indem z. B. kohlensaurer Kalk aus kalten Auflösungen als Calcit in hexagonalen Formen kristallisirt, während er aus warmen Auflösungen in Kristallen des rhombischen Kristallsystems als Aragonit herausfällt. - Während aber in der unorganischen Natur die einmal unter einem bestimmten Wärmemasse gebildete Form der Substanz eine starre ist, und darum auch zwei Formen derselben chemisch bestimmten Substanz neben einander bestehen können, da zu rerschiedenen Zeiten sich bald unter Einfluss emer grösseren Wärmemenge die eine, dann wieder unter Einfluss einer geringeren Wärmemenge die andere Form bildete, 
wird in der organischen Natur es unmöglich sein, dass zwei Formen derselben chemisch gleichen Substanz zu gleicher Zeit an derselben Stelle vorkommen, und sie werden sich entweder zu gleicher Zeit in zwei klimatisch verschiedenen Orten oder an demselben Orte in zwei klimatisch rerschiedenen Zeiträumen vertreten. - Finden sich daher zwei verschiedene Formen zu gleicher Zeit auf derselben Unterlage und unter denselben klimatischen Verhältnissen, so liegen verschiedene Form-Ideen, rerschiedene chemische Qualitäten ihrer Substanz zu Grunde und sie sind als zwei Arten aufzufassen; finden sich jedoch in zwei klimatisch rerschiedenen Gegenden unter gleichen Bodenbedingungen zwei wohl ähnliche, aber doch verschiedene Formen und zwar in der Weise, dass die eine nur dieser und die zweite nur jener Gegend zukommt, so sind sie als muthmassliche klimatische Vertreter oder klimatische Parallelformen aufzufassen. Eine Bestätigung einer solchen Muthmassung wird allerdings nur der Versuch der Versetzung unter die anderen klimatischen Verhältnisse zu liefern im Stande sein. - Südliche und nördliche Formen, Alpen- und Thalformen, Steppen- und Küstenformen einer und derselben Art werden auf diese Weise ihre Erklärung finden.

Da auch der chemische Antheil der Sonnenstrahlen unabhängig ron der Wärme chemische Verbindungen umzusetzen im Stande ist und Lichtstrahlen fast ohne Wärme für die Pflanze ron Bedeutung sind, so werden auch Modifikationen der Form entstehen, je nachdem eine Pflanze der direkten Besonnung au.gesetzt ist oder im Schatten sich entwickelt und es werden dadurch gieichfalls Parallelformen bedingt werden können.

Die Parallelformen sind demnach: durch Gleichheit der chemischen Qualität mit einander verbundene Formen, denen dasselbe Vorbild, dieselbe Form-Idee ursprünglich zu Grunde lag, sie sind Umformungen, die dadurch bedingt wurden, dass die ursprüngliche Form-Idee eben nur unter gegebenen äusseren ungleichen Umständen sich rerwirklichen konnte, und je tiefgreifender daher die Verschiedenheit der äusseren Umstände ist, desto tiefgreifender wird auch die Modifikation der Form sein, die sich aus der Form-Idee rerwirklicht hat. Man hat dicse Parallelformen die ron Na eg eli auch Subs pe zi es genannt wurden, bald als Arten, bald als Spielarten oder Varietäten aufgefasst. - Betrachtet man alle jene rerschiedenen Formen, die unter verschiedenen Lebensbedingungen aus einander herrorgehend gedacht werden können, denen aber eine und dieselbe Form-Idee zu Grunde liegt und die sich nur durch wandelbare Merkmale von einander unterscheiden, als zu einer Art gehörig, und legt man ihnen den Werth ron Spielarten bei, so sind auch die Parallelformen als Spielarten aufzufassen.

Bei bleibender Verschiedenheit der äusseren Umstände wird auch die einmal gebildete Spielart gleich bleiben und wird sich auch in einer Blendlingsart, auf welche dieselben äusseren Umstände einwirken, äussern können, da ja gleiche Ursachen in gleichen Organismen gleiche, in älnlichen Organismen ähnliche Wirkungen hervorbringen. Insoferne finden sich auch die Bastarte 
manchmal in klimatischen und gengnostischen oder Boden-Parallelformen. Auch die Frage: ob die eigenthümliche durch das Klima oder den Boden bedingte Form-Modifikation ron den Stammeltern auf den ron ihnen eizeugten Bastart übertragen werden künne, scheint bejahend beantwortet werden zu müssen.

Sind Parallelformen als Spielarten aufzufassen. so mïssen sie auch dem entsprechend bezeichnet werden. Man wird allerdings rersucht, solche in entfernten, klimatisch unterschiedenen Gegenden oder auf $z$ wei durch ihre Bodenzusammensetzung abweichenden Gebirgen sich rertretende Formen einer Art, auf eine andere Weise zu bezeichnen, als jene Parallelformen, welche an nahe neben einander liegenden Punkten eines und desselben Gebietes vorkommen, - da aber der Erscheinung der letzteren dieselhs Art ron Ursachen zu Grunde liegt, wie dem Auftreten der ersteren und sich in einem beschränkten Gebiete an nahe liegenden Orten eben so gut ein gewis-er Gegensatz der Boden- und klimatischen Verhältnisse aus:prechen kann, wie in von einander entfernten Gegenden und getrennten febirgszügen. so ist eine solche Trennung füglich nicht zulässig und man würde bei einem dahin zielenden Versuche auf unzählige Schwierigkeiten stossen. Am berechtigsten wäre es noch, diejenigen Spielarten. bei welchen sich die Aenderung nur als Reich- und Armblüthigkeit, Gross- und Kleinblätterigkeit, Ceppigkeit und Zwerghaftigkeit ausspricht und wo die äusseren Verhältnisse vermuihen lassen, dass die Aenderung nur durch eine Fülle oder durch Mangel der Bildungsbedingungen herbeigefühıt wurde, ron jenen $\mathrm{zu}$ trennen. wo eine Aenderung der Form stattfand, die, nach der rerschiedenen Qualität der Lebensbedingurgen zu schliessen, durch Aenderung des Klimas oder Bodens bedingt wurde ; ) - aber selbst diese scheinbar sehr leichte Trennung unterliegt in Wirklichkeit grossen Schwierigkeiten, da hier natürlich dasselbe gilt, was oben bei den Bastarten angeführt wurde, dass man nämlich aus der Form und aus den Verhältnissen des Torkommens einer Ptlanze wohl gewisse Rückschlüsse auf ihre Lebensgeschichte und auf die liedeutung ihrer Formänderungen zu machen im Stande sein wird, dass man aler erst danu berechtigt ist, die Muthmassung zur Bestimmtheit eines Auspruches zu erheben, wenn das Ergebniss eines Versuches vorliegt. mit welchem man die Natur befragt hat. - Ein weites Feld von Versuchen liegt in dieser Bezielnung noch vor uns und die schünsten Ergebnisse winken Denjenigen, die sich solchen, allerding's heiklichen und mühsamen, gewiss aber lolmenden und dankbaren Arbeiten widmen.

In Beziehung auf die Weiden wiesen die Erfahrungen darauf hin. dass für die Mehrzahl die chemischen Verhältnisse des Budens ziemlich gleich gültig

*) Es soll im Nachfolgenden eine solche Trennung der Spielarten in der Weise versucht werden.

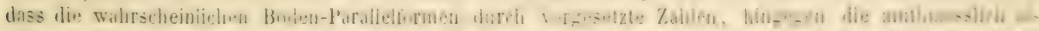

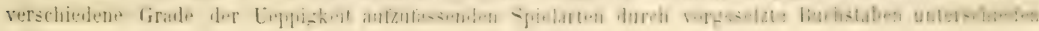
werlen. 
sind. - Dass die Mehrzahl einen bindenden thonreichen Boden verlangt, erklärt sich bei dieser wasserholden Familie wohl aus der wasserhaltenden Kraft des Thones. - Ausschliesslich auf kalkreichen Boden angewiesen sind in Niederösterreich S. incana und $S$. glabra. - Fast alle alpenbewohnenden Teiden aber zerfallen je nach der chemischen Verschiedenheit des Bodens in Parallelformen und als solche ergeben sich in den Alpen:

\section{auf kalkreichem Boden:}

Saliv retusa 1) integrifolia, Salix arluscuia 1) Waldsteiniana, Salix mursinites 1) Jacquiniana. auf kalkfreiem Boden:

Salix retusa 2) serrata, Salix arbuscula 2) foetida, Salie myrsinites 2) serrata.

Sehr auffallend ist, dass sich diese Parallelformen in Beziehung ihrer Blätter in der Art unterscheiden, dass die auf kalkreichem Boden gedeihenden meist ganzrandige, die auf kalkfreiem Boden entwickelten driisig gesägte Blätter besitzen.

Was die klimatischen Parallelformen der Weiden anbelangt, so sind vielleicht als solche $S$. bicolor, arintscula und pyrenaica - S. silesiaca und irndifolia - S. daphnoides und acutifolia - S. repens und S.rosmarinifolic anzusehen Bei der häufigen Verwechslung der rerwandten Formen, welche die Angaben über das Vorkommen der Weiden nur mit grosser Vorsicht zu gebrauchen erlaubt, ist aber die sichere Feststellung der klimatischen Parallelformen noch nicht unzweifelhaft in's Reine gebracht. - Wahrscheinlich aber dürfte sich S. bicolor als Parallelform der alpinen S. arbuscula und der pyrenäischen S. purenaica herausstellen, so wie S. silesiaca, welche durch das schottische Hochland, durch das herzynische und sudetische Gebirgssystem bis in die Karpathen verbreitet ist, ihre Parallelform in der alpinen $\therefore$ arandifolia zu finden scheint. Die $S$. silesiaca wird wohl auch in den Alpen angegeben; alle Weiden aber, welche ich unter diesem Namen von dorther zu sehen bekam, gehörten zu $S$. li andifolia, und niemals konnte ich an den dort angegebenen Standorten S. silesiaca, wohl aber S. grandifolia beobachten. Ich war früher der Ansicht, das $S$. silesiaca als BodenParallelform der $S$. grandifolir aufzufassen sei und hielt die erstere für die dem kalkfreien, letztere für die dem kalkreichen Boden eigenthümliche Modifikation; bei meinen Reisen in den Karpathen überzeugte ich mich jedoch, dass S. silesiaca dort ebenso gut auf Kalkfelsen wie auf kalkfreiem Gesteine rorkomme. Da aber $S$. inandifolia auch bei Petersburg angegeben wird, uns aber nicht Gelegenheit geboten wurde, Exemplare dieser Gegend zu vergleichen, so wagen wir es noch nicht, die Ansicht, dass S. grandijoliu die alpine Parallelform der S. silesiaca sei, als unzweifelhaft hinzustellen und werden auch in dem speciellen Theile dieser Arbeit vorläufig noch den Namen $S$. aranditolia beilsehalten, so wie wir auch die iibrigen muthmas-lichen Parallelformen ror der Hand noch mit ihren üblichen Artnamen autlïhren werden. 


\section{Morphologisches.}

In Beziehung des Werthes und der Beständigkeit deT einzelnen Merkmale, welche zur Unterscheidung der Weidenarten benützt wcrden, mögen hier noch einige Bemerkungen Platz finden.

So wechselnd die absolute Grösse der einzelnen Organe je nach der Ueppigkeit und nach den rerschicdenen Entwicklungsstadien bei den Teiden ist, so gibt doch die bezi ehung sweis e Grïsse, nämlich das Verhältniss der Länge zur Breite manchmal cinen ziemlich guten Anhalt:punkt zur Unterscheidung. - Vielfache Messungen zeigten, dass namentlich die Kätzchen eine Beständigkeit in dieser Peziehung besitzen und dass sich das relative Grössen-Terhältniss auch während der Entwicklungsstadien, welche die Kätzchen zur Blüthezeit durchlaufen, gleich bleibt, so zwar. dass in dem Verhältnisse, in welchem die Fäden der Staubgefässe und die Fruchtknoten mit ihren Stielen sich verlängern, auch die Spindel des Kätzchens an I änge zunimmt. Auch das Verhältniss der Länge des Fruchtknotenstieles zur Honigdrüse fand ich ziemlich beständig, doch muss sich dasselbe auf ein und dasselbe Entwicklungsstadium, nämlich auf die Zeit der rollen Blüthe beziehen, da sich nach dem Abblühen die Fruchtknotenstiele sehr rerlängern. die Honigdrüsen dagegen rerschrumpfen und dadurch wieder eine Unbestimmtheit eintritt. - Viel weniger gleichbleibend als an den Kätzchen und ihren Blüthenstielen ist das beziehungsweise Grössenverhältniss der Blätter; dennoch kann dasselbe manchmal zur Unterscheidung der Arten einigen Werth haben und auch zur Pestimmung der Blendlingsarten ganz gute Anhaltspunkte geben, indem die Messungen zeigen, dass die relative Länge der Blätter bei den Pastarten beständig zwischen der relativen I.änge der Blätter der muthmasslichen Stammältern die Mitte hält.

Unschwer lassen sich fast bei jeder Weidenart zwei einander gewissermassen gegenüber stehende Formen erkennen; die eine breiterblätterig mit kürzeren Jassen der Blüthentheile, die andere schmälerblättrig mit schlankeren Kätzchen und längerem Ausmasse der Blüthenorgane. Bei der Mehrzahl scheint grössere oder geringere Ueppigkeit hieron die Ursache zu sein, für viele aber vermochte ich weder im Boden und Standort noch in den klimatisehen Terhältnissen für diese fast durch die ganze Reihe der Teidenarten wahrnehmbare Erscheinung einen Erklärungsgrund zu finden, und nicht selten fand ich beide Formen dicht neben einander und untereinander wachsend. Im auffallend-ten erschien dieses Verhältniss bei S. rosmrrinifolia und S. aimyirlulina und bei letzterer z. B. zeigt die var. concolor Blätter, die 3 bis :" mal und Kätzchen, die im Mittel i mal so lang als breit sind, wïhrend die rar. discolor Blätter aut- 
weint, die $\&$ bis $8 \mathrm{mal}$ und Kätzchen, die im Mittel $\dot{k}$ mal so lang als breit sind.

Der Umriss der Blätter zeigt trołz einer grossen Mannigfaltigkeit doch bei jeder Weide mit ziemlicher Beständigkeit denselben Zuschnitt, und die Grundform des Blattes spricht sich in den breit- und schmalblättrigen Formen ebenso wie in den Schösslingen aus, obschon letztere oft auffallend in die Breite gezogen erscheinen. - Das I,androlk unterscheidet zwei Gruppen der Weiden: die Fellern und die Salchern und dieser Unterschied gründet sich ganz rorzüglich auf den Zuschnitt der Blätter. Bei den ersteren sind nämlich die Blätter mehr in die I.änge gczogen, drei- bis zehnmal so lang als breit, meist lineal oder lanzettlich länger zugespitzt und an der Unterseite ron einem rorspringenden starken Mittelnerven durchzogen, während dieSeitennerven erster und zweiter Ordnung fadenförmig zart und dünn und kaum rorspringend erscheinen. Bei den Salchern sind die Blätter kürzer und breiter nur ein bis dreimal so lang als breit, elliptisch oder eiförmig oder rerkehrteiförmig, kurz zugespitzt ader stumpf, an der Unterseite ron einem vorspringenden Adernetze durchzogen, das aus den ziemlich derben Nerven $z$ weiter und dritter Ordnung gebildet wird. Bei dieser letzteren Blattform zeigt sich - namentlich bei S. aurita, S. grandifolia, S. cinerea und S. Caprea in mehr oder weniger ausgeprägter Treise an der oberen Blattfläche ein Netz von vertieften Linien, welches dem vorspringenden Nervennetze der unteren Seite entspricht und die Unebenheit der oberen Blattseite bedingt. Bei den Blättern der Felbern hingegen ist mit Ausnahme ron S. viminalis, S. incancs und den mit ihnen rerwandten Bastarten die obere Blattfläche von keinen solchen Furchen und rertieften Linien durchsetzt und entweder eben oder wie namentlich bei $S$. daphnoides und $S$. purpurea mit etwas erhakenen glatten Nerrchen durchzogen. Letztere Erscheinung tritt insbesonders an getrockneten Blättern herror, bei einigen Weiden aber wie z. B. bei S. myisinites 1.) Jacquiniana ist sie auch im lebenden Zustande schon wahrnehmbar.

Der Rand der Blätter ist bei der Mehrzahl der Weiden gesägt oder gekerbt gesägt und zwar so, dass jeder Sägezahn an der Spitze mit einer kleinen drüsenartigen Verdickung endigt, die jedoch nur bei $S$. pentundra, S. cuspidata und S. arbuscula 1.) fütida klebrig ist. - Auf die Eigenthümlichkeit, dass die Parallelformen des kalkhältigen und kalkfreien Bodens in Beziehung des Blattrandes einen Gregensatz zeigen, wurde bereits früher aufmerksam gemacht.

Die Blätter, welche sich an den Kätzchenstielen befinden, sind, wenn sie den Blättern der Aeste ähnlich geformt erscheinen auch in ähnlicher Weise berandet; bei einigen jedoch, wie z. B. bei S. fragilis sind sie im Gegensatze zu den gesägten Blättern der Aeste ganzrandig. Das Beblättertsein des Kätzchenstieles ist für mehrere Arten, z. B. für S. nigricans und $S$. arbuscula sehr unbeständig, für andere wie $S$. pentandi $a$ und $S$. cuspidata, ist hingegen das Torhandensein feindrüsig gesägter Blättchen an Kätzchen- 
stiele ein sehr bezeichnendes Merknal, so wie für $S$.daphnoides, S. viminalis, S. Caprea und mehrere andere hervorgehoben zu werden rerdient, dass diese Blättchen entweder'ganz fehlen oder in lineale seidenhaarige Schuppen umgewandelt sind.

Die Art der Bekleidung der Blätter i.t für die Mehrzahl dce Weiden ein äusserst beständiges Merkmal und gibt höchst wichtige Anhalt:punkte, um aus der Form einer muthmasslichen Blendlingsart auf die Stammältern einen Rückschluss machen zu können. - Es lassen sich \& rerschiedene Arten der Behaarung bei den Weiden wahrnehmen:

1. Form. Die Haare sind verlängert, gerade und liegen alle parallel mit dem Hauptnerven des Blattes dicht a uf der Blattfläche auf. - Das Licht wird in Folge der parallelen Lage gleichmäsig reflektirt und wenn das von dem Blatte reflektirte Licht in das Auge des Beobachters kommt, erscheint diesem die ganze Blattfläche gleichmässig glänzend. Ausgezeichnet an S. rosmarinifolia und alla.

2. Form. Die Haare sind unendlich klein und zart, etwa sechsmal kleiner als bei der früheren Form, sie sind gerade und liegen parallel mit den Fiedernerven erster Ordnung dicht auf der Blattfläche a uf, so zwar dass die Richtungslinie der Härchen an der rechten Blatthälfte gegen jene der linken Blatthälfte einen stumpfen Winkel bildet. Da in ein und demselben Augenblicke das reflektirte Licht nur von den Härchen eines Theiles der Blattfläche in das Auge des Beobachters kommen kann, so wird auch nur dieser Theil erglänzen und bei Bewregung des Blattes erfolgt jene eigenthümliche Schimmern, welches die S. viminalis und alle durch Bastartirung aus ihr herrorgegangenen Blendlinge so sehr kennzeichnet.

3. Form. Die Haare sind derb, meist Sförmig geschwe ift und halten in ihrer Länge die Mitte zwischen der ersten und zweiten Form. Sie liegen niemals rollkommen an der Blattfläche an, aus welchen Grunde sich das Blatt, wenn anders die Haare desselben dicht gedrängt sind, sammtartig anfühlt. - In ihrer Richtung folgen sie manchmal nach einer gewissen Regel und sind parthienweice in gleicher Stellung. Nur in diesen Falle und nur dann, wenn sie gegen die Blattfläche geneigt sind, zeigt sich bei dieser Form der Behaarung das Blatt noch etwas glänzend; sind jedoch die geschweiften derben Haare regellos und ron der Blattfläche abstehend. so erscheint die Behaarung als matter Filz, der durch die rerschiedene Färbung der Blattfläche, so wie durch das Gedrängter- oder Entfernterstehen der Haare rerschiedene graue bläuliche oder weissliche Farbentöne des Blattes erzeugt. Die Salchern: S. Caprea, S. cinerea, S. aurita u. dgl. sind durch diese Art der Behaarung sehr ausgezeichnet.

4. Form. Die Haare sind verlängert, vielfach gekrümmt regellos in einander versehlungen und bilden. Wenn sie in so dichter Schichte vorhanden sind, dass dadurch die Farbe der Blattfläche ganz rerdeckt wird, einen weisslichen glanzlosen Filz, welcher die 
S incana und a:le aus ihr herrorgegangenen Bastarte augenblicklich kernzeichnet. Ist die Schichte der verschlungenen Fäden weniger dicht, so billet derselbe einen spinnenwebenartigen Ueberzug, der die Farbe der Blattflïche durchblicken lässt und dann dem Blatte einen mehr ins Graue hinüberziehenden Farbenton gibt.

Dass wirklich nur die Lage der Hare die Ursache des Glanzes sei, liisst sich sehr leicht nachweisen, indem man den silbern glänzenden Ueberzug eines Blattes ron S. al'a mit einem Messer wegschabt und die Haare dadurch in Unordnung bringt : augenblicklich erscheint dann das so gebildete Haufwerk ron Haaren als matte glanzlose wollige Flocke ganz ähnlich dem Filze, der die untere Blattlläche von S. incana bedeckt.

Der Unterschied der Belraarung junger und ausgewachsener Blätter muss stets berücksichtigt werden. Im jugendlichen Zustande sind nämlich die Blatter der meisten Weiden mit einem schmutzigen oft rostfarbigen, dabei aber etwas glänzenden, manchmal abwischbaren Flaume bedeckt, der jedoch ebenso bald schwindet wie der klebrige firnissartige Ueberzug, welchen die jungen sich eben entwickelnden Blätter von $S$. pentandia und S. frayilis zeigen.

Der blä uliche U eb er zug, den mehrere Weiđen an der unteren Blattseite zeigen, tritt bei der Mehrzahl erst an den ausgewachsenen Blättern hervor. Sehr ausgezeichnet ist derselbe an $S$. ilubra und $S$. amygdalina b.) discolor. Bei S. nigricans schwindet derselbe später wieder von der Spitze gegen ďie Basis des Blattes za, so dass jedes Blatt das Ansehen hat, als wäre der bläuliche Ueberzug durch Betasten mit den Fingern von der Spitze weggewischt worden. - Die Stärke dieses blïulichen Leberzuges so wie die Stārke der Behaarung steht unzweifelhaft mit der Besonnung und dem Feuchtigkeitszustand des Bodens in der Weise im Zusanmenhange, dass die Bekleilung an sonnigen trockenen Standorten zunimmt, und dichter wird, an schattigen feuchten Standurten abnimmt und einen mehr lockeren und dünneren Ueberzug bildet. Besonders auffallend ist diess an Formen der S. incana, S. alba, S. Caprea, S. viminalis und S. niyricans zu sehen. Sehr merkwürdig ist in dieser Beziehung auch die Kathlheit der Blïtter an Schüsslingen solcher Arten, die sonst immer nur behaart rorkommen und insbesonders sind lier $S$. aurita und $S$. rosmarinifolin herrorzuheben, welche, nachdem sie auf den Bergwiesen abgemäht wurden, ïppige Scliösslinge treiben, deren Blätter dann vollständig kahl erscheinen.

Die Blätter werden im Verwelken bei einigen Weiden Jichter oder dunkler braun, bei anderen bläulich-schwarz. Es steht diese rerschiedene Farbenwandlung offenbar mit dem ron den Clremikern nachgewiesenen Torwalten gerbsaurer Verbindungen in den ersteren und dem Vorwalten ron Salicin-Verbindungen in den Blättern der letzteren Abtheilung im Zusammenhange. Die S. nigricans, glalma, rosmarinifolia, Myrsinites, purpurea, und die Mehrzahl der aus ihnen herrorgegangeners 
Bastarte zeigen in ausgezeichneter Weise dieses Schwarzwerden der Blätter, während die an gerbsauren Verbindungen reichen Blätter der S. amuıdalina, Fragilis, viminalis, aibuscula, Cuprea und der übrigen beim Verwelken woh! dunkelbraun werden, aber niemals die eigenthümliche Farbenwandlung zeigen, die anfänglich an Neutraltinte erinnert und endlich in reines Schwarz übergelit. - Die Salicin-Terbindungen der schwarzwerdenden Weiden scheinen beim Verwelken in saliziligsaure Salze umgewandelt zu werden, welche im feuchten Zustande der Luft ausgesetzt, sich rasch schwärzen. Das Schwarzwerden tritt auch in ausgezeichneter Weise herror, wenn man die betreffenden Weiden in heisses Papier legt und alle jene Weiden. welche im Verwelken sich schwärzen, färben auch weisses etwas feuchtes Papier, wenn sie längere Zeit in demselben liegen, an den Berührungsstellen bläulichschwarz.

Die Nebenblät ter stehen in ihrer Form mit den Blättern in einem gewissen Zusammenhange, so zwar, dass sie, was Farbe, Behaarung und Nervatur anbelangt, mit jenen rollständig übereinkommen and auch in Beziehung des Zuschnittes als die Nachahmung der Blätter angeschen werdeb können, indem lanzettlichblättrige Weiden: lanzettliche oder halbherzförmige, linealblättrige auch: lineale, und endlich kurz- und breitbiätterige Teider meist halbnierenförmige Nebenblätter besitzen. - Mehrere Arten, wie $S$. gla $\boldsymbol{r}^{7} a$, S. purpurea und S. retusa haben in der Regel keine Nebenblätter und nur ausnahmsweise finlen sich deren an sehr üppigen und kräftigen krautigen Trieben.

Die $Z$ weige entsprechen in ihrer Behaarung stets den Blättern doch schwindet ihr Ueberzug häufig weit früher als jener der Blätter. Für die ein- bis dreijährigen Zweige der S. daphnoides und S. Wimmeri ist der wachsartige hechtblaue abwischbare Reif sehr bezeichnend. Auch in der Form der Rinde der Zweige liegt manchmal ein nennenswerther Unterschied, wie denn z. B. für S. firaçilis die glänzende dünnhäutige, beim Trocknen faltig werdende Rinde ein sehr auszeichnendes Kennzeichen ist. - Die Farbe der Rinde, welche im Schatten für alle einbis dreijährigen Weidenzweige eine grüne ist, bekommt durch Einwirkung des Sonnen- und Mondlichtes an den der Bestrahlung ausgesetzten Stellen einen bald mehr gelblichen und röthlichen, bald bräunlichen Farbenton. Dic Zweige der Felbern, namentlich der S. ammdalina, S. purpurea, S. dajhnoiles und glalna färben sich auf diese Art gelb bis bluthroth, jene der S. alba dottergelb bis mennigroth; die Zweige der Salchern hingegen z. B. S. Caprea, S. nigricans, S. aurita, dann einiger Felbern, nämlich S. iniana, S. Seringeani und $S$. subalpina bekommen, wenn sie dem Lichte ausgesetzt sind, eine dunkelrothbraune Färbung - Die Mehrzahl der übrigen Weiden behält aber auch rom Lichte beschienen einen aus Gelb, Grün und Braun gemi-chten Farbenton der Zweige. - Mit dem Weiterwachsen schwinden übrigens nachträglich alle diese Färbungen und machen einer blassgrünen, ins Graue lnimïberziehen ten Farbe Platz, bis endlich im rierten bi, sech ten Jahre die Kinde 
ein rissiges borkiges Aussehen bekommt. - Der Grad der Brüchigkeit oder $\mathrm{Z}$ ähigkeit der Zweige gibt zwar zur Erkennung einzelner Formen manchmal ganz gute Anhaltspunkte, doch ist es kaum möglich, diese rerschiedenen Grade durch Worte festzuhalten. Dasselbe gilt ron der Richtung der Zweige. Im Allgemeinen spricht sich aber in letzterer Beziehung ein Gegensatz der Felbern und Salchern aus, indem die Zweige der ersteren unter spitzen Winkel rom Hauptstamme abtreten und als gerade nicht hin und hergebogene schlanke Ruthen nach Aufwärts wachsen, während bei den Salchern die dickeren niemals so sehr rerlängerten Aestchen unter grösseren Winkeln von dem hin- und hergebogenen Stamme sich abzweigen und nicht selten sogar eine sparrig ästige Krone bedingen. - Es soll nicht bloss Gedankenspielerei sein, wenn wir hier auf die Aehnlichkeit zwischen der Blattnerratur und der Verzweigung der Aeste hinweisen und die Behauptung aufstellen, dass die Verzweigung der Nerren im Kleinen ein Bild der Verzweigung des Stammes darstellt. Es darf auch diese Aehnlichkeit nicht Wunder nehmen, da beide Erscheinungen einen ursächlichen Zusammenhang, nämlich die Vertheilung der Gefässbündel besitzen, welche für jede Pflanze eine ganz bestimmte ist. Die schlanken geraden, unter spitzen Winkeln sich. abzweigenden Blattnerren und $Z$ weige der $S$. alba und die hin und hergebogenen derberen Blattnerren und Aeste der S. Caprea mögen als Beispiele dieses Zusammenhanges hier angeführt werden,

Die Blattstellung ist als diagnostisches Merkmal bei den Weiden nicht rerwendbar. Die gewöhnlichste StelIung der Blätter ist $2 / 3$ und $3 / 3$, doch findet häufig ein Trechsel der nächst verwandten Stellungsverhältnisse statt, so wie auch das Ueberspringen ron einem Gebiet der Blattstellung ins andere keine seltene Erscheinung ist. - Die Kätzchen weisen allerdings den Unterschied auf, dass sich bei jenen mit gelben einfärbigen Kätzchenschuppen der Techsel innerhalb den Grenzen von 9-12 Zeilen, bei jenen mit zweifärbigen Kätzchenschuppen meistens zwischen 12-19 Zeilen bewegt, aber auch hier ist die Lnbeständigkeit so gross, dass eine Benützung dieser Verhältnisse zur Unter-heidung der Arten nicht erwartet werden kann.

Nur wenige Teiden erwachsen zu Bäumen. Die ansehnlichsten Bäume bildet $S$. alba, ron der in den Donau-Auen nicht selten alte Stämme gefällt werden, die einen Umfang ron 4 Fuss und eine Höhe ron 10 bis 12 Klaftern erreichen, Nächst $S$. allia bilden noch $S$. fragilis, $S$. excelsior und $S$. palustris, S. daphnoides und S. Caprea Bäume, jedoch von weit geringerem Stammumfange und höchstens sechs Klaftern Höhe. Die übrigen höheren Weiden wie S. incana, S. amugdalina, S. viminatis, S. purpurea u. s. f. rermügen nur in geschlossenen Auen noch baumartigen Wuchs zu erlangen, an freieren Standorten hingegen bleiben sie immer strauchartig. - Die Salchern S. grandifolia, S. aurita, S. cinerea, so wie die den Voralpen und jene der Alpen-Region eigenthïmlichen Weidenarten 
sind alle vom Boden aus yerästelt und der Stamm der letztern erscheint meist knorrig und sparrig-ästig auf die Erde hingestreckt

Die terminale Knospe rerkümmert bei allen Weiden und der aus der obersten lateralen Knospe sich entwickelnde Spross nimmt die Richtung an, welche dem terminalen zugekommen sein würde. Sämmtliche in demselben Frühlinge erscheinende Aestchen, sowohl diejenigen die nur Blätter tragen, sowie jene, welche durch Blüthenkätzchen begrenzt erscheinen, sind daher beziehungsweise der Achse, aus der sie hervorgegangen sind, als laterale zu bezeichnen. - Die lateralen kätzchentragenden Axen sind bei jenen Weiden, welche ror Entwicklung der Blattknospen blühen, sehr verkürzt und nur mit wenigen schuppenförmigen Blättchen bekleidet, welche den später erscheinenden Blättern der Laubknospen sehr unähnlich sind. -- Bei jenen Weiden, wo sich die Blüthen und Blätter zu gleicher Zeit entfalten, sind sie hingegen verlängert und mit Blättern bekleidet, welche jenen der kätzchenlosen Triebe gleichen. Die Knospenanlage in der Achsel dieser Blätter rerkümmert bei der Mehrzahl der Weiden und das ganze Aestchen fält nach den Verstäuben der Antheren oder nach dem Ausfliegen der Samen gewöhnlich ab. Yur dann, wenn an demselben Zweige bloss Blüthenknospen und nicht auch gleichzeitig Laubknospen rorhanden waren, bleiben die kätzchentragenden Aestchen stehen und die Knospenanlagen in der Achsel ihrer Blätter entwickeln sich weiter. An den Weiden der Ebene ist immer eine zwischen 1 und 8 wechselnde Zahl ron Laubknospen über den Blüthenknospen rorhanden, und bei diesen findet eine Weiterentwicklung der Knospenanlagen in der Achsel der Blätter, welche das kätzchentragende Aestchen bekleiden, nur selten statt*). Wenn jedoch durch Abschneiden der obere Theil des Zweiges und mit ihm die Laubknospen im Winter oder Frühlinge entfernt werden, so tritt die Fortbildung der Kno-penanlagen in der Achsel der Kätzchen-tielblätter bei allen Weiden ein. Wir hatten Gelegenheit diese Erscheinung an S. viminalis, S. rubra und anderen zu beobachten und jedesmal waren dabei die kätzchentragenden Aestchen des rerstümmelten Zweiges, an welchen die Knospen zur vollen Entwicklung kamen, auffallcnd verlängert. Einen ganz fremdartigen Anblick gewähren die in obiger Weise yerstïmmelten Weiden dann, wenn die rerstümmelten Arten bei regelmässigen Wachsthum aufder kurzen Kätzchen-Achse dicht gedrängt stehende kleine schuppenartige Blättchen besitzen, die in ihrem $\mathrm{Zu}=$ chnitte ron den anderen Blätteın wesentlich abweichen; die schuppenartigen Blättchen vergrössern sich nämlich nach der Verstïmmlung und bekommen die Ausdehnung der anderen Blätter, lehalten aber dabei ihren abweichenden Zuschnitt bei und ich bewahre in diescr Beziehung höchst interesante Zweige Fon S. cineiea, die mir Freund Petter mizutheilen so gütig war.

4) Wir beobachteten eine solche Weiterentwicklung der Knospen in der Achsel der KülzchenstielBlälter an S. pentandra und S. fragilis, unl bewahre! die höchst lehrreichen Zweige in unserem Herbarium. 
An den Weiden des Ilochgebirges S. herbacea, retusa, reticutata ist die Menge der Kriospen, welche ein Jahrestrieb bildet, eine sehr beschränkte; bei S. retusa übersteigt dieselbe für einen Zweig niemals die Zahl sechs; während bei den schlanken Weiden der Thäler nicht selten gegen fünfzig: Knospen an einen Zweig gezählt werden können. Bei S. herbacea und S. reticulata beschränkt sich die Zahl gar nur mehr auf zwei oder drei. - Bei den reichknospigen Zweigen ist auch die Anzahl der Laublnospen, die gewöhnlich an dem oberen und unteren Ende des Zweiges ihre Lage haben, gross. Thre Zahl vermindert sich aber je mehr die Zahl der Knospen überhaupt abnimmt. Bei S, retusa ist in der Regel nur mehr die oberste laterale Knospe eine Laubknospe, während alle übrigen Knospen Blüthenknospen sind; bei S. herbacea und reticulata, welche unter allen unseren Weiden die geringste Knospenzahl zeigen, sind gewöhnlich sämmtliche Knospen Blüthenknospen. - Wïrden bei diesen letzteren die kätzchentragenden Aestchen, die sich aus den Knospen entwickeln, ähnlich so wie bei den reichknospigen Weidenarten der Ebene nach dem Verstäuben oder Verfliegen der Samen abfallen, so wäre daduich der Bestand des Individuums bedroht, indem sich dann an dem ganzen Sträuchelchen keine lebensfähige Knospe mehr rolfinden würde. Die Erhaltung des Individuums ist daher bei ihnen geradeso wie bei dén früher besprochenen verstümmelten thalbewohnenden WTeiden an die Bedingung geknïpft, dass sich die Knospenanlagen in der Achsel der Blätter, welche die kätzchentragenden Aestchen bekleiden, weiter entwickeln. Fs stirbt daher auch nur der oberste Theil des Aestchens, nämlich das terminale Kätzchen ab, - der untere Theil mit zwei bis drei Blättern und den in ilırer Achsel befindlichen Knospenanlagen bleibt, und letztere entwickeln sich weiter und werden gew öhnlich zu Blüthenknospen. - Dabei ist natürlich nicht ausgeschlossen, dass eine oder auch alle diese Knospen Laubkrospen werden, ja bei $S$. retusa ist es sogar Regel, dass die oberste laterale Knospe kein Kätzchen herrorbringt, und ich hatte Gelegenheit, üppige in tieferen Höhenlagen sprossende Sträuchelchen dieser letzg'enannten Weide zu beobachten, wo die zwei obersten lateralen Knospen Laubknospen waren - aber an demselben Individuum waren auch in den Achseln der Blätter, welche sich unter den Kätzchen befanden, die Knospen rerkümmert und die liätzchentrag'enden beblätterten Aestchen fielen geradeso nach dem Verstäuben ab, wie bei den rielknospigen Weiden der Thäler. - Es ist nach dieser Auseinandersetzung die Unterscheidung der Weiden in solche mit endständigen und seitenständigen Kätzchen nicht zulässig und auch das Merkmal der knospentragenden und knospenlosen Kätzchenstiele nur ron untergeordneten Werth.

Die Unterscheidung der Kätzchen nach der Ungleichzeitigkeit oder Gleichzeitigkeit der Blüthenentwicklung und Blattenfaltung in : ror läufige und gleichzeitige ist wohl bei den Weiden einer und derselben Gegend müglich, da sich dort dieses Verhältniss in c'er Regel gleich bleibt; in rer- 
schiedenen Gegenden ändert sich aber diese Gleichzeitıgheit viler Vorlïutigkeit und in dem Gebiete, dessen Weiden hier besprochen werden, kann als Regel gelten, dass alle jene Arten, welche in der Ebene vorläufige Kätzchen besitzen, in den Alpenthälern die Blüthen und Blätter zu gleicher Zeit entwickeln. Nach Wi mmer ist die letztere Erscheinung „die Folge plötzlicher und starker Wärme bei hinreichender Fuuchtigkeit, zumal in späten Frühjahren," womit unsere eben angegrebene Beobachtung vollkommen übereinstimmt, indem in den Alpen die grösseren Schneemassen die pflanzliche Entwicklung länger zurückhalten, dann aber, wenn der Schnee endlich geschmolzen ist, bei schon vorgerücktem Frühlinge plützlich eine grosse Wäımemenge den Pflanzen zugeführt wird, welche die Entfaltung der Blätter schon zu einer Zeit bewirkt, wo die Kätzchen noch in roller Blüthe stehen.

Kätzchen, die gesetzmässig erst im nächsten Frühlinge zur Blüthe kommen sollten, entwickeln sich selten rorzeitig schon im vorangehenlen Jahre. Die Ursache dieser Erscheinung ist entweder ein besonders günstiger Standort und eine ausnabmsweis grosse Sommerwärme oder die Verstümmelung des Strauches durch Abschneiden seiner Aeste im Sommer, in welchem Falle gleichfalls die für das nächste Jahr bestimmten Knospen an dem zurückgebliebenen Rumpfe des verstümmelten Zweiges noch im Herbste zur Entwicklung kommen. In der Regel sind diese proleptischen Kätzchen kurz gestielt in den Achseln der ausgewachsenen Blätter und erscheinen in dieser Weise besonders häufig bei S. amudalina b.) discolor, welche Weide auch darum ron $\mathrm{Hos}$ t als S. semperglorens bezcichnet wurde. Ist jedoch die vorzeitige Entwicklung durch Verstümmlung herrorgegangen, so sind die Kätzchen lang gestielt und das Aestchen dessen Abschluss sie bilden, Blätter und Knospen tragend.

Die Kätzchenschuppen sind entweder einfärbig oder zweifürbig. Dieses Merkmal ist als eines der beständigsten herrorzuheben und spielt daher auch eine wichtige Rolle bei der Gruppirnng der Weidenarten. - Die einfärbig gelblichen Kätzchenschuppen sind bei einer und derselben Art an den Staubblüthen mehr gelb, an den Fruchtblüthen mehr grünlich gefärbt Bei S. glabra, S. retusa und S. herlacea erscheint die Spitze der gelben Schuppen an der äusseren Seite der dem Lichte zugewendeten männlichen Kätzchen häufig rosenroth gefärbt.

Die einzige S. reticulata besitzt einfärbig blassrothe Kätzchenschuppen sowohl an den Staub-wie Fruchtblüthen. - Die zweifarbigen Kätzchenschuppen sind an der Basis grün oler fast weisslich und entweder nur an der Spitze röthlichschwarz, wie angebrannt, oder sie werden beiläufig in der Hälfte roth oder rostfarbig und gegen die Spitze allmälig immer dunkler. Die grünen Schuppen der S. nimricans sind an ihrer Spitze oft nur ganz wenig mit Purpur bemalen, jene der S. rosmarinifolia hingegen sind meist bis zum Grunde roth, dann aber immer an der Spitze riel duskler, wodurch sie sich wesentlich ron den gleichmässig rothen Schuppen der S. reticulutu 
unterscheiden. - Bei der einzigen S. incan hahen die Kätzchenschuppen keine beständige Farbe, indem dieselben bald einfärbig gelb oder grünlich, bald wieder an der Spitze rosenroth oder braun bis schwärzlich bemalt erscheinen, ohne dass man einen Anhaltspunkt hätte, die eine oder andere Farbenspielart als Blendlingsart aufzufassen.

Sind die Schuppen mit geraden langen Haaren bedeckt, so erscheint das noch nicht blïhende Kätzchen in einen dichten Pelz eingehïllt. Alle vorläufigen sitzenden Kätzchen, welche in der Knospenlage nicht durch Blättchen des Kätzchenstiels umgeben werden, also die Mehrzahl der Salchern, dann S. viminalis, S. daphnoides und $S$. purpurea und die mit diesen drei Arten verwandten Formen zeigen dieses Verhältniss; die Schuppen jener Weiden hingegen, bei denen die Kätzchen an beblätterten Stielen aufsitzen und in der Knospenlage von diesen Kätzchenstielblättern schützend umhüllt werden, sind fast kahl oder nur wenig behaart, und bei der einzigen in diese Abtheilung gehörigen S. fragilis ist das herausbrechende Kätzchen in einen seidigen Pelz eingehüllt.

Die Beharung und Form der Schuppen gibt manchmal ziemlich gute Unterscheidungsmerkmale; besonders auffallend und ron allen iibrigen abweichend sind die abgestutzten Schuppen der S. retusa; ebenso eigenthümlich ist das Abfallen der Schuppen bei den mit S. fragilis rerwandten Formen.

Die Anzahl der Staubgefässe beträgt bei der Mehrzahl der Weiden zwei. Thre Fäden sind bei $S$. purpurea bis zur Spitze zusammengewachsen. Die Bastarte der S. purpurea mit anderen Treiden zeigen gleichfalls diese Zusammenwachsung, doch reicht dieselbe bei ihnen nur selten bis gegen die Antheren hinauf, und in der Regel trennen sich beide Fäden in der halben Höhe. Bei allen übrigen sind die Staubfäden bis zur Basis getrennt, hängen aber bei denen mit einfärbig gelblichen Schuppen, namentlich bei S'. incana durch ineinandergreifende Härchen, welche das untere Drittheil der Fäden bei diesen Weiden bedecken, meistens lose zusammen. - Die $S$. amygulalina besitzt drei, die S. pentandra fünf bis zwölf Staubgefässe. Die Blendlingsarten, an welchen die erstere muthmasslich betheiligt ist, zeigen in den rerschiedenen Blüthen desselben Kätzchens bald drei, bald zwei, jene, wo S. pentandra die Rolle eines der Aeltern gespielt zu haben scheint, die wechselnde Anzahl von fünf bis zwei Staubgefässen. - Die Farbe der A $n$ theren ist entweder in allen Eutwicklungsstadien gelb und gleich bleibend, oder sie ändert sich in der Weise: dass die Staubkölbchen vor der Oeffnung' ihrer Fächer purpurn, dann zur Zeit, in welcher der Pollen herausfällt, gelb und nach dem Verstäuben schwarz werden; oder endlich: die Staubkölbchen sind vor dem Klaffen der Antherenfächer röthlich, werden zur Zeit der vollen Blüthe hellgelb, verfärben sich dann wohl nach dem Verstäuben und bekommen einen schmutzig gelben larbenton, ohne sich aber wie die früheren $\mathrm{zu}$ schwärzen. 
Dieses Verhältniss ist eines der beständigsten und kann darum auch zur Gruppirung der Weiden rortrefflich" benützt werden, ganz abgesehen davon, dass die durch das Farbenrerhältniss der Antheren begrenzten Gruppen auch durch andere Merkmale noch eine natürliche Verwandtschaft zeigen, und dass die Aehnlichkeit des Farbenwechsels offenbar auch auf eine Aehnlichkeit der chemischen Grundlage hinweist.

Das Farbenverhältniss, welches die Narben zeigen, ist mit jenem der Antheren immer in einem gewissen Einklange. Die Weiden nämlich mit beständig gelben Antheren besitzen auch einfärbig gelbliche oder grünliche Griffel und Narben; bei denjenigen Arten, welche roth-gelb-schwarze Antheren zeigen, sind die Narben in der Regel zu Anfang und zur Zeit der rollen Blüthe roth und werden nach dem Abblühen gleichfalls schwärzlich, und bei den Weiden der dritten Gruppe, die roth-gelbe Staubliülbchcn liaben, sind die Narben wieder in allen Entwicklungsstadien gelblich.

Die Form der Griffel und Narben ist gleichfalls fir die Weidenarten sehr charakteristisch. Herrorhebenswerth sind die fädlichen bogenfürmig gekrümmten Narben der S. viminalis und incana, die zierlichen wachsartigglänzenden dicklichen Narben der $S$. pentandra und die unter rechten Winkel abstehenden knopffürmigen Narben der S. amyydalina. - Der S. purpurea, S. rosmarinifolia, so wie den Salchern fehlt der Griffel fast ganz; bei den Felbern mit einfärbigen Kätzchenschuppen ist derselbe wohl rorhanden, aber kurz und dick, und bei S. viminalis, daplenoides, incana und den mit ihnen verwandten Arten ist derselbe verlängert diinn und fadenförmig. Sehr merkwürdig ist die bei $S$. arbuscula oft beobachtete Spaltung des Griffels, die manchmal bis zum Fruchtknoten hinabreicht, so dass dadurch zwei vollständig getrennte Griffel, deren jeder seinem Fruchtblatte aufsitzt, sich bilden.

Die Behaarung und Glattheit des Fruchtknotens ist für alle bisher in Niederösterreich beobachteten Weiden beständig. Doch gilt diese Beständigkeit nicht als allgemein gültiges Gesetz, da z. B.S.nigricans, die in Niederösterreich nur mit kahlen Fruchtknoten bis jetzt gefunden wurde, anderwärts auch behaarte Fruchtlnoten zeigt. Schon nahe der niederüsterreichischen Grenze bei Kapellen in Obersteiermark beobachtete ich diese Weide mit sparsam behaarten Fruchtknoten, und in den Karpathen fand ich deren auch mit weisfilzigen Kapseln. An beiden Orten war die Bodenunterlage kalkfrei. während die kallffüchtige $S$, nivricans in den Alpen regelmässig auf kalkhältigen Boden angetroffen wird, - doch wage ich auf diese rereinzelten Beobachtungen hin nicht sie als zwei Boden-Parallelformen aufzutassen, um so weniger, als ich die in Beziehung der Bekleidung der Fruchtknoten mit S. nitricans übereinkommende $S$. silesiacu in den Karpathen oft an einer und derselhen Stelle mit kahlen und filzigen Fruchtinoten untereinander wachsend angetroffen habe, ohne dass ich in den äusseren Verhältnissen dafiir cinen frund autzufinden in Stande gewescon wäre. Wimmer -pricht 
sich über die Bekleidung der Fruchtknoten der Weiden folgendermassen aus: „Unter den echten Arten werden nür S. silesiaca, S. repens und S. nigricans sowohl mit kahlen als behaarten Fruchtknoten gefunden; bei S. silesiaces und S. nigricans ist der kahle, bei $S$. repens der behaarte Zustand als Regel anzusehen. Indess würde ich nicht zu widersprechen wagen, wenn Jemand behauptete und nachzuweisen rersuchte, dass die abweichenden Formen, nämlich ron $S$. silesiaca und $S$. nigricans die mit behaarten und ron $S$. repens die mit kahlen Fruchtknoten unechte seien. Wenigstens ist bei diesen drei Arten der Unfang der Variation noch nicht durchaus festgestellt und genau begrenzt. Die nicht selten rorkommenden Exemplare der S. cinerea, S. Caprea und S. aurita mit kahlen Fruchtknoten sind nicht $A$ bänderungen, sondern gehören stets der monstrüsen androgtnen Bildung an. ${ }^{*}$ *) - Auch in Niederösterreich wurden solche kallffüchtige Formen, deren androgynisches Vorhältniss auf eine Missbildung hinweist, bei S. Caprea, S. cinerea und S. aurita beobachtet. Bei $S$. C'aprea und $S$. cinerea ${ }^{* *}$ ) waren die Fruchtibnoten mannigfach rerzerrt und rerkümmert; bei einer $S$. aurita aber, welche von meinem Bruder bei Moidrams nächst $Z$ wettl beobachtet und gesammelt wurde, waren die sämmtlichen kahlen Fruchtknoten in ihrer Form regelmässig ausgebildet und unterschieden sich ron den gewöhnlichen behaarten nicht missbildeten Formen nur durch den auffallend verlängerten Fruchtknotenstiel. Die Mehrzahl der Kätzchen desselben Strauches zeigte nur Fruchtblüthen, und nur einige wenige Kätzchen liessen auch ein androgynisches Verhältniss wahrnehmen. - Uebrigens fanden wir auch androgynische Kätzchen ohne Aenderung der Behaarung und ohne Verzerrung bei: S. ambigua, S. auritoiles, S. cuspidata, S. palustris, S. anırustifuliu, S. miralilis, S. Wimmeri, lauter Formen, welche wir für Bastarte halten - woraus geschlossen werden dürfte, dass die androgynische Bildung bei den Weiden in der Mehrzahl der Fälle eine Folge zweiartiger Befruchtung ist.

Als ganz eigenthümlich in Beziehung der Bekleidung der Fruchtknoten nuss noch S.myrsinites 1) Jacquiniana herrorgehoben werden, deren Fruchtknoten zur Zeit der Blïthe mit langen wolligen Haaren bedeckt erscheint, die später abfallen, so dass die Kapsel noch vor ihrer Reife voll.tändig kahl erscheint.

An Blendlingen, die aus einer kahlfrüchtigen und behaartfrüchtigen Weide herrorgegangen sind, wird der zu Anfang der Blüthezeit ganz behaarte Fruchtknoten während des Blühens manchmal an der Basis kahl, wie diess z. B. an der S. intermedia Host, die wir für einen Bastart aus S. incana und $S$, cinerea halten, der Fall ist.

Was die.Form des Fruchtknotens anbelangt, so lassen sich folgende drei Typen festhalten:

*) Denkschrift der schles. Gesellsch. f. vaterl. Kultur. Seite 148.

4\%) Von Host abgebildet: "Salix 2 tab. 70. Fig. 2-7. 


\section{1. eiförmig stumpf, z. B. S. purpurea;}

2. eiförmig in den Griffel vorgezogen, z. B. S. viminalis, S. daphnoides;

3. aus eiförmiger Basis kegelförmig verlängert, z. B. S. Caprea, S. fragilis.

Letzterer, der am häufigsten vorkommende Fall zeichnet sich noch dadurch aus, das's die Basis nach der Befruchtung sich überwiegend ausbaucht, während die samenlose kegelförmige Verlängerung in ihrer Ausdehnung nicht gleichen Schritt hält und so der noch grüne reifende Fruchtknoten gewöhnlich eine birnförmige Gestalt bekommt.

Mit den angegebenen drci Formen des Fruchtknotens steht auch die Form der aufgesprungenen reifen Kapseln im Zusammenhange. Die zwei Klappen der aus der ersten Fruchtknotenform hervorgegangenen eiförmigen oder fast kugeligen Kapseln $\mathrm{klaffen}$ nach Trennung des oberen Endes der Naht, ohne sich zurückzukrümmen; jene der zweiten und zum Theil auch jene der dritten Fruchtknotenform krümmen sich nach dem A ufspringen sichelförnig zur ück, und die Kapseln, welche aus den sehr verlängert kegelförmigen Fruchtknoten sich entwickelten, zeigen Klappen, deren Spitze sich schneckenförmig zurückrollt.

Die Form der Samen ist zu gleichförmig, als dass sie Anhaltspunkte zur Unterscheidung der Arten zu geben im Stande wäre. Die Samen sind bei allen Weiden länglich, gegen die Spitze meist etwas keilförmig rerdickt und spitz. Nur bei S. retusa und S. lierbacea erscheinen sie algestutzt oder stumpf. Die Unterschiede in der Grösse der Samen rerschiedener Arten erscheinen gleichfalls zu geringfïgig und schwankend, als dass man sie als Unterscheidungsmerkmale benützen könnte. - Die Teiden mit gelben einfärbigen Kätzchenschuppen zeichnen sich durch grosse sehr verdickte, jene der S. viminalis und S. arbuscula durch kleine schmale Samen aus. - Die Haare des Haarschopfes, welche dem kurzen dicken Stielchen des Samens aufsitzen, hängen bei allen Weiden an der Basis zu je dreien zusammen.

Der Torus bildet bes $S$. reticulata einen Kranz von $5-6$ um die Insertionsstelle der Staubgefässe oder des kurzen Frurhtknotenstieles herumstehenden fleischigen Warzen, ron denen oft zwei benachbarte mit einandur verwachsen, so dass die Basis der Staubgefässe oder des Fruchtknotens ron einem unregelmässig zerschnittenen fleischigen Ringe umgeben ist. - Bei den Staubblïthen und Fruchtblïthen aller Weidenarten mit zweifarbigen Kätzchenschuppen und daun noch bei $S$. glatra und S. incana, welche beide sowohl mit zweifarbigen als auch mit einfarbig gelbgrünen Kätzchenschuppen rorkommen, bildet der Torus an der innerer. der Kätzchenspindel zu schenden Seite der Insertion der Staubgefässe oder des Fruchtknotenstieles nur eine einseitige Verlängerung, die als watzenförmige oder griflelfürmige innere Drüse erscheint. - Dassube gilt auch ron den Fruchtblüthen jener Teiden mit einfärbig gelblichgrünen Kätzchenschuppen, deren Blätter in der Jugend nicht klebrig sind. Diejenigen aber mit klebrigen jungen Blärtern. nämich di 
Fruchtblïthen ron $S$. pentandra, S. firagilis und jener Weidenformen, welche wir für Blendlinge halten, die aus diesen beiden hervorgegangen, so wie die Staubblüthen aller. Weidenarten mit beständig einfärbigen gelblichen Kätzchenschuppen besitzen neben der inneren Drüse noch eine zweite griffelförmige äussere, welche der Basis der Schuppe anliegt und gleichfalls ron der Insertionsstelle des Fruchtknotenstieles oder der Staubgefässe, aber ron deren äusserer Seite ausgeht.

Die Form der Dr üse ist für viele Weidenarten sehr charakteristisch, und insbesondere ist in dieser Beziehung die linsenförmige Drüse der S. incana und ihrer rerwandten Formen, so wie die lineale gelbe Drüse der S. claphnoides, die verlängerte fast fädliche und gegen die Spitze gebogene gelbe Drüse der S. viminalis, die lineale purpurrothe Drüse der S. Myrsinites, die auffallend grosse abgestutzte oder oben ausgebuchtete innere Drüse der S. retusa, die gewühnlich zweilappige innere Drüse der S. pentandra und S. herbacea besonders hervorhebenswerth. In den Drüsen der Bastarte ist immer der Typus des gleichen Organes von einer seiner Stammeltern ausgesprochen, und es gibt daher die Drïse häufig rortreffliche Anhaltspunkte zur Ermittlung der Stammarten eines in der freien Natur aufgefundenen muthmasslichen Blendlings.

\section{Blüthezeit der Weiden.}

Was die Blüthezeit der Weiden anbelangt, so geben wir im Nachstehenden cine Zusammenstellung, welche sich auf Aufzeichnungen basirt, die ron uns in den Donau-Auen Niederösterreichs, vorzüglich in jenen nächst Krems und Mautern durch acht aufeinanderfolgende Jahre gemacht wurden.

\section{Normale Zeit der ersten Blüthen.}

$\begin{array}{lr}\text { S. daphnoides } & 26 \text { März } \\ \text { S. Caprea } & 27 \text { März } \\ \text { S. viminalis } & 1 \text { April } \\ \text { S. incana } & 3 \text { April } \\ \text { S. purpurea } & 8 \text { April } \\ \text { S. rosmarinifolia } & 15 \text { April } \\ \text { S. cinerea } & 15 \text { April } \\ \text { S. fragilis } & 13 \text { April } \\ \left.\text { S. amygdalina }{ }^{*}\right) & 16 \text { April } \\ \text { S. alba } & 17 \text { April }\end{array}$

Am friliesten trat die

Entwicklung der ersten Blüthen ein am:
Am spätesten trat die

Entwicklung der ersten Blïtlie ein am :

Mit diesen Zahlen stimmen die von Fritsch **) angegebenen, aus dreijährigen Beobachtungen abgeleiteten normalen Zeiten der ersten Blüthe:

*) Die Varietät cliscolor beginnt an gleichem Standorte gewöhnlich um einige Tage früher zu blühen, als die Varietät concolor.

a Phänolog. Beob. aus d. P\&anzen- u. Thierreiche. Suppl. zu vil I. B. d. Jahrb. d. k. k. C. A.f. Jeteorologie u. Erdmag. S. 22. 
S. dephnoides 29. März, S. qurpurea 11. April und S. repens 13. April, so wie jene in Neilreich's Flora von Niedcrösterreich pg. LXYIII von ihm mitgetheilten, aus siebenjährigen, im Wiener botanischen Garten am Rennwege angestellten Beobachtungen berechneten normalen Mittel: S. daphnoides 2. April, S. purpurea 11. April, S. repens 13̈. April ganz gut überein, indem die Verspätung bei $S_{*}$ daphnoides und $S^{\prime}$. purpurea, wie Fritsch selbst pg. LXVII bemerkt, auf Rechnung der Lage des botanischen Gartens, der gegen Norden abdacht, zu bringen ist.

Die Grösse der Verspätung der Blüthezeit in den Berg- und Voralpenthälern Niederösterreichs ist nach der Meereshöhe und Richtung der Thäler, so wie nach der Breite der Thalsohle und der Höhe der ein.chliessenden Berge so unendlich verschieden, dass wir auf genauere Zahlenangaben hier verzichten müssen. - Annähernd richtig kann angenommen werden, dass in den niederösterreichischen Voralpenthälern, deren Thalsohle etwa 1000' hoch liegt (Schwarzathal bei Gloggnitz, Traisenthal bei Lilienfeld und Türnitz, Erlafthal bei Scheibs und Gamming, Ipsthal bei Waidhofen) die Verspätung: 10 Tage beträgt. In den höheren subalpinen Thälern, deren Thalsohle sich zu $1800^{\prime}$ und $2000^{\prime}$ erhebt, beträgt die Verspätung $250-30$ Tage, und in Lakenhof, dem höchsten, $2 \mathbf{2}^{\prime \prime} \mathbf{3}^{\prime}$ gelegenen Thalorte am Nordfusse des Oetscher's, sogar $40 \ddot{~ T a g e . ~ D a s s ~ h i e b e i ~ a n ~ d e r ~ S o n n-~ u n d ~ S c h a t t e n s e i t e ~ d e s ~ T h a l e s, ~ a u f ~}$ dessen Sohle so wie an dessen Gehängen an ganz nahe gelegenen Punkten noch ganz bedeutende Unterschiede in der Entwicklungszeit der Blüthen rorkommen, wurde schon Eingangs besprochen und dort ausdrücklich hervorgehoben, dass die Häufigkeit ron Weidenblendlingen in den Toralpenthälern vorzüglich darin ihren Grund zu haben scheint, dass Weiden, die an gleichem Standorte zu sehr verschiedenen Zeiten blühen würden, dort an den gegenüberliegenden Lehnen zu gleicher Zeit ihre entfalteten Blïthenkätzchen den Bienen anbieten.

Geringer als in den Alpen Niederösterreichs ist die Verspätung bei gleicher Höhenlage in dem durch seine späte Vegetationsentwicklung mit Unrecht so sehr verrufenen böhmisch-mährischen Gebirgsplateau (dessen niederösterreichischer Antheil künftighin mit dem landesüblichen Ausdrucke „Waldviertel" bezeichnet werden soll), indem die Verspätung der Blüthenentwicklung. dort bei $1000^{\prime}$ Meereshöhe auf 6--8, bei $2000^{\prime}$ auf 22 und bei 2300 auf 30-36 Tage sich beläuft.

Von den in Gebiete der Donau-Auen nicht rorkommenden und somit auch im obigen Verzeichnisse nicht aufgeführten Weiden-Stammarten beginnt S. grandifolia um 5-6 Tage später als S. Caprea, - die S. glalra um 2-3 Tage nach S. incana, - und S. nigricans und S. anrita fast gleichzeitig mit $S$. cinerea die ersten Blüthen zu öflnen.

Ton den alpenbewohnenden Treiden ist die erste $S$. myrinites 1) Jurquiniata, dann folgt S. arbuscula, S. reticulata und S. vetusa. In einer Höhenlage ron :3000' kommen diese zierlichen Weidenarten gewöhnlich Mitte Juni zur Blüthe; 
werden aber auf den $6300^{\circ}$ hohen Kuppen noch in der zweiten Mälfte des Juli in Blüthe getroffen.

Die Blüthezeit derjenigen Weiden, welche wir für Bastarte halten, fällt in überraschend übereinstimmender Weise zwischen jene der wahrscheinlichen Stammeltern, doch gewöhnlich so, dass die Blendlingsart in den einzelnen Entwicklungsphasen sich jener der Stammarten mehr nähert, mit welcher sie auch durch ihren Gesammtausdruck mehr übereinstimmt. So schliessen sich die Blendlingsarten, die mit S. incana, S. riminalis und S. purpurea verwandt sind, auch in der Zeit ihrer Blïthenentwicklung an diese Stammarten zunächst an.

\section{Geografische Verbreitung der Weiden.}

Die meisten niederösterreichischen Weiden, welche wir als St ammarten a nsehen, besitzen einen ungemein grossen Verbreitungsbezirk, der sich ron der Mittelmeerzone bis hinauf in das nürdliche Russland und ron der Westküste Europas bis ïber das Altaigebiet, ja bei einigen bis Kamtschatka und das nördlichste Amerika ausdehnt. - Nur von fünf niederösterreichischen Weiden, nämlich: S.daphnoides, S. incana, S. glabra, S. grandifulia, S. retusa, verläuft die Hauptregetationslinie innerhalb des niederösterreichischen Gebietes und soll bei den betreffenden Arten ihre Besprechung finden. - Die nordische S. myitilloides, deren südöstliche, aus der Schweiz über die südbairische Hochebene in die Karpathen (Rox nordwestlich von Kesmark) hinziehende Vegetationslinie Niederösterreich schneidet, ist demungeachtet auf den ihr zusagenden Standorten, nämlich den Hochmooren des Waldviertels, bis jetzt noch nicht aufgefunden worden.

Für mehrere der im Nachfolgenden beschriebenen Weiden soll auch der Verlauf örtlicher Vegetationslinien näher bezeichnet werden. Wir meinen damit Linien, welche innerhalb des ron der Hauptregetationslinie umgrenzten Areales der Pflanze jene Bezirke näher bezeichnet und begrenzt, in welchen die Pflanze in einer ununterbrochenen Reihe ron Standorten vorkommt, und jene, in welchen sie nicht gefunden wird. Diese örtlichen Vegetationslinien finden zum Theil in Aenderungen der Höhenlage innerhalb des Hauptareales und in der dadurch bedingten örtlichen Aenderung der klinatischen Verhältnisse, zum Theil in der Aenderung chemischer, beziehungsweise petrografischer Verhältnisse ihre Erklärung, und fallen dann mit klimatischen oder petrografischen Linien zusammen; manche ron ihnen aber lassen sich weder aus dem einen noch dem anderen Verhältnisse, sondern nur aus der Geschichte der Erdobeifläche und ihrer Pflanzendecke erklären. - Solche örtliche Vegetationslinien nehmen ein nicht geringeres Interesse als die Hauptvegetationslinien in Anspruch, stehen mit diesen natürlich auch im innigsten ursächlichen Zusammenhange und werden uns, wenn sich einmal die Beobachtungen so sehr vervielfacht haben, dass dieselben für die Mehrzahl der Pflanzen kartografisch dargestellt werden können, die wichtigsten Anhalt:punkte zur 
Erkennung der Lebenshedingungen und der Geschichte der cinzelnen Arten an die Hand geben.

Jene örtlichen Vegetationslinien, die mit klimatischen Linien zusammenfallen und rorzüglich von der Bodenplastik abhängen, erscheinen durch die Angabe der Höhengrenzen hinreichend bestimmt, und wir werden uns daher in Beziehung solcher Tegetationslinien bei den einzelnen Arten in dem speziellen Theile dieser Arbeit bloss auf die Angabe ihrer vertikalen Verbreitung beschränken; - jene örtlichen Vegetationslinien aber, welche sich aus klinıtischen Linien allein nicht erklären lassen, sollen dort bei den betreffenden Arten eine ausführliche Erörterung erfahren.

Was die Verbreitung derjenigen niederösterreichischen Weiden anbelangt, wclche wir für Bastarte halten, so steht dieselbe der Verbreitung der Stammarten wenig nach, wenn auch die cinzelnen Fundorte in der Regel nur sehr zerstreut innerhalb des Verbreitungsbezirkes angetroffen werden. - So z. B. sind die Bastarte aus S. alba und firagilis, aus S. pentandia und firgilis, aus S. purpurea und viminalis, aus S. aurita und repens so weit rerbreitet als ihre Stammarten. Die Bastarte, an welchen S. incana, S. grandifolia und die anderen Stammarten mit beschränkteren Areal betheiligt erscheinen, halten auch mit der Verb"eitung dieser ihrer wahrscheinlichen Stammeltern in der Regel gleichen Schritt.

\section{Gruppirung der Weiden.}

Nicht olne Grund bezeichnete Endlicher die rielgestaltigen Weiden als: ,botanicorum crux et scandalum." - Wenn es schon schwierig ist, die Formen durch Beschreibungen fustzuhalten, so ist die Schwierigkeit, sie in natürlich begrenzte Gruppen einzureihen gewiss noch bei weitem grösser. Bei der allseitigen Verknüpfung, welche insbesondere durch die grosse 7.ahl der Blendlingsarten herrorgebracht wird, rerzagt man auch im ersten Augenblicke, dieses Heer von Weiden naturgemäss gruppiren zu können. - Dennoch sind gewisse Vorbilder nicht zu rerkennen, an welche sich sowohl die unzweifelhaften Stammarten als auch die. Blendlingsarten anschliessen. Sehr zu statten kommt dem Systematiker auch noch die Thatsache, dass die WeidenBastarte nur selten genau die Mitte zwischen ihren Stammältern halten, dass sie fast durchgehends als goneiklinische Blendlinge in Erscheinung treten, und dass es nur selten in Zweifel gezogen werden kann, an welche der Stammältern ein Bastart zunächst angereiht werden müsse.

Ton den Schriftstellern, welche die Weiden besonders bearbeiteten, haben Koch und Fries*), welche die Möglichkeit des Vorkommens ron Weidenblendlingen in der freien Natur noch bezweifelten, Zusammenstellungen sämmtlicher ihnen bekannten Weiden in natïrliche Gruppen rersucht, und

*) W. D. Koch: De salicibus enropaeis commentatio, Erlang. 1829. - Fries. Norit. Fl. Suec. Hant. II. p. 21-76. 
jene ron $\mathrm{Koch}$ wurde als die gelungenste von allen spüteren Florister ungeändert oder mit unbedeutenden Abweichungen beibehalten.

Wimmer, der die Aufmerksamkeit der botanischen Welt durch eine Reihe von höchst wichtigen Abhandlungen in der Regensburger Flora und in den Schriften der schlesischen Gesellschaft für vaterl. Kultur auf die so schwierige Planzengattung neuerdings hinlenkte und sich die grössten Verdienste durch die Erkennung und Begrenzung der grossen Reihe ron Blendlingen erworben hat, gab gleichfalls eine Eintheilung der Stammarten in der Flora 1849, Nr. 3, und ordnete entsprechend der in dieser Eintheilung befolgten Reihenfolge der Stammarten auch die 36 Weidenbastarte, welche er in der Denkschrift der schles. Gesellschaft f. raterl. Kultur beschrieben hat.

Sämmtliche Eintheilungen legen ein grosses Gewicht auf den Tuchs und die Hühe der Weiden, so wie auf deren Standort, und gestiitzt auf diese Merkmale wurden Arten, welche sonst wesentlich ron einander abweichen, in Gruppen zusammengefasst, die zum Theil als gezwungen und unnatïrlich angesehen werden müssen. Wir dürfen bloss auf die Koch'sche Gruppirung erinnern, nach welcher die so nahe rertrandten $S$. pliylicifolia und S. arbuscula in zwei getrennte Rotten gebracht werden, so wie nach der Eintheilung: ron Fries die höchst ähnlichen $S$. Myrsinites und $S$. polaris in zwei verschiedene Abtheilungen gestellt worden sind, bloss auf das Merkmal hin, dass bei der ersteren die Achselknospen an den Aestchen, die durch Käłzchen abgeschlossen sind, nicht zur Entwicklung kommen, während sie bei S. polaris sich weiter entwickeln, ein Merkmal, dessen schwankenden Werth wir bereits in dem Früheren besprochen haben.

Die Bildung der grösseren Gruppen wird zwar immer eine mehr oder weniger gezwungene sein, die Feststellung ron Rotten aber, unter welche sich Stammarten und Blendlinge, denen in ihrer Form ein gemeinschaftliches Torbild rorschwebt, zusammenscharen, ergibt sich ziemlich ungezwungen, und wir haben im Nachstehenden eine solche Zusammenstellung rersucht, die sich allerding's zunächst nur über die niederösterreichischen Weiden ausbreitet, in deren Abtheilungen jedoch auch alle bisher nicht in Niederösterreich gefundenen Formen passend untergebraeht werden können.

Einen wichtigen Anhaltspunkt zur Ermittlung der grösseren oder geringeren Terwandtschaft gab uns das Torhandensein oder Fehlen ron Blendlingen zwischen den unzweifelhaften Stammarten. Wir gingen ron der gewiss begründeten Annahme aus, dass diejenigen Arten die geringste Verwandtschaft besitzen, welche trotzlem dass die Bedingungen der Bastartirung für sie in der freien Natur vorhanden sind, dennoch keine Bastarte eizeugten - Die Purpurweide, so hï̈ufig und gewöhnlich sie auch mit den Bruch-, Mandelund Silberweiden untermischt rorkommt, hat doch bisher mit diesen noch keine Bastarte erzeugt; ebenso wenigals sich die S. repens und ihre Parallelform $S$. rosmarinifolia mit ihnen rerbunden haben. Diese Arten betrachten wir daher auch als die Endglieder der Kette ron Weidenarten, und $z$ war schliessen 
sich die Bruchweiden durch den klebrigen Ueberzug der jungen Blätter, durch dieBrüchigkeit ihrer $Z$ weige und durch die grössere Zahl von Staubgefässen an die Pappeln an, und die klebrigste mit $\ddot{b}$ bis 12 Staubgefä̀sen, nämlich $S$. peittandia ist als das eine Grenzglied, welches die Brücke zu der Pappel-Rotte Aigeiros baut, anzusehen, so wie die S. $p u v p u r e a$ mit $\mathrm{z} w$ ei rerwachsenen Staubgefässen das andere Endglied der Weidenreihe darstellt. Zwischen diese Grenztypen gruppiren sich die übrigen Weidenarten und bilden zwei in einander fliessende Gruppen: die eine mit rerlängerten schmäleren Blättern, kürzer gestieltem Fruchtknoten und rerlängertem Griffel, und eine zweite mit kürzeren breiteren Blättern, länger gesticlten Fruchtknoten und kurzem oder fehlendem Griffel.

Dem entsprechend theilen wir die Weiden in folgende vier Gruppen:

\section{A. Ch⿻肀口itere. ${ }^{*}$ ) Kätzchenschuppen einfärbig gelbgrün. An} den Einfügungsstellen der Staubgefässe in den Blïthenboden eine innere und äussere Druise. Antheren nach dem Stäuben gelb. Fruchtknoten kahl, Griffel fehlend oder kurz: $0.3-1 \mathrm{~mm}$ lang.

II. Macrostytace. Kätzchenschuppen zweifärbig oder einfärbig gelbgrün. An der Einfügungsstelle der Staubgefässe in den Blüthenboden nur eine innere Drüse. Antheren nach dem Stäuben gelb oder schwarz. Fruchtknoten kahl oder behaart. Griffel dünn fädlich verlängert: $1-2 \mathrm{~mm} 1 \mathrm{ang}$.

C. Microstoglec. Kätzchenschuppen $z$ we if ärbig. An der Einfügungsstelle der Staubgefässe in den Blïthenboden nur eine innere Drüse. Antheren nach dem Stäuben gelb. Fruchtknoten beharrt oder kahl. Griffel sehr kurz oder fehlend. Blätter im Verwelken braun werdend.

D. MRelitece. $\left.{ }^{* *}\right) \mathrm{K}$ ätzchenschuppen,zweifärbig An der Einfügungsstelle der Staubgefässe in den Blüthenboden nureine innere Drïse. Antheren nach dem Stäuben schwarz oder gelb. Fruchtknoten behaart. Griffel sehr kurz oder fehlend. Blätter im Verwelken schwarz werdend.

Die Verwandtschaftsterhältnisse dieser vier Gruppen erhellen aus folgender Zusammenstellung, in welcher die Zahlen sämmtlicher zwischen den Stammarten von je zwei Gruppen bisher in der freien Natur aufgefundenen Bastartformen nebeneinandergestellt werden:

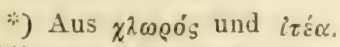

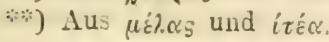


Zahl der Bastarte zwichen den Arten der

$$
\begin{aligned}
& \text { Chloriteas und Macrostylae .. . } 8 \\
& " \quad \text { Microstylae ... . } 2 \\
& n \text { M Ncliteae .... } 0
\end{aligned}
$$

Macrostylas und Microstylae. . . 22

$" \quad$ Meliteae ... 10

"

Chloritece ... 7

Microstylae und Macrostylae. . . 22

" Meliteae .... 18

$\pi$

"Chloriteas ...2 2

Meliteae und Microstylas ... 18

$" \quad "$ Macrostylae... 10

\section{A. Chloriteae.}

Die gemeinschaftlichen Merkmale, welche den Arten, die in dieser Giuppe aufgeführt werden, zukommen, sind folgende: Die Blätter sind kahl oder nit anliegenden geraden, dem Mittelnerven des Blattes parallel laufenden langen Haaren bekleidet. Die untere Blattseite ist von einem rorspringenden staiken Mittelnerven und ron schlanken zarten, entweder gar nicht oder l:aum über die Blattmasse sich erhebenden Seitennerven durchzogen, die obeie meist glänzend grüne Blattseite ist an frischen Blättern glatt, an getrockneten Bläitern von etwas ror'springenden zarten Nerrchen geadert. Die Blätter werden in Verwelken lichter oder dunkler braun (niemals bläulich schwarz). - Die lockerblüthigen Kätzchen brechen zu gleicher Zeit mit den Biättern hervor, die kurzen käizchentragenden Triebe sind mit 2-3 Bläitern besetzt, welche in der Knospe das noch unentwickelte Käizchen einschliessen. Die Achise des Kätzchens ist bei allen, selbst den sonst ganz kalılen Arten ron absteheuden krausen Haaren flaumig. Die Kätzchenschuppen sind einfärbig gelbgrün, länglich, stuṇıf oder abgestutzt, meist sparsam behaart. Die Staubgefässe 2- 12 an der Zahl; die Antheren sind vor, während und nach dem Stäuben gelb; die Staubfäden sind frei, an ihrem unteren Ende etwas flaumig und durch die ineinandergreifenden Härchen manchmal 1)cker zusammenhängend. An der Basis der Staubfäden befinden sich zwei abgestutzte kurze honiggelbe Driisen des Blüthenbodens, die eine an der Scite gegen die Kätzchenspindel, die zweite an der äusseren Seite angeschmiegt ail den Grund der Schippe. Die Fruchtknoten sind gestielt oder fast sitzend, kahl, zur Zeit der Blüthe kegelförmig, später sich an der Basis stark ausbauchend und birnförnig; Griffel fast fuhlend oder kurz, 0.ö-1 
Narben kurz, dicklich, abstehend, ausgerandet oder zweilappig, gelb, wachsartig glänzend. Die innere Drüse des Blüthenbodens an der Einfügung-stelle des Fruchtknotenstieles jener der Staubblüthen gleich gestaltet, die äussere Drüse bei der Mehrzahl der Teidenarten dieser Gruppe fehlend. Die Klappen der aufgesprungenen Kapsel sichelfürmig zurückgekrümmt.

Die Chloriteen zeichnen sich auf den ersten Blick durch ihre lockerblüthigen blassen Kätzchen, welche bei den Fruchtbliithen tragenden Bäumen und Sträuchern wegen grüner Farbe der Fruchtknoten und grünlicher Färbung der Kätzchenschuppen ron dem zu gleicher Zeit mit den Blüthen hervorbrechenden Laubwerk sich kaum herausheben, schr aus. Aus der Reihe der Weiden der nächstfolgenden Gruppe künnten nur zwei Arten, nämlich S. glalra und $S$. incana durch ihren äusseren Eindruck verleiten, sie unter die hier gekennzeichneten Chloriteen zu stellen. In der That ist auch erstere ron Neilreich, letztere ron Grenier und Godron an die hier von uns zusammengefa-sten Arten angereiht worden. S. gla ra unterscheidet sich jedoch selbst dann, wenn ihre Kätzchenschuppen an der Spitze nicht geröthet sind, ron den Chloriteen durch den Mangel der äissseren Drüse in den Staubblüthen, durch längeren Griffel und schwarz werdende Blätter; S. incaun überdiess noch durch andere Blattnervatur und fälliche Narben.

\section{Die Chloriteen zerfallen in rier Rotten:}

I. Fragizes. Koch. Bruchweiden. - Bäume oder Siräucher mit schlanken, an den Abästung-stellen brüchigen und mit glatter glänzender häutiger Rinde überzogenen Zweigen. Die lanzettlichen zugespitzten Blätter in der Jugend klebrig, kalıl, oberseits glänzend, am Batt_tiel häufig: mit Drüschen besetzt. Staubgefässe 2-12. Die zilindrischen, oft bogenfürmig gekrümmten Kätzchen an beblätterten Aestchen. Kätzchenschuppen noch vor der Fruchtreife abfallend. An den Fruchtbliithen ebenso wie an den Staubblüthen sowohl eine innere wie äussere Drüse. Fruchtknoten gestielt, Griffel $0.3-1 \mathrm{~mm}$. lang, ebenso wie die zweilappigen Narben wachsartig, dicklich, abstehend.

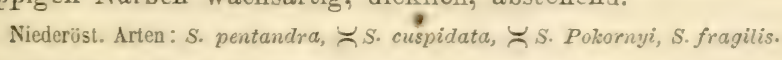

14. Abre. Silberweideu. - Bäume oder Sträucher mit schlanken, an den Abästung -stellen wenig brüchigen und mit glatter häutiger Rinde überzogen:n Zweigen. Die lanzettlichen zugespitzten Blätter sind in der Jugend mit geraden, dem Mittelnerven parallel anliegenden Haaren mehroder weniger bedeckt und seidig glänzend, nicht klebrig. Blattstiele ohne Drüscn. 1)ie zilindrischen, of bogenfömig gekrïmmten Käizchen an schr kurzen beblätterten Acotchen. Käzehenschuppen noch ror der Fruchtreife abfallend. Blüthenboden der Staublüthen zweidrüsig, jener der Fruchtbluthen eindrusig. 
Fruchtknoten sehr kurz gestielt. Griffel sehr kurz und die fast sitzenden zweilappigen wachsartigen Narben abstehend. Staubgefässe 2.

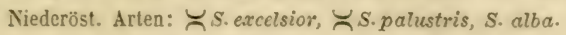

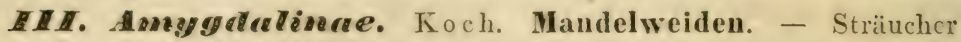
oder Bäumchen mit schlanken, zähen, kahlen, biegsamen, mit glatter Kinde ûberzogenen $Z$ weigen. Die lanzettlichen zugespitzten Blätter sind kahl, in der Jugend nicht klebrig. Blattstiel ohne Driisen, Nebenblätter halbnierenfürmig. Die zilindrischen meist geraden reichblüthigen Kätzchen an kurzen beblätterten Aestchen. Kätzchenschuppen nicht abfallend. Blüthenboden der Staubblüthen zweidrüsig, jener der Fruchtblüthen eindrüsig. Fruchtknoten lang gestielt. Griffel sehr kurz, Narben gegen das Ende zu rerdickt und unter rechtem Winkel ron dem Griffel abstehend. Staubgefässe 2-3.

Niederöst. Arten: $\asymp S$ subtriandra $a$, S. Kovátsii, S. amygdalina.

D. IBetersae. - Stumpfblättrige Weiden. - Kleine an den Boden angedrückte Alpenstrüucher mit armknospigen, leicht abbrechbaren, glatten, kahlen Zweigen. Die stumpfen oder ausgerandeten Blätter sind kahl, in der Jugend nicht klebrig. Blattstiel ohne Drüsen. Die geraden armblüthigen Kätzchen an kurzen beblätterten Aestchen. Kätzchenschuppen nicht abfallend, meistabgestutzt. Blüthenboden der Staubblüthen zweidrüsig, jener der Fruchtblüthen eindrüsig. Fruchtknoten kurz gestielt. Griffel kurz. Die wachsartigen Narben zweilappig, abstehend. Staubgefässe 2.

Wir haben keinen Anstand genommen, an die hochstämmigen Felbern mit gelbgrünen Kätzchenschuppen auch die zierlichen Alpensträuchelchen S. retusa und $S$. herlacea, welche sich allein durch ihren zwergigen Wuchs und dadurch ron den anderen Chloriteen unterscheiden, dass bei ihnen die Knospenanlagen in der Achsel der Kätzchenstielblätter gewöhnlich zur weiteren Entwicklung kommen, während sie bei den anderen in der Regel rerkümmern, hieher zu ziehen, um so mehr, als das letztgenannte Merkmal für $S$. retueu nicht einmal als beständig angefihht werden kann. Auf keinen Fall würde dieses Merkmal die Trennung dieser zwei Alpenweiden ron den anderen Chloriteen rechtfertigen, mit welchen sie in allen übrigen Merkmalen übereinkommen.

Niederöst. Arten: S. retusa, そS. Fenzliana, S. herbacea.

\section{B. Macrostylae.}

Die Blätter sind in Zuschnitt, Nervatur und Bekleidung sehr mannigfaltig, doch spricht sich bei der MIehrzahl die lanzettliche Grundform aus, und meistens sind die Blätter überdiess sehr verlängert. Beim Verwelken werden dieselben braun oder schwarz; die Kälzchen der alpenbewohnenden 
Arten brechen gleichzeitig mit den Bliittern hervor und schliessen ein beblättertes verläng'ertes Aestchen mit verkümmernden Achselknospen ab Die Arten der Ebene oder jene, welche die Thäler bewohnen, haben hingegen sitzende vorläufige Kätzchen, deren sehr kurze Stiele mit schuppenfürmigen kleinen Blättchen bekleidet sind. Die Kätzchenschuppen sind meistens zweifarbig, an der Spitze lichter oder dunkler roth gefärbt und lang behaart, jene der Fruchtblïthen von $S$. glabva und $S$. incana sind einfärb:g gelbgriun und fast kahl, der Torus sowohl an den Frucht- wie an den Staubbliithen nur zu einer inneren Drüse ausgewachsen. Staubgefässe zwei. Staubfäden frei oder theilweise mit einander verwachsen, an der Basis kahl oder flaumig. Antheren nach dem Verblïhen gelb oder schwarz. Fruchtknoten und Kapsel in Form und Behaarung bei den verschiedenen Arten sehr ver:chieden, die Griffel jedoch bei allen Arten fadlich, verlängert, $i-2 \mathrm{~mm}$. lang, und die Narben häufig bogenförmig abwärts gekrümmt.

Die hier zusammengefassten Weiden sind durch die eindrüsigen Staubblüthen und den verlängerten Griffel der Fruchtblüthen von den übrigen Gruppen unterschieden. Sie reihen sich in nachfolgende fünf Rotten:

T. MIgzosatix. Myrtweiden. - Die ausgewachsenen Blätter gleichfarbig, kahl, glänzend, schon im lebenden Zustande oberseits ron vorspringenden Nerven durchzogen, im Verwelken schwarz werdend. Die Kätzchen kurz zilindrisch, am Ende ron beblätterten Aestchen, deren Knospen regelmässig verkümmern. Kätzchenschuppen lanzettlich, lang: behaart. Torus-Drüse fädlich purpurroth. Staubgefässe 2, frei. Antheren vor dem Aufblühen roth, dann gelb, spätes schwarz werdend. Fruchtknoten kurz gestielt, eiförmig, in den verlängerten fädlichen purpurrothen Griffel vorgezogen. Narben fädlich, purpurroth, abstehend. Kapselklappen sichelförmig auswärts gebogen.

Alpenbewohnende niedere, meistens auf den Boden hingestreckte Sträuchlein, deren Kätzchen zu gleicher Zeit mit den Blättern herrorbrechen und die durch verlängerte fädliche Griffel und Narben, so wie durch die Form des Fruchtknotens und der Torusdrüse sich mit den nächstfolgenden Rotten verbinden, aber durch die rothe Farbe des Griffels und der Narben, so wie durch die schwarz werdenden Antheren sich von ihnen unterscheiden. - Durch die der S. Myrsinites verwandte S. proluris einerseits und durch $S$. herbacea anderseits rerknüpft sich die hier begrenzte Rotte mit den Chloriteen. Doch kommt die S. polaris nur durch das Merkmal der knospenreifenden Kätzchenstiele und die Form der Blätter mit S. herbacea iiberein, während sie sich durch purpurne verlängerte Torusdrüse und Griffel, so wie durch das Fehlen der äusseren Torusdrüse der Staubblüthen und die schwarz werdenden Antheren unmittelhar an S. Myrinites anschliesst. - Durch das Merkmal der nach dem Verstäuben schwarz werdenden Antheren kommen die Myrtweiden noch mit den Purpurweiden überein, 
mit denen sie aber in den übrigen wesentlichen Merkmalen keine Verwandtschaft zeigen.

Niederöst. Art: S. Myrsinites var. Jacquiniana.

II. Antoescotere. Buschweiden. - Nicdrige viel- und kurzästige Alpensträucher mit zähen Zweigen, kahlen, seidigen oder graufilizgen, im Verwelken braun werdenden Blättern, die sich zu gleicher Zeit mit den dichtblüthigen, länglich zilindrischen, geraden, länger oder kürzer gestielten Kätzchen entwickeln. Kätzchenschuppen länglich, geröthet, behaart. Torusdrüse länglich, gelb. Staubfäden frei, Antheren nach dem Verstäuben gelb. Fruchtknoten kurz gestielt oder sitzend, eiförmig, seidig behart. Die beiden bei den anderen Teiden zu einem zusammengewachsenen Griffel sind bei den Arten dieser Rotte nicht selten bis zum Fruchtlnoten hinab getrennt und der Stempel in solchen Fällen zweigriffelig. Griffel und Narben gelb. Kapselklappen sichelförmig zurückgekrümmt.

Der hier begrenzte Teidentypus bei uns nur durch $S$. arluscula rertreten, ist durch diese Art in seiner äusseren Erscheinung nit dem früheren verwandt, jedoch durch die gelbe Farbe der Narben, des Griffels und der Torusdrüse, so wie durch nicht schwarz werdende Blätter und Antheren ron ihm unterschieden. Unsere $S$. ailuscula hat kahle Blätter. Von den nicht in Niederöst sreich rorkommenden Arten dieser Rotte sind aber $S$. ylauca und viele Formen der S. Lapponum zum Theil mit langen §eraden, dem Mittelnerr parallelen Haaren bedeckt, zum Theil haben sie die Behaarung der nachfolgend beschriebenen Grauweiden, bald auch mahnt die Behaarung an jene der $S$. viminalis. Letzteres ist namentlich an den behaartblättrigen Formen der S. phylicifolia rom Brocken der Fall, deren Blätter an der unteren Seite ron geraden, zarten, anliegenden, der Richtung der Seitennerven folgenden Härchen bedeckt erscheinen und auch ganz ähnlich der S. viminalis das eigenthümliche seidige Schillern zeigen.

Niederöst. Art: S. arbuscula.

II. Viasainceses. Korbweiden. - Sträuchel mit schlanken, zähen, nicht bereiften $Z$ weigen mit gelbgrüner Rinde und verlängert lanzettlichen, am Rande nanchmal etwas welligen und umgerollten Blättern, die oherseits dunkelgrïn und gewöhnlich vertieft nerrig, unterseits erhaben nervig, blassgrün und kahl, oder ron zarten, den Seitennerren parallelen Härchen bedeckt sind und dann meist ein eigenthümliches seidiges Schillern wahrnehmen lassen. Die Blätter werden im Verwelken braun. - Die Kätzchen sind sitzend, rorläufig, dichtblïthig, eiförmig oder zilindrisch, gerade oder etwas gebogen. Dic Kätzchenschuppen sind lanzettlich spitz, gegen die Spitze dunkel geröthet, mit langen Haaren bekleidet. Torusdrüse rerlängert lineal. Staubgefässe 2, Staubfäden an der Basis kahl, frei oder theilweise verwachsen, Antheren nac h dem Stäubes 
gelb. Die Fruchtknoten sitzend oder kurz gestielt, ron anliegenden Härchen seidig filzig, eiförmig, in den fädlichen gelben Griffel vorgezogen. Die ungetheilten oder zweispaltigen fädlichen gelben Narben bogenförmig auseinanderlaufend. Kapselklappen sichelförmig auswärts gekrümmt.

Die verlängerten eigenthümlich behaarten Blätter, die eigenthümliche Form des Stempels und der Torus-Drüse lassen die Stammform dieses Weidentypus, nämlich $S$. viminalis in der Regel ziemlich leicht in den durch sie gebildeten Blendlingen erkennen. - Nur diejenigen Bastarte, welche sie mit den Chloriteen bildet (ron denen bisher keiner in Niederösterreich aufgefunden wurde, die aber anderwärts ziemlich häufig zu sein scheinen), schliessen sich in ihrer Form meistens den letzteren an; alle diejenigen Blendlinge aber, bei welchen wir dafür halten, dass sie durch Verbindung der S. viminalis mit den Arten der Gruppe Rugosae und Meliteae entstanden sind, nehmen den Typus der $S$. viminalis an.

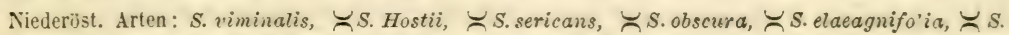
rubra, こS. Forbyana, こS. angustifolia.

TE. Cesecse. Grauweiden. - Sträucher oder Bäumchen mit brïchigen, dunkelrindigen, in der Jugend graufilzigen Zweigen ron trübgrünem Ausschen. Die lanzettlichen oder linealen Blätter sind in der Jugend immer ủnd oft auch im ausgewachsenen Zustande am Rande umgerollt, oberseitsvertieft nervig, dunkel oder schmutzig grün, glanzlos und zur Zeit der Entwicklung mit grauemabwischbaren Flaume bedeckt, unterseits mit glanzlosem, aus verworrenen langen Haaren gebildetem weissem Filze überzogen. Der Mittelnerr der unteren Blattseite ist dick, stark rorspringend, meistens kahl; die Seitennerren dieser Blattseite, obschon rom weissen Filze eingehüllt, sind dennoch vorspringend. Die sitzenden Kätzchen erscheinen verlängert zilindrisch, lockerblüthig und bogenförmig gekrümmt, in der Ebene vor, in den Alpen mit den Blättern sich entwickelnd. Die Kätzchenschuppen an der Stammform dieser Rotte länglich, stumpf oder abgestutzt, kahl oder spärlich gewimpert, jene der Staubkätzchen gelb mit schwach gerötheter oder brauner Spitze, jene der Fruchtkätzchen einfärbig gelbgrün; die Kätzchenschuppen derjenigen Arten, die wir für Bastarte halten, behaart, länglich, stumpf, an der Spitze bräunlichroth bis dunkelpurpurn. Torusdrüse kurz, linsenförmig, gelb, Staubfäden theilweise rerwachsen, an der Basis flaumig und durch die ineinandergreifenden Härchen häufig lose zusammenhängend. Antheren nach dem Verstäuben gelb. Fruchtknoten lang gestielt, zur Zeit der Blïthe aus eiförmiger Basis verlängert kegelförmig, später sich ausbauchend und birnförmig, entweder kahl oder filzig, glanzlos. Griffel fädlich, die gelben Narben tief zweispaltig und dic fädlichen Lappen zurückgerollt. Kapselklappen schneckenförmig zurückgerollt. 
Die Weiden dieser Rotte sind schon von ferne durch ihr eigenthümliches Wachsthum kenntlich. Bei den anderen schmalblättrigen Weiden mit langen Ruthen ( $S$. alba, S. amygdalina, S. viminalis etc.) entwickelt sich immer die oberste laterale Laubknospe, welche der abgestorbenen terminalen Laubknospe zunächst stand, am üppigsten und bildet einen auffallend rerlängerten Spross, der die Seitenstänmchen, welche aus den anderen nach abwärts folgenden lateralen Laubknospen derselben gemeinschaftlichen Hauptachse kommen, weit überragt. Bei $S$. incana ist jedoch die Lünge der Triebe, welche sich aus den zwei oder drei obersten lateralen Seitenknospen bilden, ziemlich gleich gross, und dieser Umstand bedingt namentlich dann, wenn die Laubknospen sehr genähert standen, eine ganz eigenthümliche, im ersten Augenblicke gabelig erscheinende Verästlung. - Diese Eigenthümlichkeit spricht sich auch in den Bastarten, an welchen wir $S$. incana betheiligt halten, immer aus und findet sich wiederholt in den früher beschriebenen, gleichfalls in die Gruppe der Macrostylae gehörigen Buschweiden, deren zierliches Ansehen rorzüglich auf dieser Art der Verzweigung beruht.

Die Grauweiden wurden ron der Mehrzahl der Autoren in die Gruppe Rugosae oder Capreae gestellt, mit denen sie die Nervatur (nicht aber die Behaarung) der Blätter und die lang gestielten Fruchtknoten gemein haben. Von Grenier und Godron wird die Stammform S. incana den Mandelund Bruchweiden, mit welchen die Fruchtkätzchen tragenden Stämme durch die kahlen Fruchtknoten und einfärbig gelbgrünen Kätzchenschuppen übereinstimmen, angereiht, und Wimmer, der die Stammform $S$. incana in der Flora 1819, Nr. 3, als selbstständigen Typus bezeichnet, welchem er unmittelbar den Typus der $S$. viminalis folgen lässt, vereinigt sie in der in Nr. 4 versuchten Eintheilung der Weiden geradezu mit $S$. viminalis in eine Gruppe. Mit dieser erscheint sie auch unstreitig am nächsten verwandt und schliesst sich namentlich in der Blattform und Nerratur, so wie in der Form der Griffel und Narben an dieselbe an, so wie sie ganz dieselbe Reihe von Bastarten mit den Arten der Gruppe Rugosae und der S. purpurea bildet. Die Formen, welche wir durch Kreuzung der Stammart S. incana mit den Arten der Gruppe Rugosae hervorgegangen halten, schliessen sich (ähnlich so wie jene aus $S$. viminalis und den Arten der Rugosae) alle an $S$. incana an und erscheinen in dem oben begrenzten Typus der Grauweiden. - Dasselbe gilt ron einem der Bastarte, an welchem sich nebst $S$. incana die S. purpurea betheiligt zu haben scheint. Ein zweiter Blendling aber aus $S$. incana und purpurea nähert sich mehr der letzteren Stammart, ebenso wie S. Wimmeri, die wir durch Verbindung der S. incana und S. daphnoides entstanden glauben, den Typus der letzteren annimmt. Blendlinge der S. incana mit den Arten der Gruppe Chloriteae sind, obschon die Bedingungen der Bastartirung bei dem häufigen Untereinanderwachsen sehr häufig gegeben sind, bisher nicht bekannt geworden.

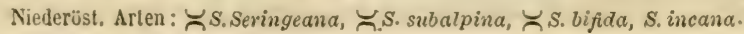


V. Previnosae. Schimmelweiden. - Bäume oder Sträucher mit brüchigen, meist hechtblau bereiften $Z$ weigen, lanzettlichen, im Alter kahl werdenden, oberseits glänzenden, glatten, im getrockneten Zustande von zarten, etwas erhabenen Nerren durchzogenen, unterseits bläulichen Blättern, die im Verwelken braun werden. Die grossen dichtblïthigen, entweder eiförmigen oder zilindrischen, manchmal bogenförmig gekrümmten Kätzchen, die selbst zur Zeit der Fruchtreife noch sitzend erscheinen, brechen vor der Entwicklung der Blätter heraus. Die Kätzchenschuppen sind lanzettförmig spitz, gegen die Spitze dunkelpurpurn oder braunroth mit langen Haaren bckleidet. Die Torusdrüse verlängert lineal, gelb. Staubfäden frei. Antheren nach dem Sätuben gelb. Fruchtknoten sitzend oder kurz gestielt, kahl, eiförmig in den dünnen gelben Griffel vorgezogen. Die fädlichen gelben Narben spreizend, ungetheilt. Kapselklappen sichelförmig auswärts gekrümmt.

Durch die vorläufigen, dichtblüthigen, grossen sitzenden Kätzchen, die vor dem Aufblühen in einen dichten weissen Pelz gehüllt erscheinen, durch die Form des Stempels und die verlängerte lineale Torusdrüse stimmen die Schimmelweiden mit den Korbweiden überein, mit denen sie auch ron Grenier und Godron in eine Gruppe zusammengefasst wurden. Durch die Blättform sind sie einigermassen mit den Chloriteen verwandt. Durch S. Wimmeri erscheinen sie mit der Gruppe der Grauweiden rerknüpft, mit deren Stammform sie auch noch die Kahlheit der Fruchtknoten gemein haben.

Ni ederöst. Arten : $\asymp S$. Wimmeri, S. daphnoides.

W. Nigrecactes. Schwarzweiden. - Vielrerzweigte Sträucher mit dicken kurzen Aesten. Die breiten kurzbespitzten Blätter sind in der Jugend kahl oder mit kurzen etwas abstehenden Haaren bekleidet. Die obere Blattfläche der ausgewachsenen Blätter ist kahl, mehr oder weniger glänzend, erhaben oder vertieft nervig, die untere gleichfalls kahl werdend, bläulich bereift oder blassgrün, matt, glanzlos, ron lichten, etwas vorspringenden Nerven geadert. Die Blätter werden im Verwelken bläulich schwarz. - Die dichtblüthigen, eiförmigen oder kurz zilindrischen Kätzchen brechen zu gleicher Zeit mit den Blättern herror, ihre Stiele sind mit $2-5$ Blättchen besetzt, welche in der Knospe das noch unentwickelte Kätzchen einschliessen. Die Kätzchenschuppen sind länğlich, stumpf, gelblichgrün, an der Spitze entweder nur röthlich angehaucht oder dunkelpurpurroth, jene der Fruchtkätzchen ron $S$. glabre und $S$. suldylubra cinfürbig gelbgrün. Torusdrüse gelb, kurz, zilindrisch. Staubgefïsse zwei, Staubfäden frei, an der Basis tlaumig, Antheren nach dem Stäuben schmutzig gelb. Fruchtknoten gestielt, aus eiförmiger Basis verlä̈gert kegelförmig. Der $1-2 \mathrm{~mm}$. lange Griflel ist der Länge nach häutig ron zwei Furchen durchzogen, welche der Verwachsung:- 
stelle der zwei Griffel entsprechen, deren jeder einem Fruchtblatte angehört; die Narben fleischig, dicklich, zweilappig, abstchend. Die Kapselklappen schneckenförmig zurückgerollt.

Die Arten dieser Rotte sind von den anderen in die Gruppe Macrostylae gehörig'en Weiden durch die dicklichen, nicht fädlichen Narben, überdiess von den Myrt-, Busch-, Korb- und Schimmelweiden durch die kurze Torusdrüse, die länger gẹtielten, verlängert kegelförmigen Fruchtknoten und schneckenförmig zurückgerollten Kapselklappen, und ron den Grauweiden durch andere Blattform und Bekleidung, so wie durch die kurzen dichterblïthigen Kätzchen unterschieden. - Von den Chloriteen grenzen sie sich durch die eiförmigen sitzenden Staubkätzchen, die meistens gerötheten Kätzchenschuppen, das Fehlen der äusseren Torusdrüse, die schneckenförmig zurückgerollten Kapselklappen und die im Verwelken schwarz werdenden Blätter ab. Die S. glubra bildet übrigens das Verbindungsglied mit der Gruppe Chloriteae und wurde auch, wie schon früher erwähnt, von Neilreich mit den Arten derselben verknüpft. Die fruchtblüthentragenden Sträucher dieser Art, deren Kätzchenschuppen einfärbig gelblichgrün erscheinen, besitzen in der That auch einige Aehnlichkeit mit $S$. pentandra und $S$. fragilis, namentlich wenn diese letzteren durch kurze Kätzchen und breite Blätter ausgezeichnet sind. - Der Mangel der äusseren Torusdrüse, so wie des klebrigen Ueberzuges der jungen Blätter geben aber immer sichere Anhaltspunkte für S. glabra, um sie von den Bruchweiden zu unterscheiden. - Von Koch wurden die Schwarzweiden mit den Sahlweiden vereinigt, und der Anschluss an diese wird auch durch $S$. nigricans vermittelt, welche sich namentlich in der Form, Nerratur und Bekleidung der Blätter den Sahlweiden nähert. Der verlängerte Griffel, die an der Basis flaumigen Staubgefässe und die schwarz werdenden Blätter ziehen jedoch die Grenze, durch welche die Schwarzweiden von den Arten der nächstfolgenden Gruppe sich absondern.

Niederöst. Arten: S. glabra, ØS. subglabra, S. nigricans.

\section{Microstylae.}

Bilden eine gut begrenzte Gruppe, die in Niederösterreich nur durch

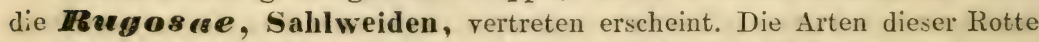
sind Sträucher oder kleine Bäume mit kurzen, dicken, ziemlich zähen Zweigen. Ihre Blätter sind breit oral, oder länglich verkehrteiförmig, kurz zugespitzt, an der unteren Seite von vorspringenden Nerven geadert und meistens mit abstehenden, sich sammtig anfühlenden kurzen Haaren bekleidet, an der oberen Seite dunkel oder graugrün, wenig glänzend, von rertieften feinen Linien durch$\mathrm{zogen}$ und dadurch mehr oder weniger runzelig. Beim Verwelken werden die Blätter braun. - Die Kätzchen, der die Alpen bewohnenden Arten brechen zu gleicher Zeit, jene der in niederen Höhenlagen rorkom- 
menden meistens vor den Blättern heraus. - Die sehrr rerkürzte Achse des Kätzchens ist mit schuppenförmigen Blättchen bekleidet und fällt nach dem Verstäuben oder Ausfliegen der Samen regelmässig ab. - Die Kätzchen sind vor dem Aufblühen in einen dichten weissen Pelz gehüllt, die Staubkätzchen eiförmig, dichtblüthig, die Fruchtkätzchen eifürmig oder zilindrisch, lockerblüthiger. Die Kätzchenschuppen lanzettlich zweifarbig, an der Spitze rostfarbig oder purpurn bis schwärzlich, mit langen geraden Haaren besetzt. A eussere Torusdrüse fehlend; innere kurz abgestutzt. Staubgefässe zwei, Staubfäden frei, an der Basis kahl, Antheren nach dem Stäuben schmutziggelb, während und vor dem Stäuben hcllgellb, vor dem Aufblühen manchmal auch etwas röthlich. Fruchtknoten lang gestielt, aus eiförmiger Basis verlängert kegelförmig, meist behaart, der Fruchtknotenstiel wenigstens 3 Mal so lang als die Torusdrüse. Griffel sehr kurz oder fehlend. Narben kurz, eiförmig, manchmal etwas ausgerandet, abstelend oder aneinanderliegend. Kapselklappen an der Spitze sich schneckenförmig zurückrollend.

Die Arten dieser Rotte unterscheiden sich ron jenen der früheren Gruppe durch den fehlenden oder sehr kurzen Griffel, ron den nachfolgenden Meliteen durch die im Verwelken braun werdenden Blätter und ron den Chloriteen durch die zweifarbigen Kätzchenschuppen. - Durch S. silesiaca, welche unter allen Arten des hier umgrenzten Weidentypus noch den längsten Griffel besitzt, schliessen sie sich an die Macrostylae an; durch die Bastarte, welche sie mit $S$. repens und $S$. purpurea bilden, rerknüpfen sie sich mit den Meliteen. Mit der letzteren Gruppe besitzen sie - der grossen Zahl der Bastarte nach zu schliessen - auch die grösste innere Verwandtschaft. Die geringste Verwandtschaft zeigen sie mit den Chloriteen und die Anzahl der Bastarte, welche sie mit diesen in der freien Natur bildeten, laat bisher: 2 nicht überschritten.

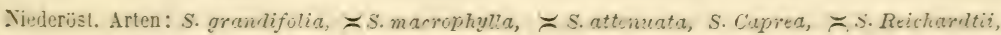
S. cinerea, $\asymp$ S.lutescens, S. aurita.

\section{Meliteae.}

Die lanzettlichen im oberen Drittheil gewöhnlich breitesten oder auch linealen und elliptischen Biätter sina $\mathrm{kahl}$ oder mit geraden den Mittelnerven parallel anliegenden seidigen Haaren bedeckt, seltener unterseits mit etwas abstehenden, kurzen, glanzlosen, sich sammtig anfühlenden Härchen bekleidet. Die obere Blattseite ist entweder glatt und im getrockneten Zustande ron feinen etwas erhabenen Seitennervehen durchzogen oder sie erscheint ron zarten etwas rertieften Linien durchfurcht. Die Jerren der unteren Blattseite sind bei jenen mit schwarz werdenden Antheren wenig. bei jenen mit nicht schwarzwerdenden Antheren stärker vorsprungend. D ie Blätter werden im Verwelken schwarz. Di. Kätzchen sind vor dem Aufblühen meistens in cinen weissen Pelz @ehüllt und brechen kurze Zevit 
ror, oler gleichzeitig mit den Blättern herror. Die blühenden Kätzchen sind sitzend und entweder eiförmig oder verlängert zilindrisch und dann häufig bogenförmig gekrümmt. Die sehr verkürzte kätzchentragende Achse ist ron linealen schuppenförmigen um die Basis des Kätzchens herumstehenden Blättchen bekleidet und fällt nach dem Verstäuben oder Ausfliegen der Samen regelmässig ab. Die zweifarbigen Kätzchenschuppen sind an der Basis blass, aufwärts roth und gegen den freien Rand meistens schwärzlich. Aeussere Torusdrüse fehlend, innere Torusdrüse sehr kurz, abgestutzt. Staubgefässe zwei, Staulfäden frei oder theilweise oder der ganzen Länge nach verwachsen, Antheren anfangs roth, zur Zeit des Stäubens gelb, später schmutziggelb oder schwarz werdend. Fruchtknoten meistens behaart, gestielt oder sitzend, so wie die Kapseln in der Form bei den verschiedenen Arten verschieden. Der Griffel sehr kurz oder fehleud, die Narben fast sitzend, rundlich oder eiförmig.

Die Meliteen zerfallen in drei Rotten:

H. Incezbrecene. - Moorweiden. - Niedere Sträucher mit kriechendem Stamme und bogig aufsteigenden, schlanken, biegsamen $Z$ weigen. Die lineal lanzettlichen oder länglich elliptischen Blätter sind oberseits: kahl, glanzlos, dunkel oder graugrün, glatt und dann im getrockneten Zustande von erhabenen feinen Seitennervchen durchzogen oder vertieft nerrig; unterseits : wenig geadert und dann ron geraden dem Mittelnerren parallel anliegenden Haaren seidig glänzend, oder rorspringend aderig und ron abstehenden glanzlosen Härchen tlaumig, in Alter häufig ganz kahl und dann bläulich. Die Staubkätzchen sitzend, dichtblüthig, eiförmig; die Fruchtkätzchen kurz zilindrisch oder kugelförmig. - Die Kätzchenschuppen länglich, stumpf, purpurroth, gegen die Spitze dunkler, von geraden Haaren zottig. Torusdrüse kurz, abgestutzt, häufig purpurroth gefärbt. Die Staubfäden frei, die Antheren im Aufblühen purpurroth, während des Stäubens gelb und später schwarz oder schmutzig gelb Die Fruchtknoten aus eiförmiger Basis rerlängert kegelförmig, lang gestielt, das Stielchen 2-4mal so lang als die Toru sdrüse. Der Griffel fehlend oder sehr kurz, Narben eifürmig abstehend, meistens purpurroth. Die Klappen der aufgesprungenen Kapsel an der Spitze schneckenförmig zurückgerollt.

Die Stammart dieser Rotte S. repens kommt in der Form des langgestielten Fruchtknotens mit den Sahlweiden überein und wurde auch von Koch mit diesen vereinigt. - Durch die Nervatur und die Bekleidung der im Verwelken schwarz werdenden Blätter, so wie durch die schwarz werdenden Antheren ist sie jedoch ron dem Typus der Salılweiden wesentlich verschieden und diese Merkmale berechtigen wohl sie von diesen zu trennen und der S. purpurea, mit welcher sie in den genannten Merkmalen übereinstimmt. anzuschliessen. Bastarte der S. repens mit S. uurita, S. Caprea und 
S. cinerea bilden übrigens den Uebergang der Moorweiden zu den Sahlweiden und schliessen sich bald diesem bald jenem Typus an. Der in Niederösterreich aufgefundene Blendling aus $S$. ropens ${ }^{2}$.) rosmarinifolia und S. aurita reiht sich in die Rotte der Moorweiden ein.

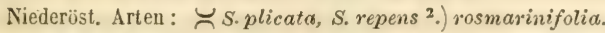

1. Sencippevapaece. - Halbschlächtige Weiden. - Kleine Bäume oder Sträucher mit a ufrechtem Stamme und geraden, biegsamen $\mathrm{Zweig}$ en. Die lanzettlichen oder länglich verkehrteiförmigen im oberen Drittheil breitesten Blätter sind oberseits kahl, mehr oder weniger glänzend, glatt oder von feinen vertieften Linien durchzogen, unterseits bläulich, in Alter kahl oder mit kurzen abstehenden glanzlosen Härchen bekleidet, von blassen etwas vorspringenden Nerven geadert. Die Staubkätzchen sind dichtblüthig eiförmig, die Fruchtkätzchen zilindrisch. Die Kätzchenschuppen lanzettlich, zweifarbig, an der Spitze braun oder schwarzpurpurn, von geraden Haaren zottig. Torusdrüse kurz, abgestutzt, gelb. Die Staubäden theil weise verwachseu, die Antheren vor dem Aufblühen roth, dann gelb und $\mathrm{nach}$ dem Stäuben schmutziggelb werdend. Fruchtknoten aus eiförmiger Basis kegelförmig, gestielt, der Stiel 1-2mal so lang als die Torusdrüse. Der Griffel fehlend oder sehr kurz, die Narben eiförmig, abstehend, ge'b. Die Klappen der aufgesprungenen Kapsel an der Spitze sichelförmig' oder schneckenförmig zurückgerollt.

Die hieher gehörigen Weiden, die sich alle in ihren Typus innig an S. purpurea anschliessen, halten wir für Bastarte aus diesen mit den Sahlund Schwarzweiden. Sie sind wie alle Bastarte, an welchen S. purpurea betheiligt erscheint, durch monadelfische Staubgefässe ausgezeichnet, unterscheiden sich aber von jenen, welche S. purpurea mit S. incana und $S$. viminalis bildet, durch die Bekleidung der Blätter und den sehr kurzen oder fehlenden Griffel, - von den Bastarten aus S. purpurea mit S. repens aber, durch nicht schwarz werdende Antheren. Von der Gruppe der Sahlweiden unterscheiden sie sich durch schwarz werdende Blätter, kürzer gestielte Fruchtknoten und monadelfische Slaubgefässe, durch diese beiden zuletzt genannten Merkmale sind sie überdiess ron den Moorweiden geschieden.

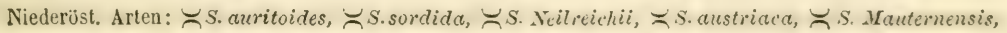
$\asymp$ S. Vandensis.

HE. Hovecrece. - Purpurweiden. - Sträucher mit aufrechtem Stamme und geraden schlanken biegsamen Zweigen. Die Blätter sind lanzettlich oder länglich und im rordersten Drittheil am breit e sten, oberseits kahl, dunkelgrün, etwas gläızend, glatt, im getrockneten Zustande von erhabenen feinen Seitennervchen durchzogen, unterseits in der Jugend manchmal etwas seidig, im Alter kahl, bläulich; die Nerven der unteren Blattseite nicht stärker als jene der oberen Blattseite vorspringend. Die Staubkätzchen sitzend, dichtblüthig, zilindrisch, zur Zeit der vollen 
Blïthe meist bogenförmig gekrümmt. Die Fruchtkätzchen schmal, zilindrisch. dichtblüthig. Kätzchenschuppen stumpf, an der Basis blass, gegen die Ränder rüthlich schwarz, mehr oder weniger behaart. Torusdrüse sehr kurz, abgestutzt, gelb. Die Staubfäden theilweiseoder der ganzen Länge nach mit ein a nder rer wa ch sen. Antheren ror dem Aufblühen roth, während des Stäubens gelb und später sehwarz werdend. Die Fruchtknoten eiförmig oder eikegelförmig, sitzend oder kurz gestielt, das Stielchen hüchstens solang als die Torusdrüse. Griffel fehlend oder sehr kurz. Narben rundlich oder eifürmig, gelb, selten röthlich. Die Kajsel zur Zeit der Fruchtreife klaffend, die Klappen kaum auswärtsgebogen oder etwas sichelförmig zurückgekrümmt.

Die Stammart dieses Weidentypus S. purpurea ist unter allen Weiden am meisten zur Bastartbildung geneigt. Die zahlreichen Bastarte, die sie nit den Arten der Microstylae und Macrostylae bildet, haben bereits an den betreffenden Orten ihre Besprechung gefunden. Die Bastarte mit S. repens fallen meist in den Typus der Furpurweiden und selbst diejenigen, welche in der Blattform sich mehr der $S$. repens nähern, reihen sich durch den kurz gestielten Fruchtknoten und die verwachsenen Staubfäden an die $S$. purpurea an. - Merkwürdig ist, dass bisher kein Blendling aus S. purpurea und einer der Chloriteen im Freien gefunden wurde, obschon gerade diese Arten ganz gewöhnlich unter einander wachsen und auch die Blüthezeit eine Kreuzung noch gestatten würde:

Niederöst Arten: $\asymp$ S. parviflora, S. purpurea.

An die Salix purpurea als das Schlussglied der Weidenreihe schliesst sich noch der ron allen genannten Weiden so ganz abweichende Typus: S. reticulata an, deren Kranz drüsiger Verlängerungen des Torus einen fünf- bis sechstheiligen Perigonrudimente ähnlich, die Basis der Staubgefässe oder des Fruchtknotens umgibt und an den perigonartigen, einen schiefabgeschnittenen Becher darstellenden Torus der Pappeln erinnert, so wie anderseits auch die benerrten Blätter durch die langen Stiele mit den Pappeln übereinkommen und einen auffallenden Gegensatz zu den kurz gestielten fiedernerrigen Weidenblättern bilden. Der Umstanl, dass ron allen europäischen Stammarten der Weiden bereits wildwachsende Bastarte bekannt geworden sind und die einzige so ungemein weit rerbreitete $S^{\prime}$. reticulutu bisher in keinem Bastarte ausgesprochen erschien, trotz dem, dass bei ihr so gut wie bei andern Alpenweiden die Bedingungen zur Bastartirung gegeben sind, weist auch auf ihre geringe Verwandtschaft mit den andern Weiden hin und wir halten uns berechtigt den Typus der S. reticulata als selbstständige Gattung aufzufassen, die wir als Chamite a bezeichnen und deren Charakteristik den Schlu.s dieser Arbeit bilden soll. 


\section{Salicum Anstriae inferioris species.}

Divisio I. Colderedere. Squamae amenti concolores. Torus in flosculis staminiferis biglandulosus. Stylus brevis. classus.

Sect. I. Fragiles Koch. Arbores vel fruticis, ramis gracilibus ad inserlionem fragilibus, foliis acutis, glaberrimis, adolescentibus viscidis. Amentorum squamae ante fructus maturitatem cadncae. Torus fosculorum staminigsum et pistilligerum bigilandulosus.

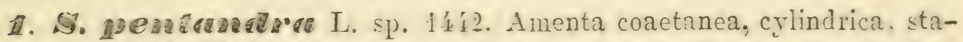
minigera bis-quinquies, pistilligera ter-sexies, plerumque quater longiora quam

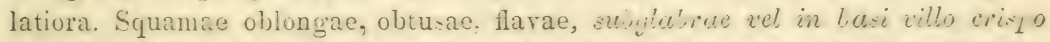
1 ruelitue. Torus biglandulosus. Glandula interna plerunque bipartita. Germen ex orata basi conicum, glabrum, brevissime pedicellatum, pe icello giandulam tori internam aequante vel vix superante, stylo brevi, stigmatibus patulis, bilobis, crassulis. Stumina j-12, filamentis in basi villosis. Folia or ato-elliptica,

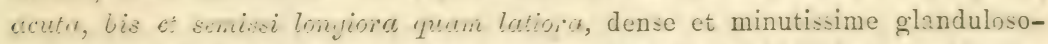
scrrata, alolecentia ulutinose, adulta subcoriacea, supra riridissima splendentia, subtus pallidiora et ut adole-centia glaberrima. I'edunculus foliorum superne

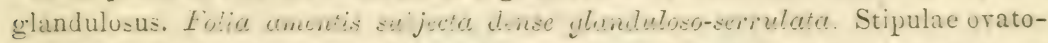
oblongae. Iiamuli tenaces, ad instrtionem tamen fragiles, glaberrimi, juniores visciduli nitidi.

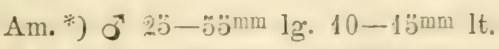

Am. $O 20-60 \mathrm{~mm}$ lg: $7-12 \mathrm{~mm}$ lt.

* Die Maasse sind in Millimetern angegeben. - Bei deu einzelnen Arten murden die übereinstiu. menten won Fries im Herb. normale ron J. r. Korits in der Fl. exsicc. Vindob., jene in Wimmer's

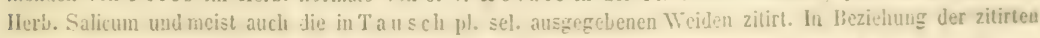




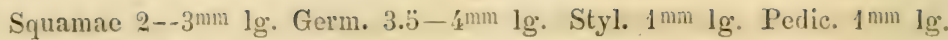
Stam. $3-6 \mathrm{~mm} \mathrm{lg}$.

Fol. $60-110 \mathrm{~mm}$ lg. $30-1 \mathrm{~J}^{\mathrm{mm}}$ it.

S. pentandia II ost Salix tab. 1 u. 2. - Fries Nor. Fl. succ. I. I. p. 41 , Neilr. Fl. r. N. Oest. p. 233. - S. pentandra $\beta$ latifolia Ko ch Syı. p. 5jü. - S. pentandra Fries Heris. norm. Fasc. 9. Nr. 6S, Wimmer IIerb. Salic. Nr. 49 u. 30 und beigegebener Text zu Fasc. V.

Eine der schönsten Weiden, deren breite, glänzend grïne, lederig’e Blätter einige Aehnlichkeit mit jenen des Lorbeerbaums he-itzen und iln den Namen Lorbeerweide erworben laben. Die Zweige ebenso wie die Blätter fïhlen sich in der Jugend klebrig an und färben das Papier, in welches sie gelegt werden, ähnlich der Schwarzpappel grïnlich gelb. - Sie erscheint auf den Hochmooren gewöhnlich strauchartig, unter gïnstigen Lmständen aber vermag sie sich zu einem bis 40 Fuss hohen Baum zu erheben. Das IIolz ist zälie, aber an den Abästungsstelien sind die Zweige brüchig. Unter allen Weiden gleicher Hühenlage blïht die I.orbee:reide am špätestun. Ihre Blïthen besitzen den intensirsten Iloniggeruch. Sie gedeiht rorzüglich auf Hochmooren und an den Rändern sumpfiger Miesen auf kalklosem Untergrunde und wird entweder rereinzelt oder in kleinen Gruppen angetroflen.

Sie ist auf der nördlichen Halbkugel rom östlichen Amerika über Britannien und Skandinarien ostwärts bis Kamtschatka verbreitet und findet si.h nördlich bis Island und Kola. Eine Linie, welche ron den Pyrenäen entlang dem südlichen Fusse der $A_{\text {pen }}$ und siebenbïgischen Kapathen, durch die Moldau in den Kaukasus zieht, bildet in Europa ilıre sildliche Vegetationslinie. - Entlang dieser Linie fällt ihre untere Grenze mit der unteren Grenze der Hochmoore zusammen, weiter nordwärts steigt die Lorbeerweide bis in die baltische Niederung herab. Ihre obere Grenze fällt in den Südalpen auf $4000^{\prime}$, in den Sudeten auf $2600^{\circ}$. - Innerhalb ihres Areals fehlt $S$. peintundru jedoch auf weiten Strecken, so in den Vogesen, in vielen Theilen der Alpen und in den Donautiefländern.

In Niederösterreich wird dieselbe ron Welwitsch an Teichrändern zwischen Naglitz bei Theitra und dem Jägerhause Facule (Tien. Mus.) angegeben. In dem angrenzenden bühmischen und mährischen Theile des ..böhmisch-mährirchen Gebirges.: sind riele Standorte dieser Treide belaunt und es ist zu rermuthen, dass auch innerhalb der Grenze Viederüsterreichs auf den Huchmooren des Tialdriertels deren noch mehrere aufgefunden werden. Im alpinen Gebiete fand sie Portenschlag bei Anmaberg. (Wien. Mus.)

Besclireibungen beschrünkten wir uns in der Fegel auf jene, bei denen uns Gelegenheit geboten war, dic Originalexemplare einzuselien. Nebst den Beschreibungen ron Fries und Wimmer wurden dalicr auch noch die von Host, dessen Originalexemplare uns aus den Wiener Gärten rorlagen, so wie jene der ausgezeichneten „Flora ron Niederösterreich ${ }^{\star}$, deren Autor, Herr A. Neilreich, so freundlich war, uns die Einsicht in sein Weidenherbarium zu gestatten, angeführt. Nebst diesen glaubten wir auch noch Koch, dessen vortrefliche Diagnosen nur selten einen Zweifel lassen, welche Formen der Autor gemeint, anfïlıren zu müssen. Alle Zitate beziehen sich auf die letzten von den genamuten Auloren verüfentlichten betrefienden Arbeiten. 


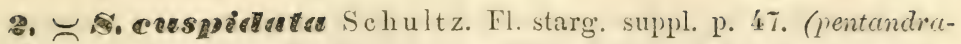
ficaitis.) Amenta coaetanea, cylindrica, staminigera ter-quater longiora quam latioia. Squamae oblongae, flarac, sulglalrae vel in busi villo crispo praeditae. Torus biglandulosus. Giandula interna obtusa, integra. Stamina.3-5, plerumque 4, filamentis in basi rillosis. Folia lanceolata, longe acuminata, ter et semissi vel quater lonviora quem lationa, glanduloso - serrata, adolescentia glutinosa, adulta supra viridissima, nitida, subtus pallicle viriclia et ut alolescentia glaberrima. Pedunculus foliorum superne glandulosus. Foliola amentis subjecta dense ylunduloso-sermluta. Ramuli ad inse rtionem fragilis, glaberrimi, juniores risciduli.

Am. ơ $30-45 \mathrm{~mm}$ lg. $10-12 \mathrm{~mm}$ lt.

Squamae $2-3 \mathrm{~mm}$ lg. Stam. $5-6 \mathrm{~mm}$ lg.

Folia $70-130 \mathrm{~mm}$ lg. $20-30 \mathrm{~mm}$ lt.

S. tetrandra L. Oel. Resa in ind. sec. Fries. - s. pentandra $*$ tetrandra Fries Nor. Fl. suec. M. I. p. 41 und Herb. norm. Fasc. XI. - S. cuspicletat K och Syn. p. 5ü6. - S. pentandrafragilis W im m. Denksch. p. 1303 und Herb. Salic. Nr. 29.

Sowohl in der Tracht, so wie in ihrem Vorkommen schliesst sich diese Weide an $S$. pentandra an und besitzt gleich dieser einen grossen Verbreitungsbezirk, der sich in Europa ron den Siddalpen und siebenbürgischen Karpathen nördlich bis Lappland ausdehnt. - In Lappland wird sie ron Fries angegeben, obschion dort die eine der wahrscheinlichen Stammeltern, nämlich S. fragilis, fehlt.

In Niederösterreich wurde diese Weide ron Dolliner in der Brühl angegeben. (Tergl. dessen Enum. pl. ph. in Austria inf. cresc. p. 118.) Exemplare, welche Herr Dr. Dolliner mir ron diesem Standorte zu senden so gütrg war, stimmen auf das Vollständigste mit den ron Wimmer in Herb. Salic. ausgegebenen überein. Im verflossenen Sommer wurde dieselbe Teide ron meinem Bruder Jos ef an Bachrändern bei Heinreichs nächst Gross-Gehrung’s am Plateau des böhm.-mähr. Gebirges auf granitischer Unterlage (2000') in mehreren Staubkätzchen tragenden Sträuchern aufgefunden.

3. $\asymp$ S. cylindrica, quater longiora quam latiora. Squamae oblongae, obtusae, pilis lonitis et rectis omni parto eillosae. Torus biglandulosus. Glandula interna

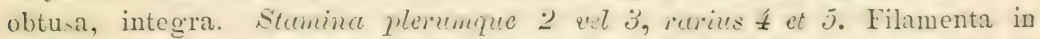
basi rillosa. Folia lanceolata. longe acuminata, quater lontiona quain latioru, glanduloso-serata, adolescentia viscidula, adulta supra riridia nitida, sultue glarececentic et ut adoleseentia glaberrima. Pedunculus foliorum superne glandulosus. Folic ainentis selijecte plerwimpe interree, rarius partim denticulata. Ramuli glaberrimi. ad inserionem fragilissimi cortice testaceo.

Am. o $30-10 \mathrm{~mm} \lg .8-12 \mathrm{~mm}$ lt.

Squam. 2mm lg. Stam. :3mm lg.

Fol. $60-10: 3 \mathrm{~mm}$ lg. $18-26 \mathrm{~mm}$ it 
S. fragilis II ost Salix p. 3. (Die S. fragilis II ost's gehürt sowohl nach der in dem zitirten Werke, S. 5 u. 6 gegebenen Diag̨nose, so rie nach dem im Wiener botanischen Garten von II $\circ$ st gepflanzten Exemplare, das offenbar seiner Beschreibung als Basis gedient hat, hieher. Die Blüthen sind 2- und 3männig, die Blättchen des Kätzchenstiels entweder ganzrandig oder an einer Seile theilweise drüsig gesïgt. Die Abbildung II ost's, tab. 18 zeigt zwar nur eine 2männige Blüthe, in der Diognose p. 5̆ heisst es aber ausdrücklich nfloribus triandris diandrisve ${ }^{4}$ und rird dieses Merkmal p. 6 mit den Worten: ${ }_{n}$ Stamina in aliquibus flosculis tria, in multis duo" nochmals herrorgehoben.) S. fragilis $\gamma$ polyandra Neilr. Fl. r. N. Oest. p. 2533.

Ein männlicher Baum bei Zwettl, am Plateau des böhm.-mähr. Gebirges, auf Granitboden im rerflossenen Sommer ron meinem Bruder Josef aufgefunden. Ein gleichfalls männlicher Baum am Wienflusse bei Penzing nächst Schönbrunn. Herr F. Pokorny, welcher diese Tride an dem leizteren Standorte ror mehreren Jahren zuerst entdeckte, möge gestatten, dicselbe mit seinem Namen zu bezeichnen.

Da S. pentandira bisher nirgends in der Flora ron Tien aufoefunden wurde, so ist das Vorkommen der hier be-chriebenen fur einen Bastart aus S. fractilis rar. a und S. pentundia ron uns gehaltenen Ticide bei Penzing, so wie der S. cuspidata in der Brühl sehr merkwïrdig. Vielleicht liesse sich dasselbe durch die Annahme erklïren dass S. pentamelica einst auch im Bereiche des Wienerwaldes rorgekommen sei, ja wir halten es selbst nicht für unmöglich, dass sie dort in den weniger besuchten abge'egenen Thälern noch jetzt gefunden werden könnte, um so mehr, als sie Portenschlag in den angrenzenden Vuralpen bei Annaberg fund.

Den zwei hier als Secupielata und S. Pormmy beschriebenen muthmasslichen Blendlingen aus S. fravilis und S. pentandia schliesst sich noch ein dritter Bastart an, welcher aber bisher in Niederösterreich nicht aufg:funden wurde. Während S. Pokormyi der S. firgilis näher steht und S. cuspiclata zwischen den genannten wahrscheinlichen Stammältern genau die Mitte hält, nähert sich dieser dritte Blending nehr der S. pentundra. Die Blätter desselben sind lanzettlich, lang zugespitzt $31 / 2$ mal so lang als breit und tragen den Typus der S. Tia filiv. Die Ilïttchen des Kätzehenstiels sind

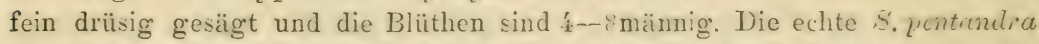
unterscheidet sich ron ihm durch breitere kurz bespitzie Blätter, die nur $21 / 2$ mal so lang als breit sind, und besitzt rollere Staubkätzchen, deren Bluthen gewöhnlich $10-12$ männig sind und nur selten Blïthen mit weniger Staubgefüssen (deren Zahl aber niemals geringer als ;) ist) beigemengt enthalten. *) - Er wird gewöhnlich als S. pentandica bestimmt und wir crhielten denselben unter diesem Namen ron mehreren Standorten aus Norddeutschland. Koch scheint mit: S. pentuindia var. $\alpha$. Syn. p. 3.36 gleichfalls diese Teide zu meinen. Ton Fries wurde dieselbe in Herb. norm. Fasc. XII mit der

*) Nach Wimmer ist jede cchte S. pentandra 10- bis 12männig. Siehe: Text zu IIerb. Salic. Fase. V. bei Nr. 49 S. pontandra mas. 
Bezeichnung .. Salix quae S. polyandia Bray. arbor S. fiorgilis facie sed rulgo emneandra! cum S. heachdia Ehrh. ad S. curpilatam pertinere apparet" ausgegeben. Die Blüthen der:elben, ron denen Jries sagt. das's sie grewïhnlich Emännig seien, sind an dem Exemplare des Herb, norm. 1-smännig.

Diese Weide, welche wir $\$$. Friesii nennen, bildet ein Ergïnzungsglied

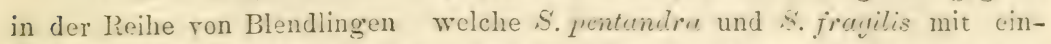
ander ver: indet, und es würde sich diese Reihe in folgender Weise ordnen lassen :

5. pentandra. Blüthen $\ddot{j}-12$ gew ühnlich 10 und 12 männig. Blätter $21 / 2 \mathrm{mal}$ so lang als breit, kurz bespitzt. Blättchen des Kätzchenstiels fein drüsig gesägt.

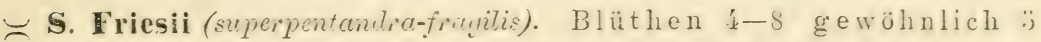
und $6 \mathrm{männig.} \mathrm{Blätter} 31 / 2 \mathrm{mal}$ so lang als breit, lang zugespitzt. Blättchen desKätzchenstiels fein drïsig g’ es ä gt.

$\asymp \mathbf{S}$. cuspidata (pentandia-fiautiti). Blïthen $3-\ddot{j} \mathrm{~g}$ ewöhnlich Lmännig: Blätter $3 \frac{1}{2}-4 \mathrm{mal}$ so lang als breit, lang zugespitzt, Blättchen des Kätzchenstiels fein drüsig ges ägt.

$\asymp$ S. Pokornyi (su? pentandia-fra ilis). Bl üthen 2-"j gew genlich 2und 3 männig. Blätter 4 mal so lang als breit, lang: zugespitzt. Blättchen des Kätzchenstiels meistens ganzrandig, oder theilweise drüsiğ gesägt.

S. fragilis. Blüthen 2 männig. Blätter $4-6$ nal so lang als breit, lang zugespitzt. Blättchen des Kätzchenstiels ganzrandig.

Die Q Teide der S. cuspicata wird ron Koch ron S. pentandra durch längere Fruchtlnotentiele und lang zugespitzte Blätter und ron $\$$. frayilis durch die fein drüsig geäggten Kätzchenstielblätter unterchieden. Von Fries wurde dieselbe in Herb. norm. Fasc. XI als $O$ S. pentandia *tetrandra ausgegeben.

Aus Böhmen liegt uns eine von W. Karl gesammelte $\underline{O}$ Teide ror, welche wir für die der oben beschriebenen ot s. I'smmin entsprechende c Weide halten. Die Bläter sind lanzettlich, lang zugerpitzt, riemal on lang als breit, die Kätzchenstielbliatter theils ganzrandig, theils einensits tiv drüsig gesägt, die Fruchthnoten sind aus eifürmiger hasis kegelfüruig, dor Fruchtknotenstiel nochmal so lang als die abgestufzte ungetheilte innere Torusdrüse, der Gr:flel so wie die Narben sind dicklich und letztere abstwend und au:gerandet. In Niederüsterreich ist dieselbe bis jeizt nicht anfigefunden worden. 
4. Fo forgitis L. Sp. Iik3. Amenta coactanca, cylindrica, staminiọa ter-quinquies, pistilligera quater - sexies longivia quam latiora. Squamae obovatae, flarae, pilis lomenis et rectis omini pirte villowae, caducae. Turus biglandulosus. Glandula interna obtusa, integra. Germen ex orata basi conicum, glabrum, pedicellatum, pelicello ylantulum internum his tere superchate, stylo brevi, stigmatibus patulis, bilobis. Stamina duo. Filamenta in basi rillosa. Folia lanceolata rel oblongo-lanceolata, acuminata, quater-sexies longiora quam latiora, serrata, adolescentia suma et sultus oldabra et viridia, viscidulu, alulta subtus rel pallide viridia vel leviter glaucescentia. glabra. Foliola amentis suljecta interverrima. Pedunculu foliorum sujerne glandulosus. Stipulae semicordatae rel semirenifomes. Ramuli glabberrimi, fiajilissimi, cortice testaceo, nitido.

Anr. o $22-38 \mathrm{~mm} l \mathrm{lg} \cdot 8-12 \mathrm{~mm}$ lt.

Am. O 20-60min lg. $6-10$ mm lt.

Squam. 2-4mm lg Germ. 3-4m lg. Pedic. $1 \mathrm{~mm} \lg$. Styl. 0.j-1 mm lg. Stam. $3-\ddot{3 m m} \lg$.

Variat foliorum forma :

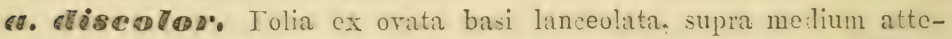
nuata ct in acumen tenue producta, quater-quinquies longiora quam latiora, adulta subtus glaucescentia.

Fol. $7 \ddot{0}-1 \dot{1} 0 \mathrm{~mm} \mathrm{lg} .20-3 \ddot{m m} \mathrm{mt}$.

S. fragilis Hos t. Salix p. 6. u. tab. 20, 21. - S. fragilissima II ost. S. t. 22. - S. excelsa

Tausch pl. sel. - S. fragilis $\mathbf{O}$ Fries herb. norm. Fasc. I. - S. fragilis $\beta$. vutgaris

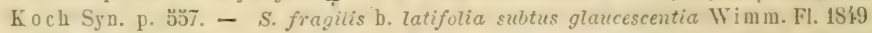
p. 3 k und Herb. Salic. Fasc. Vill. Nr. 89. - S. fragilis $\beta$. discotor Neilr. Fl. v. న. Oest. p. 2ั33. pro parte.

6. Conceld:. Folia ex orata basi oblongo-lanceolato acuminata quater-cuinquies longiora quam latiora, adulta subtus pallide riridia. Stipulae semicordatae.

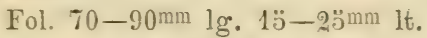

S. fragilissima IIost, nach dem ron Host gepflanzten Exemplare. - S. fragilis $\alpha$. decipiens Fries herb. norm. Fasc. II (wahrsicheiulich auch Koch Syn. p. 53̈. Das Merkmal „foliis ramulorum infimis lato-obovatis obtusissimis ${ }^{\varkappa}$, welches Ko h hür die var. decipiens festhält, zeigt sich allerdingz an den Fries' schen und den von Hos t geptanzten Exemplaren ausgesprochen, ist jedoch von sehr untergeordnetem Werthe, da sich an ein und demselben Stamme Aestchen, deren untere Blätler breit rerkelirt-eiförmig und stumpf sind, neben solchen finden, deren unterstg Blätler lanzetllich zugespitzt erscheinen.) S. fragilis $\alpha$. concolor Nieilr. Fl. r. N. Oest. p. ${ }_{2}^{2} 33$.

c. roggostefolire. Folia longa. quintuics-sexies longiora qua:n latiora, oblongo-lanceolata, in petiolum contracta et longe acuminata, adulta subtus pallide viridia. Stipulae semireniformes.

Fol. $8 \ddot{-}-170 \mathrm{mn} \lg .10 ̈-30 \mathrm{~mm}$ lt.

S. jragilissima II o st Salix tah. 23. - S. fragilis c. angustijolic subtus virida Wimm. Hor: 15\%9. ก. 3'. 
Die S. fiagilis erwächst zu einem Baume von 40 Fuss Höhe und vier Fuss Stammumfang und besitzt im unlehinderten Wuchse eine pyramidenförmige Gestalt. Ihres raschen Wuchses wegen wird sie in holzarmen Niederungen häufig als Kopfweide an den Vienen unr Teichrändern gezoren und dann gewöhnlich alle drei Jahre ihrer Aeste beraubt.

Sie findet sich in den mittleren und östichen Gubieten ron Nordanerika: ist in deralten Welt durch die Flusniederungen und Tiefländer von der Mittelmerrzone nordwärts bis in das mittlere Schweden und nürdliche Russland. o-twärts bis in den Altai verbreitet, erreicht früher ihre Nordgrenze als $S$. penturba, dehnt aber anderseits ihren Verbreitungsbezirk vicl weitcr nach Sïden aus als diese. - Die Höhe ron $1300^{\prime}$ wird als ihre obere Grenze in Rumelien, die Höhe von $1606^{\prime}$ als ihre obere Grenze in Südbaiern angegelen.

In Niederösterreich ist sie eine der häufigsten Weiden in der Ebene, insbesondere in der 1)onamiederung, wo sie ein'u wesentlichen Lestandtheil des Iaubwaldes der Auen bildet. Entlang den alpinen Zufliissen der Donau ist sie vereinzelt bis in die subalpinen Thäler verbreitet; im Ibbsthale bis Lunz, im Gebiete der Frlaf bis Gresden und Gaming, im Traisenthal bis Tïrnitz und Hohenberg, im Schwarzathal bis an den luss des Preiner Gscheides, wo sie im alpinen Gubiete bei 1\$0 ilıre obere Grenze ereicht. Im Gebiete des bühnisch-mährischen Gebirgsplateaus hebt sich ihre obere

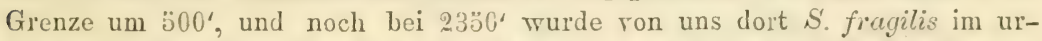
wïchigen Zustande angetroflen. - Die Form mit breiteren, im Alter unterseits bläulichen Blättern (var. a.) ist auf die Donauniederungen beschränkt, in den subalpinen Thälern und auf den Höhen des Taldriertels finden sich nur die Formen mit unterseits blassgrünen Blättern (var. b. und c.).

Die Bruchweide liebt rorzïgich feuchten lel:migen Boden und meidet schotterige Linterligen. Insbesondere sagt ihr feuchter Löss und der durch Verwitterung des Gneisses gebildete Lehmboden zu. Am gewöhnlichsten ist sie mit Alnus glutinaea und dem ihrs Aeste umstrickenden Hopfen ge-ellschaftet.

Sect. II. Albae. Arbores rel frutices ranis gracilibus, folis aru-

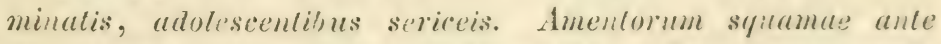
fruclus malurilulem calucae. rorus flosculorum staminigerum biglandulosus, pistilligerum uniglandulosus.

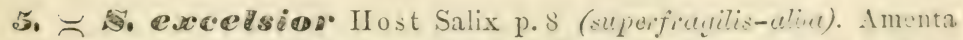
coactanea, gracilia, staminigera quinquies, pistilligera quinquies-sexies longiora quam latio:a. Squamae oblongae, obtusae, flavae, villis retis spetsis piluste, caducas. Torus in flosculis staminigeris biglandulo-us, in piotilligeris uni-

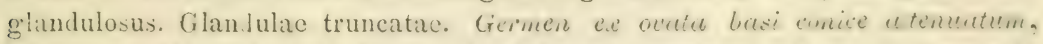

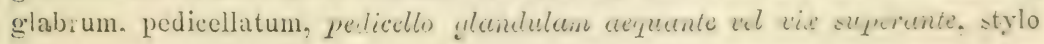


breri, stignatibus patulis, hilobis. Stamina duo, di.amentis in basi pilosis Fulia lanceulata, acuminata, quater -- sexies longiora quam latiora, serrata, arlolescentia sericea, adulta glabrata, supra subnitidu, viridissima, subtus pallide viridiar rel giauea. Petiolus foliorum superne plerumque glandulosus. Foliola amentis subjecta integerrima. Stipulae semicordatae. Ramuli glabri, tenaces, ad insertionem tamen fragiles.

Am. o $30-60^{\mathrm{mm}} \mathrm{lg}$. $6-12 \mathrm{~mm}$ it.

Am. . . 30-60mi lg. 6-9mm lt.

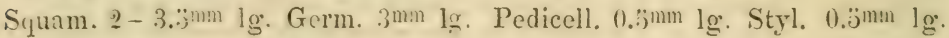
Stam. $3-\ddot{3 m m}] \mathrm{g}$.

Variat folior um forma :

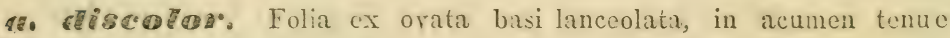
producta, juniora sericea, adulta subtus giaucescentia, glabra.

Verosimiliter hybrida ex $S$. alba et $S^{\prime}$ fragilis var. $a$.

Fol. $80-116 \mathrm{~mm}$ lg. $18-30 \mathrm{~mm}$ lt.

S. excetsior Ho st Sailix p. S. tab. 23, 29.

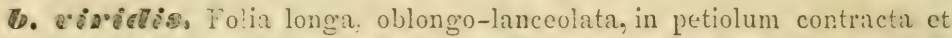
longe acuminata, juniora subtus sericea, adulta subtus pallide viridia, gialira.

Verosimiliter hybrida ex S. alla et S. fragilis rar. $U$. vel $c$.

Fol. $80-160 \mathrm{~mm}$ lg. $1 \ddot{-}-2 \mathrm{~m}^{\mathrm{mm}}$ lt:

S. gracicuta Tausch pl.sel. - S. viridis Fries Nov. Fl. succ. M. I. p. 43 und Herb. norm. Fasc. I.

In der Tracht der 5 . frectili: sehr ähnlich, durch die scidige Bakleidung der jungen nicht klebrigen Blätter, die spar:amere Behaarung der Kätzchenschuppen, die kürzer gestielten Fruchtknoten und die weniger brïchigen Zweige ron derselben rerschieden.

Die Var. b. ist ein in Niederösterreich sehr rerbreiteter Bastart, der namentlich in den Donau-duen der $\therefore$. fir ilis an Häufigkeit kaum nachsteht und fart gleichzeitig mit ihr zur Plüthe kommt. I)ie Var. $a$. selten. Im E.lafthale bei Scheibbs, im Traisenthale bei Lilienfeld.

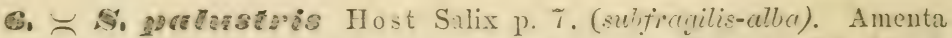
coactanea, graciila, staminigera quinquies-scxics, pistilligera laxiflora, sexies longiora gu:m latiora. Squamae oblongae. obtusae, concarae, flarae, in basi

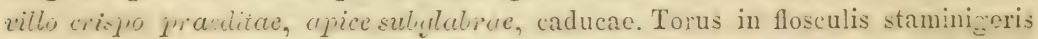
biglandulosus, in pistilligeris uniglandulosus. Glandula truncata. Gerinen ei veatu lasi conicu., glabrum, pelicellatum, pelicello glundulum internain aequants, stylo breri, stigmatibus patulis, bilobis rel emarginatis. Stamina duo, filamentis in basi pilosis. Folia oblongo-lanceolata, acuminat: in petioIun consracta. queter et semissi - quinquies longiora quam latiora, serrata,

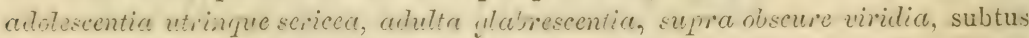
glauca. Petiolus foliorum superne ntin glandulosus. Foliola amentis subjecta integra rel rarius denticulata. Stipulate lanceolatae. Ramuli tenaces, glabri. 
Am. $\sigma^{\top} 40-\ddot{30 m m} \lg .8-9 \mathrm{~nm}$ lt.

Am. $\subsetneq 38-50 \mathrm{~mm}$ lg: $6-8 \mathrm{~mm}$ lt.

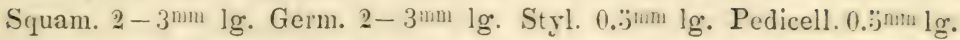
Stam. $3-3$ mm lg.

Fol. $80-10: 3 \mathrm{~mm} \lg \cdot 16-24 \mathrm{~mm}$ It.

S. palustris Uost Salix p. 7. tab. 2k. 23. - S. fragilis-alba Wimm. Denksch. p. 15̈6. - S. fragilis $\sigma^{7}$ Fries Herb. norm. Fasc. I. (F ries verstand unter S. fragilis auch S. palustris sutrie S. excelsior a. discolor. Wenigstens sind die uns im Herb. norm. Fasc. I. rorliegenden $\sigma^{\top}$ Exemplare der S. fragilis, der seidenharigen jungèn Blätter wegen, als Bastarte aus S. fragilis und S. alba anzusehen und stimmen mit der oben beschriebenen S. palustris überein. Die S. exce'sior b. viridis wurde von ihm als S. viridis (nach dem Exemplare im Herb. norm. Fasc. I.) ron S. fragilis geschieden. Wahrscheinlich begriff er aber unter diesem Namen auch die der S. excelsior b. viridis hüchst ähnliche - langblättrige S. fragilis mit beiderseits grünen in den Blattstiel zusammengezogenen auch in der Jugend ganz kahlen Blättern, welche wir oben als S. fragilis var. c. angustifolia aufgeführt haben.)

Koch und Nieilreich begriffen unter ihrer $S$. fragilis beide hier unter ŏ und 6 beschriebenen Bastarte und bei Koch bilden sie die Var. $\gamma$. Russeliana Syn. p. 55\%, bei Neilreich zum Theil die rar. $\beta$. Viscolor Fl. i. N. Oest. p. 233.

Ton S. excelsior ist S. palustiris durch oberseits trïbgrüne Blätter, durch konkare Kätzchenschuppen, die an der Spitze fast kahl und nur an der Basis mit kurzen etwas krausen, fast wolligem Flaume bekleidet erscheinen und durch etwas kürzer gestielte Fruchtknoten, - von S. alla durch die im Alter kahl werdenden Blätter und durch gestielte Fruchtknoten rerschieden.

In Niederösterreich ist $S$. palustiris eine der häufigsten Teiden. Sie bewohnt mit ihren muthmasslichen Stammeltern S. fragilis und $S$. all a gleiche Lokalitäten und wird auch gleich diesen häufig gepflanzt und als Kopfweide benützt.

Beide unter $\ddot{~}$ und 6 beschriebenen Bastarte scheinen überhaupt zu den rerbreitetsten zu gehören, und die S. Russeliana, welcher Name auf die Autorität ron $\mathrm{Koch}$ ron den Autoren auf die Zwischenformen aus $S$. alluit und $S$. fratilis bezogen wurde*), wird in den Floren ron fast ganz Europa angegeben und kommt so wie Salix alla nürdlich bis Petersburg und Kasan ror.

\%. Solbr L. sp. 1419. Amerta coactanea, gracilia, staminigera quinquies - sexies, pistilligera quinquies - septies longiora quam latiora Squanae oblongae, obtusae, concarae, flarae, in Lasi villo lirevi critipo praeditae et cum rhachit. sublanuginosae, apice plerumque glalirae, caducae. Torus in flosculis staminigeris biglandulosus, in pistilligeris uniglandulosus.

*) Koch fïgt (Syn. p. 5.ّ̃) dem Cilate: S. Russeliana Smith die Bemerkung bei : „secundum

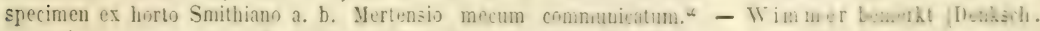
p. 1506) bei S. fragilis-alba: „Ob die $S$. Russeliana $\mathrm{Smith}$ hieher sebürt, darf bezweifelt werden.

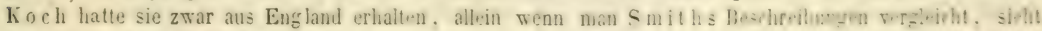

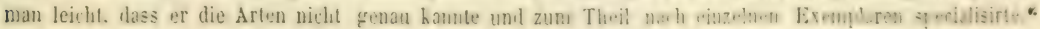


Glandula truncata, brevissima, basin germinis attingens. Germen glabrum ex orata basi conicum, obtusum, sessile vel brevissime peclicellatum, pedicello breviori quam nectarium, stylo brerissimo, stigmatibus patulis, bilobis rel emarginatis. Stamina duo, filamentis in basi pilosis. Folia oblongo-lanceolata acuminata, apicem et basin rersus acqualiter contracta, quinquies - sexies longiora quam latiora, serrata, adolescentia sericea, actulta supra obscure rividia, sultus glauca, sultus vel utrinque sericea. Petiolus foliorum superne non glandulosus. Foliola amentis subjecta serrata rel integra. Stipulae lanceolatae. Ramuli tenaces, juniores sericei, adulti glaberrimi.

Am. o $30-60 \mathrm{~mm}$ lg. $5-10^{\mathrm{mm}} \mathrm{lt}$.

Am. O $30-366^{\mathrm{mm}} \mathrm{lg} .5-8^{\mathrm{mm}} \mathrm{lt}$.

Squam. 2-3mm lg. Germ. $2 \mathrm{~mm}$ lg. Styl. $0-0.3^{\mathrm{mm}} \mathrm{lg}$. Stam. 3-.̈mm lg.

Fol. $60-100 \mathrm{~mm}$ lg. $12-18^{\mathrm{mm}} \mathrm{lt}$.

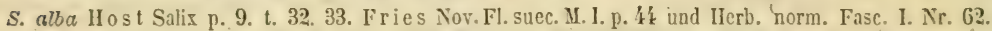
Koch Syn. p. 55\%. Wimm. Flora 18 ' 9 p. 3 k und Ilerb. Salic. Fasc. VII. Nr 99.

- Neilr. Fl. v. N. Oest. p. 252. - S. vitellina Host. Salix p. 9. tab. 30. 31. K och Syn. p. 5ว็. - S. alba rar. d. ramis bi-trimis vitellinis, saepe cernuis Wim m. Flora $18 \dot{k} 9$ p. $3 \%$. scheint eine durch hüpfen erzengte Form mit schr ïppigen goldgelben oder mennigrothen Zweigen und weniger seidigen Blättern. (Die S. vitcllina Linné's ist nach Fries: Form der S. fragilis.)

Im unbehinderten Tuchse wird S. alba zu einem bis 70 Fuss hohen Baume, dessen schmale Blätter rom leisesten Lufthauche berregt, mit bläulich weissem Schimmer erglänzen und im Somnenlichte cin anmuthiges Farbenspiel ron Grün und Silberweiss darbieten. Durch dieses Farbenspiel ist die Silberweide schon ron Weitem kenntlich und rerleiht dem gemischten Laubwalde der Auen, in welchen sie mit dunkelblättrigen Eichen und Schwarzpappeln rorkommt, einen höchst eigenthümlichen Reiz. Die Silberweide ist überhaupt für die Landschaften der Niederung als charakteristisch anzusehen und ist der einzige Baum, welcher in dem baumlosen ungarischen Tieflande stellenweise die Flüsse besäumt und kleine Wäldchen an ihren Ufern zusammensetzt.

Sie ist ron der Mittelmeerzone durch das ganze südliche und mittlere Europa bis zu einer nordüstlichen Vegetationslinie rerbreitet, welche am Lerelv im westlichen Norwegen $\left(60^{1 / 2}{ }^{\circ}\right.$ n. B.) über Petersburg $\left(60^{\circ} \mathrm{n}\right.$. Br.) nach Kasan an die Wolga und Jekaterinenburg im Lral ( $56^{1} \%^{\circ} \mathrm{n}$. Br.) zieht und sich dann östliclı in das Gebiet des Altai und in das baikalische Sibirien fortsetzt. Sie wird auch in den östlichen Gebieten der Vereinigten Staaten Nordamerikas angegeben, scheint jedoch dort ebenso wie S. frajilis aus Europa eingefïhrt worden zu sein.

In Niedelösterreich ist sie die häufigste Weide der Niederungen und ein Hauptbestandtheil des hochstämmigen Laubwaldes der Donau-Auen. Ihre obere Grenze liegt in Niederösterreich tiefer als jene von S. ficujilis und zwar im alpinen Gebiete um 200', im Gebiete des bühmisch-mährischen Gehirgsplateaus um $600^{\circ}$. In den subalpinen Thälern findet sie sich noch als 
vereinzelter Baum bei Ibbsitz im Ibbsthale, am Mitterauerbach im Gebiete der Erlaf, hinter Lilienfeld im Traisenthale und bei Reichenau und Edlach im Schwarzathale bei $17 \pi 0^{\prime}$. Am Plateau des böhm. - mähr. Gebirgess rereinzelt um Zwettel bei $1770^{\prime}$.

In Südbaiern wird ron Sendtner die obere Grenze in Gegensatze zu dem oben angegebenen Terhältnisse um $300^{\star}$ hüher als jene der S. frayilis angegeben (2弓̈l冖'). Im Kaukasus fällt ihre obere Grenze auf $3000^{\prime}$.

Die Silberweide liebt so wie S', fiagilis vorzüglich tiefgründigen lehmigen oder lehmig-sandigen Boden. Wir fanden sie sowohl auf kalkreichem, so wie auf kalklosem Substrate.

\section{Sect. III. Amygdalinae Ko cl.. Frutices trunco erecto et ramis} elongatis, tenacibus et Rexibilibus, foliis acuminatis, glabris, adolescentibus nec riscidis nec sericeis. Amentorum squanae persistentes. Torus flosculorum staminigerum biglandulosus, pistilligerum uniglandulosus.

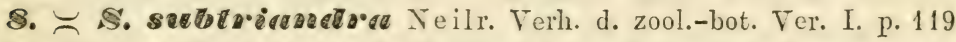
(superfiagilis-ainygdalina). Anenta staminigera coaetanea, gracilia, quinquies et semissi - septies lonvioia quam lativa. Squamae oboratae, obtusae, concarae, flarae, pilis lonyis rectis, flacescentibus pilosae et cum rhachite in basi villo brevi, crispo lanuginosac. Torus in flosculis staminigeris biglandulosus. Glandulae oroideac vel truncatae. Stamina duo vel tria, filamentis $5-6 \mathrm{~mm}$ lonitis, in basi pilosis. Folia oblongo-lanceolata, in petiolum contracta et in acumen tenue prollucta, ter - quater longiora quam latiora, serrata, glaberrima, supra saturate viridia, subnitida, subtus pallidiora, opaca. Foliola amentis suljecta integra. Stipulae semicordatae, serratae.

Am. o 50 - $85 \mathrm{~mm}$ lg. $10-12 \mathrm{~mm}$ lt.

Squam. $2 \mathrm{~mm}$ lg. Stam. $5-6 \mathrm{~mm}$ Jg.

Fol. $30-90 \mathrm{~mm}$ lg. $130-22 \mathrm{~mm}$ lt.

Ton Neilreich zwischen Mattersdorf und Forchtenau am Rosaliengebirge aufgefunden. (Uebereinstimmende Exemplare sahen wir im Herb. d. k. k. zool.-bot. Gesellschaft als S. frayilissina von Hinterhuber, mit der Angabe: "Mondsee Culta".)

In Neilreich's Fl. r. Nied. Oest. p. $23 \mathbf{y}^{4}$ wird die hier beschriebene Treide mit der folgenden Blendlingsart zusammengefasst, ron der sie sich jedoch durch die langen Haare der Kälzchenschuppen, welche das noch unentwickelte Kätzchen wie bei S. frayilis in einen Pelz einhüllen, ferner durch längere Staubgefässe, relativ kürzere Kätzchen, langzuge-pitzte Blätter und ganzrandige Kätzchenstielblätter unterscheidet. - Duich eben diese Mcrkmale schliesst sie sich an die cine Stammart: S. frourilis an, unterscheidet sich jedoch ron dieser durch die meistentheils dreimännigen Blïthen und verlängerten Kätzchen, durch welche in S. sultrianhe die zweite Stammart: S. amygdalina ausgesprochen crscheint. 
Ton der S. Pokornyi unterscheidet sie sich einmal dadurch, dass ihre Kätzchen niemals $\{$ - und z̈-männige Blïthen enthalten, vorzüglich aber durch die rerlängerten schlanken Kätzchen und unterscits blassgrünen Blätter.

In einem Aufsatze über die lyybriden Pflanzen der Wiener Flora in den Verh. d. zool.-bot. Ver. in Wien Bd. I. p. 119 wurde ron Neilreich dieser und der folgende Bastart als S. frajilis $\gamma$. subtriandra aufgeführt und wir iibertrugen den Namen subtriandra auf die hier beschriebene Blendlingsart, während wir den nachfolgenden sich an $S$. comyydulina mehr anschliessenden Bastart, welcher ron J. v. Kováts in der Flora exsiccata Vindob. als $S$. amyydalina concolor speciosa ausgegeben wurde, der aber, wie im Nachfolgenden erörtert werden soll, sich von $S$. speciosa Host wesentlich unterscheidet, als $S$. Kovátsii bezeichnen.

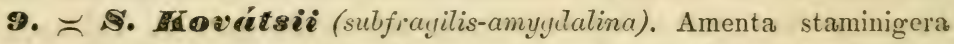
coactanea, gracilia, tenuia, septies lonyiora quam latiora. Squamae oboratac obtusae, concarae, flarae, subglabroe, in basi cum rhachite rillo brevi, crispo sublanuginosae. Torus in flosculis staminigeris biglandulosus. Glandula interna oroidea. Stamina tria vel duo, filamentis $3-4 \mathrm{~mm}$ lonyis in basi pilosis. Folia ex rotundata basi oblongo-lanceolata, breviter acuminata, quater longiora quam latiora, glaberrima, supra viridissima, subtus pallide viridia, opaca. Foliol a amentis subjecta grosse serrata.

Am. o $50-60 \mathrm{~mm}$ lg. $7-8 \mathrm{~mm}$ lt.

Squam. $2^{\mathrm{mm}}$ lg. Stam. $3-4^{\mathrm{mm}} \mathrm{lg}$.

Fol. $4: 5-90 \mathrm{~mm}$ lg. $10-20 \mathrm{~mm}$ lt.

S. amygd. L. var. concolor speciosa Ko rits Fl. exsicc. Vindob. Mr. 10'S. - S. amygralino-fragilis Neilr. Fl. v. N. Oest. p. 25k. pro parte.

Bei Gloggnitz in den Auen der Schwarza, dann am Bache im Thale ron Kaltenleutgeben bei Wien; an beiden Standorten je ein ơ Exemplar.

Sie ist der S. amyglalina a. concoler sehr ähnlich, aber durch theilweise zweimännige Blüthen von derselben unterschieden.

Den beiden hier unter 8 und 9 beschriebenen wahrscheinlichen Bastarten aus S. amyglalina und S. fragilis schliesst sich noch ein dritter an, der zuerst ron Tausch auf der Hetzinsel bei Prag aufgefunden, von ihm im Ind. Hort. Canal. 1821 als S. alopecuroides aufgefuihrt und auch unter diesem Namen in seinen Pl. sel. ausgegeben wurde. II ost, welcher diese Weide ron Tausch erhielt, beschrieb sie später, 1828, als S. speciosa (Sal. p. $\ddot{5}$ tb. 17) und pflanzte dieselbe in den Wiener botan. Garten, ron wo sie dann in mchrere andere botanische Gürten übergegangen ist. - Von Wrimmer wurde dieselbe Pflanze als $S$. amydalino-frayilis Flora 1848 p. 333 und später als S. fragilis-triandra Denksch. p. 130 beschrieben und im Herb. Salic. Fasc. VII. Nr. 77 ausgegeben, - Sie wurde bisher in Nieder- 
üsterreich nicht beobachtet. - S. alopecuroides besitzt sehr verlängerte bis zu 10 Centim. lange und 12 Millim. breite Kätzchen, die sieben Mal so lang als breit sind und durchgehends dreimännige Bliithen zeigen. - Die S. subtriandia unterscheidet sich von ilr nur durch kïrzere Kätzchen und theilweise zweimännige Blïthen. In der langen Beliaarung der Kätzchenschuppen, so wie in der Länge der Staulgefäise stimmen S. subtriundra Neilr. und S. alopecuroides Tausch (speciosa Host) rollkommen mit einander überein und unterscheiden sich hierin ron der $S^{\prime}$. Kónq'ítsii, deren Kätzchenschuppen an der Spitze fast kahl und nur an der Basis ron kurzen krausen Haaren etwas wollig sind.

$\mathrm{Da}$ alle drei Bastarte unterseits grüne Blätter besitzen, so ist es wahrscheinlich, dass sowohl ron S. amydalina als S. fiajilis die Form: concolor sich an ihrer Erzeugung betheiligte. - Die Kette der Bastarte ron der einen zu der anderen Stammart würde sich folgendermassen fe:thalten lassen:

1. S. fragilis. Staubkätzchen 3--̈̈mal so lang als breit, bis jgmm lang und $12 \mathrm{~mm}$ breit. Kätzchenschuppen mit langen geraden Haaren bekleidet, welche das herausbrechende Kätzchen in einen Pelz einhiillen. Blüthen 2männig. Staubfäden $4-6^{\mathrm{mm}}$ lang. Blätter lang zugespitzt. Kätzchenstielblätter ganzrandig:

2. $\asymp$ S. subtriandra (superficuilis-amerulatina). Staubkïtzchen dick, $6 \mathrm{mal}$ so lang als breit, bis $83^{\mathrm{mm}}$ lang und $12 \mathrm{~mm}$ breit. Kätzchenschuppen mit langen geraden Haaren bekleidet, welche das herausbrechende Kätzchen in einen Pelz einhüllen. Blïthen theils 3-, theils 2männig. Staubfäden ̈̈- crmu lang. Blätter langzugespitzt. Kätzchwnstielblätter ganzrandig.

3. $\asymp$ S. alopecuroides (ammdalino-jiacilic). Staubkätzchen dick, dabei aber sehr verlängert, 7mal so lang als breit, bis $100 \mathrm{~mm}$ lang und $12 \mathrm{~mm}$ breit. Kätzchenschuppen mit langen geraden Haaren bekleidet, welche das hèrausbrechende Kätzchen in einen Pelz einhüllen. Blïthen durchgehends dreimännig. Staubfäden $\ddot{b}-6 \mathrm{~mm}$ lang: Blätter langzuge-pitzt, Kätzchensticlblätter theils ganzrand:g: theils gesägt.

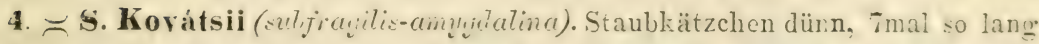
als breit, bis $60 \mathrm{~mm}$ lang und $8 \mathrm{~mm}$ breit. Kätzchenschuppen fast kahl, nur an der Basis mit kurzem wolligem Flaume bekleidet; die herausbrechenden Kätzchen daher kahl erscheinend. Blïthen theils 3-, theils 2-männig. Staubfäden 3-4mm lang. Blätter kurz bespitzt, Kätzchenstielblätter gesägt.

3. S. amygdalina b. concolor. Staublïtzchen dünn, i-limai so hang als breit, bis $70 \mathrm{~mm}$ lang und $\mathrm{S}^{\mathrm{mm}}$ breit. Kätzchenschuppen fast kahl, 
rur an der Basis mit kurzem wolligem Flaume bekleidet und die herausbrechenden Kïitzchen daher kahl erscheinend. Blïthen durchgehends 3männig. Staubfäden 3-4mm lang. Blätter kurz bespitzt. Kätzchenstielblätter meistens gesägt.

Die fruchtkitzchentragenden Weiden, welche den hier beschriebenen drei Bastarten entsprechen, sind bisher nicht bekannt geworden. Sie dürften in der Iänge des Fruchtknotenstieles, in der Länge der Kätzchen, in der Behaarung der Schuppen und in der Form der Narben ganz gute Anhaltpunkte zur Erkennung darbieten. Vielleicht siellt die ron Ilost in : Salix tab. 4 abgebildete weibliche Pflanze der S. spertal.ilis, deren Kätzchenschuppen mit langen geraden IIaaren bedeckt sind und die auch in der Form der Narben ganz und gav ron $S$. amı velalina abweicht, einen hieher gochüriggen Blendling dar.

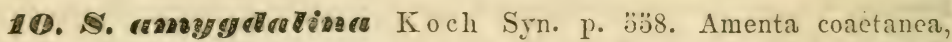
gracilia. quater - duodecies longiora quam latiora. Squamac oboratac, obtusac, concavae, flavae, subulubrae, solumodo in basi cum rhachite villo breri, crispo praeditae et sublanuginosac. Torus in flosculis staminigeris biglandulosus, in pistilligeris uniglandulosus. Glandulae oroideas, obtusae rel truncatae. Germen ex orata basi conicum, obtusiusculum, glabiun, pedicellatum, pedicello nectarium ier - quin'puies, plerumpue quater superante, stylo nullo rel brevissimo, stigmatilus per anfulum rectum direricntibus, emarginatis. Stumina trice, filamentis in basi pilosis. Folia lanceolata rel oblongo-lanccolata, ter-octies longiora quam latiora, serrata, glaberima. Foliola amentis subjecta partim integra partim grosse serrata et plerumque stipulata. Stipulae semicordatae. Ramuli glaberimi, flexibiles, ad insertionem fragiles. Cortex ramorum adultorum sponte secedens.

\section{Variat:}

60. Déseoton. Amenta staminigera quater - sexies, plerumque quater longiora quam latiora. Folia oblongo-lanceolata, acuminata, basin versus sur:um attenuata, quater - octies longrora quam latiora, supra viridia, subnitida, subtus opaca, glauca.

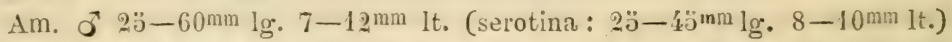

Am. $18-3: 5 \mathrm{~mm} \mathrm{lg} .5-6 \mathrm{~mm}$ lt.

Squam. 2-2.5m lg. Germ. 2-3mm lg. Pedicell. 2-3mm lg. Stamin. $4-\breve{m m n} \mathrm{lg}$.

Fol. $50-130 \mathrm{~mm}$ lg: $8-28 \mathrm{~mm}$ it.

S. amygdalina L. Spec. 14ł3. (sec. Smith.) Host (sec. specim. in Hort. IIost. Vindob.) Fries Novit. Fl. suec. p. 42 u. Herb. norm. Fasc. III. Nr. 51. - S. amygdalina $\alpha$. discolor K o ch. Syn. p. 35̈S, Kor. Fl. ex sicc. Yind. Nr. 10:6. - S. amygd. b. discolor W. et Grab. Fl. siles. u. Wimm. Her b. Salıc. Fasc. V. Nr. 5't. Ne ilr. Fl. v. N. Oest. p. 23ł. 
ש. Concodo*. Amenta staminigera septies - duodecies, p stilligera plerumque sexies longiora quam latiora. Folia ex rotundata basi oblonga, breviter acuta vel abrupte acuminata, ter - quinquies longiora quam latiora, supra viridissima, subtus pallidiora, attamen viridia, utrinque subnitida.

An. ठ $405-70 \mathrm{~mm} \mathrm{lg} .508 \mathrm{~mm}$ lt.

An. O 24-45mm lg. $4-7 \mathrm{~mm}$ It.

Squam. 1.5-2mm lt. Germ. 2-3mm lg. Pedicell. 1-2mm lg. Stamin. $3-4 \mathrm{~mm} \lg$.

Fol. $4 \breve{b}-100 \mathrm{~mm}$ lg. $150-2 \ddot{m m} 1 t$.

S. tirandra L. spec. 14t2. (sec. Smith.) S. ligustrina Host Salix p. 4. tb. 13. - S. amygdalina $\beta$ concolor Koch Syn. P. S̆อ̆S. Kov. Fl. exsicc. Vind. Nr. 1047 u. 1019. S. amygd. a. concolor Wimm, u. Grab. Fl, siles, u. Wimm. Herb. Salic. Fasc. IV. Nr. 38. Neilr. Fl. v. N. Oest. p. 2วł'.

Im Süden erwächst die Mandelweide nach Grisebach*) zum Baume. Bei uns kommt sie nur als Strauch ror und rermag sich als solcher auf dem ihr vorzïglich zusagenden feuchten, tiefen, angeschlemmten Sande an den Ufern der Bäche und Flüsse im geschlossenen Buschwalde zu 20 Fuss Hühe $\mathrm{zu}$ erheben. Sie erreicht kein hohes Alter und rerkümmert alsbald, wenn andere baumartige Teiden, wie $S$. alla und S. firajitis oder Erlen und Pappeln über sie emporwachsen. Gewöhnlich siedelt sie sich auf dem nach Ueberfluthungen abgelagerten Schlamme an den Ufern oder auf den Schotterbänken im Stromlaufe der Donau und ihrer grösseren Nebenflüsse mit S. purpureu und $S$. incanc an. Im letzteren Falle sammelt ihr dichtes Buschwerk, so wie jenes der beiden andern genamnten Weiden, den ron den Hochwässern mitgebrachten Schlamm an und gibt Teranlassung zur Bildung einer über dem Schotter sich ablagernden oft sehr mächtigen Sandschichte, auf der dann erst andere Heiden, wie S. fravilis, und $S$. allia anfliegen und weiter wachsend die niederen Buschweiden unterdrïcken. **;

Die Rinde der Mandelweide löst sich selbstständig fetzenweise ron den älteren Stämmen los. Die honigduftenden, schlanken, geraden, kahl aussehenden Kätzchen sind nächst jenen der früher beschriebenen S. Kö'ritsii und S. alopecuroides, die längsten unter allen Weiden. Am meisten rerlängert erscheinen dieselben bei den in subalpinen Thälern an den Lfern der kaiten Gebirg:sächc rorkommenden Sträuchem. Wir fanden an den Ufern der Frlaf' bei Scheibbs und an der Traisen bei Türnitz männliche Sträucher, deren Kätzchen, 10-12mal so lang als breit, eine ab=olute Länge ron 7 Centim. erreichten und wo die einzelnen Blïthen an der verlängerten Axe so sehr auseinandergerïckt waren, dass dadurch die Kätzchenspindel theilweise ganz nackt erschien. Uebcreinstimmende Exemplare liegen uns auch aus der Gegend ron Laibach und ron den Ufern der Enns ror, und die ron Host an den

*; Spicileg. Fl. rum. et bith. p. $34 k$,ad ripas pr. Brussa hine inde arborea! 4

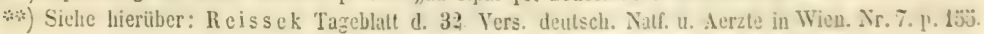


Ufern der Salzach im Salzburgischen angegebene S.tenuiffera (Salix. p. 2 th. 7 und 8) scheint gleichfalls auf diese Form bezogen werden zu mïssen, obschon die Host'sche Abbildung unterseits blauliche Blätter zeigt, die von uns erwïhnten Weiden hingegen eine blassgrüne untere Blattfläche aufweisen.

Regelmässig sind sowohl die Schuppen der Kätzchen, so wie die Fruchtknotenstiele und Staubfäden bei der Tar. concolor absolut kïrzer als jene der Var. discolor. Da sich aber bei den ersteren nicht auch die Kätzchenspindel ent.prechend rerkürzt, sondern im Gegentheil melhr verlängert ist als bei der Var. discolor, so erscheinen ihre Kätzchen immer schmäler und schlanker als bei der letztgenannten.

Das grössere Ausmass, welches die Tar. discolor in allen Organen zeigt, weist darauf hin, dass sie das Erzeugniss eines der Mandelweide besonders zusa genden Bodens und Klimas ist. ${ }^{*}$ ) - Nur bei der üppigen Spielart: Var. discolor finden sich auch häufig proleptische nicht durch Verstïmmlung prorozirte Kätzchen, wclche aus den Blüthenknospen in der Achsel der im Frühlinge entwickelten Blätter schon im Laufe der darauf folgenden Sommermonate ihre Blïthen entfalten und Host Veranlassung gaben, solche Exemplare als S. semperfloiens (Salix p. 2. tb. 5 u. 6. - S. amyjd. $\gamma$. serotina Kor. Fl. exsicc. Vindob. Nr. 10:0) zu beschreiben. Bemerkenswerth ist aber, dass diese Kätzchen kürzer als die normalen Frühlingskätzchen erscheinen, und dass auch die Stiele meistens schr verkürzt sind, so dass dadurch die Kätzchen fast sitzend erscheinen.

Die Blätter der Var. concolor, welche ron Host als S. ligustiina beschrieben wurde, sind an der oberen Seite dunkelgrïn, an der unteren Seite wohl blasser aber rein grïn und gewöhnlich ebenso wie an der oberen etwas glänzend. Sie kommen durch dieses letztere Merkmal mit den nachfolgenden Weiden: S. retusa, S. herbacea, S. Myrsinites und der nördlichen S. polaris ïberein, welche gleichfalls unterseits etwas glänzende Blätter besitzen und sich dadurch ron den ïbrigen Arten auszeichnen. Die Blätter der Var. concolor erscheinen ferner gewöhnlich länglich, in den Blattstiel zugerundet und plötzlich kurz zugespitzt. - Die Blätter der Var. discolor sind oberseits freudig grün, unterseits hechtblau oder fast weisslich bereift. Sie erscheinen meistens länglich lanzettlich in den Blattsticl zusammengezogen und gleichmässiger zugespitzt. Nur selten sind sie breit, fast elliptisch und in den Blattstiel zugerundet, wie sie Host an seiner rothzweigigen S.venusta (Salix. p. 3 tb. 9 u. 10) und an S. varia (Salix. p. 3 tb. 11 u. 12) abbildet. An sehr üppigen Exemplaren der Var. discolor werden die Blätter am Rande etwas wellig, die durch das Kätzchen abgeschlossenen Aestehen verlängern sich und sind mit Blättern bekleidet, welche die Grösse der anderen Blätter

*) In Schweden findet sich nach Fries nur die Var, discolor mit unterseits blaugrünen Bliltern. Auch in Tirol kommt nach Hausmann nur diese Varietät vor. 
erreichen, eb€ıso wie diese gesägt und mit rerhältnissmässig grossen Nebenblättern rersehen sind. Die S. spectabilis Host (Salix. p. 1 tb. 3), welche ron dem Autor in Polen und in der Bukowina angegeben wird, stellt eine solche sehr üppige Form dar, wie sie auch in den Donau-Auen Nicderösterreichs nicht selten angetroffen wird.

Die Mandelweide ist in Europa ron der Mittelmeerzone nordwärts zu einer nordöstlichen Vegetationslinie verbreitet, die ron den schwedisch-nordländischen Flüssen und dem Uferlande des bottnischen Meerbusens durch das mittlere europäische Russland in den Lral zieht, und wird ostwärts noch in altaischen und baikalischen Sibirien angegeben. Fehlt in der neuen Welt und wird dort durch die ähnliche S. lucida rertreten. -- In den Südalpen findet

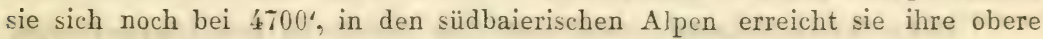
Grenze bei $3376^{\circ}$, in den obersteirischen Alpen bei $2400^{\circ}$.

In Niederösterreich erscheint sie in dem Inundationsgebiete der Donau, so wie in den anderen Niederungen als eine der häufigsten Weiden. Die Var. discolor ist vorzüglich an der Donau zu Hause und fehlt auf den Hölen des Waldriertels, so wie sie auch im alpinen Gebiete nur hüchst selten und rereinzelt angetroffen wird und dort schon bei $1100^{\prime}$ (höchster von uns beobachteter Standort an der Erlaf in der Nähe des Töperischen Hammerwerkes) ihre obere Grenze erreicht. Die Tar. concolor hingegen, ist in den Donauauen selten, umsäumt dagegen vorzüglich die Ufer der kalten Bäche der südlichen Bucht des Wiener Beckens und findet sich an den alpinen Zuflïssen der Donau bis in die subalpinen Thäler zu $1800^{\prime}$ rerbreitet (höchstcr ron uns beobachteter Standort an dem Ufer der Schwarza zwischen Reichenau und Prein).

Am Plateau des böhm.-mähr. Gebirges wird die Var. connolor bis zu Höhen von $1600^{\prime}$ angetroffen, so z. B. an dem Lfer der Krems bis Hartenstein, am Kamp bei Zwettl, an dem Ufer der Lainsitz bei Weitra.

Sie findet sich an den zuletzt angeführten Standorten auf ganz kalkfreier Unterlage in dem schlammigen Sande des rerwitterten Granit- und Gneissbodens - an den Wiesenmooren in der siidlichen Bucht des Wiener Beckens, so wie auf den Dilluvialterassen, an den Ufern der Erlaf und Traisen gedeibt sie aber eben so gut auf kalkreichem Substrate.

\section{S e c t. IV. Retusae. Fruticuli pygmaei trunco decumbente et ramulis} abbreriatis, ad insertionem fragilibus, foliis glaberrinis, emarginatis, obtusis vel acutis (nunquam acuminatis). Anentorum squamae persistentes. Torus flosculorum staminigerum biglanilulosus, pistilligerum uniglandulosus.

18. $\asymp$ S. Fearaderara. (superietusa - glubia). - Amenta coaetanea in pedunculo foliato non yeminifero, gracilia, 20-30 for $a$, bis longiora quam latiora. Squamae oboratae, obtusae vel truncatae, primo ciliatae, postea glabratae, e viridi flavae. Torus in flosculis staninigeris biglandulosus. Glandulia 
interna oblonga, sublinearis dupplo longior et crassior quam externa. Stanina duo, filamentis in basi pilosis. Folia obovata, obtusa vel emarginata, in petiolum brevissimum attenuata, bis longiora quam latiora, toto ambitu serirta, glaberrima, supra saturate viiidia subnitida, sultus opaca, leviter ylaucescentico penninervia. Nervi secundarii subtus vix elevati utrinque 4-6, a nervo medio sub angulis $20^{\circ}-30^{\circ}$ descendentes. - Fruticulus trunco decumbente, ramulis adscendentibus, fragilibus, glaberrimis.

Am. of $14-18^{\mathrm{mm}} \lg .6-8 \mathrm{~mm}$ lt.

Squam. 2mm lg. Stam. 4-5mm lg. Gland, tori int. $0,5 \mathrm{~mm} \mathrm{lg}$.

Fol. $13 ̈-2 \mathrm{gmm}^{\mathrm{mm}} \lg 8-10^{\mathrm{mm}}$ lt.

In der Krummholzregion am westlichen Abfall des hohen Schneeberges bei : $3000^{\prime}$ auf kalkreichem felsigen Boden, ein ơ Sträuchelchen.

Die hier beschriebene Blendlingsart, welche ich ror mehreren Jahren an dem angegebenen Standorte auffand und nach Herrn Prof. Fenzl. S. Fenzliana benannt habe, bringt beim ersten Anblick den Eindruck von $S$. retusa herror und stimmt mit dieser namentlich im Zuschnitt und in der Nervatur der Blätter, so wie in den einfärbig grünlichgelben abgestutzten Kätzchenschuppen und den zweidrüsigen Torus überein. Die Blätter sind aber unterseits matt, etwas bläulich bereift und im ganzen Unfang gesägt, die Kätzchen ind reichblüthiger, die Blüthen stchen gedrängter und die Staubfäden sind an der Basis flaumig, welche Merkmale auf S. ylabra hinweisen, die auch mit $S$. retusa zusammen häufig an dem Standorte des hier beschriebenen Blendlings angetroffen wurde.

Sie verknïpft die Rotte: Retusae nit der Rotte der Schwarzweiden. namentlich mit $S$. glalira, die ohnehin in der Bildung der Fruchtknoten und Narben, so wie in der Farbe der Kätzchenschuppen mit S. rotusa eine grosse Uebereinstimmung zeigt, sich aber wesentlich durch den eindrïsigen Torus der Staubblüthen, und etwas mehr verlängerten Griffel unterscheidet.

12. A. petesse L. sp. 144\%. Amenta coaetanea, laxiflora, staminigera bis, pistilligera ter longiora quam latiora, pedunculo bi-quadrifoliato !lemmifero, rhachite pilosa vel glaberrima. Squanae obovatae, emarginatae vel truncatae, glaberrimae rel primo ciliatae et postea glabratae, e viridi flarae. Torus flosculorum pistilligerum uniglandulosus, staminigerum biglandulosus. Glandula interna oblonga, sublinearis, dupplo longior et crassior quam externa. Germen ex orata basi conicum, obtusiusculum, glabrum, pedicellatum, pedicello ylandulan internam aequante vel paululum superante, stylo brevissimo, stigmatibus bipartitis, laciniis patulis, crassis. Stamina duo, filamentis glabris, antheris post anthesin sordide flavis. Folia obovata vel oblomyoobonatr, obtusa rel emarginata in petiolum brexissimum attenuata, bis longiora quan latiora, plerumque inte:lerrima, rarissime basin versus dente uno alterove 
instructa, glaberrima, supia et subtus viridia, subnitentia, penninervia. Nervi secundarii subtus vix elevati utroque latere $4-6$, a nerro medio sub angulis $20^{\circ}-30^{\circ}$ descendentes. Truncus humifusus. Ramuli decumbentes, radicantes, glaberrimi, fragiles, juniores cortice rufescente, nitido, testaceo tecti.

Variat in solo calcareo alpium Austriae inferioris foliorum forma:

a) Folia obtusa, oblongo-obovata, bis et semissi longiora quam latiora.

b) Folia emarginata, obovata, bis longiora quam latiora.

Am. o $6-15^{\mathrm{mm}}$ lg. $4-8 \mathrm{~mm}$ lt. Am. O $8-20 \mathrm{~mm}$ lg. $3-7 \mathrm{~mm}$ lt.

Squam. 2-2.5m $\mathrm{lg}$. Gland. tori int. $4^{\mathrm{mm}} \lg$. Germ. 3-4mi lg. Styl.

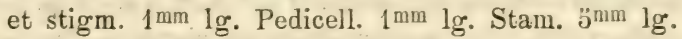

Fol. $8-20 \mathrm{~mm}$ lg. $5-8 \mathrm{~mm}$ lt.

S. retusa Host. Salix tb. 103. - Koch Syn. p. 570 (rar. $\alpha$.) - Neilr. Fl. พ. N. Oest. p. 266. - W imm. Hb. Salic. Fasc. VII. Nr. 82.

Der hier beschriebenen auf dem Kalkboden der Nord- und Südalpen sich entwickelnden $S$. retusa mit ganzrandigen, bald verkehrteiförmig n ausgerandeten, bald länglichen stumpfen Blättern schlies.en sich die Formen an, welche vorzüglich in den Centralalpen, am häufigsten auf Glimmerschiefersubstrat rorkommen und mit Blättern bedeckt sind, die rom Blattstiel bis beiläufig gegen die Mitte gesägt erscheinen. Die Blätter dieser S. retusa 2.) denticulatı sind so wie bei der Form des Kalkbodens: S. retusa 1.) inteyrifolia bald ausgerandet. bald stumpf oder etwas spitz, und überdiess tritt sowohl die ausgerandetblättrige wie die stumpfblättrige $S$. retusca 2 .) denticulata in einer der Hochalpenregion angehörigen form mit kleineren Ausmasse der Organe und einer in der tieferen Alpenregion rorkommenden Form mit grösseren Dimensionen der Blätter und Bliithentheile auf. Diese Formen der S. retusa थ.) denticulita liessen sich folgrendermassen an die zwei obenangegebenen Spielarten unserer S. ret. 1.) integrijoliu: a) und b) anreihen :

c) Folia oblongo-cuneata 4-16mm longa, semel et semissi-bis longiora quam latiora, emarginata, in basi denticulata. Amenta ad $6^{\text {min }}$ longa, pauciflora, 3-6 imo uniflora. Rhachis et squamae glaberrimae. Stamina $3^{\mathrm{mm}}$ longa. Germen $2-3^{\mathrm{mm}}$ longum.

d) Folia oblonga $4-10^{\mathrm{mm}}$ longa, semel et semissi - bis longiora quam latiora, acuta, coriacea, in basi denticulata. Amenta a 1 6mm longa, pauciflora $3-6$, imo uniflora. Rhachis et squamae glaberrimae. Stamina $3^{\text {man }}$ longa. Germen $2-3^{\mathrm{mm}}$ longum.

c) Folio oborato-cuneata $\$-20$ mu longa, bis longiora quam latiora. cmarginata, in basi denticulata. Amcnta ad $13^{\text {mm }}$ longa, li-10 flora. Rhatchis pilosa. Squamae truncatac apice ciliatae. Stamina $4-6$ man longa. Germen $2.3-4^{m ! n}$ longum. 
f) Folia oblonga, 8-20mm longa, bis - ter longiora quam latiora, obtusa rel acuta, in basi denticulata. Amenta ad $18^{\mathrm{mm}}$ longa, 6-13 flora. Rhachis pilosa. Squamae truncatae, apice ciliatae. Stamina $4-\ddot{z}^{m m}$ longa. Germen $3-4^{\text {mm }}$ longum.

Die mit c) bezeichnete Spielart scheint die Hochalpenform ron e) zu sein. so wie die mit d) bezeichnete Varietät wahrscheinlich die Hochalpenform von f) darstellt.

Die beiden Formen c) und d) wurden ron den Autoren grewöhnlich unter dem Namen S. serpyllifolia, (zuerst ron Scopoli Fl. carn. II. p. 2:3̈̈., t. 61 als Art aufgestellt) zusammengefasst und von Ko ch (Syn. p. อ̈70) als var. $\gamma$. der S. retısa aufgeführt. Sie stellen äusserst zierliche Zwergweiden dar, deren am Boden angedrückte Aeste gewühnlich ineinandergeflochten sind, so dass die Sträuchelchen ein fast rasiges Ansehen erhalten. Ihre kleinen steifen Blättchen sind gegen die Basis zu beiderseits mit ein paar drüsigen Zähnen rersehen und ron $3-\ddot{~}$ Fiedernervenpaaren durchzogen. Die armblüthigen Kätzchen sind rollkommen kahl, die Staubfäden und Fruchtknoten absolut kleiner als bei den anderen Formen der S. retusa, die Kätzchenschuppen und die Torusdrüsen jedoch verhältnissmässig gross und die innere Torusdrüse ein Drittel so lang als die Staubfäden. Die Form c) mit eusgerandeten Blättchen ist ziemlich selten, häufig hingegen die Var. d) mit stumpfen oder etwas spitzen Blättchen.

Die Formen e) und f) entsprechen im Zuschnitt der Blätter und in dem Grössenverhältnisse aller Organe den beiden in Niederösterreich rorkommenden Spielarten der ganzrandigblättrigen Kalkform und unterscheiden sich ron diesen überhanpt nur durch die gegen die Basis gesägten Blätter. Unter allen in den Alpen rorkommenden Varietäten der S. retusa ist übrigens die unter f) angeführte die üppigste und stellt die $S$ retusa $\beta$. K och Syn. p. 070 und die S. Kitciletiana der meisten Autoren dar. Sie wird jedoch an Grösse und Ueppigkeit ron der in den Karpathen rorkommenden Parallelform der alpinen S. retusa, nämlich: S. Kitaibeliana Willd. sp. pl. 4. p. $683=$ S. retusa $\gamma$. W a hlb. Fl. Carp. princ. p. 314 noch bei weiten übertroffen.

Der Vollständigkeit der Formenreihe halber möge hier die Diagnose dieser üppigsten aller Formen von S. retusa Platz finden:

g) Folia oblonga rel oblongo-oborata obtusa rel acuta, basin versus attenuata, et serrata, bis - ter et semissi longiora quam latiora $(1 \ddot{3}-32 \mathrm{~mm} \mathrm{lg}$. $5-16 \mathrm{~mm}$ lt.). Amenta staminigera ter, pistilligera quater longiora quam latiora ad $30 \mathrm{~mm}$ longa, rhachite lanuginosa. Squamae 2-3mm longae. truncatae ante anthesin pilis longis albidis subcrinitac. Stamina $4-5 \mathrm{gmm}^{\mathrm{mm}}$ longa

In der Form. und Grösse der Fruchtknoten, sowie der Griffel und Narben stimmt die S. Kitaileliana der Karpathen auf das rollständigste mit üppigen Formen der alpinen S. retusa überein und sie kann, so verschiedenartig auch 
ihr Habitus ist, ron dieser ebensowenig getrennt werden, als S. eerpullifolia. Sämmtliche hier umgrenzte Formen bilden eben eine Kette, deren eines Grenzglied S. serpullifolia, deren anderes Grenzglied die karpathische S. Kitaibeliana ist. - Sendtner, wel her der S. serpullifolia die Artrechte wahren will, behauptet zwar (Veg. Yerh. Süd-Baierns. 1. 86.3), das diese nie in einer Mittelform mit $S$. retusa beobachtet wurde. Wir haben jedoch die Formen der $S$. retusa in den Alpen und Karpathen mit besonderer Aufmerksamkeit rerfolgt und sind $\mathrm{zu}$ der Ceberzeugung gelangt, dass die Natur weder zwischen S. retusa und S. serpyllifolia, noch zwischen S. retusu und S. Kitaileliana eine scharfe Grenze zieht. Sendtner selbst gibt auch für S. serpyllifolia eine höhere Region an, als für S. retu:a und wir wiederholen, dass wir die erstere als die hochalpine Form der letzteren ansehen.

Der Stamm der auf den niederösterreichischen Kalkalpen rorkommenden S. retusa erreicht den Durchmesser ron $1 \mathrm{Ctm}$, und zeigt dann gegen 30 Jahresringe, die einseitig meistens riel stärker entwickelt erscheinen. Das Holz ist zähe, die Zweige aber nichts destoweniger an den Abästungsstellen brüchig. Die glänzendbraune Rinde der 2 -4jährigen Aeste ist ähnilich jener der S. firailis häutig und hebt sich im Trocknen faltenwerfend ron dem Holzkörper los, später wird sie glanz:os, ron kreisürmig um den Stamm laufenden Sprüngen rissig und zierliche Flechten, rorzïglich die hellgelbe Cetraria nicalis siedeln sich an der borkigen schwärzlichen Rinde an. Die $S$. retusa liebt in unseren Alpen rorzüglich die steinigen Kuppen, findet sich dort meist gruppenweise in Gesellschaft ron S. Mursinites und bildet mit ihrer treuesten Begleiterin der Armeria alpina, so wie mit Cherleria sedoides, Carex fima, Silene acuulis, Potentilla Clusiana, Pirmula Clusiana, Divas octopetalu und rasenbildenden Saxifragen eine sehr charakteristische Pflanzenformation. - An solchen sonnigen Kuppen erscheint sie mit Blüthenkätzchen bedeckt, ihre Blätter sind ausgerandet, ihr Stamm sowie ihre Aeste sind kurz, knorrig, sparrig verzweigt und liegen oft in einander versthlungen ohne Adrentivwurzeln zu treiben dem felsigen Bolen auf. Zwischen dem Knicholz hingegen, nimmt sie einen wesentlich anderen Habitus an. Die im Laubmoose und Humus eingeketteten Stämme sind dort fast schlangenfürmig gewunden, langgestreckt. nicht selten bis $1 / 2$ Meter lang. und senden nach beid.n Seiten üppige, reichlich mit Adrentirwur eln rersehene Aeste ab. Die Blätter sind dann länglich, stumpf, bis $20^{\text {mm }}$ lang, aber die Blïthenkätzehen nur sehr sparsam an den Zweigen rertheilt.

Noch mehr abweichend erscheint die S. Fitailieliana im Krummholze der Karpathen. Wur das Bild der alpinen Kalkform festhält, der erkennt dort auf den ersten Eindruck kaum noch diese Weide als $\therefore$, returw. denn sie erscheint ihm als ein bis zu 2 Decim. hohes buschiges Sträuchelchen mit weichen bis über 3 Centim. langen gexägten IBläitern und anfïnglich weis-shaarigen schlanken Kätzchen. Ihre kätzchentragenden Aestchen sterben und 
fallen an solchen ïppigen Exemplaren auch nicht selten gleich jenen der anderen Chloriteen ab, ohne dass die Knospenanlagen in den Achseln ihrer Blätter zur Entwicklung kamen. Wenn nicht schon die schlanken lockerblüthigen Kätzchen, die gelblichgrünen einfärbigen Kätzchenschuppen, der zweidrüsige Torus der Staubblüthen, die kahlen Blätter und Fruchtknoten der kurze Griffel und die zweitheiligen dicklichen fleischigen Narben der Retusas mit Entschiedenheit ihre innige Verwandtschaft mit den anderen Chloriteen beurkunden würden. so zeigten solche Exemplare der S. Kitaibeliana auf das unzweideutigste, dass die zwergigen Alpenweiden S. vetusa und $S$. herbacea ron den anderen strauchartigen und baumartigen Chloriteen nicht getrennt werden können, da durch sie der Unterschied der endständigen und seitenständigen Kätzchen als unhaltbar erscheint und endlich nur mehr den Zuschnitt der Blätter und die Höhe des Strauches übrig bleibt um die S. retusa und herbacea von den im Habitus wohl sehr abweichenden, sonst aber in allen Merkmalen innig rerwandten Mandelweiden abzugrenzen.

Die S. retusa ist in Europa auf die Hochgebirge des südlichen und nittleren Theiles beschränkt. Ihre nordwestliche Vegetationslinie rerläuft von den Pyrenäen durch die Alpen der Dauphiné und den Jura. entlang der Kette der Nordalpen in die nordungarischen und galizischen Karpathen.

In Ledebours Fl, ross. wird S. retusa in Altai, im östlichen und arktischen Sibirien und im arktischen Amerika am Kotzebue's-Sund angegeben, und es würde sich demnach die nordwestliche Vegetationslinie nach grossen Unterbrechungen dahin fortsetzen. - Im sudetisch-herzynischen Gebirgssy:teme fehlt $S$. retusa, ebenso auf den skandinarischen und schottischen Gebirgen und in der europäischen arktischen Zone.*)

In Nordtirol wird sie in dem Höhengürtel ron $5000-7000^{\prime}$, in den südbaierischen Alpen zwichen $5100-7600^{\prime}$ angegeben.

In Nied rösterreich erreicht sie ihre untere Grenze bei $4750^{\prime}$ und findet sich von da an, an Häufigkeit zunehmend, bis zu den höchsten Erhebungen am Hochkar, am Oetscher, am Güller, auf den Kuppen der Raxalpe und des Schneeberges: $6: 366^{\star}$ - obschon letztere Höhe nicht als ihre absolute obere Grenze in den östlichen Nordalpen anzusehen ist, da sie noch auf der Spitze des benachbarten Hochschwabs bei $722^{\prime} 3^{\prime}$ angetroffen wird. Niemals steigt S. retusa in unseren Alpen gleich den Rhododendron-, Primula- und SoldanellaArten und anderen Alpenpflanzen in die Thäler unterlalb die untere Grenze der Krummföhre herab.

*) Die S. retusa $\neq$ sarmentacea Fries. Nor. FI. suec. p. 73, welche der Autor als cine „Forma maxime regreta luxurians $S$. retusae $L^{*}{ }^{*}$ bezeichnet unil wefcher er ${ }_{\text {folia }}$ suhtus primo longe pilnsa, demum glabrata, nnaca; antherae purjurascentes" zuschreibt, und sie weiters mit ${ }^{\prime}$ aflsulis longe peilicellatis subpilosis, stylo elongato diagnostizirt, ist offenbar nicht $S$. retusa L. und scheint zu S. Myrsinites zu gechïren, welche Ansidat auch Blytt (Bot. Nut. 18\%̈. p. 41) ausspricht. - Vielleicht ist dieselbe ein Bastart aus S. Myrsinites und herbacea oder aus S. Myrsinites und S. arbuscula; auf keinen Fall ist sie unsere S. retusa. - Auch die Angate sm Fries, lass Exemplare vin Breadalblane in Schothand im Herbar Hornemann's zu $S$. retuse grehören, dürte demnach zu bezweiteln sein und von den cuglischen Floristen wird auch $S$. retusa nicht aufgefülırt 
13. .. Theobucere (I. sp. 144\%.) Amenta coaetanca, semel - bis longiora quam latiora, laxiflora et paucitlora, brevissime pedunculata. pedunculo bifoliato, demifero. Rhachis glaberrima rel longe villosa. Squamae concavae. oblongae, obtusae, e viridi flarae. pilosae vel glaberrimae. Torus flosculorum pistilligerum uniglandulosus, staminigerum biglandulosus. Glandula externa oblonga, obtusa, integra; interna plerumque bipartita, laciniis divergentibus, basin germinis superantibus. Germen ex orata basi conicum. glabrum, brevissime pedicellatum, stylo brevissimo, stigmatibus bifidis, laciniis patulis crassiusculis. Stamina duo, filamentis ylaliris. Folia brevissime pedicellata, ovalia vel orliculatu, obtusa vel emarginata, rarissime acuta, in basi rotundata, majora etiam eximie cordata, omnia toto amlitu crenato-serrata, glaberima, utinque nitida et unicoloria viridia, subnervigera et venis utrinque prominentibus eleyanter reticulata. Ramuli decumbentes, radicantes, fragiles, juniores nonunquam pilosi, adulti glaberrimi.

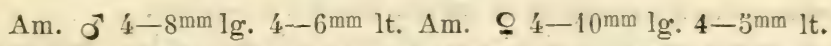

Squam. $2 \mathrm{~mm} \mathrm{lg}$. Gland, tori int. $1 \mathrm{~mm} \mathrm{lg}$. Germ. $2 \mathrm{~mm} \mathrm{lg}$. Styl. et stigm. $1 \mathrm{~mm}$ lg. Stam. $2.5-3 \mathrm{~mm}$ lg.

Fol. $8-20 \mathrm{~mm}$ lg. $7-20 \mathrm{~mm}$ lt.

S. herbacea Host. Salix p. 32 tb. 10k, Fries Nor. Fl. suec. Mant, I. p. 76. Herb. norm. Fasc. V. Nr. $67, \mathrm{~K} \mathrm{och} \mathrm{Syn.} \mathrm{p.} \mathrm{570,} \mathrm{W} \mathrm{imm.} \mathrm{Flora} 1849$ p. 38, Herb. Salic. Fasc. IV. Nr. 41, Neilr. Fl. v. N. Oest. p. 267.

Die S. herbacea, welche Linné als "minima inter omnes arbores" bezeichnet, entfaltet in den Alpen erst im Hochsommer ihre winzigen $3-12-$ blüthigen Kätzchen, die anfänglich in die zwei rerhältnissmässig grossen Kätzchenstielblätter eingewickelt ersche:nen und selbst noch zur Zeit der vollen Blïthe ron diesen überragt werd.n. Die Narben, Fruchtknoten und Kätzchenschuppen sind manchmal an der dem Lichte ausgesetzten Seite etwas röthlich übrrlaufen. Die steifen rundlichen beiderseits gleichfarbig hellgrünen glänzenden, fast benerrten und zierlich geaderten Blätter steben zu zwei oder drei am Ende der kurzen brüchigen Zweige. Die dünnen $Z$ weige werden erst im dritten Jahre holzig und sind dann mit einer braunen glänzenden Rinde überzogen, die sich im Trocknen, ähnlich, jener der S. retusu, faltenbildend rom Holzkörper emporhebt. Im 6. Jahre verliert die Rinde ihren G anz, wird bräunlich-grau und die Stämmchen besitzen in diesem Alter gewöhnlich ein n Durchmesser ron 2-3mm. Nach etwa 12 Jahren. wo der älteste Theil des Stammes eine Dicke ron fmum erreicht hat. oder auch schon früher, stirbt derselbe ab und rermodert; die durch Adrentirwurzeln an den Boden befestigten Seitenstämmchen entwickeln sich aber als getrennte Individuen weiter und bilden zusammen eine Gruppe von Sträuchelchen. - Die Entwicklung ron Adrentirwurzeln findet insbe-onders an den 2-4iährigen Zweigen statt und ist bei solchen Ex:mplaren, welche in Mrouspolster eingebettet liegen, sehr reichlich. An den moosbewachsenen Standorten erscheinen 
die $Z$ weige manchmal fast peitschenfürmig hingestreckt, bis zu 3 Decimeter lang, und die einjährigen Triebe bis zu :̈ Centim. verlängert. Im festen Thonboden sind die Stämmchen dagegen sehr rerkürzt, das ganze Sträuchelchen zwergig, die Stämmchen nur 3-4 Centim. und die jährigen Triebe oft kaum einige Miilim. lang.

Die Veränderlichkeit der Merkmale beschränkt sich ganz vorzüglich auf die Blattform, auf die Behaarung der Kätzchenspindel und Kätzchenschuppen. Die Blätter sind nämlich entweder ellyptisch, an der Basis zugerundet und fast zweimal so lang als breit - oder sie sind breit, kreisrund, manchmal sogar breiter als lang, an der Basis herzförmig und gewöhnlich gleichzeitig etwas ausgerandet. - Bei der ersteren Form sind die jährigen Triebe, die Kätzchenspindeln und die Kätzchenschuppen rollständig kahl, bei der letzteren meistens ron geraden weissen zerstreuten Haaren etwas zottig. Manchmal erscheint dann selbst die untere Fläche der sich entwickelnden Blätter von solchen zerstreuten, aber bald abfallenden Haaren bekleidet.

Die S. herlacea findet sich fast auf allen mit Krummholz bewachsenen Hochgebirgen Liuropa's und ist anderwärts bis über den Polarkreis auf Kola, und Lappland und bis Spitzbergen rerbreitet. Ebenso findet sie sich in Asien auf den Hochgebirgen des Altai, des baikalischen Sibiriens und Dauriens; im arktischen Sibirien und im arktischen Amerika bis Grönland. - In den südlichen und Centralalpen wird sie in dem Höhengürtel ron 7000-9300' gefunden. In der nördlichen Alpenkette erscheint sie: Südbaiern 3300-7200، Yordtirol $3: 500-7000^{\circ}$, Oberösterreich $5800-7: 300^{\circ}$. In den Karpathen zwischen $5900-7200^{4}$. In dem sudetischen Gebirgssystem $4400-4700^{\circ}$, im schottischen Hochgebirge 1800-4000', in Lappland 1800-2 $\mathbf{i}^{\prime} 0^{\prime}$, in Grönland im Meeresniveau.

Sie liebt thonreichen Boden, kommt aber ebensowohl auf kalkreichem Lehm in den Kalkalpen wie auf kalklosem Untergrunde über granitischen Gesteinen und kristallinischen Schiefern ror. Letztere Substrate scheint sie allerdings vorzuziehen.

In Niederösterreich wurde dieselbe auf den letzten Erhebungen des Schneeberges ron Jaquin und Diesing gefunden. Gegenwärtig ist jedoch der nähere Standort unbekannt, doch dürfte sie am ehesten in Gesellschaft ron Azalea procumbens und Arctostajlyylos alpina, welche anderwärts mit ihr an gleichen Standorten rorzukommen pflegen, wieder aufgefunden werden. 
Divisio II. Facrostylde. Squamae discolores vel concolores. Torus uniglandulosus. Stylus elongatus, tenuis et filiformis, stigmatibus filiformibus, vel crassus, stigmatibus crassiusculis.

Sect. V. Myrtosalix. - Fruticuli pyymati, ramulis humifusis. Folia ellyptica rel lanceolata, adulta utrinque glahra, viridia et nilin'a. dum marcescunt nigricanlia. Amenta coaetanea, pedunculata, recla. Squamae discolores. Gilandula tori oblongolinearis purpurea. Anlherae post anthesin nigricantes. Germen brevissime pedicellatum. Stylus temis. Stigmata breria bilolia, lobis linearibus, everlo-patulis, purpureis. Valtae capsulae post dehiscentiam extrorsum arcuatae, falcalae.

14. S. Mggosimeites. 1. Jaquiniana. (Koch Syn. ed. 2. p. Tïs). A menta coaetanea, cylindrica. den siflora, staminigera et pistilligera semel et semissi - bis longioßa quam latiora, pedunculo longo qual li - sexfolinto, nom greminizfero. Squamae oboratae, obtusae vel lanceolatae, acutae, purpureae, versus apicem nigricantes, longe rillosae. Glandula tori oblongo-linearis, purpurascens, basin germinis supe:ans. Germen brevissime pedicellatum, ex ovata basi conicum, compressum, in stylum tenuem, productum, ante ainthesin

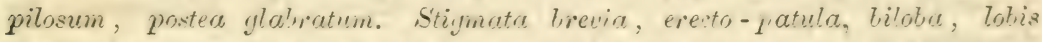
filiformilus purpureis. Valvae capsulae atropurpureae, post maturitatem falciformes, extrorsum arcuatae. Stamina duo, filamentis glabris, apicem versus purpurascentes. Antherae aite anthesin puripurene, demum violurene ot post anthesin nigricanles. Folia ellyptica vel oborata, bis longiora quam latiora, acuta, in basi rotundata, interyerrima, adolescentia longe pilosa, adulta

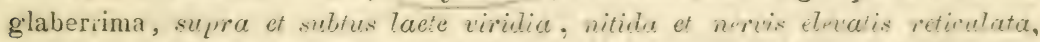
dum marcescunt nifricaintia. Nerri secundarii ad marginem decurrentes utroque latere $6-8$. Ramuli decumbentes, radicantes, glaberrimi, flexibiles et tenaces.

Am. of $12-20 \mathrm{~mm} \lg .8-10 \mathrm{~mm}$ It. A m. O $10-20 \mathrm{~mm} \mathrm{lg} .6-8 \mathrm{~mm}$ lt.

Squam. 1.5-2mm lg. Gland. tori $0.3-1 \mathrm{~mm} \lg$. Germ. 1.3-2.5 1.ij-2mm lg. Stam. $4^{\mathrm{mun}} \mathrm{lg}$.

Folia $12-35^{\mathrm{mm}} \lg .6-18^{\mathrm{mm}}$ lt.

S. Jaequiniana Host. S5n. p. ̈̈29. Salix p. 31. tb. 102. - S. Myrsinites $\gamma$. Jacquiniana Koeh

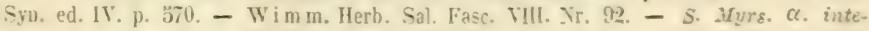
grifulia Neilr. Fl. 1. X. Oest. p. 266.

1)er dem Boden aufliegende Stamm ist rielfach verzweigt und rerkrämmt. seine Aeste niodergestre kt, sparsame Adrentivwurzeln treihend. Die jüngeren 
/weige sind mit häutiger, brauner, glärubler Rinde berleckt. die iilteston 20) bis 30 Jahresringe zeigenden knorrigen 1 Decim. dic en Stämme sind ähnlich jenen der s. retusa schwärzlich und die wulstige Rinde ist ron kreisfürmig um den Stamm lauf nden Sprüngen durchfurcht. Die Blätter, Zweige. Fruchtknoten und Kätzehenschuppen sind in der ersten Zeit ihrer Entwicklung von langen unendlich dünnen und weichen seidigen Haren zottig und die verhältnissmässig grossen Kätzchen ror dem Aufblïhen in einen dichten Pelz eingehüllt, durch welchen wie durch einen Schleier die dunkelpurpurnen Kätzchenschuppen durchschimmern. Zur Zeit der Blüthe wo die rothen langen Griffel oder Staubgefässe aus den weissen Seidenharen der Schuppen herrorragen gewähren die zwischen den glänzendgrünen Blättern rurtheilten Kätzchen ein besonders zierliches Ansehen. Alsbald schwin let aber die seidige Bekleidung und zur Zeit der Fruchtreife ist die ganze Weide vollständig liahl. An der dem Lichte ausgesetzten Seite färben sich dann die kahl gewor.lenen Fruchtknoten gewöhnlich purpurn. Die Blätter werden in Verwelken schwarz und färben auch feuchtes Papier, auf welchen sie liegen nach einiger Zeit mit schwärzlichen Flecken.

Die S. Myis. 1.) Jucquimiana findet sich in Europa in den östlichen Nord- und Südalpen, in den ungarischen und siebenbürgischen Karpathen; in Asien auf den Alpen des Altai, des baikalischen Sibiriens und Dauriens.

Eine Linie, welche in nordöstlicher Richtung von der Etsch an die Quellen der Enns, dann entlang der Ka!kalpen des Ennsthales an den Dürenstein und S:hneeberg und weiter in die Tatra zieht, dann aber nach Süden umbeugt und ron dem südlichen siebenbürgischen Hochgebirge in westlicher liichtung längs dem Südrande der julischen und karnischen Alpen sich bis Südtirol verfolgen lässt, umgrenzt in Europa das Areal dieser Ptlanze. - Innerhalb dieses Areals ist S.Murs 1.) Jucjuiniana nur auf die Kalkalpen, welche sich über $5000^{\prime}$ erheben beschränkt und fehit daher in den Centralalpen, so wie sie auch in den ungarischen Karpathen nur auf die Kalkberge beschränkt ist, w:lche den östlichen und westlichen Flügel der Tatra bilden. Sie wächst auf den Karpathen in dem Höhengürtel ron $5000-6400$. In den niederösterreichischen Kalkalpen findet sie sich auf dem Dürrenstein, Ostscher, Göller der Raxalpe und dem Schneeberge. Ihre untere Grenze fällt daselbst auf 47000 , und run dieser Höhe an ist sie bis zu den höshsten Kuppen 6.366' als gewöhnliche Begleiterin der $\mathbf{S}$ retusa rerbreitet. In den obersteirischen Kalkalpen wie am Huchschwab, Griming, Buchstein erreicht sie ihre obere Grenze bei $7200^{\prime}$.

Viel weiter verbreitet ist die durch feindrüsig gesägte Biätter sich untersheidende S. Myrsinites 2.) serrata Neilr., wilche auf den Apeninnen, P’rrenien, den Alpen der Dauphiné und der ganzen Centralkette der Alpen, auf dem schotticchen und skandinar. Hochgebirge und im ganzen arktischen Europa rorkommt und ebenso im altaischen Sibirien, auf Kamtschatka und i.r Tschucktschen Halbinsel, auf Labrador, Grönland, Island angetroften wird. 
Die nördliche S. polaris Wahlbg. und Fries schliesst sich durch die $\mathrm{g}$ a $\mathrm{nz}$ randigen kahlen beiderseits glïnzend grïnen Blätter, zweifarbig* Kätzchenschuppen sparsam behaarte Fruchtlnoten, purpurne verlängerte Griffel und purpurne lineale Torusdrüse an $\therefore$. Inninites 1.) Jacquiniana an. unterscheidet sich jeloch durch die stumpfe ellyptische oder fast krei-runde 1 lattform und stehen bleibende kürzere. nur mit 2 Blättern bekleidete Kätzchenstiele. Mit S. herbacea mit der sie ron den Autoren gewöhnlich verglicheu wird, stimmt sie nur in dem letzten Merkmal und im Zuschnitt des Blattes. überein, gehört aber durch die Bildung ihrer Blüthen in die Rotte Nyrtozalix.

An die Rotte Murtocalix schlicsst sich der in Niederösterreich nicht vertretene Weidentypus der $\triangle$ cassia an, welche wir als eigene. Rotte Ce esiae auffassen und folgendermassen charakterisiren:

Sect. Cassiae. Fruliculi ramosissimi ramis brevibus, erectis rel adscendentibus, senioribus torulosis. Folia ellyptica, brevissime acuminata, integra, margine reflexa, utrinque opaca et subtus g'auca, glabra rel sericea, dum marcescunt, rufescentia. Siguamae e riridifiarae unicolores rel apice rubescentes. Glasdula tori oblon:ya, flara. Antherae post anthesin fiatae. Germen sessile rel brevissime pedicrllatum, tomentosum. Stylus elongatus, purpurascens, stigmatibus purpureis oratis breribus, integris rel emarginatis capitatus. Valrae capsulae post dehiscentiam extrosum arcuatae, falcalae, purpurascentes.

Hicher gehört ron europäischen Weiden. S. cnesia. - Sie mahnt in der Blattform an die S. myrtilloides, in der Form der fast kopfförmigen Narben an die S. purpmea, stimmt aber in der Verästlun?, in der Form des Fruchtknotens und des Torus, so wie in der Farbe des Griffels und der Varben mit den Myrtweiden, durch erstere zwei IIerkmale auch mit den Buschweiden überein, dem entsprechen 1 sie auch am richtigsten zwischen dicse beiden Rotten eingeschoben wird.

Sect. VI. Arbusculae. Fruticuli ramosissimi, ramis brerinns, erectis rel humifusis, senioribus toru!osis. Folia lanceolala, oblonga rel ellypiaca, acuta, margine plana, supra viridia nitida. subtus glanca, glabra rel rarie pubescentia, dum marcescunt, rufesrentia. Amenta coatanca, pedunculata rel sessilia recta. Syuamae discolore's. Glandula tori obionga. flara. Antherae post anthesin fialate. Gromen bretissime pedicellatum tomeri- 


\section{tosum. Stylus elongatus tenuis. Stigmula biloba vel bipartila, laciniis fliformibus, patentibus rel extrorsum arcuatis, faris. Tallae capsulae post dehiscentiam extrorsum arcualae, fulcaine.}

15. S. rovescerte 1.) Waldsteiniana ( $\mathrm{K} 0 \mathrm{ch}$. Syn. ed. 2. p.576.) - Amenta coaetanea, gracilia, staminigera bis-ter, pistilligera terquater Inngiora quam latiora, pedunculata. Pedunculus foliatus, post anthesin cum rhachite amenti fructiferi elongatus, caducus. Squamae oblongae, acutae vel obtusae, versus apicem rubiginosae vel purpurascentes, longe villosae. Glandula tori oblonga, truncata, Hara, basin germinis superans. Germen orato-conicum, albido-tomentosum, brevissime pedicellatum, stylo elonjato, stiymatibus lifidis, lolis filiformibus, patentibus vel extrorsum aicuatis, flavis. Talrae capsulae post maturitatem falciformes, extrorsum arcuatae. Stamina duo, filamentis glabris, antheris flavis. Folia ellyptica, bis longiora quam latiora, acuta, apicem et basin versus aequaliter attenuata (rarius obovata et obtusa) integra rel paucis dentibus remotis serrata, adolescentia sultus sericea, adulta glaberrima, supra saturate viridia, nitida, laerigata, subtus gluuca opaca. Nervus medius flavescenti-rubiginosus, eleratus. Nervi secundi ordinis utroque latere 10-14. minus elerati, tenuissimi. Folia dum marcescunt rufescentia. Rami breres, erecti rel adscenlentes, subfurcato-ramosi, cicatricibus torulosi.

Am. бَ $15-26 \mathrm{~mm}$ lg. $8-12 \mathrm{~mm}$ It. Am. ㅇ $150-30 \mathrm{~mm} \lg . \ddot{5}-8^{\mathrm{mm}} \mathrm{lt}$.

Squam. 1.5- $2 \mathrm{~mm} \lg$. Germ. 2-3mm lg. Styl. et stigm. 1-1.0̈ lg. Stam. วั-6mm $\mathrm{lg}$.

Fol. $18-40 \mathrm{~mm} \lg .8-20 \mathrm{~mm}$ lt.

Wir haben den Linnéschen Namen $S$. arbuscula für unsere Pflanze beibehalten. Nach der einstimmigen Ansicht der schwedischen Botaniker verstand Linné unter seiner $S$. arbuscula allerdings die gegenwärtig von den meisten Autoren so benannte Weide, aber auch noch mehrere verwandte Weidenformen in deren Erklärung die genannten Botaniker wesentlich abweichen. - Die S. phylicifolia Linnés. soll nach Fries mit der S. bicolor. Ehrh. identisch sein. Es ist jedoch höchst unwalırscheinlich, dass Linné eine mit S. arbuscula 1) Waldsteiniana $\mathrm{Koch}$ so sehr verwandte Pflanze wie die S. bicolor Ehrh. von seiner S. arbuscula sollte getrenat und anderseits eine so ausgezeichnete häufige Weide wie die S. nigricans $\mathrm{Sm}$. u. Fries ist, nicht als Art sollte beschrieben haben. Wir schliessen uns daher Wahlenberg's Ansicht an, welcher unter $S$. arbuscula nebst der hier beschriebenen Weide ( $=S$. Waldsteiniana Willd. Koch com.) auch die $\boldsymbol{S}$. bicolor Ehr. (=S. Weigeliana Willd., S. arbuscula K och com.) die auf die Autorität von Fries in der 2. Auflage von Koch Syn. unrichtig mit der Linnéschen S. phylicifolia identificirt wurde, begreift, - und halten mit Wahlenberg die S. nigricans Smi th, Fries und der späteren Autoren für die Lin nésche S. phylicifolia. Da jedoch der Name S. phylicifolia vieldeutig geworden, so wollen wir im Folgenden den jetzt von den meisten Autoren für die Linnésche $S$. phylicifolia gebrauchten Namen $S$. nigricans adoptiren.

S. pulchella, alpestris, fluvescens Host Sal. p. 30-31. tb. 98-101. - S. coruscans Host Sal. p. 28 tb. 9k plant. fem. fig. $\$-6$. - S. arbuscula F ries Nor. Fl. suec. M. I. p. 49. Herb. norm. V. Nr. 61 . W imm. Herb. Salic. Nr. 75 u. 76. Neilr. FI. พ. N. Oest. 1. $26 \%$. 
Nur auf den höheren felsigen Kuppen erscheint $S^{\prime}$. a.lusenla in unseren Alpen mit liegendem Stamme und aufsteigenden Aesten. Gewöhnlich erwächst sie zu einem 2-3 Schuh hohen aufrechten, vielästige.n. buschigen Strauch, dessen kurze zähe biegsame Aeste fast gabelig verzwei_t und ron den stark vorspringenden Narben der abgefallenen Kätzchenstiele knorrig erscheinen. Die Rinde der $1-3$ jährigen $Z$ weige ist braun, giatt, wenig glänzend und wird im vierten bis fünfter Jahre von zarten dichtgedrängten Längsrunzeln durchzogen und glanzlos. Selten erscheint die Rinde jüngerer Zweige gelblich, wie sie Host an der von ihm auf den niederö-terr. Dürenstein angegebenen S. flavescens (Host Sal. p. 31 tb. 101) beschreibt und abbildet. Die obere Blattseite ist glatt glänzend dunkelgrün, im getruckneten $\mathrm{Zu}-$ stande ron etwas vorspringenden feinen Seitennervchen geadert. die untere Seite ist bläulich, der Mittelnerr gelb oder röthlichgelb stark vorspringewd, die Seitennerven der unteren Seite lingegen mit der Blattlläche gleichfarbig wenig ror:pringend. Fiedernerven 11)-1'.́ Paare. Die gewöhnlichste form der niederösterreichischen Kralkal,en die mit Exemplaren aus den bairischen, salzburgischen, tirolischen, karnischen und julischen Alpen so wie mit Exemplaren aus den siebenbürgischen Karpathen vollkommen übereinstinmt. besitzt ellyptische, spitze, gegen den Blattstiel und die Spitze gleichmäsig rerschmälerte Blätter, die nochnal so lang als breit, im Alter beilerseits kahl und entweder vollständig ganzrandig oder dort wo sie am b1eitesten sind mit einigen entfernt stehenden Sägezähnen vershen erscheinen. Seliener ist der rerkehrteifürmige Blattypus ausgesprochen und eben so seiten werden auf der Raxalpe schmalblätterige Formen angetrofien, deren Blätter dreimal si lang als breit und fast lanzettlich sind und dann den Blättern der Exemplare gleichen, die von Fries in Herb. norm. Fasc. V. Nr. 61 ausgegeben worden sind. Auf den westlich angrelzenden steirischen und obeiösterreichischen Kalkalpen, namentlich auf dem Dachsteingebirge wo s. arbuscula ungemein häufig auftritt, finden sich Formen, deren Blätter von entfernt stehenden Sägezähnen im ganzen Umkreise gesägt $\sin$, häufiger als bei uns, und auf kalkfreien Substrate in den Centralalpen, so wie auf dem skandinarischen Hochgebirge erscheinen die Blätter der s. artuscula mit dicht nebeneinander stehenien grossdrüsigen Sägezähnen beraudet und stellen die. . arbuscula $\beta$. foetida lioch (Syn. p 369 ) dar.

Die Kätzchen unserer Pllanze sind schlank und na:h dem Blühen sehr verlängert. Es liegen uns Exemplare vor, deren fruchttragende Kätzchen bis $i$ Centim. lang sind. - Auf die manchmal bis zum Fruchtknoten getrennten Griffel dieser Art wurde schon im Eingange (Seite 33) auf:nerksam gemacht.

s. arbuscula ist eine weit rerbreitete Gebirgsweide, die in Eu.op:a nur den Hochgebirgen auf den südlichen Ifalbinseln fehlt. Si. findet sich in den Pyrenäen, in dem ganzen Alpensysteme, in den Karpathen, auf dem schottischen und norwegischen Hochgebirge und in der arktizchen Zunue in 
Lappland: in Asich am Kaukasu*, Mtai, auf den Iluchgebirgen Dauriens und des baikalischen Sibiriens.

In der montanen Region Skandinariens. auf der fimischen Seenplatte, auf dem baltisih-uralischen Landrücken und dem herzinisch-sudetischen Gebirgswalle (vorzüglich also in den Uferländen der Ostsee. welche diever ihr Wasser zusenden) ist die S. arbuscula 1) Waldst iniana durch die Paraliclform \&. ailuscula 2) Weitcliana vertreten und letztere findet sich im Riesengebirge bei $4000^{\circ}$ und am Harze in dem Höhengürtel von $3000-3500$.

Im Gebiete der Nordalpen erscheint s. armssulu 1) Waldsteinians in Baiern zwischen $4300-6640^{\prime}$, in Niederösterreich im Höhengürtel von $4:(0) 0^{\prime}$ bis 6:300\%. Innerhalb dieser angegebenen Grenzen wächst sie auf den nieder̋̈terreichischen Kalkalpen: auf der Esslingalpe, dem Dürenstein, den grossen Zellerhut, dem Göller, der Raxalpe und dem Schneeberge. Sie liebt rrrzïglich westliche mit Krummföhren bewachsene Lehnen und bilùet mit Vaccinien und Rhododendren eine buschige Strauchformation.

Die S. arbuscula 2) Weigeliana ") (S. Writriana Willd. Sp. pl. IV. p. 678 - S. bicolor Ehrh. Beitr. V. p. 162. Koch. Syn. ed. 1. p. 6.33) verhält sich zu der alpinen S. arbusevlic 1) Waldsteiniant ganz ähnlich wie S. retusa var. Kitchireliana zu S. restsa var. serpullifolia und wie die Thalformen der striricans und s. tulwa zu ihren alpinen Formen. Sie stimmt in der Forri der Blätter der Torusdrüse. der Fruchtknoten. der Staubfäden und Kätzchenschuppen nach Exemplaren aus dem Rie.sengebirge. rom Brocken und aus Dalecarlien rollkommen mit $s$. aibursulu 1) Waldsteiniana überein und stellt nur eine in allen Theilen srössere üppigere l'arallelform tieferer Höhenlagen dar. Ilure Blätter sind bis zu :j Centim. lang und 3 Centm. breit, die Aeste sind weniger knorrig, die Kätzchen-chuppen Staubfäden und Griffel von grösseren Ausmasse und die Fruchtknoten etwes länger gestielt als bei un-erir $\&$ athuscula 1.) Tredsteiniana. Bei diescin grösserem Ausmass der Blüthentheile ist aber die Kätzchenspindel der $S_{\text {, } a}$ hiscculia 2) Wei, relium nicht entsprechend verlängert und darum erscheinen ihre Kätzchen kürzer gestielt und sind, wenn sie auch in Beziehung ihrer absoluten Länge jenen der s. arvacula 1.) Wallsteinisan gleichen, röllicr und dicker als jene der letztgenannten Weide und zwar die of nur $11 / 2$ bis $2 \mathrm{mal}$, die $\mathbf{Q}$ nur $2-3 \mathrm{mal}$ so lang als breit. Die Verlängerung der kätzchentragenden Aestchen und das dadurch bedingte etwas abweichende Aussehen koumt aber in ganz ähnlicher Weise auch den alpenbewohnenden formen

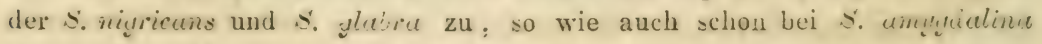

* Wir wählten hier dm Xamen S. Weigcliana. weil der Name S.bicolur den Gedanken involviren Lïnnte, dass nur diese Form dur. s. utuscula zweifarbige Blatter brsitze, wilirend doch beide Parallelfurmen hierin gauz mit einander ibbereishumen. Leberdiess wird durch diese der sudetisch-lurzinischen

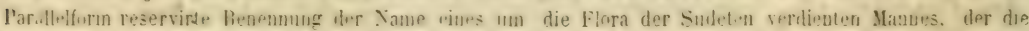

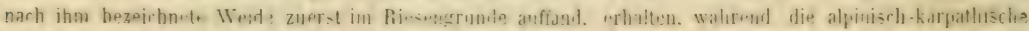

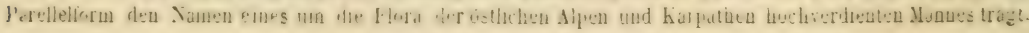


erwïlnt wurde, dass die in subalpinen Gegenden heimischen Sträucher bei kleinem Iusmass der Blüthen eine selır verlängerte Kätzchenspindel zeigen. Vergleicht man die $\therefore$ mijriras aus der Ebene ron Wien und jene aus d:r Krummholzregion der Alpen, stellt man endlich die S. alubra aus den subalpinen Thälern und jene der hüchsten Kuppen unserer Alpen neben einander, so findet man, dass bei der einen wie bei der anderen die der tieferen Höhenlage angehörige Form bei grösserem Ausmasse aller Organe fist sitzen le an der Basis nur mit wenigen schuppenförmigen Blättern umgebene Kälzchen besitzt. währeud die gleiche Art aus höheren Regionen lang gestielte Kätzchen zeigt deren Kätzchenstiele mit Blätiern bekleidet sind die denen der anderen Zweige rollkommen in Form und Grösse gleichen. Ja sulbst an ein und demselben Strauche kann man beobachten, dass sich in jenen Jahren wo nach langem Winter die warmen Tage des Frühlings erst spät aber plützlich eintreten, die kätzchentragenden Aestchen mehr verlängern und die Blätter der Kätzchenstiele mehr entwickeln. - Die S. ariusucula 1.) Waldsteiniuna findet sich in den Alpen und Karpathen nirgends unterlialb der unt. Grenze des Knieholzes. Sie liebt vorzüglich feuchte westlich exponirte Lehnen und ihre untere Grenze wird wie die so rieler anderer Alpenpilanzen durch die abnehmende Feuchtigkeit gegen unsere contin ntalen Ebenen bedingt. In dem Bergwalle, welcher die baltische Ebene in Südosten abschliesst, auf welchen sich daher der Einfluss des Meeres entschieden geltend macht, ist die untere Höhengrenze der $S$. arlusculı (ebenso wie jene de! s. herbacea) auffallend deprimirt und wann wir noch näher gegen die Meeresküste zum baltisch-uralischen Landrücken hinabsteigen, so finden wir dort dieselbe Weidenart in der Ebene wieder. Ganz in demselben Verhäitnisse aber wie sich an rielen anderen Weiden bei rasch eintretender Wärme das Laub der kätzchentragenden Aestchen mächtiger entwickelt und die Kätzchenspindel mehr in die Länge streckt, bei langsam zunehmender Wärme jedoch die Kätzchen in ihrer Entwicklung den Blättern mehr vorauseilen aber kurz gestielt bleiben, - finden wir auch in unserem continentalen Alpenbezirke und in den Karparthen, wo nach Schmelzen des Schnees den PHanzen plützlich eine grusse Wärmemenge zugeführt wird, das Laub der verlängerten Kätzchen mehr entwickelt, auf den niederen Landrücken längs der Küste, wo durch

*) Wir stellen hier die Extreme der Maasse ron S. arbusculu 1.) Wil.1steiniana und 2.) Weigetiana neben einander:

S. $a \cdot b$. 1.) Waldsteiniana.

Am. ơ 15-26mm lo. 8-12 mm lt.

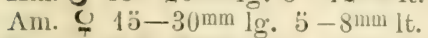
Squam. $1.5-2 \mathrm{~mm} / \mathrm{g}$.

Styl. et stigm. $1-1.3 \mathrm{~mm} \mathrm{lg}$.

Stan. 5-6 $6^{\mathrm{mm}} \lg$.

Fol. $18-40^{\mathrm{mm}} \cdot 1 \mathrm{~g} .8-20^{\mathrm{mm}} \mathrm{lt}$.
S. $a \cdot b .2$.$) Weigetiana.$

Am. ơ $20-26 \mathrm{~mm} \lg .12-10$ mm $1 \mathrm{t}$.

AnI. C 13̈-30̈m lg. $8-12 \mathrm{~mm}$ lt.

Squam. 2-4. $\mathrm{mm}$ lg.

Styl. et stigm. 1.5-2mm le.

Stam. 6-7mm lg:

Fo!. 28- $32 \mathrm{~mm} \mathrm{lg} .10-30 \mathrm{~mm} / \mathrm{t}$. 
den Einfluss des Meeres die klimatischen Extreme mehr eliminirt werden, die Kätzchen fast vorläufig, sitzend und an der Basi< nur mit kleinen Blättchen bekleidet.

Die S. pyrenaica Gouan. der Pyrenäen vermögen wir nach Exemplaren rom Pic d. Nidi im Herb. Jordan von S. arluscula gleichfalls nicht zu scheiden. Sie kommt in der Form aller Organe vollkommen mit S. arbuscula überein und weicht nur wie die südlithen Parallelformen vieler anderer Pilanzen durh die Rehaarung ab. Die Fruchtknoten sind nemlich ron abstehenden Haaren etwas mehr zottig, di: Blätter in der Jugend flaumig und selb t im Alter noch an den Nerven der unteren Blattseite so wie an den Rändern ron abstehenden etwas krausen Haaren gewimpert.

Die S. prencica *norvegica Fries (Nor. Fl. suec. M. I. p. 74. Herb. norm. Fasc. VII.) halten wir nach dem Original-Exemplar in Heibarium normale für einen Bastart aus S. herbacea und S. artuscula, welchen wir nach dem Entdecker Prof M. Blytt, S. Blyttii nennen. Sie stimmt durch die nicht abfallenden Kätzchenstiele (...amentis ramulo subterminali foliato persistente pedunculatis." Fries), die einfarbigen abgestutzt.n gelblichen Kätzchenschuppen und die armblüthigen zwischen zwei rerhältnissmässig grossen Blätter steckenden Kätzchen, so wie durch dic stumpfen am Rande fein gekerbten. fast benerrten, netzig-adrigen Blätter mit S. herbaceu, - durch die Behaarung der kurzgestielten Fruchtknoten und den verlängerten fädlichen Griffel mit $S$. arbuscula überein.

S. glauca L., welche in der nördlichen arktischen Zonne der alten und neuen Welt und ron den Pyrenäen durch den westlichen Theil der Alpen bis zum Oetzthalerstock rorkommt, dann S. Lapponum L., die in den Sudeten, in der europäisch-arktischen Zonne und ron den skandinavischen Gebirgen und den Uferländern der Ostsee über den baltisch-uralischen Landrücken ostwärts bis Kamtschatka und in das nördliche Amerika verbreitet ist und in dem Alpensysteme durch die Parallelform S. helvetica Vill. rertreten erscheint, fehlen in Niederö.terreich, sn wie in der ganzen Kette der nördlichen Kalkalpen.

Sect. VII. Viminales Koch. - Frutices, ramislongissimis, erectis, non pruinosis. Folialanceolata rel sublinearia, elongala, acuminata, sublus rel sericeo-micantia rel glabra, dum marcescunt rufescentia. Amenta praecocia, sessilia, recla. Squamae discolores. Glandula tori linearis, flara. Antherae post anthesin Inteae rel sordide farae. Germin sessile rel breriter pedicellatum. cano-tomentosum. Stylus ternis. Stigmata linearia et putula, rel filiformia et extrorsum arcuata, fara. Valiae capsulae post dehiscentiam prtrorsum arcuatae, falcatae. 


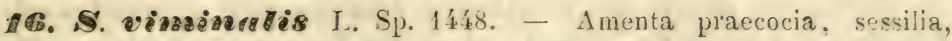
densillora, oblonga, staminigera et pistilligera bis - ter longiora quam latiora. Squamae discolores ovatae vel oblongac, acutiusculae, longe villowae. Glandula tori linearis, incurva, basin germinis superans, flava. Germen sessile, sericeo-tomentosum ovatum, in stylum elongatum productum, stimatitus elongatis. sfulum ampandibus, indivisis, extrorsum arcuatis, flaris. Valvae capsulae post maturitatem falciformes, extrors:m arcuatae. Stamina duo, filamentis liberis, glabris, antheris luteis. Folia linearia vel linea i-lancenlata elongata, acuminata, decies longiora quam latiora. margine undulata et subrevoluta, intertia vel subrepanda, supra glab:a, obscure riridia. subtus agenteo-sericea, micantia. Stipulae lineari-lanceola:ae. Rami cloncati. tenaces, juniores pulsescentes, adulti glabrati, e viridi llavescentes. Cortex interior virescens.

Am. o 20-40mm lg. $12-16 \mathrm{~mm}$ lt. Am. ㅇ $1 \ddot{3}-30 \mathrm{~mm} \mathrm{lg} .8-10 \mathrm{~mm} \mathrm{lt}$.

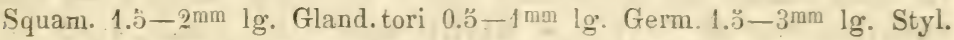
$1-1 . \mathrm{m}^{\mathrm{mm}}$ lg. Stigm. $1^{\mathrm{mm}}$ lg. Stam. $8-10^{\mathrm{mm}} \mathrm{lg}$.

Variat foliorum forma:

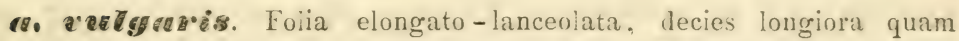
latiora.

Fol. $80-120 \mathrm{~mm} \lg .8-12 \mathrm{~mm}$ lt.

S. viminalis Host Salix p. 16. tb. Jik. pl. masc. - Fries Nor. Fl. snec. p. 61. Herb. norm. Fasc.

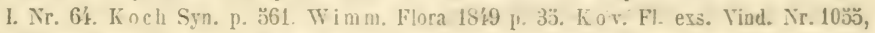
1056. Ne eilr. Fl. vे. N. Oest. p. 239.

7. Teseetfoled. Folia linearia, longisima, duodecis-octodecies longiora quam latiora.

Fol. $100-1 \ddot{30 m m ~ l g . ~} \ddot{m}-10 \mathrm{~mm}$ lt.

S. viminalis b. folits angustissimis Wim m. Flora 1819. p. 33 .

Durch die reichbeblätterten langen Ruthen und da; beim ge:ingten Lufthauche atlasart:g schillernde Laubwerk fällt dise Weide schon ron Weitem auf und bildet in kräftigen Wuchse einen prächtigen Anblick. Ihre jahrigen Triebe sind unter allen Arten der Abtheilung Mucionlue am meisten rerlängert. Demungenchtet ist der jürliche Zuwachs an Hühe bei diesen Strauche nur sehr gering, da die am oberen Ende der Zweige sitzenden Laubknorpen nach dem Abfallen der Kä̈zchen gewöhnitch rerkümmern und die neuen aus den unteren Lauhkno-pen sich entwickelnden Sprossen sich nur wenig mehr erheben als die rorjührigen. So kommt es, dass man nach einem Zeitraum von 10 Jahren. in welchem benachbarte junge Weidenanflïge zu einem Teidenwald herangewacheen sind. die scimimulis immer noch als Strauch ron fast gleicher Gröse sieht, der auch niemals eine bedeutende Höhe erreicht und bei uns sich nur selten zu 2 Klafiern erhebt. - Die Blätter sind bei der Var. a, verlängert lanzettlich und der grösste Breitendurchmesecr fällt auf da untere Drittheil ierselben; hei der schr seltenen Var. 1). sind sie vollständig lineal. Sie sind ctwae wellig und fart zurück- 
gerollt und manchmal lassen sich drüsige Verdickungen, wie sie bei den Ferägtblïtrigen Weiden an den Sägezähnen aufsitzen, an einzelnen Stellen des geshweift n Randes wahrnehmen, ohne dass eigentliche Sägezähne rorhanden wären. Der Jittelnery so wie die Seitennerrehen sind an der oberen schmutzig-dunkelgrünen Blattseite etwas eingedriickt und dadurch diese Fläche ron einem sehr feinen vertieften Linien-Netze durchzogen. Die Nerven der unteren Blattseite sind rorspringend. Der Mittelnerv ist rüthlich-gelb; die bogig gegen den Rand verlaufenden Fiedernerven sind abwechselnd länger und kürzer, so zwar, dass zwischen je zwei bis zum Rand deutlich sichtbar vorsplingenden Nerven $1-3$ kürzere nur bis zur Mitte der entsprechenden Blatthälfte deutlich vorspringende Nerven zu stehen kommen. Von den längeren Fiedernerven sind an cinem Blatte gewöhnlich 20-30 vorhanden. - Der aus unendlich zarten kurzen parallel den Fiedernerven anliegenden Härchen gebildete atlasartig glänzende Veberzug lor unteren Blattseite ist an sonnigen Standorten silberweiss, an schattigen Plätzen wird derselbe dünner und die I3lattfläche erscheint grünlich schimmernd. Sonst ist der Kreis der Abänderungen bei dieser Weide ein sehr beschränkter.

Erwälnenswerth ist nur noch eine am Brückendamm bei Mautern an der Donau und in der Aue zwischen Penzing und Hitteldorf vorkommende Form, die sonst mit $S$. viminulis a. vulyaris übereinstimmt, aber tief zwei-paltige Narben mit fädlichen Lappen besitzt. Host hat dieselbe Pllanze (und merkwürdiger Treise nicht die gewöhnliche verbreitete $S$. viminalis mit ungetheilten fädlichen Narben) als Salix viminalis $\subseteq$ tiab. :3:3. abgebildet und sagt auch in der Beschreibung pag. 16 ...Stigmata bifida ${ }^{\circ}$. Ob diese Teide nur eine Spielart der $S$. viminalis darstellt oder als ein der $S$. viminalis sehr nahe stehender Bastart anzuschen sei, wage ich nicht zu entscheiden. Weder die Blätter noch die Blïthen geben irgend eimen Anhalt.punkt um auf eine zweite Stammart schliessen zu künnen. Da ron den bisher bekannt gewordenen Blendlingen, an welchen man $s$. viminalis betheiligt hält, jene mit $S$. aimutululinu durch zweispaltige Narben sich auszeichnen, so künnte sie vielleicht noch am ehesten diesen Blendlingen (S. huppophatifolia, undulatu, mollissina) angereiht werden. Mit S. mallis-ime Ehrh., welche als eine S. stperviminalis-dimy dalina anzusehen ist, kommt übrigens unsere Pflanze nicht überein, unterscheidet sich ron ihr durch spitze braunpurpurne gegen die Spitze schwärzliche Kätzchenschuppen, dichtere silberweisse Bekleidung der unteren Blattseite und ist. wie gesagt, nur durch die zweispaltigen Narben ron der S. viminalis a. zu unterscheiden.

Die Korbweide ist durch die Niederländer von fast ganz kuropa, vom Poiarkreis sïdwärts bis in die südrussischen Steppen, Rumelien und das siidliche Frankreich rerbreitet und scheint nur siidlich der Alpenketts zu fehlen. ) In Asien wird sie gleichfalls an den Ufern des Irtisch, an der

*) Nach Bertoloni südlich der Alpen nur gepflanzt. - Auch in Ostindien und Nordamerika ist sic nicht ursprünglich einhıimisch, sondern aus Europa eingeführt. 
Tunguska und in Daurien angegeben. Doch scheint die asiatische Form nach Exemplaren aus der Hand Ledebours im Wiener Museum von der europäischen specifisch verschieden.

Die Korbweide ist bei uns recht eigentlich eine Ireide der Niederungen und dringt aus den Donau-Ebenen weder in die subalpinen Thäler der Alpen noch der Karpathen vor, so wie sie sich auch nirgends auf das Plateau des böhmisch-mährischen Gebirges zu erheben vermag. *) In Baiern fällt ihre obere Grenze auf $14.000^{\prime}$, in Niederösterreich schon auf l(mol. I'nter dieser Höhe findet sie sich in Niederünterreich vereinzelt oder in kleinen G. uppen zwischen anderen Weiden im ganzen Donauthal und im Bereiche des Lnterlaufes aller in die Donau mündender Flüsse; am häutigsten in den Donau-Auen bei Thallern, an der Wien bai Schönbrunn und an der Pielach bei Haunoldstein. Wir beobachteten sie nur im Inundations-Terrain der Flüsse und Bäche und am besten gedeiht sie dort auf angeschlemmten tiefgründigen Boden an den rersumpfenden seitenarmen. Sie rerkümmert sobald sie ron höheren schattengebenden Bäamen ïberwachsen wird. - Die Var. b. bisher nur am Donauufer nächst Rossatz.

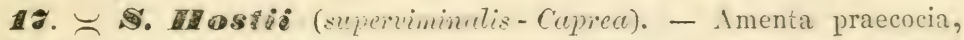
sessilia, densiflura. staminigera crata bis -, pistilligera oblongo-cylindrica ter-quater longiora quam latiora. Squamae discolores, oblongae, acutiusculae, longe villosae. Glandula tori linearis, incurva, flava, i a-in terminis superans. Germen brevisime pedicellutum, sericeo-tomentosum. ex orata basi conicum et in stylum elongatum productum. Sitimata stylo Lieviora, filiformia, indivisa, extrorsum arcuata. flava. Talvae capsulae post maturitatem falciformes, extrorsum arcuatae. Stamina duo, filamentis liberis, glabris, antheris

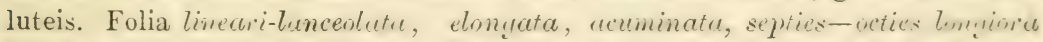
quam lationa, margine undulata et subrepanda, snpa glabira, obscure riridia, subtus sericea et miccatic. Stipulae lanceolatae. Rami elongati, tenaces, juniores saepe pilis adpressis pubescentes, cululti gluberimi, e riridi flarescentes. Am. o $30-40 \mathrm{~mm}$ lg. $18-24^{\mathrm{mm}} \mathrm{It}$. Am. 우 $3 \not 3-33 \mathrm{~mm}^{\mathrm{mg}}$. $10-12 \mathrm{~mm} \mathrm{lt}$.

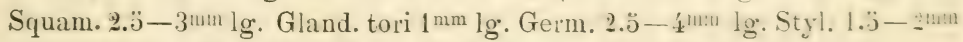
lg. Stigm. $1^{\mathrm{mm}} \mathrm{lg}$. Stam. $10-12 \mathrm{~mm} \lg$.

Fol. $100-150 \mathrm{~mm} \lg \cdot 10-22 \mathrm{~mm}$ It.

S. longifolia Host Salix. Lb. 63. - Host verstand unter sciner S. longijoliz Arei verschiedene Bastarte, nimulich: 1. die hier beschriebene der $S$. viminalis sehr nahe stehemele lourm [nach d. Q Exemplare im II ost'schen Garten], 2. einen Bastart ans S. riminalis und S. Caproce, welcher so ziemlich die Mitte zwischen den beiden Stammeltern häll und sich aut' Tal, 62 von Ifost Salix abgebildet findet [nach d. O' Exemplare im Wien. bot. Gart.] und 3. cinen Blendling aus S. viminalis und S. cinerete [nach $\mathbf{O}$ Exemplaren im Wien. bot. Garten]). - Koch erhielt die erste und zweite Weide ans den Wiener Giorten und zitirte die $z$ weite unter seiner $S$. acuminate (rplanta masc. secund. spece ex horto vindob.* Syn. P. 562), die erste aher unter S. stipularis Smith. - Die Smith'sche $S$.

*j) Ein verkimmerter Stranch bei Gross-Gehrungs im Waldviurtel bei $1600^{\prime}$ - unzweifellath aber dort nicht urwitchsig, sondern gephlanzt. 
stiputaris aber, welche Koch von der Insel Nordeney und aus Eugland crhalten hatte, ist wohl der O S. longifolia des Host'schen Gartens sehr ähnlich, unterscheidet sich aber von ilar durch die oberseits etwas llaumigen Blätter und starke sammtige Beharung der ein- und zweijälırigen Zweige. Sie ist diesen Mterkmalen nach zu schliessen ein Bastart aus $S$, viminatis und $S$. cinerea und nimmt in der Reihe ron Blendlingen, durch welche $S$, viminalis mit $S$. cincrea verknilyft erscheint, ganz den analogen Platz ein, welchen S. Hostii in der Bastartreihe ron $S$. viminalis zu S. Caprea behauptet. - Wimmer

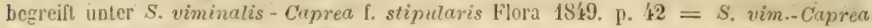
b. angustifolia Denkschr. p. 160 nach dem Citate "S. stipularis II os $t^{6 * 3}$ ) ersteus den hier besclriebenen Blendling, dann aber noch eine bei Breslau ron ilım gefundene Weirle, die wohl in der schmalen langen Blattform mit S. Hostii übereinstimmt, sich aber durch längere Fruchtknotenstiele (wclche der Torusdrüse an Länge gleich kommen) unterscheidet. In nachfolgeuder Uebersicht der Bastartreihen von S. viminalis zu S. cinerea und S. Caprea wird diese letztere nach dem Fundorte Breslau als S. Vratislaviana aufgefiilurt werden.

Die S. Hostii unterscheidet sich von s. viminalis durch weniger lang zugespitzte, verhältnissmässig breitere Blätter, längere Staubfäden und daher dickere Staubkätz:hen, doppelt so grosse $\odot$ Kätzchen, etwas gestielte Fruchtknoten, rerhältnissmässig kürzere Narben und durch ein grösseres Ausmass fast aller Organe.

Der Typus der S, viminalis ist in dieser Pflanze so vorwiegend, dass es ohne Ueberblick über alle die Reilien ron Blendlingsarten, welche die S. viminulis mit anderen Stammarten bildet, unmöglich wäre die zweite Stammart auch nur annähernd zu errathen. Vergleicht man aber die rorliegende Pllanze mit allen bisher von s. viminalis bekannt gewordenen Bastarten, so findet man. dass dieselbe unter ilınen das letzte an $S$. viminalis sich unmittelbar ansch'iessende Glied einer reichhaltigen Kette von Bl-ndlingsarten ist, welche die S. viminalis und S. Caprea rerknüpfen und dass sich an sie die von Trimmer in der Flora 1819 p. 42 charakterisirten Blendlinge aus S. viminalis und Caprea in der Weise anreihen, dass rar. f. stipularis zunächst auf die hier beschriebene Form folgt, während. b. acuminatı und a. intermediu die weiteren Glieder bilden und endlich c. cupraeformis das Schlussglied der Bastartreile darstellt, das sich schon mehr dem Typus der S. Carren nähert. Die hier als $S$. I Hortii bezeichnete Blendlingsart ist mit der im Hostischen Garten von Host gepflanzten $O$ s. lim iffolia iibereinstimmend.

Sie wurde von uns in mehreren Sträuchern in Gesellschaft von S. viminalis nächst dem Brückendamme bei Mlautern an der Donau (600') neuerdings aufgefunden.

13. $\asymp$ sevicesues Taush pl. sel. (uminalis - Capreri). Amenta praecocia, sessilia. densiflora, ovato-oblonga, staminigera semel et semissi pistilligera bis - ter longiora quam latiora. Squamae discolores, lanceolatae,

*) Host hat keine S. stiputaris beschrieben und auch die von uns so genaunte S. Hostii bcfand sich als S. longifolia im Host'schen Garten. Es ist jedoch unzweifellaft, dass Wimmer unter S. stipularis Host diese S. longifolia des Host'schen Gartens meint, dieselbe, welche $\mathrm{K}$ och aus Wien erhalten und zu seiner S. stipularis gezngen lat. 
acutiusculae, supra medium jurpureo-nigricantes. villosae. Glandula tori linearis, flava. Gornen ex ovata basi conicum. sericeo-tomentosum. in stylum elungatum

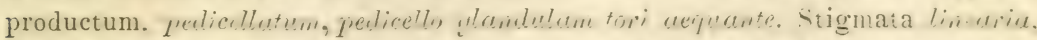
stulum aequantia, indivisa. extrorsum arcuata, post anthesin connirentia. Stamina duo, filamentis glabris, liberis, antheris llavis. Folia oldome-lanrenlutu,

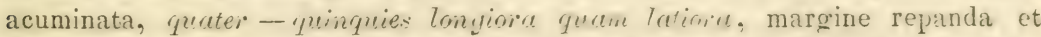
subundulata, adolescentia subtus cana, subsericeo-tomentosa. adir?a sultus ojue tomentosa, supu ublia, obscure ririlia. Stipulae semicordatae, acuiat. Ramuli juniores pubescentes, adulti glaberrimi.

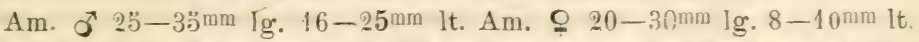

Squam. 3min lg. Germ. 3-3.3m lg. Styl. $1^{\text {ma }} \mathrm{lg}$. Stigm. $1^{m} \mathrm{lg}$. I'edicell. $1 \mathrm{~mm} \lg$.

Folia $80-130 \mathrm{~mm}$ lg. $15025 \mathrm{~mm} \mathrm{lt}$.

S. longifolia Host Salix tb. 62 (specim, masc. hort. bot. Yindob.' Tide Syn. S. Hostii) - S.lanceolata Fries Nov. Fl. snec. M. I. p. 61 pro parte. (Fries hat unter dem Tamen S. lanceolata sehr verschiedene Bastarte aus S. viminalis und $S$. Caprea, so trie auch aus $S$. viminatis und S. cinerca verstanden. Es geht diess sowoll aus seiner Beschreibung so wie aus den im Herb. normale ausgegebenen Esemplaren hervor. So ist z. B. die im Herb. norm. Fasc. II. als S. lanceolata ausgegebene Form die S. viminalis-Caprea rar. capraeformis W imm., während die S. lanceolata in Fasc. I. Mr. 63 einen Bl endling aus $S$, viminalis und $S$. cinerea darstelit.) - S. acuminata Koch Srn. p. ว̌61. (Die oben beschriehene Pflanze wirl ron Koch bei S. acuminata Sin. zilirt. Die Smitlisc e S. acuminata ist aber nach der Ansicht ron Patze gleich der $S$. dasylctados Wimm. [siehe Wimm. Denksch. p. 161] und wurde ron Koch mit dem ilh etwas ähnlichen oben beschriebenen Blendling rerwechselt oder zusammengelasst. Da der Name $S$, acuminata überdiess von $\mathrm{H}$ offman $\mathrm{n}$ auf die S. cinerea L., von $\mathrm{Host}$ auf die S. daphnoides Vill. und ron R ot ha auf eine Pflanze übertragen wurde, welche W im mer als S. Capreadasyclados beschrieben hat, somit der Name S. acuminata sehr vieldeutig getrorden ist und sich ursprünglich [bei $\mathrm{Sm}$.] auf eine andere Planze bezog, als die beschriebene $*$ ? so wählten wir den T au schischen Namen S. sericans, um so mehr, als die in Tausch pl. sel. ausgegebenen Exemplare rollständig mit der hier beschriebenen Blendlingsart übereinstimmen.) - S. viminalis-Caprea b. acuminata Wimmer Flora 18'S. p. 321. und Flora $18 \not 9$ p. 42. Herb. Salic. Fase. III. Nr. 32. - S. viminalis-Caprea c. latifolia Wimm. Denksch. p. 160. - S. viminalis-Capiea Neilr. Fl. r... Oest. p. 259 pro parte.

Ein Strauch mit Stempelblüthen im Thale der Wien bei Hacking.

Der Standort, an welchem Host seine S. lonififolia gefunden hatte und ron welchem auch jenes chemals im Wiener botan. Garten kultivirto o Exemplar herstammte, das $\mathrm{Koch}$ mit seiner \&. a uminuta identiticinte. ist ron der Donau wegrerissen. Auch der Strauch im botanischen Garten ist eingegangen.

Nebst den hier beschriebenen zwei Planzen. welche Ifost unter siner

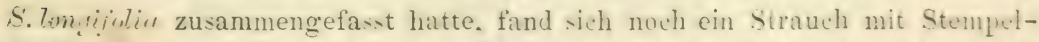
blïthen im botanischen Garten als \$. lom rifilid II ost bezeichnet, welehen der

*) Der Host'sche Name S. longifolia kam, ahgesehen daron, dass er melirere Weiden begrein, sehon vor Host einer nordamerikanischen Weilte zut. 
Autor gleichfalls in Niederösterreich gefunden zu haben scheint, der sich ron den beiden früheren vorzüglich durch die oberseits flaumigen ausgewachsenen 13 lätter unterscheidet und auf das vollständigste mit $\$$. viminalis-cinerea var. a. W i m m., von der uns durch die Güte des Autors Originalexemplare mit dem Standorte Zedlitz in Schlesien vorliegen, übereinstimmt. - Es wird dieser Blendling von W $\mathrm{Wm}$ mer als eine genaue Mittelform zwischen S. viminalis und S. cinerea bezeichnet. Er mahnt im Zuschnitt der Blätter noch an S. viminalis, während die zwei ron Wimmer in If rb. Salic. unter Nr. 23 und Nr. 24 ausgegebenen Formen durch die im oberen Drittel breitesten Blätter sich mehr dem Typus der S. cinerea anschliessen. - Die S. day.ycludos W $\mathrm{W} \mathrm{m} \mathrm{m}$., so wie die S. dasyclados-vininalis stellen nach unserer Ansicht zwei näher gegen S. riminalis hinneigende Blendlinge aus S. viminalis und S. cinerea dar. - Die grosse Aehnlichkeit der zwei ron $\mathrm{Koch}$ unter seiner $S$. stipularis zusammengefassten formen: S. Hostii (superiminalis-Carivea) und S. stipularis Smith (reperviminaliscinerea), findet auf diese Weise ihre naturgemässe Erklärung und die Blendlinge aus $S$. riminalis und Caprea würden sich demnach mit jenen aus S. viminalis und $S$. cinerea in folgende zwei parallel laufende Reihen ordnen:

\section{A. Bastartreilhe ron S. viminalis zu S. Caprea.}

S. viminalis L. - Folia lineari-lanceolata, elongata, decies longiora quam latiora, subtus sericeo-micantia, supra glabra. Germen sessile. Glandula tori basin germinis superans.

$\asymp$ S. IIostii (superviminalis-Caprea). - Folia lineari-lanceolata, elongata, septies - octies longiora quam latiora, subtus sericeo-micantia, supra glabra. Germen brevissime pedicellatum. Glandula tori basin germinis superans.

(S. longifolia Host Salix th. 63 et specim. 9 in Hort. Host ii.)

$\asymp$ S. Vratislaviana (superviminalis-Caprea). - Folia lineari-lanceolata, elongata, quinquies - septies longiora quam latiora, subtus subsericeo-tomentosa, supra glabra. Germen pedicellatum, pedicello glandulum tori aequante.

(S. viminalis-Caprea f. stipularis Wimm. Flora $18 \mathrm{i} 9 \mathrm{p} .42$. - b. angustifolia Wimm. Denksch. p. 160. - Die var. argentata IV imm. Flora 18 19 p. 42. Ilerb. Salic. Fasc. VII. Nr. Th stellt eine Spielart dieser Weidenform mit mehr silbern schimmernder Bekleidung der unteren Blattläche dar.)

$\asymp$ S. sericans Tausch pl. sel. (riminalis - Cuprea). - Foliz oblongolanceolata ter - quinquies longiora quam latiora, adolescentia subtus subsericea, adulta subtus opace tomentosa, supra glabra. Germen pedicellatum, pedicello nectarium àequante.

(S. longifolia Host tb. 62. - S. viminalis-Caprea b. acuminata W imm. Florn 1819 p, 2.. Herb. Salic. Nr. 32.) 
$\asymp$ S. Neisseana (viminalis-Caprea). - Folia orato-lanceolata, ter - quater longiora quam latiora, subtus tomento laxo opaco tecta, supra glabra. Germen pedicellatum, pedicello glandulam tori vix superante.

(S. intermedia Wimm. Flora 18 19 p. 42. Der Name $s$. intermedia bezielit sich bei Host auf einen Blendling aus S. incana und $S$. cinerea - oder vialleicht aus S. incana u.S. grandifolia. Wir benannten daherdiese so wie zwei in der nachfolgenden Bastartreihe rorkommende Blendlinge nach den Standorten, an welchen sie Herr Director Wim m e r zuerst aufiand.)

$\asymp$ S. capraeformis $\mathbb{W}$ inm. Flora 4849 . p. 42 (culmimimoli-Cirpina). Folia ovato - lanceolata, ter et semissi longiora quam latiora, subtus tomento albido laxo tecta, supra glabra. Germen pedicellatum, pedicello glandulam tori bis superante.

(S. vim.-Caprea a. latifolia Wimm. Denksch. p.160. - S. lanceolata Fries Herb. norm. Fasc. II.)

s. Caprea L. - Folia ellyptica rel lanceolata-ellyptica, bis longiora quam latiora, subtus tomento albido laxo tecta, supra glabra. Germen pedicellatum, pedicello glandulam tori quater - sexies superante.

\section{B. Bastartreihe ron S. viminalis zu S. cinerea.}

S. viminalis L. - Folia lineari-lanceolata, elorgata. decies longiora quam latiora, subtus sericeo-micantia, supra glabra. Germen sessile. Glandula tori basin germinis superans.

$\asymp$ S. stipularis $\mathrm{Smith}$ (supertiminali-cinerea). - Folia lineari-lancelata, elongata, subtus tomento subargenteo adpresso tecta, supra lerissime puberula. Germen brerissime pedicellatum. Glandula tori basin germinis superans.

(S. viminalis-dasyclados Wim m. Denksch. p. 160.)

$\asymp$ S. dasyclados Timm. Flora 1849 . p. 3̈̈ (ciminalis-cinerea). - Folia late lanceolata, elongata, longe acuminata, quater - sexies longiora quam latiora, subtus glauca, puberula, opaca, supra levissime puberula. Germen brevissime pedicellatum. Glandula tori basin germinis superans.

(W im m. Herb. Salic. Nr. 7. - S. acuminata S mith.)

$\asymp$ S. Zedhitxiana (riminalis-cinerea). - Folia oblongo - lanceolata ter quinquies longiora quam latiora, subtus cana, subsericeo-tomentosa, supra puberula. Germen pedicellatum, pedicello glandulam tori aequante vel rix superante.

(S. vim-cinerea a. Wimm. Denksch. 1. 161.)

$\asymp$ S. nitens Gr. e. Godr. Fl. d. Fr. p. 131 (viminalis - cinerea). - Folia lanceolata, sub apice latiora, ter - quinquies longiora quarm 
latiora, subtus subcericea, cano-tomentosa supra puberula. Fermen pedicellatum, pedicello glandulam tori aequente rel vix superante. (S. vim.-cinerea b. Wim m. Denksch. p. 161. Herb. Salic. Nr. 23.)

$\asymp$ S. Canthiana (subciminalis - cineren). - Folia oborato-lanceolata, ter longiora quam latiora, subtus cinereo-tomentosa, supra puberula. Germen pedicellatum, pedicello glandulam tori bis superante. (S. vim.-cinerea c. Wimm. Denkscl. p. 161. Herb. Salic. Nr. 2'k.)

S. cinerea L. - Folia olorato-ianceolata reloblongo-obovata, ter longiora quam latiora, subtus cinereo-tomentosa, supra puberula. Germen pedicellatum, pedicello glandulam tori ter - quinquies superante.

Yebst den angegebenen Merkmalen liesse sich für die hier nur skizzenhaft berïhrten Weiden auch noch die Form der Fruchtknoten, so wie das relative I.ängenrerhältniss der Narben und Griffel zur Unterscheiłung festhalten. Im Allgemeinen lässt sich sagen, dass jene Blendlingsarten, welche sich mehr zu S. Caprea oder S. cinerea hinneigen, in dem frade als sie kürzere und breitere Blätter zeigen auch kürzere Torusdrüse, kïrzeren Griffel und kürzere weniger gebogene Narben aufweisen. - Die Blendlinge aus s'. viminalis und cinerea unterscheiden sich von jenen aus s. viminulis und Caprea zunächst durch die oberseits beharten Blätter und die absteliende sarımtige liehaarung der jungen Zweige. - An sehr kräftigen Exemplaren ist dịese abstchende sammige Behaarung sehr auffallend. Sie kommt übrigens in dieser starken Entwicklung nicht bloss den zu S. timinalis hinneigenden zwei Blendlingen

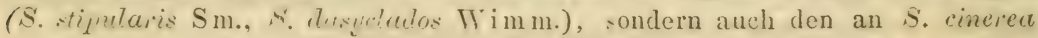
sich anschliessenden Formen zu, wie uns denn auch ein zu S. Canthiana gehöriger Blendling vorlicet, dessen üppige Zweige in ihrer Bekleidung: ganz mit $S$. dasiclalos Wimm. und S. stipulaits $\mathrm{Sm}$. übereinstimmen.

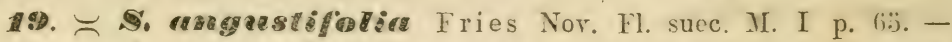
(viminalis-iepus). - Amenta pistilligera ovato-cylindrica, bis - ter longiora quam latiora. Squamae discolores, oboratae, obtusae, villo-ae. Glandula tori oblongo-linearis. Germen oratum, sericeum, pedicellatum. pelicello illomeluleme inri bis terve supercente. Stylus tenuis filiformis. Stigmata linearia. stylo aeruilonga, patentia, flara. Folia linedi-lanceotutu, mursine sibunduldia et

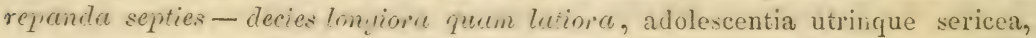
adulta supra glabra, subtus sericea, argenteo-micantia.

Am. ㅇ 15-28mm lg. $8-10 \mathrm{~mm}$ lt.

Squam. $2 \mathrm{~mm}$ lg. Germ. $3^{\mathrm{mm}}$ lg. Styl. et stigm. $1^{\mathrm{mm}} \mathrm{lg}$. Pedic. $2^{\text {nmm }} \mathrm{lg}$.

Fol. $3 \ddot{3}-68 \mathrm{~mm}$ lg. $5-9 \mathrm{~mm} 1 \mathrm{t}$.

S. rosmarinifolia L. sec. W imm er (conf. Flora 18 i p. 52). 5) S. angustifolia Fries 1. c. et Herb. norm. Fasc. II. Ko ch Syn. n. 567 (nicht Wulfen, dessen S. angustifolia nach

*) Obschon wir die Ansicht Wimmer's vollständig theilen, dass Linné unter seiner $S$. rosmarinifolia wahrscheinlich jene Pflanze gemeint habe, welche Fries und $\mathrm{Koch}$ : S. angustifolia nannten, und dass L inné unter seiner S. Helix die S. rubra der späteren Autoren verstanden, so glaubten wir doch die iiblich gewordenen Namen der S. angustifolia und $S$. rubra beibehalten zu müssen. * 
den Exenplaren seines Herbariums in Wiener $k$. bot. Hofkabinete, die $S$. repens 2) rosmarinifolia darstellt). - S. viminalis-repens Wimm. Denksch. p. 162. (Die von uns beschriebene Pflanze stimmt nicht rollständig mit der dort gegebenen Diagnose übereiu, ist aber walısscheinlich identisch mit dem im bot. Garten zu Breslau;befindlichem Eremplare, ron welchem Wimmer bemerkt, dass dessen Blüthen einen $z$ war kurzen aber deutlichen Griffel und längere Narben zeigen.)

Der ganze Strauch macht den Eindruck einer Miniatur-Auflage ron S. viminalis. Die Blätter sind nur halb so gross als jene der Korbweide und der ganze Strauch erreicht nur die Höhe von $2-3$ ', seine Zweige sind aber schlank, aufrecht und reich beblättert. Im Zuschnitt, in der fast welligen Berandung, in der Nerratur und in dem silberweissen Leberzug der unteren Fläche, tragen die Blätter ganz den Typus der einen Stanmart S. viminalis. Sie sind lang zugespitzt, die Fiedernerren an der obern Blattfläche sind etwas eingesenkt, und treten unter Winkeln ron $43-60^{\circ}$ rom Mittelnerven ab, die Haare an der unteren Blattfäche sind sehr kurz und liegen theils der Richtung der Fiedernerren, theils der Richtung des Mittelnerven parallel an - während bei S. repens 2) rosmarinifolia, welche die zweite Stammart zu sein scheint, die Blätter kurz zugespitzt erscheinen, die Fiedernerren, welche unter spitzen Winkeln ron $30-40^{\circ}$ sich rom Mittelnerren abzweigen. an der oberen Blattfläche rorspringen (namentlich im getrockneten Zustande), und die rerlängerten Haare an der unteren Blattfäche alle parallel dem Mittelnerven aufliegen. Ausserdem ist $S$. anyustifolia ron $S^{\prime}$.repens 2) rosmarinifolia durch den fädlichen wohl kurzen aber deutlichen Griffel und die linealen längeren Narben geschieden, während anderseits der lange Fruchtknotenstiel die S. antustifolin ron S. viminalis, den Bastarten aus S. viminalis und S. purpurea und den schmalblätterigen Bastarten aus S. viminalis uni S. C'avea oder S. cinerea unterscheidet.

Wurde ron Neilreich auf Moorwiesen bei Moosbrunn $\left(600^{\prime}\right)$ in Niederösterreich aufgefunden.

Vollständig damit übereinstimmende Exemplare sahen wir unter den von J. Ch. Neumann gesammelten Pflanzen mit dem Standorte Friedersdorf in der sächsischen Lausitz, so wie wir dieselbe Weide im rerflossenen Jahre am Rákos bei Pest beobachteten. Sie scheint übrigens verhältnissmässig selten zu sein und die meisten unter dem Namen $S$. anyustifolia in den Herbaricn liegenden Pflanzen stellen die S. repens 2.) rosmarinifalia dar.

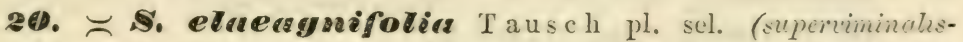
purpurea). - Amenta praccocia, scssilia, densiflora, staminigera oblunga, ter, pistilligera quater - quinquies long:ora quam latiora. Squamae discolores, oratae, obtusae rel acutiusculae, rillosae. Glandula tori ohlonga, ljasin germinis superans. Germen oratum, sericeum, seseile. Stylus filiformis, tenuis, Stigmata oblongo-lineari, patentia rel extrorsum arcuata, stylum subaequantia. Valrae capsulae post maturitatem extrorsum arcuatac. Staminc in la-i vel usque ad medium connatu. Antherae ante et post anthesin flavac. Foliu lineuri-lunceolata, breviter acuminutu, sexies - octies lon!rora quam lationa, cienuto-seriata, 
adolescentia utrinque sericea, adulta supra glabrescentia, obscure viridia, sulute cana, sulisericeo-tomentosa. Stipulac lincari-lanceolatac. Rami elongati flexibiles et tenaces, juniores pubescentes, annotini glabrescentes.

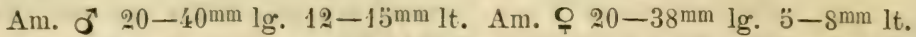

Squan. $2-3^{\mathrm{mm}} \mathrm{lg}$. Gl. tori $0.3 \mathrm{~mm} \mathrm{lg}$. Germ. $1.3-2 \mathrm{~mm} \lg$. Styl. $0.03-1 \mathrm{~mm} \mathrm{lg}$.

Stigm. 0.5 min $\lg$. Stam. $506^{\mathrm{mm}} \mathrm{lg}$.

Fol. $76-115 \mathrm{~mm} \lg .10-18^{\mathrm{mm}} \mathrm{lt}$.

S. elacagnifolia Tausch jl. sel. (Originalexemplare rom Moldauufer bei Prag mit der vorliegenden Pflanze rollkommen übereinstimmend). - S. rubra $\alpha$. sericea Koch Syn. p. 560. -

S. purpurea-viminalis c. sericea Wimm. Denksch. 1. 151. - S. rubra $\beta$. viminaloides Gr. e. Godr. Fl. d. Fr. p. 129.

Ton S. viminalis durch schmächtigere Kätzchen, kürzeren Griffel, külzere und kürzer zugespitzte, unterseits weniger schimmernde, gesägte Blätter, ron den Bastarten aus S. viminalis mit S. Caprea, S. cinerea und S.repens durch sitzende Fruchtknoten und ron den beiden folgenden Bastarten durch die im Alter unterseits dicht seidig-filzigen Blätter . und etwas mehr fädliche Narben verschieden.

Am Ufer der Wien bei Penzing ein Strauch mit Stempelblüthen; beim Hiitteldorfer Bahnhof ein Strauch mit Staubbliitlien.

21. $\asymp$ S. Amenta praecocia, sessilia, densiflora, staminigera bis - ter, pistilligera quater - quinquies longiora quam latiora. Squamae discolores oratae, acutiusculae villosae. Glandula tori oblonga, basin germinis superans. Germen ovatum, sericeum, sessile. St.ylus tenuis, filiformis. Stigmata lineari-oblonga, patentia rel extrorsum arcuata, stylum aequantia. Valrae capsulae post maturitatem extrorsum arcuatae. Stamina al medium usque conna'a. Antherae flarae post anthesin sordidae. Folia lanceolata vel lineari-lanceolata, acuminata, crenato-serrata, septies lonyiora quain latiora, adolescentia sericea, adulta supra glabra, obscure viridia, subnitentia, subtus pallidiora, opaca, attamen viridia, pilis sparsis alpressis minimis tecta eel ylubrata. Rami elongati, flexibiles et tenaces, glabrescentes.

Am. o $2 t-36 \mathrm{~mm} \lg .12-14 \mathrm{~mm}$ lt. Am. $915-24^{\mathrm{mm}} \lg .4-6 \mathrm{~mm} \mathrm{lt}$.

Squam. $2^{\mathrm{mm}} \mathrm{lg}$. Gl. tori $0.5 \mathrm{~mm} \mathrm{lg}$. Germ. $2^{\mathrm{mm}} \mathrm{lg}$. Styl. $0.5-1^{\mathrm{mm}} \mathrm{lg}$.

Stigm. $0.5 \mathrm{~mm}$ lg. Stam. $\tilde{b}-6 \mathrm{~mm}$ lg.

Variat foliorum forma:

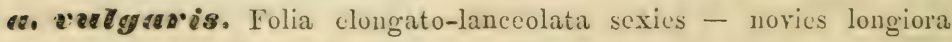
quam latiora.

Fol. $4 \ddot{3}-133^{\mathrm{mm}} \mathrm{lg} .8-18^{\mathrm{mm}} \mathrm{lt}$.

S. Helix I. sec. Wimm. (conf. Flora 1849 p. 52). - S. concolor Host. Salir pl. 우 tb. $35 \mathrm{ct}$ sec. specim. hort. bot. Vindob. - S. rubra et Hoffmanniana Tausch pl. sel. S. mebra Fries Herb. norm. Fasc. X. Nr. 60. Koch Syn. p. 360 (excl. var.). Ko r. 


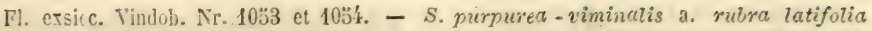
W imm. Flora $18 ! \mathrm{S}$ p. 312. - S. rubra (excl. variet.) Wimm. Flora 18 k9 p. 40, Denksch. p. 13̈1. Herb. Salic. Fasc. VIII. Nr. 86. Neilr. Fl. v. N. Oest. p. $25 \%$.

6. adogeestofolers. Folia lineari-lancenlata, sexies - novies longiora quam latiora.

Fol, $430-70^{\mathrm{mm}} \mathrm{lg}$. $4-7^{\mathrm{mm}} \mathrm{lt}$.

S. rubra $\gamma$. angustifolia T a sch fl. sel. - S. viminalis-purmurea a. rubra angustifolia $\mathrm{TH}$ imm. FIora 18 is p. 312. - S. rubra e. angustifolia Wimm. Denksch. p. 1 Ĭl.

Die S. rubra ist einer der verbreitetsten Bastarte, der mit $S$. viminalis dasselbe Areal besitzt und dessen Blendlingsnatur am Frühesten erkannt worden ist. Unter den aus S. purpurea und $S$. viminalis entstandenen Bastarten hält derselbe genau die Mitte und ist auch weit häufiger als die beiden andern goneiklinischen unter 20 und 22 beschriebenen Formen. - Die beiden Varictäten a. und b. ent-prechen den analogen Formen der S. viminalis. - Die untere blassgrüne Blattllïchs ist bei beiden Spielarten nur selten ganz kahl. Gewöhnlich ist dieselbe mit unendlich kleinen den Fiederserven parallel anliegenden Härchen bekleidet, die aber so diinn gesäet sind, dass der blassgrïne Grundton des Blattes dadurch nicht geändert wird. - Die Staubfäden sind genau bis zur Mitte verwachsen, während sie bei S. elaengnifalia gewöhnlich nur bis zum unteren Dritttḷeil und bei der folgenden Weide bis zu zwei Dritttheilen und oft sogar noch weiter hinauf verbunden erscheinen.

In Niederösterreich findet sich die Spielart a. in Staub- und Fruchtblüthen tragenden Sträuchern an den Ufern des Wienflusses ron Penzing aufwärts bis Hacking; die Spielart b. wurde von Neilreich im Marchfelde bei Marchegg gefunden.

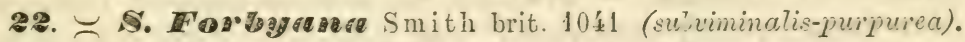
- Amenta praccocia, sessilia, densiflora, staminigera oblonga, ter, pistilligera cylindrica quater - quinquies longiora qnam latiora. Squamae discolores, oratae, acutiusculae, villosae. Glandula tori oblonga, basin germinis supcrans. Germen oratum sericeum sessile. Stylus tenuis, filiformis. Stigmata linearioblonga, patentia, stylum aequantia. Talvac capsulae post maturitatem hiantes, non extrorsum arcuatae. Stamina ad duo tricintes connata. Antherce ainte anthesin pupurascentes, poster flawe et post anthesin nitricantes. Folia lanceolata, supra melium lutinie, breviter acuminata octies longiora quam latiora, crenato-serrata, supra ob-cure viridia, subnitentia, sul,tus pullide viridia, utrinque glabra rel subtus pilis adpressis minimis levi-sime puberula. Rami glaberrimi flexibiles.

Am. ơ $30-33^{\mathrm{mm}} \lg \cdot 11-13^{\mathrm{mm}} \mathrm{lt}$. Am. ㅇ 222-36 mm lg. $5-7^{\mathrm{mm}} \mathrm{lt}$.

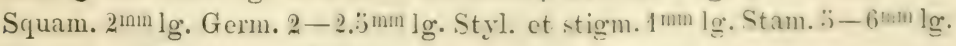
Fol. $70-90^{\mathrm{mm}} \mathrm{lg} .8-12 \mathrm{~mm} \mathrm{lt}$. 
S. concolor II os $1 \mathrm{ll}$. $\delta$ sec. specim. in hort. bot. Vindob. (Die Abbildung in II ost Salix th. 3r kommt zwar mit der Pflanze des bot. Gartens darin überein, dass die Antheren vor dem Aufblülien roth und nach dem Verstäuben. schwärzlich dargestellt werden, - die beiden Staubfäden sind aher Fig. 3 kaum bis zur Mitte verwachsen und die Blatter an Fig. 1 lineal-lanzettlich, während an Exemplaren aus dem botanisehen Garten die Staubfaden bis zu zwei Drittheilen verwachsen und die Blatter im obersten Drittel am breitesten erscheinen.) - S. heliciflora O Tausch pl. sel. - S. rubra Koch Syn. p. 560 (pro parte). S. viminalis-purpurea c. Forbyana $\mathbf{Q}$ Wimm. Flora 18 iS p. 312 . - b. Forbyana Flora 1819 p. 40. Denksch. p. 151. Herb. Salic: Nr. 15. - S. nubra $\beta$. purpureoides Gr. e. Godr. Fl. d. Fr. p. 129

Die S. Forbyana bildet das Verbindungsglied, welehes die Korbweiden mit den Purpurweiden rerknïpft. Sie nähert sich durch die im oberen Dritttheil breitesten, unterseits gewöhnlich kahlen, manchmal etwas bläulich angehauchten Blätter, so wie durch die vor dem Stäuben rothen, nach dem Stïuben schwärzlichen Antheren der S. purpurea und macht auch auf den ersten Anblick den Eindruck derselben. Der fädliche dünne Griffel, die spreizenden länglich-linealen Narben weisen sie jedoch in die Rotte der Korbweiden, in welche wir sie auch hier gereiht haben.

Die 9 Pflanze findet sich in Niederösterreich in den Traisenauen bei Herzogenburg und an der Salamilake in Prater bei Wien. Die männliche Pflanze in einem Strauche am Ufer des Tienflusses ror dem kaiserl. Schlosse in Schönbrunn.

Alle drei hier aufgeführten Bastarte aus $S$. viminalis und S. purpurea sind in Niederösterreich immer nur in der Nähe der zwei muthmasslichen Stammeltern aufgefunden worden, und lieben wie S. viminalis angeschlemmten tiefgründigen Boden. Ihre obere Grenze fällt mit jener der $S$. viminalis $\left(1000^{\prime}\right)$ zusammen.

\section{Sect. VIII. Canae. - Frutices rel arbores minores ramosissimi,} ramis erectis subfurcatis, non pruinosis. Folia lanceolata rel linearia et elongato-acuminata, adolescentia margine revoluta, subtus tomento albo opaco subarachnoideo tecta. Amenta praecocia rel coaetanea arcuata, breviter pedunculata vel subsessilia. Squamae discolores vel concolores. Glandula tori lenticularis, fava. Stamina duo, in variis distantiis connata. Germen pedicellatum, glabrum vel tomentosum. Stylus tenuis elongatus. Stigmata bipartita, laciniis filiformibus extrorsum arcuatis vel recurvis. Valia capsulae post dehiscentiam extrorsum arcuatae, falcatae vel circinatae.

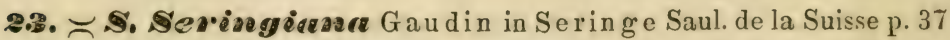
(incano-Caprea). - Amenta praecocia et subsessilia rel subcoaetanea et pedunculata, pedunculo foliato, arcuata, pistilligera ter longiora quam latiora. Squamae oblongae vel sublinear'os, obtuscee, pilosae, discolores, in basi flave- 
scentes et versus apicem puipureo-fuscue. Glandula tori lenticularis, flara. Germen ovato-conicum opace albo-tomentosum, pedicellatum, pedicello alandulam tori ter superante. Stylus tenuis filiformis. Stigmata bipartita, laciniis flavis, filiformibus extrorsum arcuatis rel recurvis. Valrae capsulae post dehiscentiam circinatae. Folia lanceolita vel ollongo-lanceslata, ter lonitionia quam latioia, acuta, a picen ct basin versus aequaliter cotracta, in basi nonnunquam et rotundata, adolescentia reroluta, utrinque albo-tomentosa, adultio margine plana, denticulata, supra glabrescentia, obscure viridia, subtus opace albo-tomentosa. Stipulae semicordatae. Ramuli juniores albido-tomentosi, adulti glabrescentes atro-sanquinei.

Am. $\%$ 20-30 mm lg. $8-10 \mathrm{~mm}$ lt.

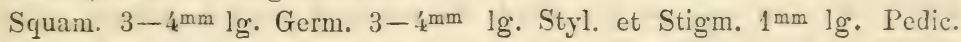
$1-2^{\mathrm{mm}} \lg$.

Folia $5 \ddot{3}-110^{\mathrm{mm}} \mathrm{lg} .20-40^{\mathrm{mm}} \mathrm{lt}$.

S. lanceolata Seringe Essai d'une Monographie des Saulus de la Suisse p. 37. (Sering e rereinigt in der zitirten Monographie unter dem Namen S. lanceolata, die in seinen Sal. exsicc. ausgegebenen: S. Kanderiana und S. holosericea und zitirt den Namen S. Seringiana, ron welchem er sagt, dass er rom Pastor Gaudin der Pllanze gegeben worden sei. Seringe unterscheidet ron seiner $S$. lanceolata die Varietäten B. macrophylla, C. angustifolia, D. gemmata, E. coatanea. - Die seiner Monngrayhie beigegebene Abbildung tb. 1 stimmt im Ganzen gut mit der ron uns beschriebenen Weide überein, nur ist das abgebildete Blatt schmäler, $4^{1} / 2 \mathrm{mal}$ so lang als breit, wälırend die Blätter der von uns in Niederösterreich gefundenen Weide nur $3 \mathrm{mal}$ so lang als breit sind. Wahrseheinlich ist daher die ron uns oben aufgeführte Form mit der Var. B. macrophylla von Seringe identisch, ron welcher der Autor sagt: „les feuilles acquièrent jusquà 4-3 pouces de longueur et 1 pouce et demi de largeur". Die Var. C. angustifolia [Sal. exsicc. Nr. 72], die auch schwächer bekleidete Blätter besitzt, ist vielleicht ein Bastart der S. incana mit S. grandifolia oder S. cinerea.) - S. Seringeana Koch Syn. p. 562 pro parte ( $\mathrm{K}$ och hat nach dem Zitate ${ }_{n}$. intermedia $\mathrm{Hos} \mathrm{t}^{\text {s }}$ unter seiner S. Seringiana gleichfalls zweierlei Weiden begriffeu. - Obschon sich demnach derName S. Seringiana Ga ud. bei Sering e und $\mathrm{K}$ o ch mahrscheinlich auf rerschiedene Bastarte aus $S$. incana mit $S$. Caprea, S. cinerea, S. grandifo'ia bezieht, so haben wir doch für den oben beschriebenen muthmasslichen Bastart aus $S$. incana und $S$. Caprea den Namen S. Seringiana beibehalten, weil derselbe in der Nomenklatur bei den neueren Botanikern [v. Hausmann, Neilreich, dann in Löhr Enum.] bereits als synonym mit $S$. incana-Caprea angeführt ist.) - S. cinereo-incana Wimm. Flora 1818 p. 333. - S. incana-Caprea Wimm. Flora 18 p. 46. Denksch. p. 159. Neilr. Fl. T. N. Oest. p. 260. (Die unter Nr. 64 in Wimm. Herb. Salic. ausgegebene Weide aus dem Valée du lac de Joux in der Schweiz ron Dr. La gg er ist elwas schwächer bekleidet, als der hier ron uns beschriebene Weidenblendling. Ilire Blätter zeigen 16-1S Fiedernerrenpaare, sind $4 \mathrm{mal}$ so lang als breit, gegen die Basis keilfürmig zulaufend und über der Mitte breiter, verkehrteiförmig - lanzettlich und sie scheint mit einer von uns bisher nur in Blättern gefundenen Weide, die wir für einen Bastart aus S. incana und grandifolia halten, identisch.)

Erwächst zu einem drei bis vier Klafter hohen Baum der mit Recht von Wimmer seines schünen zweifürbigen Laubes wegen zur Kultur in l'arkanlagen anempfohlen wird. Die blätter sind rein lanzettlich oder länglichlanzettförmig, an beiden Seiten fast gleichmässig zusammengezogen, an der Basis manchmal auch zugerundet, niemals über der Mitte rerbreitert. Der 
Rand ist nur in der Jugend zurïckgerollt, an den ausgewachsenen Blättern ist er flach und unregelmässig ausgebissen gezähnelt. Die obere Blattseite ist dunkelgrün, wenig glänzend, ron vertieften Nerrenlinien durchzogen, Die Fiedernerren der unteren Blattseite, obschon ron dichtem weissen glanzlosen Filze überdeckt, sind dennoch deutlich rorspringend, etwas winkelig gebogen und rerbinden sich nahe dem Rande noch durch ziemlich kräftige Anastomosen miteinander. Zwischen je zwei und zwei solcher bis zum Rand verlaufender Fiedernerven, deren Zahl zwischen 12 und 13 schwankt, finden sich immer 1-2 kleinere, nur bis zur Mitte der Blatthälfte deutlich vorspringende Fiedernerven. - Die Kätzchenschuppen sind lang und schmal, in der Regel an der unteren Hälfte gelb, an der oberen braunpurpurn; manchmal findet man aber auch an demselben Kätzchen einzelne fast ganz gelbe oder nur an der Spitze schwach geröthete Schuppen. Die verschiedenen Farben der Blüthentheile, nämlich die weisse Farbe der Fruchtknoten, die gelbe Farbe der Narben und die purpurne Färbung an der Spitze der Schuppen verleihen den Kïtzchen ein buntscheckiges Ansehen, welches um so mehr hervortritt als die Bekleidung der Schuppen nicht sehr dicht ist.

In der Nervatur und dem Zuschnitte der Blätter, so wie in der Bekleidung der langgestielten Fruchtknoten ist $S$. Caprea nicht zu rerkennen; in der Verzweigung der Aeste, Bekleidung der Blätter, Form der Torusdrüsen, Griffel und Narben ist hinwiederum $S$. incana auf das unzweideutigste ausgesprochen.

Die S. Seringiana wurde bisher immer in rereinzelten Exemplaren innerhalb des Areals der S. incana, in der Schweiz, in Tirol, Krain, Schlesien aufgefunden. - In Niederösterreich fanden wir sie im Gebiete des Traisenflusses zwischen Sct. Pölten und dem Schwaighof $\left(900^{\prime}\right)$ dann im Gebiete der Erlaf an der sïdlichen Abdachung des Josefsberges an der Strasse (beiläufig in der halben Höhe des Berges) bei 2800' in mehreren \& Sträuchern, und am Gruebberg zwischen Lunz und Gaming bei $1900^{\prime}$ in zwei baumartigen 9 Exemplaren, ron welchen sich das eine noch gegenwärtig im kräftigsten Tachsthum in der Thalschlucht des Mitterauerbaches hinter der Karthause erhalten hat, während das zweite durch den Strassenbau dort verschwand. - An allen drei Standorten findet sich sowohl S. incana wie S. Caprea in der Nähe.

Die S. intermedia (Host. Salix p. 17. tb. $36, \ddot{3} \%$. S. incana-cinerea Wi m m. Flora 1849. p. 46. Denksch. p. 10̈9. Herb. Salic. Nr. 61), die bisher in Niederösterreich nicht aufgefunden wurde, unterscheidet sich ron S. Seringiana schon auf den ersten Blick dadurch, dass ihre Kätzchen schmutzig-grau und um die Hälfte schmäler sind. Die Fruchtknoten erscheinen in Folge dünncrer Bekleidung zur Zeit der vollen Blüthe grau (ncht weissfilzig wie bei S. incana) und werden zu Ende der Blüthezeit ron der Basis gegen die Spitze zu kahl und grün. Die ausgebissen gezähnelten Blätter sind entweder lineal oder verkehrteifürmig-lanzettlich und über der Mitte am breitesten, fünfmal so lang als breit und unterseits viel schwächer bekleidet als jene der S. Seringiance, 
so zwar, dass die blïulich-aselgraue Gruıdfarbe deutlich hervortritt. Dic Nerren sind gelblich oder fast rostfarlig, die Anzahl der Fiedernervenpaare schwankt zwischen 20 und 30, während sie bei s. Seriagiana $12-20$ beträgt, das Nervennetz ist viel zarter und zierlicher als das der Blätter von S. Seringiana und erinnert mehr an jenes der S. cineia und S. giandifolia. Von Wimmer wird in der Denkschrift p. 159 ausge:prochen, dass diese ron ihm als S. incano-cinerea bezeichnete Blendlingsart, möglicherweise auch aus S. incana und S. arccindifolia entstanden sei, was nicht unmöglich wäre. Es würde dann $S$. intermedia Host einen zu S. incanu hinneigenden Bastart darstellon, während wir eine andere am Josefsberge mit S. Serintiana an gleichem Standorte, nur in Blättern gefundene Weide für einen mehr zu S. wratifulia hinneigenden Blendling halten und als $S$. sulal pina bezeichnen, seine Beschreibung aber bis zur Zeit, wo uns auch Blüthen desselben rorliegen werden, suspendiren.

Da ron Wimmer an der zitirten Stelle bei S. intermedia angegeben wird, dass Tausch die Pllanze in Böhmen gefunden labe, in Bühmen aber $S$. incana nicht rorkommt, so künnte diess einige Bedenken gegen die oben gegebene Deutung dieses Weidenblendlings hervorrufen und wir erlauben uns daher hiezu folgendes zu bemerken. Tausch hat zwar allerding: unter seinen Weiden auch S. intermedia Host ausgegeben, dieselbe aber ebensowenig wie die ron ihm ausgegebene S. incuna in Böhnen gesammelt. Es stammen diese Exemplare höchst wahrscheinlich aus den Wiener Gäıten . ron den durch Host ge flanzten Sträuchern, denn in dem ron Tausch angefertigten Cataloge der Flora l,ühmens, in welchen sich selbst die unbedeutendsten von $\mathrm{T}$ a usch unterschiedenen Varietäten der in Bühmen aufgefundenen Treiden sorgfältig verzeichnet finden, fehlt sowohl S. intermeilia II st wie s. in wha Schrank. (Vergl. Catalog der Hlora Böhmens nach Prof. Ta uschis Herb. Fl. Boh. von Joh. Ott.)

Host fanil seine S. intermedia ..in Carniolia ad aquarum fluenta, riguis montium declivibus ad montium pedes." Sie wird in Fleisclimann's 1lo.a Krain's am Gruberischen Kanal bei Laibach und in Sagor angegeben. Auch S. Strinumina wird in demselben Werke bei Sagor, Seisenberg und Möttling aufgefïhrt und es scheinen daher dort Bastarte aus $s$. inchu ziemiich häuifig $\mathrm{zu}$ sein.

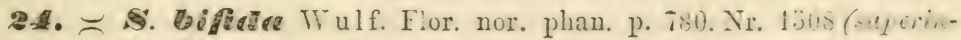
cano-jer.ue(1). - Amenta cuactanca, breviter pedunculata. arcuata, staminigera ter longiora quam latiura. Squame oboratae truncule, ciliatae, fictue of unicolores rel apice rebesentes. Glandula tori lenticularis. Stamina duo. Filementu tota vel all den trientes coninute, intra medium pilusa. Anherae ante

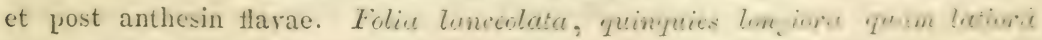

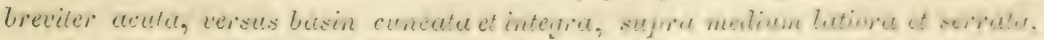

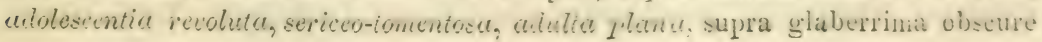


riridia, subtus alba, arachnoideo-tomentosa. Rami subfureati, torulosi, juniores albido-tomentosi, adulti glabrescentes.

Am, o $20-32 \mathrm{~mm} \mathrm{lg} .8-10^{\mathrm{mm}}$ It.

Squam. 2_2.5 $\mathrm{mm}$ lg. Stam. $4-6 \mathrm{~mm} . \mathrm{lg}$.

Fol. $20-32 \mathrm{~mm}$ lg. $8-10 \mathrm{~mm}$ lt.

S. bifida Wulf. l. c. (nach dem im Wien. bot. Hofkabinete befindlichen Exemplare in Wu ulf en's Herb.) - S. incano-purpurea Neilr. Verh. d. z.-b. Vereines. 1851. p. 119. Fl. v. N. Oest. p. 260 excl. syn. (nach dem in Neilreic h's Herb. befindlichen an der Schwarza bei Gloggnitz gesammelten Blattexemplare.)

Die hier beschriebene Weide macht den Eindruck der S. incana. Die Verzweigung der Aeste, der charakteristische Ueberzug, der in der Jug'end umgerollten Blätter, die Farbe und Form der Kätzchenschuppen, die gewimperten Staubfäden, die linsenförmige Torusdrüse lassen auch bei näherer Untersuchung diese Stammart erkennen. Die Blätter zeigen aber den Zuschnitt der S.purpurea, sind im Alter flach, über der Mitte am breitesten und gesägt, gegen die Basis keilförmig und garzrandig. Die entweder zu zwei Dritttheilen oder bis zu den Antheren verwachsenen Staubfäden deuten gleichfalls auf S. purpurea und wir betrachten daher diese Weide als einen der S. incanca nahe stehenden Bastart aus S. purpurea und S. incana.

Wir fanden diese Weide bisher nur mit Staubblüthen. Auf der Donauinsel zwischen Rossatz und Dürrenstein ein baumartiges Exemplar. - Strauchartig bei Herzogenburg an der Traisen. - Bei Gloggnitz an der Schwarza (Neilreich). - Ueberall in Gesellschaft beider muthmasslichen Stammeltern.

Die S. bijula ist mit der ron $T$ immer als S. incana-purpurea (Uebers. d. schl. Gesellsch. 1847. t. 1. f. 1. Flora 1848 p. 311., 18:9, p. 39. Denksch. p. 13̈1) beschriebenen und im Herb. Salic. unter Nr. ö ausgegebenen Weide nicht zu verwechseln. Diese letztere unterscheidet sich nämlich von S. bifula durch lineale im Zuschnitte mit $S$. incana übereinstimmende, aber im Alter unterseits fast kahle Blätter, die acht bis zehnmal so lang als breit sind und gewissermassen einen Gegensatz zu den Blättern der S. bifida bilden, welche, wie bemerkt, im Zuschnitt mit S. purpurea übereinstimmen aber selbst im Alter noch den weissfilzigen Ueberzug der S. incana behalten. Im Herbarium Reichhardt's fanden wir einen beblätterten Zweig einer Weide mit dem Standorte „Hütteldorfer Aue bei Wien", welche auf das vollständigste nit den Blattexemplaren der $S$. incana-purpurea Wimmer's übcreinstimmt. Ohne Blüthen wagen wir es jedoch nicht sie mit derselben zu identifiziren.

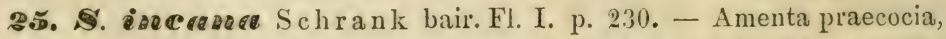
rel subcoactanea, subsessilia, gracilia, arcuata vel deflexa, fructifera erecta, staminigera bis -- quater, pistilligera quinquies-decies (plerumque sexies) longiora quam latiora. Squamae oboratae, truncatae vel emainginatae, margine ciliatae rel glaberrimae, flosculorum staminigerum flavae unicolores vel apice rubescentes, flosculorum pistilligerum e viridi flarae unicolores. Torus lenti- 


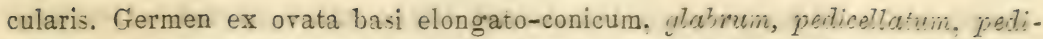
cello ulandulam tori bis superante. Stylus elongatus, lenuis, stigmatibus bifidis, laciniis filiformibus, extrorsum arcuatis rel recurratis, flaris. Stamina duo, pilamentis injra medium comatis et pilosis, antheris ante et post anthesin flaris. Folia lanceslato-linearia vel linearia, elongata in acumen asuguliter prouluota, in petiolum atfenuata rel contracta, sevies-luodecise (plerumque decies) lompina quain lationa, margine repundo-dentirulata ef revluta, adolescentia utrinque albo-tomentosa. subarachnoidea, adulta supra glabrescentia, sordide et obscure viridia, opaca, subtus alba, subarachnoideo-tomentosa. Nervus medius in facie supeiori impressione significatus, in facie inferiori eximie prominens. glabrescens et flarescens. Nerri secundarii supra depressi. subtus tlerati. tomento arachnoideo rero tecti et rix conspiciendi. Rami subfurcati. plerumque torulosi, juniores cano tomentosi, annotini glabrescentes, cortice rufescenti vel flarescenti tecti.

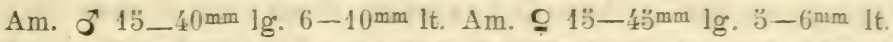
Squam. 2-3mm lg. Germ. 2-3mm lg. Styl. et stigna 1 1 ma lg. Pedie. $0.5^{\mathrm{mm}} \mathrm{lg}$. Stam. $3-6^{\mathrm{mm}}$ lg.

Fol. $40-160 \mathrm{~mm} \mathrm{lg} .0 ّ-12 \mathrm{~mm}$ lt.

S. incana Koch Syn. p. 562. Wimm. Flora 1849 p. 3ł. Herb. Sal. Fasc. VIl. Nr. S1. Fasc. ViII. Nr. 9 t. Neilr. Fl. v. N. Oest. p. 260, $K$ or. Fl. exs. Vind. Nr. 976 u. 105ĩ. $-S$. riparia Willd. Spec, pl. IV. p. 698. H ost Salis p. 17 tb. 28. ă9.

Ein meistens rom Boden aus reich rerästeter bis drei Klafter hoher Strauch, dessen Aeste sich in fast gabelig getheilte*) Zweige auflisen. Die Zweige sind reich beblättert; die schmalen biätter stelen genähert. sind steif nach aufwärts gerichtet und rerleihen dem Strauche durch die Mischung des dunklen schmutzigen Grüns der oberen Fläche und des weissen glanzlosen Filzes der unteren Seite einen düstern grauen Farbenton. In den Voralpen, wo $S$. incuna auch manchnal als Feloenptlanze mit $S$. ylubia und $S$, growlifulia rergesellschaftet auftritt, wird sie zwergig, erreicht kaum meln die Höhe von 4 Schuh und besitzt dann auffallend kurze Kätzchen und Blätter. Ueberdiess sind an solchen Standorten ebenso wie auf den Schotterebenen der präalpinen Niederung die Blätter dichter bek keidet, mehr zurückgerollt und stehen, da die Zweige dort sehr verkürzt sind, so dicht gedrängt wie bei keiner anderen Weide. - An schattigen Standorten der Donau-Auen sind die Blätter fast flach, am Ranle ausgebissen gezähnelt und nur schwach bekleidet; unterseits dünn. spinuwebig-wollig. der bläulich-aschenfarbige Grundton der unteren Blattlläche. welcher sonst gewöhnlich ron dem dieken weissen Filze verdeckt ist, tritt danu deutlich hervor und auch die liedernerven, welche sonst gewölnlich rom Filze verhüllt und kaum sichtbar sind, erscheinen an solchen Schattenexemplaren deutlicher und etwas vorspringend. An der obenen Seite sind aber die Terven immer cingesenkt und

*) Ceber den eigenthümlichen Wuchs der S. incana und der ihr verwandten Furmen siehe p. כo. 
die Blattfläche daher runzelig. Die Anzahl der bis zum Blattrand rerlaufenden Fiedernervenpaare schwankt zwischen 20 und 30 .

Die Kätzchen sind vor dem Aufblühen und zur Zeit der vollen Blüthe herabgeschlagen oder bogenfürmig gekrümmt, nach dem Abblühen jedoch und zur Zeit der Fruchtreife gerade. Die zarten, dünnen Schuppen der Staubkätzchen sind entweder hellgelb einfärbig oder an der Spitze scharlachroth angehaucht oder auch rostfarbig und braunpurpurn. Die Schuppen der Fruchtkätzchen sind immer einfärbig gelblich-grün. - Die Staubfäden scheinen bei S. incance immer von der Basis an bis nahe an die Höhe des oberen Schuppenrandes verwachsen zu sein. Wir waren früher mit Wimmer *) der Ansicht, dass unter allen Weiden nur S. purpurea und deren Bastarte ganz oder theilweise verwachsene Staubgefässe besitzen und dass die Vereinigung der Staubfäden der $S$. incana an der unteren Partie nur durch die ineinandergreifenden Wimperhaare, welche die Filamente dieser Art, so wie jene der Chloriteen und Schwarzweiden bekleiden, hergestellt werde, um so mehr als sich bei Untersuchungen an frischen Staubgefäs:en selbst bei leisem Auseinanderziehen beide Fäden immer ganz leicht isolirten w). Sorgfältige wiederholte Untersuchungen belehrten uns jedoch, dass eine wahre Verwachsung beider Fäden existire und Exemplare, welche wir aus dem Balkan, aus Siebenbürgen, Oberungarn und Krain, so wie von vielen Standorten Niederösterreichs aus den Donauiuen und den Alpen vorliegen haben, zeigen alle in ganz übereinstimmender Weise diese Verwachsung. Koch und Rejchenbach und jene Autoren, welche ron diesen Beiden die Diagnosen abgeschrieben haben, übergehen ganz diese Eigenthümlichkeit. Von Anderen werden die Staubfäden als getrennt beschrieben. Host, Grenier und Godron, und Mathieu beschreiben dieselben bereits ais zur Hälfte rerwachsen.

Diese Eigenthümlichkeit, welche somit S. incana mit S. purpurea gemein hat, spricht sich auch in den Bastarten der S. incana aus. Bei S. Wimmeri sind die Staubfäden immer an der Basis verwachsen; bei S. intermedia $\mathrm{Host}$, die gewölhnlich mit freien Staubgefässen beschrieben wird, reicht die Verwachsung manchmal bis zur Hälfte und auch die Host'sche Abbildung (Scalie tb. 36. fig. 3.) zeigt deutlich an der unteren Parthie verbundene Filamente. Auch ron S. Scrinituna sagt Seringe pg. 38: „29 étamines réunies à leur base."

S. incunce gehört dem Süden von Europa an. Sie ist in der ganzen Mittelmeerzone heimisch und dchnt ihr Areal bis an den nördlichen Fuss der

* Denksch. d. Schles. Ges. f. Iaterl. Kult. Bresluu 1833 p. 1's. mille Weidenformen, welche halbverwachsene Staubfäden haben, sind Hybride aus S. purpurca und einer andern Art ${ }^{\star}$.

**; In der Einleitung p. 3' wurde daher auch noch $S$. incana als Beispiel für jene Form der Stauhgefasse angeführt, bei welcher die Faileu im unteren Drittheil behaart und durch die ineinandergreilenden Harcheu lose zusammenhitrond erscheineu, wie diess bei S. firagilis, S. glabra, etc. der Fall ist. 
Alpen und Karparthon aus. Die Linie, welche ihr Areal nordwärts begrenzt, zieht ron Agen an den Ufern der Garonne anfänglich als nordwestliche Vegetationslinie durch das suidliche franzö.ische Plateau in die Ardennen nach Luxemburg und Echternach bei Trier, von da als nordüstliche Vegetations-Linie in das Rheinthal nach Karlstuhe und ïher Pforzheim an die Donau nach Ulm. Von Ulm ïber Ingolstadt, Passau, Linz, Krems, Wien bis an die March bildet das Donauthal die Nordgrenze des Areals; ron der March aber verläuft die Vegetationslinie wieder als eine nordwestliche entlang den Karpathen anden Oberlauf der Oder und Weichsel nach Troppau, Bielitz und Lstron und folgt dem Bogen der Karpathen bis hinab in die Moldau, um dann als üstliche Vegetationslinie in den Balkan zu ziehen. - Innerhalb des so begrenzten Areals hält sich diese Weide insbesonders an die kiesreichen Ufer der Gebirg:strüme und an die Schotterbänke der präalpinen Niederungen. fehlt aber sowohl in den höheren Regionen ïber $4000^{\prime}$, so wie auch in den Tiefebenen der Donau und in dem ron der Teichsel und Oder durchstrümten Tieflande.

In Niederösterreich findet sich S. incance an den felsigen Lfern der Alpenbäche, auf den Dilurialterassen und den Schotterbänken der alpinen Zuflüsse der Donau (Enns, Ibbs, Erlaf, Pielach, Traisen und Hallbach. Perschling, Weidlingerbach, Wien, Schwechat, Mödling. Piesting, Prein. Sirning u. Schwarza) bis in das Donauthal, dann noch vereinzelt auf Kalkfelsen in den subalpinen Thälern und truppenweise auf den Kiesflächen der präalpinen Niederungen (dem Steinfelde bei Wiener-Neustadt, der s ogenannten Wilhelmsburger, Wieselburger. und Welser Haide) an welch letzterem Standorte sich als treueste Begleiter der S. incunu das Elutotium rosmarinifolium und Hierucium staticefolium zu ihr gesellen.

In der Höhenzone von 1.300 bis $2000^{\prime}$ in welcher die Chloriteen verschwinden ist sie mit S. purpurea an unseren Alpenwässern die hersrchende Weide. In den Donawuen tritt sie gleichfalls gesellig als Bestandtheil der ersten und zweiten Waldgeneration auf, findet sich aber nur streckenweise bei Enns, Melk, Rossatz, Mautern, Krems, Hollenburg, Wien; im Allgemeinen im oberen Donauthale häıfiger als im Bereiche des Wiener-Peckens. In den Auen an der Mündung der Enns, so wie in den Donau-Auen bei Rossatz, Krems

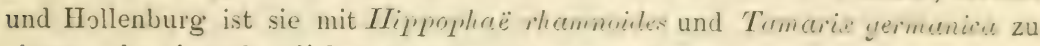
einem sehr eigenthümlichen Buschwalde verbunden.

Sie fehlt im Bereiche des bühmisch-mährischen Grebirges mit Ausnahme des Thales, welches von der Donau durchströmmit wird.

Ihre obere Grenze findet $S$. incand in Niederösterreich bei 3100 (hüchster Standort in der Yähe von Josefsberg:) In dieselbe Ilöhe fältt ihre obere Grenze in Obersteiermark. - In den baierischen $A l p e n$ jeluch ist dieselbe wie fast alle Höhengrenzen bedeutend höh:r gerïckt und wird anf fono angegeben. 
Sect. IX. Pruinosae Koch. - Arbores vel frutices, ramis erectis, junioribus plerumque rore caesio, abstergendo tectis. Folia oblongo-rel lineari-lanceolata, acuminata, adulta glabra, subtus glanca, dum marcescunt, rufescentia. Amenta praecocia, sessilia rel breviter pedunculata, arcuata rel recta. Squamae discolores. Glandula tori oblonga, fara. Antherae post anthesin fla:ae. Germen sessile rel breriter pedicellatum, glabrum, compressum, aculum. Stylus tennis. Stigmata linearia, erecto-patula. Valrae capsulae post dehiscentiam extrorsum arcuatae, falcatae.

86. $\asymp$ S. Wimbneve Kerner. Verh. d. z. b. Vereins II. p. 61. (incano-daphoides). - Amenta praecocia, densiflora, arcuata, brevissime pedunculata, pedunculo folicato, staminigera oblongo-ovata, bis, pistilligera cylindrica. quater - sexies longiora quam latiora. Squamae oblongae vel oratae, obtusae, discolores, in basi ferrugineae, apicem versus atratae, longe villosae. Glandula tori oblonga, truncata, llava. Germen ex ovata basi conicum, acutum subcompressum, glabrum, peclicellatum, pedicello ullandulam tori aequante, plerumque ciliato. Stylus tenuis, elongatus. Stigmata lineari-oblonga, erecto-patula. Valrae capsulae post maturitatem extrorsum arcuatae, falcatae. Stamina duo, infra medium pilosa, in basi colicerentia. Antherae flavae. Folia oblongolanceolata vel lineari-lanceolata, adolescentia revoluta, utrinque albido-arachnoileo-tomentosa, adulta supra obscure viridia, glabra et subnitida vel villo albido absteryendo tecta et opaca, subtus allido-glauca, glabrata, summa tantum arachnoideo-tomentosa. Ramuli fragiles, juniores arachnoidei, adulti glabrati, obscure oliracei vel atrosanquinei, biennes plerumque pruinosi.

Am. of $22-40^{\mathrm{mm}} \mathrm{lg}$. $12-22 \mathrm{~mm} \mathrm{lt}$. Am. $922-40^{\mathrm{mm}} \mathrm{lg} .6-8^{\mathrm{mm}} \mathrm{lt}$.

Squam. 2-3 $3^{\mathrm{mm}} \mathrm{lg}$. Gl. tori $0.3^{\mathrm{mm}} \mathrm{lg}$. Germ. 2-2..5m $\mathrm{lg}$. Styl, $1^{\mathrm{mm}} \mathrm{lg}$.

Stigm. $0.5-1^{\mathrm{mm}} \mathrm{lg}$. Stam. $8-10^{\mathrm{mm}} \mathrm{lg}$.

Fol. $60-10 \mathrm{Jmm}^{\mathrm{mg} .} 12-24 \mathrm{lt}$.

S. Wimmeri Kerner Flora 1832. p. 511. W imm. Herb. Sal. Nr. 88 u. Text zu Fasc. VIII. S. incano-daphnoides TV imm. Jahresb. d. schles. Gesellsch. 18ว2. p. 6í. Denksch. p. 158. Neilr. Fl. v. N. Oest. p. 220.

Die hier beschriebene IVeide, welche wir vor acht Jahren zuerst in mehreren $\%$ baumartigen Exemplaren auf einer Donauinsel zwischen Dürenstein und Rossatz aufanden und nach Herrn Direktor IT im mer, dem die Wissenschaft ror Allen den richtigen Einblick in das rielgestaltige Yolk der Weiden rerlankt, benannten, wurde inzwischen ron C. Erdinger mit Staubkätzchen in den Donauauen bei Krems und ebendaselbst auch von uns in mehreren Fruchtkätzchen tragenden Sträuchern aufgefunden. Sie findet siclı an beiden Standorten mitihren wahrscheinlichen Stammältern $S$. incana 
und S. daphnoides und mit Hifpophaë ihamnoides auf angeschlemmten Sandboden als Bestandtheil der zweiten Waldgeneration der Donauin:eln ( $\left.300^{\prime}\right)$. Bei Krems er:cheint sie nur in Strauchform; bei Rossatz jedoch erhebt sie sich in Baumform zu ə̋ Klaftern Höhe. - Sie stellt ein genaues Mittelglied zwischen ihren beiden wahrscheinlichen Stammältern dar. In der Form der Staubfäden, Fruchtknoten, Griffel und Narben stimmt sie mit S. daplinoides fast vollkommen überein. Die Staubfäden sind aber an der Basis verwachsen und mit zerstreuten Haaren besetzt. Die Fruchtknoten sind gestielt und der Fruchtknotenstiel, welcher der Torusdrüse an I.änge gleicht. behaart. - Die Kätzchen sind kurz gestielt und an der Basis mit zeitlich abfallenden an dem Kätzchenstiele sitzenden Blättchen umgeben, während die sitzenden Kätzchen der S. dap $h_{l}$ noides an der Basis niemals solche Blättchen wahrnehmen lassen. Sie sind zur Zeit der vollen Blüthe bogenförmig abwärts gekrümmt, wodurch insbesondere die volien dicken Staubkätzchen eine sehr eigenthümliche Form bekommen. Die Staubfäden hängen an der Basis etwa 1/2 Millim. weit zusammen und erinnern hierdurch an S. incona. - In der Form, so wie in der Bekleidung der Blätter ist diese Blendlingsart sehr wechselnd. Zur Zeit der Entfaltung tragen die Blätter den Typus der S. incana: sie sind am Rand zurückgerollt, beiderseits in dichten weissen glanzlosen Filz eingehïllt. Zuerst verliert sich diese Bekleidung ron der oberen Blattfläche; der schmutzig-weisse matte Filz hängt dann nur mehr lose an der oberen Seite an, lässt sich leicht mit den Fingern abwischen und alsbald ist die obere dunkelgrüne Blattfläche fast ganz kahl und nur mehr die untere Seite ron weissen Filze bedeckt. Im Alter endlich erscheinen die Blätter meistens vollständig kahl, sind flach, oberseits etwas glänzend und unterseits mit bläulich-weissem Reife überzogen und haben dann grosse Aehnlichkeit mit jenen der S. daphnoides. - In der Nerratur schliesst sich S. Wimmeri mehr an S. incana an. Die Nerren sind an der unteren Fläche gelblich oder rostfarbig und schneiden sich ganz zierlich aus der matten bläulich-weissen Blattseite heraus. Die Fiedernerven erscheinen daselbst etwas kräftiger, treten unter stumpferen Winkeln $\mathrm{ab}$ und sind in grösserer Anzahl rorhanden als an $\mathbf{S}$. daphnoides, so zwar, dass bei $S$. Wimmeri $20-2: 3$ bis zum Rand rerlaufende Fiedernerven erscheinen, während sich bei S. claplinwides deren Zahl auf $12-13$ beschränkt. Die obere Fläche der ausgewachsenen Blätter ist glatt; die Nerven sind dort weder vorspringend wie bei s. daplinoides, noch auch eingesenkt, wie jene der S. incana. - Der hechtblaue Reif der Rinde erscheint insbesonders an den ein- und zweijährigen Zweigen und tritt manchmal erst während des Trocknens aus der Rinde herror.

2\%. S. d(applesoides Vill. Prosp. p. 31. - Amenta praecucia, sessitia densiflora, staminigera recta, orata, maxima inter omnes Salices, fere bis longiora quam latiora, pistilligera cylindrica, quater longiora quam latiora. Squamae oratae, acutiusculae, discolores, in basi ferrugineae, versus apicem atratae, longissime rillosac. Flandula tori oblonga, truncata, flava, basin 
germinis superans. Germen sessile vel brevissime pedicellutum, orato-conicum, acutum, compressum, glabrum. Stylus tenuis, elongatus. Stigmata linearia, crecto-patula post anthesin connirentia. Valrae capsulae post maturitatem extrorsum arcuatae, falcatae. Stamina duo, likera, glabra, antheris flaris. Folia oblongo-lanccolata, plerumque abrupte acuminata, ter et semissi-quinquies longiora quam latiora, serrata, adolescentias nonnunquam sordide vel ferrugineovillosa, adulta semper ulaberrima, supra riridissima et splendentia, subtus Illancescentia et opaca. Stipulae lanceolatae rel semicordatae, dentatae. Ramuli fragiles, juniores nonnunquam hirsuti, adulti glaberrimi, e viridi flavescentes rel rubescentes. Rami juniores rore caesio, abstergendo tecti.

Am. o $30-56 \mathrm{~mm}$ lg. $16-28^{\mathrm{mm}} \mathrm{lt}$. Am. $\% 23-50 \mathrm{~mm} \lg .8-12 \mathrm{~mm} \mathrm{lt}$.

Squam, $3^{\mathrm{mm}} \mathrm{lg}$. Gl. tori $0.5 \mathrm{~mm} \mathrm{lg}$. Germ. $2-3^{\mathrm{mm}} \mathrm{lg}$. Styl. $1^{\mathrm{mm}} \mathrm{lg}$. Stigm. $0.5-1^{\mathrm{mm}} \mathrm{lg}$. Stam. $8-11^{\mathrm{mm}} \mathrm{lg}$.

S. daphnoides Till. Hist. d. pl. d. Dauph. III. p. 76ว. K och Syn. p. 5ä9. Wim m. Flora 18ł9. p. 33. Neilr. Fl. v. N. Oest. p. 20ّง. - S. cinerea Host Salix p. 8. tb. 26. 27.

Variat foliorum forma:

a. Intifotice. Folia ter - quater longiora quam latiora, oblongolanceolata, abrupte acuminata, subtus glauca, adolescentia cum ramulis hirsuta. Stipulae semicordatae.

Fol. $60-110^{\mathrm{mm}} \mathrm{lg} .18-32 \mathrm{~mm}$ lt.

S. cinerea Willd, sec. Link et Koch. - S. daphnoides Wimm. Herb. Salic. Nr. 28.

b. Ingestifotia. Folia quater - quinquies longiora quam latiora, obrerse-lanceolata, supra medium latissima et abrupte in acumen tenue producta, glaberrima, subtus leviter glaucescentia vel virescentia. Stipulae lanceolatae vel lineari-lanceolatae. Ramuli glaberrimi.

Fol. $60-100 \mathrm{~mm}$ lg. $12-20^{\mathrm{mm}} \mathrm{lt}$.

S. praecon Hoppe et Willd. sec. Koch. - S. diphnoides Fries. Nov. Fl. suec, I. I. p. 46. Herb. norm. Fasc. VI. Nr. 5i. W imm. Herb. Salic. Nr. 37.

Erwächst gewühnlich zu einem zwei bis fünf Klafter hohem Baume, der in der Regel nur als solcher und nur ausnahmsweise auch als Strauch zur Bliithe gelangt. Die blühreifen Zweige zeichnen sich schon im Herbste durch die grossen Bliithenknospen aus. In den ersten milden Tagen des Jahres werden die Knospenschuppen abgeworfen und die in dichten weissen Pelz gehüllten grossen Kätzchen werden sichtbar. Die erste von allen Teiden entfaltet dann S. daphnoides die grossen goldigen Staubkätzchen, die den süssesten Honigduft aushauchen und gewöhnlich von Bienen reichlich umschwärmt werden. - Die Blätter haben in der Nervatur einige Aehnlichkeit nit jenen der Chloriteen, so wie mit S. ylabra, an welche wir sie auch hier anknüpfen und zeichnen sich namentlich dadurch aus, dass die zarten, fast haarfeinen Fiedernerven an der oberen und unteren Flattläche gleichmässig rorspringen. Auch dadurch kommen sie mit den Blättern der sulalia überein, dass die obere Fläche sich glänzend und 
fast wie gefirnisst ansieht, während die untere Seite matt und bläulich bereift erscheint. - Die Zweige sind kurz, etwas brïchig und die zwei bis fünfjährigen Aeste sind mit bläulichem abwischbaren Wachsüberzuge bedeckt, der insbesondere nach dem Abdorren oder nach künstlichem Trocknen aus der Rinde herrortritt. Die Fruchtkätzchen sind im Gegensatze zu den abwärts gebogenen Kätzchen der S.incana, gewöhnlich bogenfürmig aufwärts gekrümmt. Die Fruchtknoten sind glänzend grïn, stark zusammengedrückt, fast zweischneidig lanzettlich und sitzen so auf der Spindel, dass ihr längerer Querdurchmesser mit der Achse des Kätzchens parallele Lage hat.

Die behaart-blättrige Form a. scheint das Erzeugniss eines günstigeren Standortes zu sein, da meistens das Ausmass ihrer Blätter grösser ist, als jenes der kahlen Spielart. - Fries hebt zwar herror, dass in Skandinarien nur die letztere Form erscheine und hält die behaarte Spielart auf die Alpen beschränkt, was jedoch unrichtig ist, da diese auch in Norddeutschland neben der kahlen Varietät gefunden wird.

In Europa ist $S$. daphnoides auf den mittleren und westlichen Theil beschränkt, und ihr Areal wird durch eine Linie umgrenzt, welche in Norden ron Norwegen $\left(62^{\circ}\right.$ n. B. Guldbrandsdalen am Glomen) und Schweden (Dalekarlien am Dalelf) in das westliche Russland (Petersburg) zieht, ron da nach Süden umbeugt, sich durch Galizien in die westlichen Karpathen an die Wraag fortsetzt und dann über Pressburg und Wien, durch Steiermark (Leoben, Gratz) als südöstliche Vegetationslinie an die Mündung des Tessin und in das mittägige Frankreich hinzieht.

Ein hieron getrenntes Areal dehnt sich in Asien ron Persien über das Gebiet des Altai und baikalischen Sibiriens aus. - In Ostindien scheint sie aus Europa eingefuhrt. - Innerhalb der Grenzen ihres Vorkommens ist sie in Europa vorzüglich an den Ufern der Flüsse der Gebirgsländer und in der baltischen Niederung zu Hause. Trockenes Klima scheint sie nicht zu ertragen. Bei Pest gepflanzte Exemplare kümmerten einige Zeit und gingen bald vollständig ein. Sie fehlt daher auch den kontinentalen Bezirken und dem Südosten Europas.

In Niederösterreich findet sie sich vereinzelt oder in kleinen Gruppen zwischen anderen Weiden durch das ganze Donauthal so wie entlang den Seitenflüssen dieses Stromes, und steigt in den Thälern der Alpen bis zu 2100', in den Thälern des bühm. - mähr. Gebirges bis zu suo' hinan. (An der Ibbs bis Lakenhot, an der Erlaf bis Scheibbs, am Aggsbach bei Wolfsstein, an der Traisen bis Türnitz, an der Schwarza bei Reichenau, an der Wien bis Nauerbach, am Weitenbach bis Leimbach, an der Krems bis Senftenberg, am Kamp bei Haindorf, an der Schmida bei Wiesendort.) Im oberen Donauthale und an den westlichen Zuflissen der Donau häufiger als ostwärts; insbesonder's an der Traisen bei St. l'ülten und Wilhelmsburg und an der Erlaf bei Wieselburg und Weinzierl, wo sie schion ron IIost als häufig angegeben wird. 
An den alpinen Zuflüssen der Donau findet sie sich strauchartig auch auf Schotterbänken. Auf den Donauinseln hingegen erscheint sie nur sehr selten in Gesellschaft niederer Buschweiden (S. purp. und $S$. amygd.) als Bestandtheil der ersten Waldgeneration auf Schottergrund und siedelt sich dort meistens erst als Bestandtheil der zweiten Waldgeneration an. Sie ist dann als solcher ein gewöhnlicher Begleiter ron S. incana. Sie fehlt bei uns auf ganz kalklosem Substrate ebenso wie auf humusreichem Moorboden und liebt insbesonders etwas sandigen Lehm.

In Tirol und Baiern fällt ihre obere Grenze auf $4000^{\prime}$, in Niederösterreich auf $2100^{\prime}$. Ihre natürliche obere Grenze ist somit in Niederösterreich um fast $2000^{\prime}$ deprimirt, offenbar eine Folge der melır kontinentalen Lage Niedcrösterreichs, welehes Land, wie oben erwähnt, ron der das Areal der Pllanze gegen den kontinentalen Südosten abgrenzenden Vegetationslinie berührt. wird.

In der Nähe der Bauernhäuser in den Alpen wird $S$. daphnoides nicht selten gepflanzt und gedeiht dort kïmmerlich noch in Höhen, die über ilurer ursprünglichen oberen Höhengrenze liegen, wie z. B. auf der Ginselhöhe bei Scheibs (2000^) und bei Annaberg noch in einer Höhe ron 2900. - Da ihre grossen, vor dem Aufblïhen in einen weissen sammtigen Pelz gehüllten schünen Kätzchen unter allen einheimischen Weiden die ersten die Knospen sprengen und besonders in die Augen fallen, so schneidet man in den üsterrcichischen Gebirgsgegenden insbesondere ron dicser Teide am Palmsonntage die Reiser, um sie mit den immergrünen Blättern der Stechpalme, des Epheus, Buchsbaumes, Sinngrüns und Sadebaumes straussförmig zu den sogenannten "Palmbuschen" zu binden. Diese werden, nachdem sie in der Kirche geweiht wurden, unter gewissen Fürmlichkeiten über der Thüre, dem Fenster oder einem Heiligenbilde in der Meinung befestigt, dass dadurch das Haus vor dem Einschlagen des Blitzes gesichert sei. Diese Sitte scheint durch den grössten Theil des deutschen Alpenlandes verbreitet zu sein und hat der $S$. daphnoicles den Namen Palmweide oder Palmreis erworben.

„Im Vatikan bedient man sich

Palmsonntags echter Palmen,

Die Kardinäle beugen sich

Und singen alte Psalmen,

Dieselben Psalmen singt man auch,

Oelzweiglein in den Händen,

Muss im Gebirg zu diesem Brauch

Stechpalmen gar verwenden,

Zuletzt, man will ein grünes Reis,

So ninmt man Weidenzweige. . .

Göthe. 
Sect. X. Nigricantes. - Frutices ramis brevibus, patentibus, non pruinosis. Folia lata, ellyplica, orata rel lanceolata, breviter. acuta, glabra rel pubescentia, supra nitida, sublus opaca el plerumque glauca, dum marcescunt nigricantia. Amenta coaetanea, pedunculata rel subsessilia, recta. Squamae discolores rel concolores. Glandula tori truncata, subquadrata, Rara. Antherae post anthesin flarae. Germen glabrum rel tomentosum, pedicellatum, in stylum elongalum productim. Stigmata patentia, biloba, crassinscula. Valrae capsulae post dehiscentiam circinatae.

8S. S. glubrer. Scop. Fl. carn. II. p. 25̈3̆. - Amenta coaetanea, pedunculata, pedunculo foliato, staminigera densiflora, oblonga, bis terve longiora quam latiora, squamis lineari-lanceolatis, luteis, upice rulescentilus, pilosis, pistilligera cylindrica, laxa, quater - sexies longiora quam latiora, squamis oratis, obtusis, concoloribus e viridi flavis, pilosis. Glandula tori truncata, subquadrata. Germen glabrum, ovato-conicum, in stylum elongatum productum, pedicellatum, pedicello plerumque piloso, allandulam tori vel vix vel duplo superante. Stigmata crassiuscula, patentia, emarginata vel biloba. Yalrae capsulae post maturitatem extrorsur arcuatac, circinatae. Stamina duo, filamentis infic medium villosissimis, antheris ante et post anthesin flaris. Folia ellyptica vel obovata, rarius lanceolata, bis longiora quam latiora, brevissime acuta, serrata, adolescentia et adulta slaberrima, supra laete viridia, splendentia, subtus caesio-glauca, utrinque nervis subelevatis renosa, dum marcescunt nigricantia. Stipulae semireniformes. Ramuli flexibiles juniores et adulti glaberrimi.

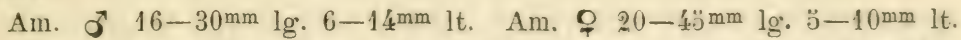
Squam. $1.5-4^{\mathrm{mm}} \lg$. Germ. $2-4^{\mathrm{mm}} \mathrm{lg}$. Styl. et stigm. $4^{\mathrm{mm}} \lg$. Pedic. $0.5-1^{\mathrm{mm}} \mathrm{lg}$. Stam. $5-6^{\mathrm{mm}} \mathrm{lg}$.

Fol. $30-88^{\mathrm{mm}} \mathrm{lg}$. $15-42 \mathrm{~mm}$ lt.

S. Wulfeniana Host Salix p. 29. tb. 95. 96. - s. corruscans H $n$ st th. 9'. fig. 1-3 (excl. fig. 1-6 ad $S$. arbusculam pertinentes). - S. glabra Koch Syn. p. 565. Wimm. Herb. Salic. Nr. 78 et 79. Neilr. Fl. v. N. Oest. p. 20't.

Ein kleiner, höchstens drei Schuh hoher Strauch mit zähen, dicken, kurzen, armblättrigen Zweigen. Die längsten einjährigen Triebe sind 2 Decim. lang und mit 10 Blättern besetzt; in der Regel beträgt aber die Länge eines jährigen Triebes nicht mehr als 2-3 Centim. und die Anzahl seiner Blätter gewöhnlich nur: vier bis sechs. Die meist elliptischen breiten Blätter sind oberseits freudiggrün, starkglänzend, wie lackirt, unterseits seegriü und matt, beiderseits von den im Trocknen etwas stärker rorspringenden zarten, fadenfürmigen Nerren geadert. Die Anzahl der bis zum Rand verlaufenden Fiedernerven schwankt $z$ wischen 10-16. Der Blattstiel ist 
$1 / 5-1 / 6$ so lang als der Längendurchmesser der Blattspreite. Blätter und Zweige sind zu allen Zeiten rollständig kahl, beim Trocknen in feuchter Wärme schwarz und färben feuchtes Papier, auf welches sie zu liegen kommen, mit schwarzen Flecken. Nebenblätter finden sich nur an sehr üppigen Sprossen; sie sind halbnierenförmig, am Rande gesägt und so wie die Blätter zweifarbig.

In subalpinen Thälern sind die Kätzchen fast sitzend und die Blätter des sehr kurzen Kätzchensticles klein, lanzettlich und ganzrandig, in höheren Regionen aber ist die kätzchentragende Achse verlängert und mit 4-5 grossen, den Blättern der anderen Zweige gleichgestalteten, gesägten Blättern bekleidet. Zur Zeit der Fruchtreife sind die Kätzchen ähnlich jenen der S. arbuscula gewöhnlich sehr verlängert und locker, und ihre Spindel erreicht dann nicht selten die Länge ron 8 Centim. Die Schuppen der Staubkïtzchen sind goldgelb und entweder nur an der Spitze scharlachroth angehaucht, oder weit hinab roth überlaufen, jene der Fruchtkätzchen aber immer einfarbig gelbgrün. Zur Zeit des Aufblühens sind die Schuppen von zerstreuten geraden Haaren lang gewimpert, während des Blühens aber fallen die Haare ab und im letzten Stadium der Blüthe erscheinen die Kätzchen gewöhnlich ganz kahl und bieten in dem Wechsel der gelben Antheren und der scharlachroth bemalenen Schuppen eine ganz hïbsche Farbenmischung dar. Die Staubfäden sind bei keiner Weiłe so dicht zottig, wie bei $S$. glabra. Die Behaarung beginnt unterhalb der Mitte und setzt sich manchmal auch auf die Kätzchenspindel fort. Auch die Fruchtknotenstiele sind gewöhnlich mit zerstreuten Haaren besetzt, sonst aber erscheint die ganze Weide rollkommen kahl und rerdient mit rollem Recht den ihr ron Scopoli gegebenen Namen.

Yon der ähnlichen S. nigricans, mit der sie ron Bertoloni (Fl. ital. X. p. 312) ohne weiteres vereinigt wurde, unterscheidet sie sich durch die Kahlheit der jungen, krautigen $Z$ weige, die geringere Anzahl der Blätter an den jährigen Trieben, die grüssere Anzahl der näherstehenden Fiedernerven, durch das auf der oberen stärker glänzenden Blattläche etwas rorspringende Adernetz, die schmächtigeren Kätzchen, die goldgelben, (nicht grünlichen) an der Spitze scharlachrothen (nicht purpurnen) Schuppen der Staubkätzchen, die einfärbig gelbgrünen (nicht zweifärbigen) Schuppen der Fruchtkätzchen, endlich durch die dickeren, zottigen Staubfäden und die kürzer gestielten Fruchtknoten. - Die älnliche S. hastata zu der die S. glalra früher von Koch (Comm. de sal. europ. p. 43) als Varietät gezogen wurde, besitzt glanzlose, im Verwelken braun werdende Blätter, lang-zottige Kätzchenschuppen und kürzeren Griffel, und S. ailuscula unterscheidet sich ron $S$. glabra durch die nicht schwarz werdenden Blätter, purpurn bemalene Kätzchenschuppen, behaarte Fruchtknoten, fädliche Narben, kahle Staubfäden und sichelförmig auswïits gekrümmte (nicht schneckenförmig zurückgerollte) Kapselklappen. Manchual findet sich $S$. glabra mit S. nigricans an derselben Lokalität 
(z. B. Mausrodel bei Lunz) und zeichnet sich dann durch etwas spätere Blüthezeit aus.

Sie ist auf die östlichen Alpen beschränkt, $\left.{ }^{*}\right)$ und findet sich auch in diesen nur auf dem Kalkboden der nördlichen und südlichen Kette. Eine Linie, welche ron den Quellen der Iller an den Gardasee zieht, bezeichnet die westliche Grenze ihres Areals. Tom Gardasee angefangen, ist sie aber ebenso, wie ron den Allgäuer-Alpen an in östlicher Richtung eine häufige Treide und findet sich im nördlichen Kalkalpenzuge in den tyrolischen, salzburgischen, obersteirischen und oberösterreichischen Alpen bis in die Alpen Niederösterreichs zum Schneeberge verbreitet.

Sie verbindet sich in unsern Alpen mit Rhododendron hirsutum und Chamaecistus, Erica carnea und Salix grandifolia zu einer sehr charakteristischen Strauchfoımation, welche in tieferen Regionen die schattigen feuchten Felsterrassen überkleidet und sich in den höheren Lagen an die Hecken der Krummföhren anlehnt. Nienals fand ich sie iiber die nüraliche Vegetationslinie des Rhododendion hirsutum hinausgehend. Die nördlichsten Punkte ihres Vorkommens in Niederösterreich sind: Felsen am Gruebberg bei Gaming, Lakenhof am Fusse des Oetschers, Lassingfall bei Josefsberg. und Felsen an der Schwarza nördlich ron Schwarzau, gegenüber der Falkenwand. Südlich von der durch diese Stanlorte bezeichneten Linie findet sie sich auf allen Kalkalpen von der Esslingeralpe an über das Hochkar, den Dürenstein, Oetscher, Güller, die Raxalpe bis zum Schneeberge und in den Thälern bei Göstling, Lunz, Neubaus und St. 1egyd. Ihre untere Grenze fällt in Baiern auf $4300^{\prime}$, in nördlıchen Tyrol auf $3000^{\prime}$, in Oberösterreich auf $1800^{\circ}$, in Niederösterreich auf $1900^{\prime}$. Ihre obere Grenze fällt in Baiern auf $6100^{\prime}$ in Tyrol auf $0000^{\prime}$. In Niederösterreich findet sich $S$. glabra bis an die höchsten Kuppen des Hochkars zu $39222^{\prime}$ verbreitet; noch höher jedoch rückt ihre Grenze auf der benachbarten obersteirischen Hochschwabgruppe, wo ich in den Hirschgruben ober der Hochalm ihre obere Grenze mit 6302 ' bestimmte.

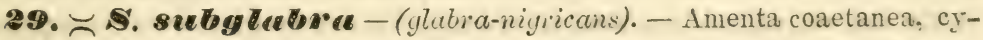
lindrica, laxa, ter - quater longiora quam latiora, pedunculata, pedunculo foliato. Squamae obovatae, obtusae, concolores, e viridi flavae, sparsim pilosae. Glandula tori truncata, subquadrata. Germen ovato-conicum, glabrum, in stylum elongatum productum, pedicellatum, pedicello glendulam tori duplo superante. Stigmata patula, biloba, crassiuscula. Folia subrotunda rel ellyptica et bis longiora quam latiora, serrata, adolescentia in neris sultus pubescentia, achulta gla'serrima, supra nitida, subtus glauca, dum marcescunt nigricantia. Stipulae semicordatae. Rumuli juniores pubescentes adulti gliabri, cortice flavescenti tecti.

*) Der vercinzelte Standort auf Kola im arkt. Russland (Fell m. Iml. Kild Mr, 21) berulit liëchst wahrscheinlich auf einer Verwechslung. 
Am. ㅇ 20-36 $\mathrm{mm}$ lg. 6-8mm lt. Squam. $2 \mathrm{~mm}$ lg. Germ. 2-4mm $1 \mathrm{~g}$. Styl. et stigm. $1^{\mathrm{mm}} \mathrm{lg}$. Pedic. $1^{\mathrm{mm}} \mathrm{lg}$.

Ein kurz- und dickstämmiger, 1-2 Schul hoher Strauch rom Ansehen der $S$. glatra, der auch in den Blüthen fast ganz mit dieser Weide übereinkommt, sich aber durch kürzere Kätzchen so wie durch behaarte junge Zweige und Blätter an die S. nijricans anschliesst. Die Blätter sind oberseits auch weniger glänzend als jene der $S$. glabra und an den jungen Blättern ist das Netz der Nerrenanastomosen wie bei $S$. nigricans etwas eingesenkt. An den ausgewachsenen Blättern ist die Fläche glatt oder ron den etwas erhabenen Fiedernerven durchzogen. - Durch die grössere Zahl der Fiedernervenpaare (g'ewöhnlich 10) so wie durch die geringe Anzahl der Blätter ("̈-6) der einjährigen Triebe und die gelbliche, etwas häutige Rinde der Aeste nähert sich jedoch $S$. subylatira wieder mehr der S. glabia.

Auf Kalkfelsen an Lassingfalle bei Josefsberg und in der Mausrodel bei Lunz (2200'). An beiden Standorten in Gesellschaft der zwei nahe verwandten wahrscheinlichen Stammältern. - Im Tiener bot. Hofkabinete befinden sich ron $Z$ ois gesammelte Exemplare unter den Namen S. phylicifolia aus Krain, welche mit dem oben beschriebenen Bastart rollkonmen übereinstimmen.

30. S. vergyeicesos Smith in Transact. of the Linn. soc. VI, p. 120. - Amenta praecocia brevissime pedunculata, rel coaetanea et longe pedunculata, pedunculo foliato, staminigera densiflora, oblongo-orata, semel-bis longiora quam latiora, pistilligera orata vel cylindrica, laxa, bis longiora quam latiora. Squamae lanceolatae in basi vivides, ver'sus apicem fuscae vel purpureo-nigicictintes, plus minusre pilosae. Glandula tori truncata, subquadrata. Germen glabrum, ovato-conicum, in stylum elongatum productum, pedicellatum, pedicello glandulam tori lis terve superante. Stigmata crassiuscula, patentia, emarginata rel biloba. Valrae capsulae post dehiscentiam circinatae. Stamina duo, filamentis infra medium pilosis vel glaberrimis, antheris flavis. Folia lanceolata, vel ovata rel obovata rel ellyptica rel rotunda, semel-ter longiora quam latiora, serrata vel margine undulato-crispa, adolescentia plus minusve pubescentia et supra venis depressis subrugosa, adulta glabrata rel rillosa, supra viridia, sutnitida, laevigata, subtus vel pallide viridia vel glauca et apice solummodo virescentia vel tota facie glauca, nervis elevatis reticulcato-venosa, dum marcescunt, nigricantia. Foliola amentis subjecta rel foliorum forma et margine serrata, vel squamaeformia et inteĝra. Stipulae semicordatae, serratae. Ramuli flexibiles, juniores pubescentes, adulti glabrati.

Am. o $10-2.3^{\mathrm{mm}} \mathrm{lg} .8-16^{\mathrm{mm}} \mathrm{lt}$. Am. $ᄋ 10-30 \mathrm{~mm} \mathrm{lg} .6-13^{\mathrm{nmm}} \mathrm{lt}$.

Squam. 1.j̈-3mm lg. Gl. tori $0.5 \mathrm{~mm} \mathrm{lg}$. Germ. $2-4 \mathrm{~mm} \mathrm{lg}$. Styl et stigm. $1-2 \mathrm{~mm} \mathrm{lg}$. Pedic. $1-1.5 \mathrm{~mm} \mathrm{lg}$. Stam. $6-8 \mathrm{~mm} \mathrm{lg}$.

Folia $24-90 \mathrm{~mm}$ lg. $12-33 \mathrm{~mm}$ lt.

S. phylicijolia L. suec. Mr. 880 (sec. Wahlen b.) Koch comm. de sal. europ. p. 40. - S. nigricans Fries Nov. Fl. suec. \$. I. p. ว22. Koch Syn. p. 363. Neilr. Fl. v. N. Oest. p. 263. - Salix 
migricans est nirum in moulum rariabilis salix, fujus formae multis nominibus descriptae sunt. In Austria inf. occurrit semper germinibus et pedicellis glabris, in confnibus locis Styriae superioris autem ad ripas fluvii Mürz prope Kapellen formas cum pedicellis villosis et germinibus hirtis inveni ad var. $\beta$. eviocarpam Ko ch Syn. p. 563 (S. nigricans a. capsulis villosis $\mathrm{F}$ ries. Nov. M. I. p. 52, Herb. norm. Fasc. VIll. S. nigricans W imm. Flora 18 p. 37. S. nigr, b. vestita Gr. et. Godr. Fl. d. Fr. p. 138) pertinentes.

Formas Salicis nigricantis in monografia salicum Austriacarum ab Hostio (Salix tb. 74-S6) descriptas ad S. nigricantem ce. leiocarpam Neilr. Fl. v. N. Oest. p. 263. (S. phylicifolia WV a hl. Fl. carp. p. 318. - S. nigricans b. capsulis glabris Fries Nov. M. I. p. 52. Herb. norm. Fasc. V. - S. nigricans Wimm. Herb. Salic. Nr. 2't. - S. nigr. a. muda Gr. et. Godr. Fl. d. Fr. p. 138) pertinent et praecipue foliorum forma ab Hostio distinctae sunt.

Variat autem foliorum forma:

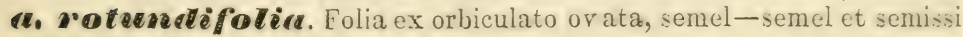
longiora quam latiora, basi subcordata, crenato-serrata adolescentia supra et subtus pubescentia, adulta supra glabra, subtus in nerris pubescentia, glauca vel virescentia.

S. aurita Host Salix 1. 2'k tb. 78 . Formam cum descriptione et i.one IIosti i convenienton in monte Preiner Gschaid inveni.

b. meatherefolied. Folia subrotunda rel ellyptica, semel et semissi-bis longiora quam latiora, recur rato-apiculata, basi rotundata rel subcordata, margine undulata vel crispa, serrata, supra rugosa, puberula, subtus glauca, cano-hirsuta, ab apice ad basin glabrescentia et virescentia, adulta deinde saepe supra et subtus glabra et viridia.

S. menthaefolia Host. Salix p. 2'k tb. 79. S0. Forman acuratissime cum diagrosi et ieone Hostii convenientem ad fontem ad Neubruck prope Scheibbs legi.

C. Concolon. Folia ellyptica et ovata, sem el et semissi-bis longiora quam latiora, basi subcordata rel rotundata, margine plana, dentato-serrata, juniora utrinque pubescentia, adulta supra glabra, subtus in nerris pilosa, pallidiora, attamen viridia.

S. rivalis Host Salix p. 23 tb. 81. 82. Prope Josefiserg ad fontes fluvii Erlat hane forman ab Hiostio descriptam inveni.

d. ylucecescens. Folia orata, semel et semissi - bis longiora quam latiora, breviter acuminata, basi rotundata, margine plana, crenulatoserrata, juniora pubescentia, adulta supra glaberrima, subtus glabra rel in nervis pilosa, glauca, versus apicem saepe virescentia.

S. glaucescens Ho st Sal. p. 23 th. 76 . $\pi$. (foliis adultis subtus glaberrimis.) - - . urata Hiost Sal. p. 23. tb. 74. 75. (foliis adultis subtus in nerris pilosis.) - S. niyricans $\mathrm{K} \circ \mathrm{v}$. Fl. exs. Vind. Nr. 1060. 1061. Wimm. Herb. Sal. Fasc. IV. Nr. 42. - Fratices ô ad Bockbrunn prope Kaltenleutgeben crescentes cum $S$. glaucescenti Hos t conveniunt, frutices autem in pratis turfosis prope Moosbrunn, partim ad S. ovatam Hustii, partim ad proximam formam accedunt.

e. purieturicefolice. Folia ovato- vel oborato-lanceolata, versus basin et apicem attenuata et breviter acuminata, bis - bis et semissi longiora quan latiora, crenato-serrata, juniora utrinque pubescentia, adulta supra glabra, subtus pubescentia, glauca, apicem versus virescentia.

S. parictariaefolia HI ost Sal. p. 26. tb. S̈̈. 86. (foliis adultis subus vilosis.) - S. prarijuiin Hl o st Sal. p. 25. tb. 83. 8́. (foliis adultis subtus glabrescentibus.) - Ad ripam đluvii Oiss prope Güssing et ad Annaberg ad fontes duvii Erlaf iumas hiwe yertineates reperi. 
Ein rom Boden aus vielästiger Strauch mit aufrechten oder sparrig abstehenden, braunrindigen Zweigen, der durch sein dunkles Laubwerk ein dïsteres Aussehen bekommt. Gewöhnlich erreicht er Manneshöhe, seltener erhebt er sich bis zu zwei Klaftern. Er mahnt in seiner Erscheinung lebhaft an die Sahlweiden und schliesst sich auch in der Nerratur der Blätter an dieselben an. Aehnlich wie bei S. Caprea sind die bis zum Rand verlaufenden Fiedernerren rerhältnissmässig weit entfernt und etwas hin- und hergebogen. Ihre Anastomosen treten an der unteren Blattflïche noch deutlich hervor und bilden dadurch auf dieser Seite ein rorspringendes Adernetz. An der oberen Seite der jungen sieh entfaltenden Blätter sind dieselben etwas eingesenkt, und hierin ist ganz rorzïglich ein Merkmal gegeben, wodurch sich das Blatt der S. nigricans ron dem im Zuschnitte sehr ähnlichen Blatte der $S$. arbuscula und $S$. vlabra unterscheidet, indem bei diesen, ganz so wie bei den Chloriteen und der S. purpurea das zarte Nervennetz der Anastomosen an der oberen Seite der jungen sich entfaltenden Blätter niemals eingesenkt, sondern im getrockneten Zustande sogar etwas erhaben ist. - Die Anzahl der Fiedernerrenpaare ist bei S. nigiricans eine rergleichsweise geringe und schwankt zwischen 6 und 12 , während an S. arbuscultu und S. glalra die Anzahl derselben zwischen 10 und 16 wechselt. - Die Bekleidung der Blätter ist ganz die der Sahlweiden. Die von den Nerren zuletzt schwindenden Haare sind kurz und abstehend und fühlen sich, wenn sie das Blatt dicht bekleiden, sammtig an. Die jungen noch krautigen Triebe ebenso wie die Knospendecken sind immer kurz flaumig, während jene der S. arbuscula und S. glabi a immer vollständig kahl erscheinen. - Die obere Blattfläche ist dunkel, fast schwärzlichgrün, wenig glänzend; die untere, gewöhnlich ron der Basis an gegen die Spitze bläulich bereift, an der Spitze aber blassgrün, so dass das Blatt aussieht, als wäre der blaue Reif von der Spitze weggewischt worden. Manchmal schwindet aber dieser Ueberzug bis zur Basis oder fehlt auch schon ron Jugend an ganz, und die Blätter erscheinen dann an der unteren Fläche glanzlos grasgrün. - Die Blätter werden so wie jene der S. glabra und $S$. subglabra im Verwelken schwarz und färben feuchtes Papier nach längerem Liegen mit schwarzen Flecken, während die Blätter der S. arbuscula und S. hastata im Verwelken rostfarbig werden.

Die Kätzchen sind kurz, bei den in der. Ebene oder in tieferen Höhenlagen des Berglandes rorkommenden Sträuchern manchmal sitzend, bei den subalpinen Exemplaren dagegen immer gestielt und der Stiel beblättert. Die Kätzchenspindel ist dicht wollig. Die Schuppen sind grïnlich, gegen die Spitze zu purpurn oder rostfarbig. Die Staubfäden sind im Vergleich mit jenen der $S$. glabra dünner und zarter, riel weniger zottig und gewöhnlich nur gegen die Basis ron zerstreuten Haaren bewimpert. Die Fruchtknoten sind schmal, zur Zeit der Blüthe an der oberen Hälfte kaum dicker als der Griffel; die Narben wachsartig glänzend, dicklich, zweispaltig, jenen der S. pentandra 
und S. fragilis sehr ähnlich. Die Klappen der aufgesprungenen Kapsel sind gleich jenen der Sahlweiden schneckenförmig zurïckgerollt.

Die S. nigricans ist eine der verbreitetsten Weiden, welche in Europa ron Calabrien hinauf bis Kola und ron der baltischen Ebene bis an den Ural hin rorkommt. In den südlichen Gegenden ist sie auf die Gebirgsthäler besthränkt, in mittleren und nördlichen Gebiete aber steigt sie bis in die Niederung'en herab. - Dabei fehlt sie auf weite Strecken, um dann oft plötzlich an einem vereinzelten Standorte wieder aufzutauchen, ohne dass sich immer für diesen Wechsel des Vorkommens und Fehlens eine Ursache in den Verhältnissen des Bodeus und Klimas ermitteln liesse. - Ein von dem europäischen getrenntes Areal besitzt diese Weide im östlichen Asien in Kamtschatka und im baikalischen Sibirien. - Sie fehlt in Amerika.

In Niederösterreich findet sie sich gruppenweise an den Ufern fast aller Alpenbäche, namentlich dort, wo S. frayilis und alla nicht mehr vorkommen; ferner auf Bergwiesen in der Umgebung der im Wiesenlande entspringenden Quellen; auch auf den Hochmooren der Alpen (Mitterbach) und den Wiesenmooren der Niederung (Moosbrunn). Sie nimmt ron West nach Ost in Niederösterreich an Häufigkeit ab und ist am häufigsten im Flussgebiete der Ibbs. - In Baiern findet sie sich entlang den alpinen Zuflüssen bis in die Auen der Donau hinab, - in Niederösterreich bleibt sie hingegen weit von den Mündungen der Alpenflüsse zurück und die nördlichsten Standpunkte, welche mit einander verbunden eine der Alpenkette parallele Linie ergeben, sind: Waidhofen an der rbbs, Gresden, Scheibb:, Hohenberg, Kaltenleutgeben, Moosbrunn. Die beiden letzteren Standorte Moosbrunn (600') und Bockwiese bei Kaltenleutgeben $\left(\tilde{}\left(00^{\prime}\right)\right.$ bezeichnen zugleich die untere Grenze. Am häufigsten ist sie in dem Höhengürtel von 1800 bis 2800'; ihre obere Grenze erreicht sie in Niederösterreich bei $3800^{\prime}$. - In Baiern wird ihre obere Grenze auf $4200^{\prime}$ angegeben. Am Dachsteingebirge in Oberösterreich fand ich sie noch bei $3000^{\prime}$ unter Krummföhren und in Tirol findet sie sich noch bei $5300^{\prime}$.

Sie erscheint in Niederösterreich insbesonders auf kalkhältigem Thonboden. Insbesonders sagen ihr die Gesteine der Gresdner Schiefer zu. - Im österreichischen Antheil des böhmisch-mährischen Gebirges fehlt S. niwiricans.

An die Schwarzweiden schliesst sich der in Niederösterreich nicht vertretene Typus der S. hastata an, welcher im Zuschnitt und in der Nerratur der Blätter, so wie in der Form der Stempel, der Griffel und der Torusdrüse mit S. glabra und S. nigricans übereinkommt, aber durch die im Verwelken braun werdenden Blätter, die sehr kurzen eiförmigen Xarben und die kahlen Staubfäden sich ron ihnen unterscheidet und auf folgende Weise charakterisirt werden mag:

Sect. Hastatae. - Frutices ramis brevibus patentibus non pruinosis. Folia lata, ellyptica rel lanceolata, breviter acula, glabra, 
utringue opace riridia, dum marcescunt rufescentia, supra lacrigata, subtus nerris subeleratis venosa. Amenta coaetanea. Squamae discolores vel concolores. Glandula tori truncata subquadrata, Rara. Antherae post anthesin flarae. Germen pedicellatum, glabrum. Stylus elongatus. Stigmata brevia, oruta, ereco-patula. Valrae capsulae post dehiscentiam extrorsum ariuatae, falcatae.

Durch die Form der Narben schliessen sich die Arten der Sect. Hastatae unmittelbar an die Arten der nächstfolgenden Rotte an, unterscheiden sich aber ron ihnen durch die oberseits glatten Blätter und den längeren Griffel. Die $S$. hastata-silesiaca W i m m. bildet übrigens ein Mittelglied, durch welches die Kette mit $S$. silesiaca und durch diese mit den anderen Arten der Rotte Rugosae geschlossen wird.

Divisio III. Mrierostylae. - Squamae amentorum discolores. Torus uniglandulosus. Stylus brevissimus vel nullus. Folia dum marcescunt rufescentia.

S e ct. XI. Rugosae Rch b. - Arbores vel frutices ramis tenacibus, brevibus, patentibus. Folia ellyptica vel obovata vel obovatolanceolata, breviter acuta, supra venulis anastomoticis impressis rugosa, subtus nervis eleratis reticulata, opace tomentosa vel glabrescentia, dum marcescunt rufescentia. Amenta ovata rel breviter cylindrica, praecocia et sessilia vel coaetanea et pedunculata. Squamae discolores. Glandula tori breris, truncata. Filamenta libera. Antherae post anthesin sordide flavae. Germen ex orata basi conicum, longe pedicellatum, pedicello glandulam tori ter- sexies superante. Stylus brevissimus vel nullus. Stigmata brevia, oblonga rel ovata, patentia vel conniventia, flava. Valvae capsulae post dehiscentiam circinatae.

31. S. granatifolia Seringe Saul. de la Suisse p. 20. Amenta coaetanea, breviter pedunculata, pedunculo foliolis squamaeformibus mox caducis cluobus vel tribus vestito, staminigera ovata, semel-semel et semissi, pistilligera cylindrica, bis longiora quam latiora. Squamae lanceolatae, acutae, pilosae, in basi pallidae, supra medium ferrugineae vel atratae. Glandula tori brevis, truncata. G"rmen ex ovata hasi conicum, cano-tomentosum, longe pedicellatum, pedicello glandulam tori quater-sexies superante. Stylus brevissimus. 
Stigmata breria, patula, biloba, lobis divergentiluse. Capsula rircscens, in pedicello elonyato oblique affixa. Valvae capsulae post dehiscentiam circinatac, Stamina duo, antheris rotundis, post anthesin sordide flaris, filamentis liberis. in basi pilosis vel glabris. Folia oblongo-oborata, bes-quater lonyiora quam latiora, undulato-serrata, adolescentia sericea, flarescentia, adulta s"ino alaberrima, obscure viridia et subnitentia, subtus cinereo-glanca, in neivis hivto-pubescentia. Nerri secundarii ad marginem decurrentes utroque latere $10-18$, flexuosi, in pagina inferiori flari, prominentes et cum venis anastomoticis prominentibus reticulum elegans constituentes. Venulae anastomoticae in pagina superiori lineis impressis significatae, quare folium rugulosum. Stipulae semicordatas vel semiscigittatae, acutae rel acuminatae. Ramuli torulosi, annotini pubescentes, biennes glabrati. Gemmae per hiemen glabrescentes.

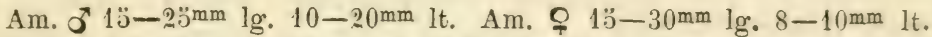
Squam. 1.5-2mm lg. Germ. 2-2.0 $\mathrm{mm}$ lg. Pedicell. 1.3-2mm lg. Stam. $7-8^{\mathrm{mm}} \lg$.

Variat foliorum forma:

c. Ietifolie. - Folia oblongo-obovata, breviter acuta rel recurratoa piculata, bis-ter longiora quam latiora.

Fol. $30-100 \mathrm{~mm}$ lg. $18-35 \mathrm{~mm}$ lt.

b. angeestifolies. - Folia oborato-lanceolata, acuminata, elongata, quater longiora quam latiora.

Fol. $40-130 \mathrm{~mm}$ lg. $15-32 \mathrm{~mm}$ lt.

S. grandifolia K o ch Syn. p. 56'. Neilr. Nachtr. z. 11. v. Wien p. 119. Fl. v. N. Oest. p. 262. K ov. Fl. exsicc. Vindob. Nr. 1062 u. 1063. W imm. im Jahresb. d. scliles. Ges. 185̆2 p. 66. Herb. Salic. Fasc. VII. Nr. 33 u. S4. - S. monandra Host Salix p. 22 th. 72. (Die weibliche Pflanze stimmt sowohl in der Beschreibung, so wie in der Abbildung rollkommen mit unserer $S$. grandifolia überein, und ist unzweifelhaft hieher zu ziehen. Auch die Abbildung des Blattexemplares, welches neben der männlichen Pflanze ( $\mathrm{tb}$. 71) steht, so wie die kleinen Staubkätzchen des blühenden Zweiges (Fig. 2) weisen auf $S$. grandifolia hin. Host beschreibt jedoch die Blithen dieser Kätzchen mit: „Filamentum unicum, anthera unica terminatum* und bildet auch dieser Bezchreibung entsprechend nur ein Staubgefiss ab, ein Vorkommen, welches nur dadurch erkliirt trerden kann, dass das zweite Staubgefäss jener Blithe, welche $\mathrm{H} \cap \mathrm{st}$ bei sciner Beschrcibung vorlag, zufällig verkümmert oder entfernt war, denn da $\mathrm{Hos} t$ bei s.monandsa ansdrücklich von einer Anthere spricht, hingegen seinen Formen der $S$. purpurea: ,antherae du a e, apice unico filamento affixae vindizirt, so konnte er hier keinen jener Fäle meinen, wo wie in der Gruppe der Purpurweiden, die zwei Staubgefïsse der ganzen Länge nach verwachsen sind. Eine Weide aber mit einem einzigen Staubgefass, respective einer einzigen Anthere in der Blüthe, ist ausser von IIost, von keinem einzigen Botaniker jemals erwähnt worden und es würde eine solche Weide die Charakteristik der Ord. Salicineae umstossen. - Da II ost auch keine andere Weide beschreibt, welche auf S. grandifolia bezogen werden künnte, die er doch bei ihrer Häufigkeit gewiss nicht übersehen da ferner der von ihm angegebene Standort „In Austria, Styria in subalpinis, alpium declivibus et convallibus* rollkommen auf jenen der $S$. grandifolia passt, so dürfte es weiter gar keinem Zweifel unterliegen, dass S. monandra Host zu S. grandifolia Ser. als synonym zu ziehen ist.) 
Auf den felsigen Kuppen der Alpen und an den Felswänden der subalpinen Thäler erscheint S. giandifolia als ein sparriger Busch mit knorrigen, kurzen, armknospigen Zweigen, der sich oft kaum zu zwei Fuss ïber den Boden erhebt. Unter Krummholz und an den Waldrändern erwächst sie zu cinem buschigen drei bis fünf Schuh hohen rielrerzweigten Strauch und an den Felsterassen der Flussufern wird sie selbst bis über eine Klafter hoch. - Der Stammumfang bleibt aber immer ein geringer und die dicksten Stïmme zeigen nur einen Durchmesser ron 3 Zoll. - Die krautigen Triebe sind ebenso wie die verholzten jüngsten Zweige flaumig-filzig. Erst nach dem Abfallen der Kätzchen rerschwindet ron den einjährigen Zweigen der schmutzig-graue Flaum, welcher bis dahin ihre Rinde bedeckt hatte. Die durch stark vorspringende Narben knorrigen Aestchen erscheinen dann kahl und ihre Rinde gelblich oder grünlich gefürbt. Die Knospendecken bleiben gewöhnlich bis zum Durchbruche des Kätzchens oder der Blätter etwas flaumig, seltener werden sie schon im Laufe des Winters ganz kahl. Die Blätter sind anfänglich, nachdem sie die Knospen gesprengt haben, unendlich zart und weich, gelblich und durchsichtig und welken alsogleich, nachdem man den Zweig, dem sie entknospet sind, abschneidet. Im Alter werden sie jedoch etwas lederig starr und sind an der Unterseite von gelblichen, rorspringenden, rigiden und scharf markirten Nerven durchzogen, die sich zu einem äusserst zierlichen feinmaschigen Netze verbinden. Die Kätzchen brechen auf den Alpen ebenso wie in den Thälern fast gleichzeitig mit den Blättern herror und auch an den in der Ebene kultirirten Exemplaren erhielt sich diese Gleichzeitigkeit der Blüthen und Blattentwicklung. - In Folge der dünnen Behaarung der Schuppen sind die Kätzchen bei ihrem Hervorbrechen in keinen weissen Pelz, wie jene der S. Caprea und S. cinerea, eingehïllt und unterscheiden sich daher in diesem Stadium von jenen der S. Caprea und $S$. cinerea schon auf den ersten Anblick. Die kurzen Kätzchenstiele sind nur mit 1-3 meist schuppenartigen Blättern bekleidet die schon vor dem gänzlichen Verblühen des Kätzchens gelb werden und abfallen. Die Staulkätzchen sind fast um die Hälfte kleiner und die Fruchtkätzchen zur Zeit der vollen Blüthe riel schmäler und zarter als jene der S. Capreca und S. cinerea; überhaupt zeigen alle Blïthentheile: Kätzchenschuppen, Staubgefässe und Fruchtknoten ein riel kleineres absolutes Ausmass als die beiden eben genannten nahe verwandten Weidenarten von denen S. grandifolia überdiess durch den deutlicheren Griffel, abstehende Narbenlappen, fast kahle Blätter, spitze oder zugespitzte, halbherz-oder halbpfeilförmige Nebenblätter, feinmaschigeres Adernetz, grössere Anzahl der Fiedernervenpaare und die schon erwähnte geringe Zahl der Kätzchenstielblätter sich unterscheidet. - Nach dem Verblühen erscheint der Fruchtknoten an dem Stiele unter stumpfem Winkel aufsitzend, eine Erscheinung, die wohl auch bei anderen Sahlweiden vorkommt, aber bei der auffallenden Verlängerung der Fruchtknotenstiele an S. aranclifolia am meisten augenfällig ist und als sehr 
constantes Merkmal angeführt werden kann. Zur Zeit der Fruchtreife erscheint die Kätzchenspindel bis zu 6 Centim., der Kapselstiel bis zu $3^{\mathrm{mm}}$ rerlängert. Die reife Kapsel erreicht kurz vor dem Auf pringen 6-8mm Länge. Die Antheren sind rund, nach dem Terstäuben schmutzig gelb und wenn Regenwetter in die Blüthezeit fällt auch schwärzlich, niemals aber so schwarz wie diess z. B. bei S. Mursinites und purpurca der Fall ist.

Das Areal der auf das südliche und mittlere Europa beschränkten S. grandifolia wird durch eine Linie begrenzt, die im grossen Bogen das alpine Gebiet im Norden umrandet.*) Aus den Pyrenäen zieht dieselbe anfänglich als nordwestliche Vegetationslinie entlang der Kette des Jura nach Oberbaden auf den Feldberg, und dann als nürdliche Tegetationslinie durch Südbaiern über München nach Gmunden und nach Lilienfeld in das Thal der Traisen. Dort beugt sie nach Südosten um und zieht entlang dem Ostende der Alpen als nordüstliche Vegetationslinie in die serbischen Gebirge. - Südlich von dieser Linie ist S. grandifolic av? Kalkboden der Alpen und an den Ufern der Alpenbäche eine der häufigsten Weiden und durch alle österreichischen Alpenländer, dann in der Schweiz, in den Alpen der Dauphiné und Saroyens und in den Apenninen verbreitet.

Thre obere Grenze wird in Baiern auf $3 \$ 8 \%{ }^{\prime}$ angegeben. In Niederösterreich wurden die obersten Sträucher am IJochkar bei $3680^{\prime}$ gefunden.

In der Region des Krummholzes ist sie in Nicderösterreich auf Kalkboden ganz allgemein verbreitet und findet sich namentlich an nördlich exponirten ferchten Abstürzen, an Quellrimnsalen und Bächen. In der tieferen Region wird sie eine wahre Lferweide, die mit S. purpurea, nigricans. incana und Alnus incana die felsigen Uferterassen bis zum Austritt der Flüsse in die präalpinen Ebonen bewohnt. - Verbindet man die nördlichsten Standpunkte, so erhält man eine dem Hauptkamm der Alpen genau parallel ron West nach Ost zichende Linie: Hilm nördlich ron Waidhofen an der Ibbs 800', zwischen Purgstall und Scheibbs an der Erlaf 900', am Tege zum Wasserfall bei Lilienfeld im Traisenthal 1090', hinter Klcin-Zell im Hallbachthal $1100^{\prime}$, an der Piesting bei Gutenstein 1400'.

Eine in den östlichen Alpen bei rielen Pflanzen wahrnehmbare Erscheinung, dass nämlich die untere Grenze geg’en Osten immer höher und höher rïckt, während die obere Grenze gleichzeitig tiefer herabsinkt, so dass also der IIöhengürtel der Pflanze gegen Osten zu ein schmälerer wird, ist, wie aus obigen Höhenangaben herrorgeht, auch bei $s$. Irandifolia in ausgezeichneter Weise wahrnehmbar.

S. silesiaca, welche ron Britannien und Skandinarien durch das sudetische und karpathische Gebirgssystem bis in den Kaukasus rerbreitet

2) Die in Schweden ron Fries als $s$. grandifolia angrzebene Wide. ist nach den Eremplaren des Herb. norm. ein muthmasslicher Bastart aus S. Citprea und silesiaca. Die in We in m. Fl. petrof.

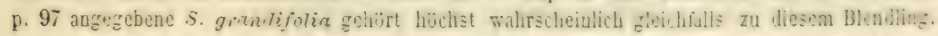


ist, halten wir für die klimatische Parallelform der S. grandifolia. Sie bewohnt innerhalb des angedeuteten Areals analoge Standorte wie die S. grandifolia in dem ihrigen, und findet in den Sudeten bei $4000^{\prime}$, in den Karpathen bei $3370^{\circ}$ ihre obere Grenze. - Sie wird in den Thälern der Karpathen Uferweide und steigt bis $1800^{\circ}$ herab. - Der erste Eindruck, den S. silesiaca auf den Beschauer macht, ist ganz jener der S. grandifolia. Sie kommt auch in dem zarten Bau der Blüthentheile, in der Form des Griffels und der Tarben, in der geringen Anzahl der Kätzchenstielblättchen, in dem Nervennetze und der Bekleidung ganz mit S. grandifolia überein und unterscheidet sich nur durch elliptische oder eiförmige (nicht verkehrt-eiförmige) oberseits fast glatte Blätter, welche, wenn sie eben aus den Knospen sich entfaltet haben, meist blutroth gefärbt erscheinen. In der Regel sind auch die Fruchtknoten der S. silesiaca kahl, was bei S. grandifolia nie der Fall ist.

32. $\asymp$ S. nttementa (supergrandifolio-Caprea). - Amenta coaetanea, breviter pedunculata, in pedunculo foliolis mox caducis $2-3$ restita, pistilligera orato-cylindrica, semel et semissi longiora quan latiora. Squamae lanceolatae, acutae, in basi flarescentes, versus apicem atratae, pilosae. Glandula tori breris, truncata. Germen ex orata basi conicum, cano-tomentosum, longe pedicellatum, pedicello glandulam tori quater-sexies superante. Stylus lirevissimus. Stigmata brevia, patula, biloba, lolis diver.rentibus. Folia ellyptica, veress apicein et basin aequaliter attenucata, acuminata, undulato-serrata, bis terre longiora quan latiorch, adolescentia, sericeo-tomentosa, adulta supra obscure viridia, subnitida, glaberima, subtus cinerto-glauca, in nervis hirto pubescentia rel glabrata. Nervi secundarii ad marginem decurrentes utroque latere 10-12, flexuosi, in pagina inferiori prominentes et cum venis anastomoticis prominentibus reticulum elegans constituentes. Venulae anastomoticae in pagina superiori lineis impressis significatae, quare folium rugulosum. Stipulae semicordatae, acuminatae. Ramuli annotini pubescentes, biennes glabrati. Gemmae per hiemem glabrescentẹ.

Am. $\%$ 16-20mm lg. 10-12mm lt.

Squam. 1.5-2mm lg. Germ. $2-3 \mathrm{lg}$. Pedicell. $1.3-2 \mathrm{~mm} \mathrm{lg}$.

Fol. $40-100 \mathrm{~mm}$ lg. $18-50 \mathrm{~mm}$ lt.

Durch die behaarten cinjährigen Zweige, den deutlichen Griffel, die abstehenden Narbenlappen, die geringe Anzahl der Kätzchenstielblätter, die Nerratur der Blätter, die halbpfeilfürmigen Nebenblätter, so wie, durch den ganzen Habitus, stimmt diese Wreide mit $S$. grandifolia überein. Die Kätzchen sind aber kürzer und dicker, jenen der S. Caprea in der Form fast gleichend, so wie auch dic elliptische Grundform des Blattes mit dem Blatttypus der S. Caprea übereinstimmt.

Wir fanden diese Weide mit Stempelblüthen am Erlafufer bei Scheibbs 1100' und am sog'nannten Alpel des Schneeberges bei 4000', an beiden Standorten in Gesellschaft ihrer muthmasslichen Stammältern. 
3.8. $\asymp$ S. moncrophoylda (subyiandifolio-Caprea). - Amenta sub coactanea, breviter pedunculata, in pedunculo foliolis $4-6$ mox caducis vestita, staminigera ovata, semel- semel et semissi, pistilligera ovato-cylindrica, semel et semissi-bis longiora quan latiora. Squamae lanceolatae, acutae, in basi flavescentes, versus apicem atratae, villosae. Glandula tori breris, truncata. Germen ex ovata basi conicum, cano-tomentosum, longe pedicellatum, pedicello glandulam tori quater-sexies superante. Stylus brovissimus, istigmata oblonga, emarginata, conniventia. Stamina duo, antheris oblongis, filamentis liberis, glabris vel in basi pilosis. Folia ellyptica, bis terve longiora quain latiora, acuminata, in basi rotundata, margine undulato-serrata, adolescentia utrinque subsericeo-tomentosa, adulta supra glaberrima, obscure viridia et subnitentia, subtus glaucescentia et allido-tomentosa. Nervi secundarii ad marginem decurrentes utroque latere 10-1t, flexuosi, in pagina inferiori prominentes et cum venis anastomoticis elevatis reticulum constituentes. Venulae anastomoticae in pagina superiori lineis impressis significatae, quare folium rugulosum. Stipulae semicordatae, acuminatae. Ramuli annotini sicut gemmae glabri.

Am. O $18-2 . \mathrm{mm}^{\mathrm{mm}} \mathrm{lg} \cdot 14-18^{\mathrm{mm}} \mathrm{lt}$. Am. O $18-25^{\mathrm{mm}} \lg \cdot 10-12^{\mathrm{mm}} \mathrm{lt}$. Squam. 2-2.5m lg. Germ. 2-3 $3^{\mathrm{mm}} \mathrm{lg}$. Pedic. $2^{\mathrm{mm}} \mathrm{lg}$. Stam. $7-10^{\mathrm{mm}} \mathrm{lg}$. Fol. $60-120^{\mathrm{mm}} \mathrm{lg} .30-56^{\mathrm{mm}} \mathrm{lt}$.

Der hier beschriebene Blendling, welcher unter allen ron uns untersuchten Weiden den absolut grüssten Breitendurchmesser der Blätter zeigte und den wir einerseits darum, andererseits aber um an den gleichbedeutenden Namen einer der muthmasslichen Stammältern: S. grandifolia zu erinnern, S. maciophylla nennen, erscheint als fast baumartiger Strauch und stimmt in der Form der vor dem Aufblühen in einen dichten weissen Pelz gehüllten Kätzchen, durch die zusammenneigenden Narben, die länglichen Antheren, die elliptische Grundform und die Bekleidung der Blätter durch die Zahl der Kätzchenstielblätter endlich durch die kahlen einjährigen Zweige mit S. Cuprec überein; die Fruchtknoten sind aber mit einem deutlichen Griffel g'ekrünt, die Fiedernervenpaare der Blätter sind zahlreicher und das stärker markirte kleinmaschigere Nervennetz so wie die halbherzförmigen zugespitzten Yebenblätter weisen deutlich auf $S$. grandifolia hin.

Am Erlafufer bei Scheibbs und am Gruebberg bei Gaming 1100'-1300', in Staub- und Stempelbliithen. An beiden Standorten in Gesellschaft der muthmasslichen Stammältern.

34. S. Cappear L, sp. 1448. - Amenta praccocia, sessilia, in basi foliolis squamaeformibus $4-7$ fulta, orata, staminigera semel et semissi, pistilligera bis-bis et semissi longiora quam latiora. Squamae lanciolatae, acutiusculae, in basi ferrugineae, versus apicem atratae, longle villosate. Glandula tori breris, truncata. Germen ex orata basi conicum, cano-tomentosum, 
longe pedicellatum, pedicello glandulam tori quater-sexies superante. Stylus nullus. Stigmata sessilia, oblonga, emarginata, conniventia: Stamina duo, antheris oblonais, filamentis liberis, glabris. Folia elluptica vel sulvotunda. semel-bis et seinissi longiora quam latiora, undulato-serrata, adolescentia utrinque molliter subsericeo-tomentosa, adulta supra ylaberrima, obscure riridia et subnitida, subtus allido-tomentosa, opaca. Nerri secundarii ad marginem decurrentes utroque latere 6-12, flexuosi, prominentes, cum vinis unctomoticis subelevatis reticulum constituentes. Venulae anastomoticae in pagina superiori lineis impressis significatae. Stipulae semireniformes. R'amuli annotini sicut gemmaie glabri.

Am. o $30-46 \mathrm{~mm}$ lg. $18-24 \mathrm{~mm}$ lt. Am. 우 $1 \ddot{3}-40 \mathrm{~mm}$ lg. $12-16 \mathrm{~mm}$ It. Squam. 2-3 $3^{\mathrm{mm}} \mathrm{lg}$. Germ. $3-4^{\mathrm{mm}} \mathrm{lg}$. Pedicell. $2^{\mathrm{mm}} \mathrm{lg}$. Stam. $6-10^{\mathrm{mm}} \mathrm{lg}$.

Variat foliorum forma:

a. orbeceleted. - Folia subrotunda, recurrato-apiculata, in basi subcordata.

Fol. $30-70^{\mathrm{mm}} \mathrm{lg} .20-50 \mathrm{~mm} \mathrm{lt}$.

S. Caprea var. b. Wimm. Flora 18ł9. p. 35.

b. eIf icer. - Folia ellyptica, rersus apicem et basin acqualiter attenuata, bis longiora quam latiora.

Fol. $30-100^{\mathrm{mm}} \mathrm{lg} .25-50 \mathrm{~mm}$ lt.

S. Caprea var. c. Wimm. Flora 18k9. p. 3ว. Herb. Salic. Nr. 56.

S. Caprea Host Salix p. 20. tb. 66. 67. Koch Syn. p. 564. Fries Nov. Fl. suec. M. I. p. $5 \dot{\text { t. }}$ W $\mathrm{i}$ in m. Flora 18ł9. p. 3ว̆. Herb. Sal. Nr. 40. N eilr. Fl. v. N. Oest. p. 261.

In der Regel nur als Baum blühreife Knospen entwickelnd. - Die ältesten Bäume besitzen hüchstens einen Stammdurchmesser von sechs Zoll und niemals rermag sich S'. Carrea über fünf Klafter zu erheben. Die Aeste sind abstehend und die Krone hat immer ein etwas sparriges Ansehen. Die noch krautartigen Triebe sind dicht abstehend sammtig behaart und auch die Rinde der verholzten jüngsten Zweige ist bis in den Winter hinein noch mit zerstreutem Flaume bekleidet. Zur Zeit der Blüthe im Vorfrühling sind jedoch die Zweige rollständig kahl geworden. Die eiförmigen Knospen, welche so lange, als das sie stützende Blatt noch vorhanden ist, gleichfalls flaumig erscheinen, werden schon im Herbste kahl und etwas glänzend. Der Ueberzug der Blätter fuihlt sich sammtig an. An den jungen Blättern liegen die Haare etwas an der Blattfläche an, haben fast gleiche Richtung und der aus ihnen gebildete weisse Filz zeigt daber auch einen fast seidigen Schimmer; - an den ausgewachsenen Blättern sind aber die Haare abstehend und der Filz glanzlos. An schattigen Standorten ist der Ueberzug lockerer und die durchblickende bläuliche Grundfarbe des Blattes bedingt einen bläulichgrauen Farbenton; an somnigen Standpunkten aber wird der Filz oft so dicht, dass die ganze untere Blattlläche weisssammtig aussieht. - Die braunen 
blühreifen Knospen fallen schon im Winter durch ilne Grüsse schr in die Augen. Fast gleichzcitig mit S. daphnoides sprengen die in dichten wcissen l'elz gehüllten Kätzchen nach den ersten warnen Tagen des Jahres die braunen Decken und sind zur Zeit, wenn an demeclben Standpunkte s. reritn oder S. grantifolia zu blühen beginnen, gewöhnlich schon abgeblüht.

Die Kätzchenspindel verlängert sich zur Zeit der Fruchtreife bis zu $4-6$ Ctm. Die Fruchtknotenstiele aber, die sich bei S. grandifolia nach dem Abblühen gleichfalls sehr verlängern, behalten bei $S$. Caprea dieselbe Länge, welche sie zur Blüthezeit besassen (2mm), und sind meistens an die Spindel nach abwärts geschlagen. Dic Kapseln, welche gerade, und nur sclten unter stumpfem Winkel gleich jenen der $S$. grandifolia am Sticle befestigt erscheinen, messen kurz vor dem Aufspringen 6- $8 \mathrm{~mm}$.

In Europa ist $S$. Caprea ron der Mittelmeerzone und Taurien hinauf bis Island und Lappland, und in Asien rom Kaukasus und Ural ostwärts in das östliche Sibirien verbreitet. In Ostindien ist sie eingeführt.

Ihre obere Grenze fällt in den Sudeten auf $3630^{\circ}$, in den Karpathen auf 4.3.4, in den niederösterreichischen Alpen auf $4180^{\prime}$ und in den baierischen Alpen auf $5332^{\prime}$.

In Niederösterreich ist sie eine der häufigsten Weiden und findet sich in den gemischten Laubwäldern des Hïgel und Berglandes und zwar am liebsten gesellschaftet mit Birken, Führen und Zitterpappeln. - In Holzschlägen wuchert sie anfänglich rasch empor, stirbt aber $a b$, wenn sie rom hochstämmigen Holze ïberho lt und überwachsen wird und findet sich daher als alter Baum niemals im geschlossenen Walde, sondern immer nur an den Waldrändern oder auf Waldblössen vor.

Sie wächst auf Granit, Serpentin, kristallinischen Schiefern, Sandstein. Kalk und Löss; insbesonders aber sagt ihr etwas kalkhältiger trockener Lehmboden zu. Auf sumpfigem Boden fehlt $S$. Caprea und ist in den Donauauen sehr selten, wohl aber findet sie sich häufig an den felsigen Ufern der Alpenbäche und zwar nicht selten in Gesellschaft ron S. yrandifolia.

Die kätzchentragenden Zweige werden ähnlich jenen der s. deplanoides manchmal zu „Palmbuschen" geschnitten und es findet sich zu diesem Ende S. Caprea auch an Bauernhöfen oder auch neben den Kirchen hie und da gepflanzt. Im Taldriertel erscheint sie auch an den Strassen als Allecbaum - kultirirt.

35. $\asymp$ S. Heichavatii (Caprea-cinciea). - Amenta praccocia, sessilia, in basi foliolis squamaeformibus $4-7$ fulta, staminigera ovata, semel et semissi, pistilligera breviter cylindrica, bis-bis et semisi longiora quam latiora. Squamac lanceolatae, acutae, in basi ferrugineac, rersus a pirem atratac. longe villosae. Glandula tori brevis, truncata. Germen ex ovata basi conicum. cano-tomentosum, longe pediccllatum, pedicello glandulam tori ter-quinquie superante. Stylus brevissimus. Stigmata oblonga, conniventia, liluba, fedio 
paralletis. Stamina duo, antheris oblantis, filamentis liberis, itcalris. Folia

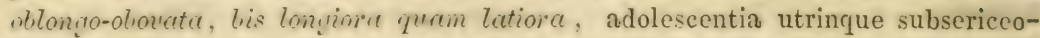
tomentosa, adulta supra sordide viridia puberulu, subtus cinerea, cano-tomentosa. Nerri secundarii ad marginem decurrentes utroque latere 8-12, flexuosi, prominentes, cum venis anastomoticis sulelevatis reticulum constituentes. Venulae anastomoticae in pagina superiori lineis impressis significatae. Stipulae semireniformes. Ramuli annotini sicut gemmae pubernli vel cano-tmentosi.

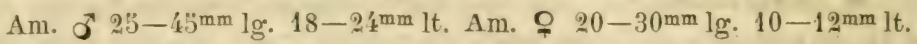

Squam. $2-3^{\mathrm{mm}} \mathrm{lg}$. Germ. $3-4^{\mathrm{mm}} \mathrm{lg}$. Pedicell. $2 \mathrm{~mm} \mathrm{lg}$. Stam. $6-10^{\mathrm{mm}} \mathrm{lg}$. Fol. $30-60^{\mathrm{mm}} \mathrm{lg} .18-30^{\mathrm{mm}} \mathrm{lt}$.

S. polymorplat Host Salix tb. 69 (excl. 68 et 70 ). Die abgebildete Pflanze stelit genau S. Reichardtii dar und stimmt auch in den zusammenneigenden Narben mit dem hier beschriebenen Biendling überein. - S. Caprea-cinerea Wim m. Flora 1849. p. 43. Denksch. p. 162 (In der Diagnose werden ihr abstehende Narben zugeschrieben. Die uns vorliegenden niederüsterreichisclien oben beschriebenen Exemplare, besitzen zusammenneigende oder aneinanderliegende Yarben, stimmen übrigens snust mit der Wimmer'schen Diagnose überein.)

Alle bisher in Niederösterreich aufgefundenen hieher gehörigen Weiden zeigten baumartigen Wuchs. Dadurch, so wie durch die kurzen Blätter, die nur wenig rortretenden Anastomosen an der unteren Blattseite, die länglichen Antheren und die zusammenneigenden Narben stimmt dieser Blendling mit $S$. Caprea ïberein. Die grauflaumigen oder graufilzigen Knospen und einjährigen Zweige. der verkehrteifürmige Zuschnitt der Blätter, die Bekleidung der oberen Blattfäche, endlich der wohl kurze aber deutliche Griffel weisen hingegen auf' $S$. cinerea.

Bei Dornbach ron Reichardt, bei Döbling ron Neilreich in Staubblïthen aufgefunden. Ausserdem fanden wir sie noch mit Stempelblüthen bei Bergern nächst Mautern. An allen Standorten finden sich auch beide muthmassliche Stammältern in der Nähe.

36. S. cinerere L. sp. 1449. - Amenta praecocia, sessilia, in basi foliolis squamaeformibus $4-7$ fulta, staminigera orata, semel et semissi, pistilligera cylindrica, bis - ter longiora quam latiora. Squamae lanceolatae, acutae, in basi ferrugineae, rersus apicem atratae, longe villosae. Glandula tori brevis, truncata. Germen ex orata basi conicum, cano-tomentosum, longe pedicellatum, pedicello glandulam tori ter - quinquies superante. Stylus lievissimus. Stigmata erecto-patula, emarginata vel biloba, lobis parallelis. Stamina duo, antheris subrotundis, filamentis liberis, glabris rel in basi pilosis. Folia obovata, ter longiora quam latiora, undulato-serrata, adolescentia lutescentia, opaca, utrinque molliter cano-tomentosa, adulta supra sordide viridia, puberula, subtus cineier, cano-tomentosa. Nerri secundarii ad marginem decurrentes utroque latere $10-15$, flexuosi, in pagina inferiori prominentes, cum venis anastomoticis eletatis reticulum constituentes. Venulae anastomoticae in pag na superior lineis impressis significatae, quare folium rugulosum. Stipulae 
semireniformes. Ramuli crassi, annotini et biennes sicut gemmae relutinotomentosi.

Am. $\sigma^{7} 20-30^{\mathrm{mm}} \lg .12-20^{\mathrm{mm}} \mathrm{lt} . A \mathrm{~m} . ? 20-40 \mathrm{~mm} \mathrm{lg} \cdot 10-18 \mathrm{~mm} \mathrm{lt}$.

Squam. $2-3^{\mathrm{mm}} \mathrm{lg}$. Germ. 2.5- $4^{\mathrm{mm}} \mathrm{lg}$. Pedicell. $1.5-2 . .^{\mathrm{mm}} \mathrm{lg}$. Stam. $8-11^{\mathrm{mm}} \lg$.

Variat foliorum forma:

c. Iertifotie. - Folia obovata vel oblongo-oborata, in basi rotundata vel in petiolum contracta, semel et semissi - ter longiora quam latiora.

Fol. $50-100^{\mathrm{mm}} \mathrm{lg} .20-45^{\mathrm{mm}} \mathrm{lt}$.

S. cinerea var. b. Fries Nov. M. I. p. 53.

6. angestifolia. - Folia oborato-lanccolata, rersus basin cuneata, ter et semissi longiora quam latiora.

Fol. $50-120^{\mathrm{mm}} \mathrm{lg} .15-30^{\mathrm{mm}} \mathrm{lt}$.

S. cinerea var. a. Fries Nov, fl. suec. M. I. p. B̈. - S. cinerea var. b. Wimm. Flora 1849. p. 36.

S. polymorpha IInst Salix p. 21. tb. 68. 70. (excl. 69). - S. cinerea Koch Syn. r. 362. Fries Nov. fl. suec. M. I. p. 5't (escl. var. c.). Herb. norm. Fasc. VII. Nr. 59. Wimm. Flora 1849 p. 36. Herb. Salic. Fasc. V. 57 et 58. Neilr. Fl. v. N. Oest. p. 261. K o Fl. exsicc. Vindob. Nr. 1058 u. 1059.

Ein vielästiger Strauch, dessen Höhe ron einigen Schuhen bis zu einer Klafter schwankt. Seine Zweige sind kurz, dick, abstehend, graubraun und glanzlos. Die braunen Decken der grossen eifürmigen Knospen sind noch zur Zeit, wo sie abgeworfen werden, graufilzig. Auch an den verholzten Zweigen bleibt der graue filzige oder fast sammtartige Ueberzug und fällt ïberhaupt bei $S$. cinerea nicht wie bei $S$. Caprea und $S$. mandifnlia später ab, sondern verwittert am Stamme und bedingt durch seine rerwitterten Reste das rauhe oder grau bestäubte Aussehen der Rinde, welches sich oft bis in das dritte und vierte Jahr erhält. Häufig sind diese verwitterten Haare auch der Sitz ron Uredineen, wodurch die Zweige dann wie berusst aussehen. - Die Blätter sind nur zur Zeit, wo sie die Knospen sprengen, etwas seidig, sobald sie sich entfaltet haben, erscheinen sie schmutzig graugrün, aschenfarbig und glanzlos und sind beiderseitig ron kurzen Ḧ̈rchen mehr oder weniger filzig. Diese lärbung des Laubes verleiht dem Strauche ein düsteres Aussehen, das ganz und gar mit seinem Standorte an schleichenden trägen Gewässern in sumpfigen ïden Niederungen harmonirt. - Das Netz der Yerven an der unteren Blattseite ist bei weitem markirter als jenes der $S$. Ciprea. Während bei $S$. Caprer die Anastomosen der Fiedernerren nur wenig erhaben sind, springen sie bei s. cinerere deutlich herror und sind bei ilir auch bei weitem zallreicher, als an der $S$. Caprea. Mit dem Nervennetze der $\&$. arandifolia besitzt die Nerratur der S. cinerea grüssere Aehnlichlieit, doch ist an S. grandifnlia das Netz der Nerren kleinmaschiger und zierlicher, und da bei der letzteren die gelben Nerven an der fast kahlen, bläulichen 
unteren Blattfläche mehr kontrastiren, als an dem filzigen Blatte der $S$. cinerea, so erscheint auch das ganze Nerrennetz viel schärfer und markirter. - Die Kätzchen sind regelmässig sitzend und an der Basis ron 4-9 kleinen schuppenartigen Blättchen umgeben. Durch dieses Merkmal ist S. cinerea immer sicher ron S. grandifolia zu unterscheiden. Ein wesentlicher Unterschied dieser beiden Weiden liegt in Beziehung auf die Kätzchen auch noch darin, dass jene der S. cinerea beim Herausbrechen aus den Knospen immer ähnlich denen der S. Caprea in einen dichten weissen die Antheren und Fruchtknoten ganz überdeckenden Pelz eingehüllt sind, während diese Umhïllung wegen viel schwächerer Behaarung der Kätzchenschuppen bei $S$. grandifolia, ähnlich wie bei S. anvita, schwach und durchsichtig ist und dalier gleich nach dem Sprengen der Knospendecke die Antheren und Fruchtknoten durchblicken lässt. Zur Zeit der Fruchtreife ist die Spindel des Kätzchens zu 4-6 Centim. verlängert; die Kapselstiele hingegen sind kaum länger als zur Zeit der vollen Blüthe. Die Kapseln, die entweder gerade oder unter stumpfem Winkel an ihren Stielen befestigt sind, besitzen zur Zeit der Reife unter allen Weiden das grösste Ausmass, indem sie vor dem Aufspringen eine Länge ron $9-12 \mathrm{~mm}$ zeigen, während bei den andern Arten der Rotte Ruyosae die Kapseln in diesem Stadium höchstens $8^{\mathrm{mm}}$ lang erscheinen.

In Europa ist S. cinerect von der Mittelmeerzone (Griechenland, Kalabrien, Korsika, Trafalgar) bis hinauf in das mittlere Sclıweden, Finnland, Perm verbreitet. Innerhalb dieses Gebietes wohnt sie rorzüglich in den Sümpfen der Flachländer, wie in den pontinischen Sümpfen, in der Ebene des Po und der Garonne, in den Niederländern der Donau und in der baltischen und sarmatischen Tiefebene und ron diesen Flachländern zieht sie sich einwä!ts läng's den sumpfigen Tha!sohlen oft weit hinein bis in die Moore der Gebirge.

Ihre obere Grenze erreicht sie in Macedonien bei $2800^{\prime}$, in den siebenbiirgischen Karpathen bei $2700^{\prime}$, in den niederüsterreichischen Alpen bei $2100^{\prime}$ und in den bairischen Alpen bei $2000^{\prime}$. - Auffallend hoch ist die obere Grenze im Bereiche des böhm.-mähr, Gebirges gerückt, wo S. cinerea weit aufwärts in die Flussthäler (Schönbach, Zwettl, Hartenstein) und bis auf die Moore der höchsten Kuppen, zu $2700^{\prime}$ enporsteigt, während sie wie oben angegeben wurde, in dem alpinen Gebiete Niederüsterreichs schon bei $2100^{\prime}$ ihre obere Grenze erreicht. - In den weiten Sümpfen des ungarischen Steppengebietes ist sie der einzige Repräsentant strauchartiger Gewächse und liebt dort, so wie auch in anderen Gegenden insbesonders die Ufer trägfliessender Bäche, deren schlangenfürmiger Verlauf gewöhnlich schon ron Ferne durch das einsäumende niedere graue Buschwerk der S. cinerea gekennzeichnet wird.

In Niederüsterreich ist sie am liäufigsten in der südöstlichen Niederung. des Wiener Beckens, dann in den Sümpfen an der March und Schmida, in der Ungebung von St. Pülten und auf der Forsthaide bei Waidhofen an der Ibbs. 
3\%. $\asymp$ S. Vutesceres (cinereo-aurita). - Amenta praecocia, sessilia vel brevissime pedunculata, in basi foliolis squamaeformibus $4-7$ fulta, pistilligera cylindrica, bis - ter longiora quam latiora. Squamae lanceolatae, acutae, in basi pallidae, rersus apicem ferrugineae vel atratae, pilosae. Glandula tori brevis, truncata. Germen ex orata basi conicum, cano-tomentosum, longe pedicellatum, pedicello glandulam tori ter - quinquies superante. Stylus brevissimus. Stigmata oblonga, erecto-patula, bifida, lolis pravallelis. Folia oblongo - ol:ovuta lis - lis et semissi longiora quam latiora, undulatoserrata, adolescentia lutescentia, opaca, utrinque molliter tomento:a, adulta supra obscure viridia, mulerula, subtus cinerascentia et canc-tomentrasa. Norri secundarii ad marginem decurrentes utroque latere $10-12$, Hexuosi, in pagina inferiori prominentes et cum venis ancstomoticis elecatis reticulum constituentes. Nervi sicut venulae anastomoticae in pagina superiori lineis impressis significati, quare folium rngosum. Stipulae semicordatae, acutae. Ramuli tenmes, annotini puberuli, biennes glabrati. Gemmae puberulae.

Am. 우 $16-3 \% \mathrm{~mm} \mathrm{lg} .8-12 \mathrm{~mm} \mathrm{lt}$.

Squam. 1.5-2mm lg. Germ. 2-3.5mm lg. Pedicell. 1-1.5 mm lg.

Fol. $30-56 \mathrm{~mm} \mathrm{lg} .15020 \mathrm{~mm}$ lt.

S. cinerea-aurita Wimm. Flora 18k9. p. 43. Denksch. p. 163.

Vielästiger Strauch mit sparrigen Acsten, der durch seine dümnen Zweige den Eindruck der S. aurita hervorbring't und mit diescr Stammart auch durch die kahl werdenden Zweige, das kleinere Ausmass allcr Bliithestheile und die kurzen reifen Kapseln übereinstimmt. Die Kätzchen sind jedoch länger zilindrisch als bei s. curitu, der Fruchthnoten ist ron einem wohl kurzen, aber deutlichen Griffel gekrünt, die Blätter sind länglichverkehrteifürmigg und haben den Zuschnitt und die Bekleidung der S. cincien. - Die Kützchenspindel ist zur Zeit der Fruchtreife bis zu 3-4 Centim. und die reifen Kapseln zu 6-8mm verlängert.

Die hier beschriebene Pflanze stimmt rollkommen mit Exemplaren der S. cinerca-curita Wimm. ron Goldschmiede bei Breslau, welche ich der Güte des rerehrten Autor's verdanke, überein.

Sie wurde ron mir an eirem Bache am Jauerling in der Nähe des sogenannten hohen Standes, 2.j00', dann im rerflossenen Jahre ron meinum Bruder bei Gross-Weissenbach im Waldriertel, an beiden Orten mit Stempelblüthen, aufgefunden. An beiden Fundorten wachsen auch die beiden nutlimasslichen Stammältern in der Nähe.

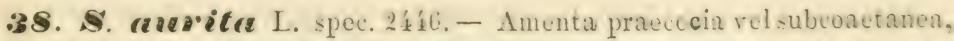
sessilia vel breviter pedunculata, in basi fuliulis squamauformlbus $t-i$ fulta, staminigera orata, semel - semel et semisri, pistilligera ovata vel breviter cylindrica, semel ct semissi - bis longiora quam latiora. Squamav lanceolatae. acutae rel obtusae, in basi pallidae, supra medium ferruginate, pilosas. Glandula tori brevis, truncata. Germen ex orata basi conicum, cano-tomen- 
tosum, longe pedicellatum, pedicello glandulam tori ter quaterre superante. Stylus nullus. Stigmata oblonga, emarginata rel biloba, erecto-patula. Stamina duo, antheris rotundis, ante anthesin flaris, (rarissime rubescentibus) post anthesin sordide flarescentibus, filamentis liberis, glabris vel in basi pilosis. Folia obovata, brevissime recurvato-apiculata, undulato-serrata, semel et semissi - Lis longiora quain latiora, adolescentia utrinque subsericea, cano-tomentosa, adulta supra obscure et sordide riridia, opaca, puberula, subtus glaucescentia, lirto-tomentosa. Nerri secundarii ad marginem decurrentes utroque latere 6-12, Hexuosi, in pagina inferiori prominentes et cum venis anastomoticis prominentilus reticulum constituentes, in pagina superiori lineis impressis significati, quare folium rugosum et subplicatum. Stipulae senicordatae vel remireniformes. Ramuli tenues, tenaces, annotini sicut gemmas glabri vel levissime puberuli.

Am. o $10-20 \mathrm{~mm}$ lg. $10-16^{\mathrm{mm}} \mathrm{lt}$. Am. $\%$ 6-18mm lg. 5-10 $\mathrm{mm}$ lt. Squam. 1-2 ${ }^{\mathrm{mm}} \mathrm{lg}$. Germ. 2-3 $\mathrm{mm} \lg$. Pedicell. 1-2 $\mathrm{mm} \lg$. Stam. 5-8 $\mathrm{mm} \lg$.

Variat foliorum forma:

a. Motemedifolia. - Folia subrotundo-oburata. (Confundere nequit hanc rarietatem cum forma monstrosa: putata. In pratis montanis nempe post messem foeni arbusculi minores falce detonsi e trunco remanente ramulos erolvunt foliis subrotundo-oboratis restitos. Folia hujus formae autem multo minus rugosae, sublaevigatae et plerumque subglabrae inveniuntur. Conf. Fries Nov. 丹l. suec. M. I. p. 56.)

S. aurita var. b. Wimm. Fl. 18 p. 36.

b. oblosgifolice. - Folia oblongo- rel lanceolato-oborata, bis longiora quan latiora.

S. aurita var c. W imm. Flora $18 \$ 9$ p. 36.

S. heterophylla Host Salix p. 26. tb. S7. SS. - S. aurita Fries Nov. fl. suec. M. I. p. 5ว. (excl. var.) Herb. norm. Fasc. VII. Nr. 60 (excl. specim. „var. c. ambigua $)^{4}$ K och

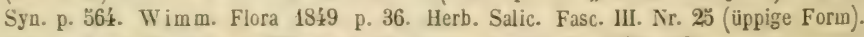
Nieilr. Fl. r. N. Oest. p. 262. Ko v. Fl. exsicc. Vindob. Nr. 1067. 1068.

Ein rielverzweigter Strauch, der durch die dünnen $Z$ weige, so wie durch die kleineren stärker runzeligen fast gerifften Blätter ein ron S. cineren und S. Cuprea abweichendes Aussehen bekommt. - Die Wandelbarkeit der einzelnen Merkmale ist jedoch bei $S$. aurita, so wie überhaupt bei der Rotte Rugosae unendlich gross. Bald erscheint diese W'eide auf den Torfmooren als ein sparriges spannhohes Sträuchelchen mit rechtwiukelig abstehenden armkno:pigen Zweigen, bald als mannshoher Strauch mit schlankeren Zweigen, deren einer manchmal bis zu zwanzig Blüthenkätzchen trägt. - Die noch krautartigen Triebe erscheinen immer graufilzig, und noch im darauffolgenden Frühling ist die Rinde der bereits rerholzten Zweige stellenweise etwas flaumig; bis zum Sommer aber ist diese Bekleidung rollständig verschwunden, die Rinde wird dann dunkelbraun, glatt und manchnal sogar etwas glän- 
zend. Im zweiten Jahre hebt sich die Epidermis in zarten Falten und Runzeln empor und die Rinde erscheint von jetzt an uneben, glanzlos und ron aschgrauem Farbentone. - Die braunen, im Herbste flaumigen Decken der eifürmigen Knospen sind zur Zeit, in welcher sie abgeworfen werden, kahl und etwas glänzend. - Die Blätter sind in Zuschnitt, Grösse und Bekleidung unendlich mannigfaltig. Die zwei Formen, in welchen $S$. aurita bei uns am häufigsten auftritt, sind oben unter a. und b. aufgeführt. Die jungen aus den Knospen herausbrechenden, dichtfilzigen und tiefgefurcht runzeligen Blätter besitzen in der Jugend manchmal etwas seidigen Schimmer; sobald dieselben aber rollständig. entfaltet sind, erscheinen sie dunkelgraugrün und glanzlo:. Am gewühnlichsten ist dann ihre starkrunzelige, obere Blattfläche nur von zerstreuten sparsamen Härchen bekleidet und die untere Seite an den Nerven von abstehenden Härchen filzig; seltener sind beide Flächen mit dichtem grauen Filze bedeckt, welch letztere Form von Wimmer in d. Flora $18 \mathrm{k} 9$ p. 36 als var. d. aufgeführt wurde und sich auch in Niederösterreich am Jaucrling und auf den Neuntagwerkwiesen bei Bergern vorfindet. - Die weiblichen Kätzchen sind anfänglich eiförmig oder fast kugelig, und dichtblüthig, verlängern sich aber bald, werden zilindrisch und - indem sich gleichzeitig mit der Verlängerung der Spindel auch die Fruchtknotenstiele rerlängern - lockerblüthig. Zur Zeit der Fruchtreife schwankt die Länge der Kätzchenspindel zwischen 2 und 3 Centim. In der Regel sind die Kätzchen selır kurz gestielt und ihre Basis mit 4-9 seidig-filzigen, kleinen schuppenartigen Blättchen ungeben; an schattigen Standorten aber vcrläng'ern sich die Kätzchenstiele so sehr, dass manchmal ihre Länge der Läng'e des Kätzchens gleichkommt. Sieben bis neuı Blätter, deren jedes an der Basis mit Nebenblättern versehen ist, bekleiden dann die so verlängerten Kätzchenstiele und verleihen der Wride ein auf den ersten Blick ganz abweichendes Aussehen. - Die Kätzchenschuppen sind an solchen Schattenexemplaren an der Spitze nur schwach bräunlich bemalen, sonst aber erscheinen die Schuppen in der vorderen Hälfte dunkelrostbraun. Sie sind immer viel weniger zottig als jene der $S$. Caprea und $S$. cinerea und die herausbrechenden Kätzchen daher auch in keinen =0 dichten Pelz gehüllt, wie diess bei den zuletzt genannten zwei Arten der Fall ist. - Die Fruchtknoten sind graufilzig. Zur Zeit der Fruchtreife verlängtrn sich die Fruchtknoten bis zu $6-8^{\mathrm{mm}}$ und sind bei geringem Durchmesser $\left(2^{\mathrm{mm}}\right.$ an der Basis, $1 \mathrm{~mm}$ gegen die Spitze) fast pfricmenförmig gestaltet. Eines bei Moidrams im Waldviertel ron meinem Bruder aufgefundenen Strauches der S. aurita mit kahlen Fruchtknoten wurde schon früher (Seite 36i) Lrwähnung gethan. Einige androgynische Kätzchen, welche sich an demselben Indiriduum neben der Mehrzahl won Kätzchen befanden, die sonst nur Stempelbliithen trugen, weisen darauf hin, dass die kahlen Fruchtknoten als monstrüse Bildungen anzusehen seien, wie sie bei der Gruppe Ruyosue nicht selten sind. - Auch der Fruchtknotenstiel, welcher schon zur Zeit der rollen Blüthe zu $4^{\mathrm{mm}}$ verlängert erscheint und dalurch an einen Staubfaden mahnt, der statt 
der Anthere einen Fruchtknoten trägt, deutet an, dass diese Bliithen zu jenen wunderbaren Bildungen gehören, bei denen die bildende Kraft der Pflanze zwischen Staubgefäss und Fruchtknoten schwankt. - $\mathrm{Zu}$ bemerken ist übrigens, dass die Fruchtknoten bei dieser kahlfrüchtigen Form jenen der normalen behaartfrüchtigen $S$. curvitu ganz gleich gebildet erscheinen, und dass sich sugar Samen in den Kapseln ausgebildet hatten.

Die S. aurita ist in Europa ron den Pyrenäen, den Südalpen, den serbischen und macedonischen Gebirgen nordwärts bis Lappland und in Asien rom Kaukasus bis in den Altai verbreitet.

Thre obere Grenze fällt in den südbairischen Alpen auf 4742' in den nordtirolischen Alpen auf $40000^{\prime}$, in den niederösterreichischen Alpen auf $3200^{\prime}$. - In den Sudeten findet $S$. aurita ihre obere Grenze bei 3500'. - Sie meidet Kalkboden und liebt insbesonders thonreiche Gesteine als Unterlage, dem ent:prechend sie auch im alpinen Gebiete Niederösterreichs auf die nördliche Zone des thonreichen Wiener-Sandsteines, auf die thonreichen Gresdner Schiefer und die Schiefer der Grauwackenzone beschränkt ist. Sie findet sich auf diesen im alpinen Gebiete, namentlich am Preiner Gschaid, dann im Thale bei Gresden, im Burgerhofwald und am Hochpyra bei Scheibbs, im Teufelhofwald bei St. Pölten und durch die ganze Kette des Wienerwaldes bis Heiligenkreuz und über den Riederberg bis Hütteldorf, Dornbach und Weidling, wo sie bei $700^{\prime}$ ihre untere Grenze erreicht. *)

Viel häufiger noch als im alpinen Gebiete ist sie auf dem niederösterreichischen Antheil des bühmisch-mährischen Gebirgsplateaus, wo sie auf dem thonreichen Boden des Granits, Gneisses, Weisssteines und Hornblendschiefers ron den Thälern aufwärts bis zu den höchsten Kuppen zu 3300' allgemein rerbreitet ist und insbesonders die Ränder der Wälder und Hochmoore, die Rinnsale der Bäche und die Wiesengräben mit ihrem dichtrerzweigten Buschwerk besäumt.

\section{Divisio IV. RTelitere. - Squamae amentorum disco-} lores. Torus uniglandulosus. Stylus brevissimus vel nullus. Folia dum marcescunt nigricantia.

\section{Sect. XII. Semipurpureae. - Frutices rel arbores minores trunco éreclo, ramis erectis tenacibus. Folia oblongo- rel oborato-lanceolata, supra medium plerumque dilatata. Amenta staminigera ovata. Stamina duo, flamentis in rariis distantiis}

*) Sie fehlt in der Ebene des Wienerbeckens, dann in Leithagebirge und in mittelungarischen Berglande und erscheint erst jenseits der grossen pannonischen Ebene in den siebenbürgischen und banatischen Karpathen. 
connata, antheris ante anthesin rubescentibus, sul, anthesi luteis, demum sordide farescentibus. Amenta pistilligera cylindrica. Germina orato-conica, pedicellata, pedicello glandulam tori aequante rel bis superante. Stylus brerissimus vel mullus. Stigmata brevia, ovata.

$39 \smile$ S. aeritoides (sutipurpureo-curita). - Amenta praecocia, sessilia, in basi foliolis squamaeformibus $\ddot{b}-6$ fulta, pistilligera culindirica, bis et semissi - ter longiora quam latiora. Squamae oboratae acutae, supra medium atratae, pilosae. Glandula tori oblonga, truncata. Germen oratoconicum, obtusum, cano-tomentosum, pedicellatum, pedicello glandulam tori bis superante. Stylus nullus. Stigmata brevissima, ovata. Folia obovato-lancenlata, ter longiora quam latiora, supra obscure viridia, glabra rel levissime puberula, subtus glaucescentia, hirto-tomentosa. Nervi secundarii ad marginem decurrentes prominentes, et cum renis anastomoticis eleratis reticulum constituentes. Venulae anastomoticae in pagina superiori lineis impressis simnificatae, quare folium rugulosum. Stipulae semicordatae, acutae. Ramuli annotini glabri, rufescentes.

Am. ㅇ 14-22 $14 \mathrm{~mm}$ lg. $6-7 \mathrm{~mm}$ lt.

Squam. 1-2mm lg. Germ. $2 \mathrm{~mm}$ lg. Pedicell. $1 \mathrm{~mm} \mathrm{lg}$.

Wimmer unterscheidet in Denksch. p. 153 drei Blendlinge aus S. purpurea und $S$. aurita, von denen $z$ wei zur $S$. purpurea hinneigende Formen in dem genannten Werke unter b. glaucescens subsumirt werden. Die Form a. cinerascens stellt hingegen nach Wimmer einen zur $S$, aurita näher stehenden Bastart dar. Die unter diésem letzteren Namen im Herb. Salic. Nr. 60 ausgegebene und uns ron dem Autor freundlichst mitgetheilte Weide scheint jedoch mit dem oben bescliriebenen Blendling nicht identisch und unterscheidet sich namentlich durch die sammtig belaarten jälrigen $\mathrm{Z}$ weige. Wir möchten dieselbe auch dieser sammtigen abstehenden Bekleidung wegen für einen Bastart aus $S$. purpurea und S. ciuerea halten.

Strauch rom Ansehen der $S$. aurita, dessen braune, etwas glänzende Zweige aber unter spitzeren Winkeln $\left(30-40^{\circ}\right)$ aufrecht abstehen. Die Kätzchen sind gleichfalls aufrecht abstehend, fast an die Axe des Zweiges angelehnt, und sind mehr zilindrisch und schmäler als jene der $S$. auritu; die Fruchtknoten sind kürzer gestielt, die Blätter mehr verlängert, die zwei sehr kurzen, rundlich-eiförmigen Narben koptförmig auf den kleinen Truchtknoten sitzend. - Alle diese Merkmale lassen den Typus der S. purpreu nicht verkennen. Lebrigens stellt $S$. curitoides cinen zu $s$, aurita näher als zu $S$, purpurea hinneigenden Blendling dar.

Thurde im Sommer des verflossenen Jahres ron meinem Bruder bei Moidrams nächst Zwettel auf der Höhe des bühm.-mähr. Gelirg:plateaus bei 20̈00' in Gesellschaft der beiden muthmasslichen Stammältern aufgefunden.

40. $\longleftarrow$ S. sosdede (sutpurpuron-cinereu). -- Amenta pracecia sessilia, cylindrica, pistilligera ter longiora quam latiora. Squamae oblongate 
obtusae, supra mediun atratae, villosae. Glandula tori brevis, truncata, subquadrata. Germen orato-conicum, sericeo-tomentosum, pedicellatum, pedicello glandulam tori aequante rel ter superante. Stylus brevissimus. Stigmata breria, ovata. Stamina duo, antheris ante anthesin rubescentibus, sub anthesi luteis et serius sordide flarescentibus, filamentis usque ad medium connatis. Folia obovato-lanceolata, ter-quater longiora quam latiora, adolescentia utrinque molliter subsericeo-tomentosa, adulta supra obscuve viridia, spaca, puberula vel alabrata, subtus cinerea, livto-tomentosa. Nerri secundarii ad marginem decurrentes utroque latere $11-13$, in pagina inferiori prominentes et cum renulis anastomoticis eleratis reticulum constituentes. Venulae anastomoticae in pafina superiori lineis impressis significatae, quare folium rugulosum. Stipulae semicordatae. Ramuli annotini velutino-tomentosi, biennes glabrati.

Am. $\% 20-36 \mathrm{~mm}$ lg. $8-12 \mathrm{~mm}$ lt.

Sq. 2-2.5mm lg. Germ. $2^{\mathrm{mm}} \mathrm{lg}$. Pedicell. $1-1.5^{\mathrm{mm}} \mathrm{lg}$.

Fol. $50-130^{\mathrm{mm}} \mathrm{lg} .18-38^{\mathrm{mm}} \mathrm{lt}$.

S. purpurea-cinerea a. cinerascens Wim m. Jahresb. d. schles. Ges. 1817. t. 3 fig. 11. 17. Flora 18ł9. p. 40. Denkscl. p. 1522. Herb. Sal. Nr. 59.

Strauch mit dicken, in der Jugend kurz-sammthaarigen, grauen Zweigen, der einer schmalblättrigen $S$. cinerea ähnlich sieht, aber durch die im Alter oberseits fast kahl werdenden Blätter, die länger zilindrischen Kätzchen, die kürzer gestielten Fruchtknoten und die bis zur Mitte verwachsenen Staubfäden sich von ihr unterscheidet.

Ein Strauch mit Stempelblüthen wurde ron meinem Bruder vor mehreren Jahren nächst Herzogenburg an der Traisen aufgefunden; cinen Strauch mit Staubblïthen entdeckte Herr E. Weiss im rerflossenen Sommer hinter dem Auhofe bei Mariabrunn. In zahlreichen männlichen und weiblichen Sträuchern fanden wir diese Teide heuer an Wiesengräben bei Viehhofen nächst St.Pölten, in männlichen Sträuchern auch bei Neuwaldegg. An allen diesen Orten finden sich die muthmasslichen Stammältern in der Nähe.

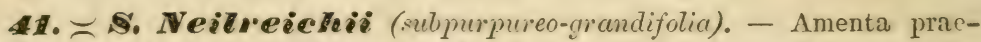
cocia, sessilia, in basi foliolis squamaeformibus $2-3$ fulta, staminigera orata, bis longiora quam latiora. Squamae oboratae, obtusae, villosae, in basi ferrugineae, supra medium atratae. Glandula tori oblonga, truncata. Stamina duo, antheris rotundis, ante anthesin rubescentibus, sub anthesi luteis, serius sordide flaveseentibus, filamentis in bavi connatis. Folia obovato-lanceolata, ter-quater longiora quam latiora, acuta, in basi cuneata, toto margine serratc. adolescentia subtus sericeo-tomentosa, supra villo abstergendo, sordido tecta et renulis anastomoticis impressis rugulosa, adulta utrinque glabrata, supra olscure-viridia, sulnitida et lacigata, subtus glaucescntia, opaca. Nerri secundarii ad marginem decurrentes utroque latere 20-22, flari, prominentes et cum venulis anastumoticis prominentibus numerosis reticulum elegans constituentes. Stipulae semisagittatae, dentatae. Ramuli annotini glaberrimi. 
Am. 万ั 16-28mm lg. $10-14^{\mathrm{mm}} \mathrm{lt}$.

Squam. $1.5-2 \mathrm{~mm}$ lg. Stam. $6 \mathrm{~mm}$ lg.

Fol. $60-100^{\mathrm{mm}} \mathrm{lg} .10-26^{\mathrm{mm}} \mathrm{lt}$.

Ein Strauch, der durch seine aufrechten gelblichen. mit häutiger glatter und kahler Rinde üh rzogenen jungen 7weige. durch die in Verwelken sich schwärzenden Blätter, durch die im gstrockneten Zustande oberseits etwaerhabenen Nerven-Ana-tomosen, durch die bis zum unteren I rittheil verwachsenen Staubfäden, die ror dem Aufblïhen rothen Antheren und abgerundeten, an der Spitze schwärzlichen Kätzchen-chuppen seine Verwandtschaft mit $s$. purpurea beurkundet, in den Bläitern aber den schmaib)ättrigen Formen der S. grantifolia so sehr ähnlich sieht, dass er im Sommer leicht mit derselben verwechselt und nur durch die schlankeren, mshr autrechten $Z$ weige, die glatte (nicht ron rertieften Linien durclizogene) obere Blattseite und die gröwere Anzahl der bis zum Rande verlaufenden Fiedernerven unterschieden werden kann.

Bisher ist bloss ein Staubkätzchen tragender Strauch dieses Weidenblendlings bei Gaming bekannt. - Derselbe wurde dort auf dem an Weidenbastarten so reichen Gruebber 9 im Sommer des Jahres 18030 zucrst ron Neilreich aufgefunden und möge auch den Namen seines um die Flora. Niederösterreichs so hochverdienten Entdeckers tragen. - An dem Standorte finden sich beide muthmassliche Stammältern häufig in der Nähe.

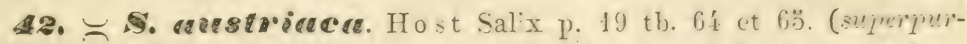
pureo-irentifulia). - Amenta praecocia vel subcoactanea. brevis-ime pedunculata et in basi foliolis sqamaefurmibus $3-.5$ fulta, pistilligera cylindrica, ter et semissi - quater, staminigera oblongo-cylind i i a, bi et semi-i lungiura quan latiora. Squamae oboratae, obtusae, villosae. in ba-i ferrugineas, supra medium atratae. Glandula tori oblonga, truncata. Germen orato-conicum, sericeo-tomentosum, pedicellatum, pedicello glanlulam turi aequante. Stylus brerissimus. Stigmata brevia, oblonga, patula. Stanina duo, anthris ante anthesin rubescentibus, sub anthesi luteis et serius sordide flarecentibur,

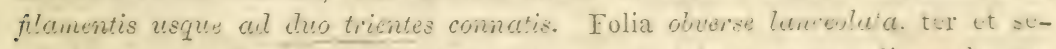
missi longiora quan latiora, infra medium angu-tata supra medium plerum-

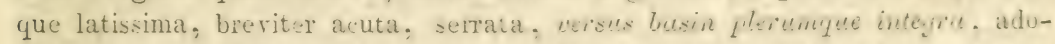
lescentia villo abstergendo subsericeo, albicanti vel sordide-rubigitu-o tecta,

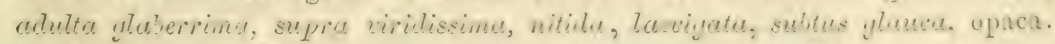
Nerri secundarii ad marginem decurentes utroque latere 12-21), in pagina inferiori prominentes, Hexusi et cum renulis anastumuticio cleratis reticulum constituentes. Stipulae lanceolatae. Ramuli annotini glaberimi.

Am. o $203-30 \mathrm{~mm}$ lg. $12-16 \mathrm{~mm}$. It. Am. $20-32 \mathrm{~mm}$ lg. $7-10 \mathrm{~mm}$ lt. Squam. $2^{\mathrm{mm}} \mathrm{lg}$. Germ. $2^{\mathrm{mm}} \mathrm{lg}$. Pedicell. $0.5^{\mathrm{mm}} \mathrm{lg}$. Stam. Fol. $50-90 \mathrm{~mm}$ lg. 10 - 20 mm it.

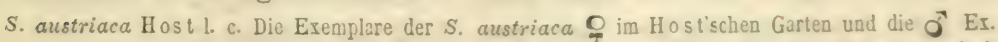
aus dem bot. Garten gehören hieher; die S. austriac $\mathbf{Q}$ aus den bot. Garten ist jedoch 
mit Wimmer's $S$. purpureo-cinerea b. glaucescens identisch. - S. austriaca Fries Herb. norm. Fasc. XII. - S. Pontederana Bertol. Fl. ital. X. p. 331 (nach Exemplaren aus dem Valle di Fassa von Ambrosio, ron welchem sie auch Bertoloni erbalten zu haben angibt.). - (Die S. Pontederae Villars ist nach Seringe [Saules d. I. Suisse p. 90] gleich der S. hastata L. Ebenso ist die S. Pontederana Wılld. nach einem Exemplare ron Bellardi in Willdenow's Herbar $=S$. hastata [siehe W imm. Denksch. p. 153]. Bertolon i hingegen erklärt 1. c. ein Exemplar der S. Pontederana Bellar di's für S.nigricans. Die S. Pontederana Schleicher Cat. Sal. 1809, bei Seringe, T a u s ch, dann bei den deutschen Autoren $\mathrm{K}$ och, R eich $\mathrm{n} \mathrm{b}$ ach bezieht sich auf rerschiedene Bastarte aus S. purpurea mit den Arten der Rotte Rugosae). - S. purpureo-grandifolia Wi mm. Jahresb. d. schl. Ges. 1852 p. 6ł. Denksch. p. 15้. Neilr. Fl. F. N. Oest. p. 2338.

Mannshoher Strauch mit glänzenden, kahlen, grïnen oder braunen, schlanken, aufrechten $Z$ weigen, der bei seinem ersten Eindruck einigermassen an eine breitblättrige S. purpurea erinnert, aber durch die noch kürzeren, unterseits rorspringend aderigen Blätter, die dickeren Kätzchen, die gestielten, ei-kegelfürmigen Fruchtknoten, die niemals rollständig rerwachsenen Staubfäden und die nicht schwarz werdenden Antheren sich von derselben unterscheidet. - Ton S. Neilreichii unterscheidet sich dieser Blendling durch etwas längere Kätzchen, durch die bis zum oberen Drittel oder fast bis zu den Antheren hinauf mit einander verwachsenen Staubgefässe und die oberseits stärker glänzenden, unterseits weniger netzaderigen Blätter, durch welehe Merkmale sich eben S. anstriaca mehr dem Typus der S. purpurea anschliesst. - Der deutliche Griffel unterscheidet die muthmasslich aus S. purpurea und $S_{\text {. }}$ trandifolia herrorgegangenen Blendlinge ebenso, wie jene Bastarte, welche aus S. purpurea und S. cinerea entsprungen scheinen, ron den höchst ähnlichen Blendlingen aus $\$$. purpurea und $S$. Caprea. - Wenn aber schon diese Unterscheidung eine sehr subtile genannt werden muss, so ist die Trennung der Blendlinge, welche $S$. purpurea mit S. cinerea erzeugt, ron jenen, welche sie mit S. grandifolia bildet, noch schwieriger, und nur bei jenen, welche sich näher den Stammformen: S. g:andifolia oder S. cinerea anschliessen, lassen sich Lnterschiede noch durch Beschreibungen festhalten. Bei jenen, welche der S. purpurea näher stehen, fehlen uns fast Worte, um die Formen noch abzugrenzen, und es fällt die Bestinmung des Ursprung's dem richtigen Blicke des Beobachters anheim. Der schmutzige, mehr aschgraue Farbenton, der sich an der unteren Blattseite der Blendlinge aus $S$. puipurea mit $S$. cinerea ausspricht, anderseits das mehr markirte Nervennetz der Blendlinge aus $S$. purpurea und $S$. grandifolia sind rielleicht Merkmale, welche noch als Anhaltspunkte dienen können. Es sind diess freilich Anhaitspunkte ron sehr kleinlicher Natur; dennoch wird sich der Botaniker bei Ermittlung des Ursprunges einer muthmasslichen Blendlingsart an derartige unbedeutende Kennzeichen halten müssen. Thre richtige Schätzung, die Würdigung einer Menge durch Worte kaum festzuhaltender, bei einer Pflanze zusammentreffender Anzeigen ist eben das, was man als den "richtigen Blick des Botanikers" zu bezeichnen 
pflegt. - Auch der Standort wird in vielen Fällen zu diesen Anzeigen gehören, indem die Bastarte aus $S$. purpurea und $S$. grandifolia in den Alpen ganz ähnlich, wie jene aus S. purpurea und S. silesiaca in den Sudeten bisher nur in einem schmalen, subalpinen Gürtel aufgefunden worden sind, in welchem die Areale der thalbewolinenden $S$. purpurea und der alpinen $S$. grandifolia respectire $S$. silesiaca ineinandergreifen. - Allerdings ist auch dieser Anhaltspunkt nicht unter allen Umständen untrüglich, da bei dem leichten Transporte der Weidensamen durch die Luftströmungen eine Ansiedelung auch ausserhalb dieses Gürtels möglich ist, geradeso, wie anderseits möglicherweise ein Blendling aus S. cinerea und S. purpurea noch tief in den Alpen aufgefunden werden könnte.

Die beiden oben aufgeführten Weiden: S. Neilreichii und S. austriaca glauben wir jedoch nach allen Anzeigen als Blendlinge aus S. purpurea und S. grandifolia auffassen zu können, womit auch $W$ in mer's Ansicht in Betreff der S. austriaca übereinstimmt.

In Niederösterreich fanden wir S. austivaca mit Stempelblüthen an einem kleinen Bache, auf der Höhe des Preiner Gschaides $\left(3000^{\prime}\right)$, dann in Blättern am Südabhange des Josef berges $\left(2800^{\prime}\right)$, und auf dem Gruebberge hinter der Karthause bei Gaming (1300 ). - Sie stimmt vollständig mit S. austriaca $\mathcal{O}$ des Hostischen und der gleichnamigen $\sigma$ Teide des botanischen Gartens überein, ebenso mit Exemplaren aus Fassa in Südtyrol ron Ambrosi und mit Exemplaren rom Mont Cenis, welche Herr Professor Huguenin in Chambery uns zu senden so guitig war*). - Auch die $S$. austriaca im Herb. norm. fasc. XII. ron Fries, die wahrscheinlich ron Stecklingen aus den Wiener Gärten abstammt und die Fries mit der Bezeichnung "S. austriaca Host. (nomen definitum S. Pontederanae duplici errore huic translatum) incerta civis" ausgegeben hat, stimmt mit der oben beschriebenen Pflanze genau überein.

\section{3. $\asymp$ 5. Flnaterseensis (purpureo-Caprea). - Amenta prac-} cocia, sessilia, cylindrica, densiflora, pistllligera ter et semissi - quater longiora quam latiora, in basi foliolis squamaeformibus 2-0̈ fulta. Squamae oblongo-obovatae, obtusae, supra medium purpureo-nigricantes, villosae. Glandula tori oblonga, truncata. Germen ovato-conicum, sericeo-tomentosum, pedicellatum, pedicello glandulam tori vix superante, stylo nullo, stigmatibus breribus, oratis, integris, conniventilus. Talrae capsulae post dehiscentiam extrorsum arcuatae, falcatae. Folia ellyptica vel obovato-ellyptico utrinque attenuata, acuminata, undulato-serrata, ter longiora quam latiora, alolescentia supra tomento obstergendo tecta, subtus sericeo-tomentosa, adulta supra glaberrima, laevigata, viridissima et nitida, subtus pallide glauca, villis

*) Ueber die S. Pontederae Vill., welche gleichfalls auf dem Nont Cenis angegeben wird, siehe oben bei den Synonymen der S. austriaca Host. 
dispersis pulierula. Stipulae lanceolatac, acuminatas. Nerri secundarii ad marginem decurrentes utroque latere $11-16$, flexuosi, in pagina inferiori elerati, pallidi, cum renulis anastomoticis tenuissimis reticulum constituentes. Ramuli annotini glabri.

Am. $\% 20-4.0^{\mathrm{mm}} \mathrm{lg} .7-10^{\mathrm{mm}} \mathrm{lt}$.

Squam. $2^{\mathrm{mm}}$ lg. Germ. 2-3mm lg. Pedicell. $0.5-0.8^{\mathrm{mm}} \mathrm{lg}$.

Fol. $70-130^{\mathrm{mm}}$ lg. $25-40^{\mathrm{mm}} \mathrm{lt}$.

S. rliscolor Host Salix p. 18. tb. 61. Der hier bescliriebene Bastart stimmt mit den ron Host gepflanzten Exemplaren der S. discolor vollkommen überein. Da jedoch der Name: discolor schon for Host einer nordamerikanischen Weide zukam, so bezeichneten wir obige Weidenform nach dem Standorte Mautern, wo wir sie seit 10 Jaliren beobachteten, mit dem Namen S. Mauternensis.) - S. purpureo-Caprea W imm. Ilerb. Salic. Nr. 53 stimmt gleichfalls rollkommen überein. Die $S$. purpureo-Caprea W imm. Herb. Salic. Nr. 15. Flora 1849 p. 44 unterscheidet sich lingegen durch die im Alter unterseits vollständig kahl werdenden, oberseits mehr glänzenden, schmäleren Blätter und stellt einen der S. purpurca näher stehenden Blendling dar. Diese letztere stimmt, wie auch ron WV imme r bereits (in Denksch. p. 152) herrorgehoben wird, rollkommen mit der ron $\mathrm{H}$ os t gepflanzten und als $S$. oleijolia bezeichneten Weide überein, von welcher sich Exemplare im Herb. Fenzl im Wiener botanischen Hofkabiuete befinden.

Ein Strauch mit armdickem Hauptstamme, der rom Grunde aus in zahlreiche aufrechte Aeste aufgelöst erscheint. Die Rinde der jüngeren Zweige ist gelblich-grün und etwas glänzend, jene der 3-4jührigen Acste graugrün, glatt, glanzlos. Die Knospen haben ganz die Form wie bei $\mathbb{S}$. purpurea, sind kahl, gelb, länglich, an beiden Seiten etwas gekielt. Die Blätter sind in der Jurend im oberen Drittel entschieden am breitesten und rom Zuschnitt der S. purpurea, im ausgewachsenen Zustande aber sind sie länglich-elliptich, zugespitzt gegen die Spitze und Basis gleichmässig verschmälert und erinnern dann in den Konturen an die Blattform, welche die Var. b. der S.Cajrea zeigt. Die obere Blattseite ist in der Jugend mit wegwischbarem Flaume bedeckt, im Alter kahl, glat und glänzend grün, die untere Blattläche erscheint in der Jugend seidig; im Alter von kurzen Hïrchen zerstreut behaart, bläulich, glanzlos und ron zarten Nerren fein geadert. Dic blassn, weisslichen Neiren schneiden sich scharf aus der bläulichen unteren Blattläche heraus, sind aber bei weitem weniger scharf markirt als jene der Bastarte aus S. purpurea mit $S$. rundifila. - Die Kätzchen sind, nachdem sie die glänzenden Kno pendecken gesprengt, in seidigen Pelz gehüllt, durch welchen wie bei $S$. purpurer die dunklen, schwarzpurpurnen Kätzchenschupen wie durch einen Schleier durchschimmern. Zur Zeit der Biüthe sind die Kätzchen rerlängert zilindrisch, gedrängtblüthig und haben ganz den Typus der Kätz hen ron S. purpuree. Der Stiel der seidig-filzigen Fruchtlinoten ist zu Anfang der Bluithe nur wenig länger, zu Ende der Bliithezeit doppelt so lang als die Torusdrüse. Die gelben, eiförmigen Narben sind sitzend und zusammenneigend und weisen auf $S$. Caprea hin, die sich auch in der elliptischen Form der ausgewachsenen Blätter und in der geringeren Zahl der Fiedernerven ausspricht. Diese leizteren Merkmale sind auch die- 
jenigen, durch welche sich die hier heschriblene If cide ron den schr ähnlichen Bastarten, die aus $S$. cinerert oder $S$. yrandifolin und $S$. purpuren herrorgegangen zu sein scheinen, unterscheiden lässt. Allerdings ist als diessfälliger Unterschied auch noch erwähnenswerth, dass bei den oben beschriebenen zwei Blendlingsarten: S. Neilieichii und S. austriaca das Nerrennetz der unteren Blattseite noch deutlicher hervortritt und schärfer markirt ist, als bei S. Nuternensis, aber es ist geradezu unmöglich. den Grad des Herrortretens rurch Worte noch näher und bestimmter auzudrücken.

Bisher wurde S. Mantemenais in Niederïstencich in zwei Sträuchen beobachtet: der eine mit Stenjelblüthen am Lfer der Donau vor dem Schönbornischen Schlosse zu Mautern, der zwrite. his jetzt nur in Blättern in einer Seitenschlucht des Donauthales zwischen der Ruine Wolfstcin und dem ehemaligen Karthäuserkloster ron Aggsbach.

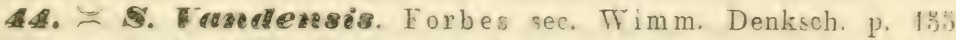
(jurpuren-nifriccins). - Amenta praecocia rel subcoaetanea, sessilia, in basi foliolis squarnaeformibus $3-i$ fulta, staminigera ovata, bis longiora quam latiora. Squamae oblongo-lanceolatae, acutae, in basi ferugineae, apicem versus atratae, pilosae. Glandula tori breris, oblonga, truncata. Stamina duo, flamenti, reque ad medium vel, an duo trientes comnatis, antheris ante anthesin rubercentibus, sub anthesi luteis et serius sordide flarescentibus. Folia obvers: lanceolata, quater longiora quam latiora, supra medium serrota, dilatutu, contracto-cummunicata, in basi cumeata et interra, adolescentia sericca. aduitu

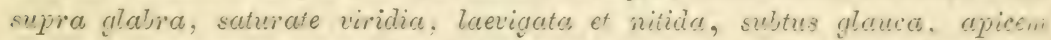
qcrsus plerumque virescontia, glabrata vel in neruis pilis dipersis vestitu. Xerri secundarii ad marginem decurrentes $12-16$, in pagina inferiori elevari et cum renis anastomoticis subeleratis reticulum constituentes. Ramuli annutini glaberrimi, subnitidi, castaneo-nigricantes.

A.m. o $150-20 \mathrm{~mm}$ lg. $10-12 \mathrm{~mm}$ lt.

Squam. $2 \mathrm{~mm}$ lg. Stam. $5-6$ mm 1 t.

Fol. $60-90 \mathrm{~mm} \mathrm{lg} .10 \mathrm{D}-2 \mathrm{~g} \mathrm{~mm}$ lt.

S. purpurea-ñigricans Wi mm. Denksch. p. 155. - Wir haben den Namen S. Tandensis F or bes für diesen Blenuling gewählt, da nach Wimmer (1. c.) sich ein Exemplar mit dieser Bezeichnung aus England im Berliner bot, Garten vorfindet.

Strauch vom Typus der $S$ purpusu. Die Zweige sind jedoch sparriget und dicker, als an S. purpurea und in Folge des stärkeren Forspringens der Narben etwas knorriger. Die Rinde ist dunkelbraun, glänzend. Die Blätter zeigen wohl den Zuschnitt der S. purpurece, sind aber kürzer und breiter und unterseits etwas mehr geadert. Die untere Blautseite ist blaulieh, wird aber an der Spitze gewöhnlich grün und erimert dann lebhaft an die gleiche Eigenthümlichkeit der misten Formen von s. migricans. Auch das auffallend leichto Schwarzwerden der Bldtter beim Trovlenon weiset auf 
S. nigricans hin und unterscheidet $S$. Vandensis ron der sonst ähnlichen S. austriaca, deren Blätter zwar im Verwelken auch den schwärzlichen Farbenton bekommen, aber beim Trocknen im Papier sich nicht so leicht und schnell schwarz färben, wie jene des hier beschriebenen Bastartes.

Bisher wurde von uns nur ein Strauch mit Staubkätzchen am Ufer des Baches zwischen Göstling und Lassing aufgefunden, an welchem Standorte auch die muthmasslichen Stammältern, beide gleich häufig, rorkommen.

Sect. XIII. Incubaceae Fries. - Fruticuli trunco subterraneo et ramis gracilibus, arcuato-adscendentibus. Folia ellyptica rel tineari-lanceolata. Amenta breviter cylindrica vel ovata vel globosa. Stamina duo, filamentis liberis, antheris ante anthesin rubescentibus, deinde luteis et post anthesin nigricantibus vel sordide faris. Germina ex orata basi conica, pedicellata, pedicello glandulam bis - qualer superante. Slylus brevissimus vel nullus. Stigmata brevia, ovata vel oblonga.

45. $\asymp$ S. pleates Fries 2.) globosa (superrosmarinifolio-aurita). - Amenta praccocia, sessilia, orata et bis longiora quam latiora rel aequaliter longa ac lata et subrotunda, fructifera globnsu. Squamae obovatac, obtusae, purpureo-nigricantes. pilosae. Flandula tori brevis, truncata, flavescens. Germen ex orata basi conicum, sericen-tomentosum, pedicellatum, pedicello glandulam tori ter superante. Stylus brevissimus rel nullus. Stigmata brevia, oblonga vel orata, erecto-patula, flavescentia. Stamina duo, antheris ante anthesin rubescentibus deinde luteis et post anthesin sordide faris, flamentis liberis. Folia lanceolata vel ellyptica, bis - quater longiora quam latiora, plana, in acumen rectum breviter producta. integra vel paucis denticulis instructa, adolescentia sericea, adulta supra sordide riridia, opaca, subtus glauca, utrinque subericeo-tomentosa vel supra glabrata et subtus solummodo, subsericeo-tomentosa. Nervi secundarii utroque latere $6-8$, in pagina inferiori piominentes et cum paucis venis anastomoticis subelevatis reticulum constituentes, in pagina superiori lineis impressis significati, quare folium rersus apicem nonnunquam plicatum. Stipulae lanceolatae vel semicordatae. Ranuli annotini sicut gommae glabri.

Am. ơ 8-12mm lg. 8-10mm lt. Am. ₹ 6-14 mm lg. 6-8mm lt.

Squam. 1. ${ }^{\mathrm{mm}} \mathrm{lg}$. Germ. 1.3̈-2.3 $\mathrm{mm} \mathrm{lg}$. Ped. 1-2 $\mathrm{mm} \mathrm{lg}$. Stam. 6-7mm lg.

Variat foliorum forma :

c. Catifolies. - Folia elliptica, bis longiora quam latiora.

Fol. $20-36^{\mathrm{mm}} \mathrm{lg}: 10-18^{\mathrm{mm}} \mathrm{lt}$. 
quam latiora.

Fol. $25-50^{\mathrm{mm}} \mathrm{lg} .6-15^{\mathrm{mm}} \mathrm{lt}$.

S. aurita-repens Wim m. Denksch. p. 171 (pr. parte). Neilr. Fl. ז. ‥ Oest. 1. 262.

Niederes spannhohes Sträuchelchen mit bogig aufsteigenden Zweigen und unterirdisch kriechendem Hauptstamme. Die einjährigen Aestchen sind bis gegen den Frühling zu flaumig, werden aber während der Blüthe kaht und ihre Rinde erscheint dann braun und glänzend. In der Tachithumsweise, so wie in der Physiognomie kommt der hier beschriebene Blendling ganz mit $S$. repens überein (siche diese), die Aeste sind aber bei weitem nicht so schlank, sind steifer und sparriger und nur mit $2-8$ Kätzchen $b c=$ setzt, während die biegsamen Ruthen der S. repons gewöhnlich cine ricl grössere Zahl von Kätzchen tragen. Die Blätter sind lanzettlich und entsprechen in den zwei oben angegebenen Formen a. und b. den beiden später zu beschreibenden Varietäten der S. repens 2.) rosmarinifolia. - Die Fiedernerven sind an der unteren Seite stark rorspringend, und ithnlich wie bei S. aurita auf der oberen Seite durch vertiefte Linien angedeutet, die namentlich gegen die Spitze zu. manchmal selir tief sind und der Pflanze den Namen S. plicata (Fries Nor. Fl. suec. M. I. p. 66) erworben haben. - Die Anastomosen springen jedoch an der unteren Seite chon bei weitem nicht mehr so vor, wie bei $S$, aurita. Nur bei einem kleinen Strauche von den "Neuntagwerkwiesen" bei Bergern. der sich durch die im obersten Dritte! breitesten, verkehrteiförmigen Blätter näher an S. auita anschliesst und vielleicht in die Rotte Rugosae gestellt werden nuss, dessen Beschreibung wir jedoch wegen mangelnder Blüthen suspendiren, sind die Anastumosen sehr stark vorspringend und das Blatt aurh mehr runzelig. - In der Belileidung hält S. plicata 2.) globosa genau die Mitte zwischen S. repens und S. awita. Die Haare liegen wohl nicht wie bei S. repens an der Blattläche an, sind aber alle in gleicher Richtung nach rorwärts geneigt und in Folge dessen erscheint auch die behaarte Fläche etwas glinzend. Im Alter werden die Blätter manchmal fast gan kahl und sind dann oberseits braungriin, unterseits bläulich. Die rerwelkten Blätter sind schwarz und die getrockneten Blattexemplare färben etwas feuchtes Papier, in welchem sie durch längere Zeit liegen, mit schwarzen Flecken. Die Kätzchen sind klein, zur Zeit der Blïthe und Fruchtreife rundlich. - Durch diese rundlichen Kätzchen unterscheidet sich der hier beschriebene Blendlingronden zwei als S. uuritu-iejuns in Herb. Salic. Nr. 36 u. 33 von Wrimmer ausgegebenen W eiden. mit denen er sonst ganz gut übereinstimmt. - Diese, von denen die letztere nach W i mmer genau der $S . p$ licata. Fries und $S$. amlinge Ehrlh. entspricht, besitzen nämlich zilindrische Kätzchen, die schon zur Bliithezeit fast dreimal so lang als breit sind, während bei dem oben beschriebenen Bastarte die Kätzchen höchstens zweimal so lang als breit erscheinen und bei der Fruchtreife fast kugelig aussehen. Wir haben dem entsprechend obigen Bastart auch als \&. 
plicata var. glntosa bezeichnet und glauben, dass jene Form der S. repens bei seiner Frzeugung sich betheiligte, die nachfolgend als s. repens 2.) rosmarinifolia aufgefiihrt werden wird. - Die beiden obenerwähnten Blendlinge (Wrimm. Herb. Salic. Nr. 33 u. 36) hingegen scheinen aus S. repens 1) cylindrica *) hervorgegangen und sind mit den beiden oben angeführten Yarietäten a. und b. in Parallele zu stellen.

Ko ch und Fries haben unter S. plicata und S. amlingu nicht bloss die hier berührten Bastarte, sondern auch noch eine der S. aurita viel näher stehende Form, so wie Blendlinge aus S. cineren und S. repens zusammengefasst. Lm nicht neue Tamen schaffen zu müsen, machen wir den Vorschlag, die S. aurita-repens Wimm. Herb. Sal. Nr. $3 \ddot{3}$ u. 36 als S. plicatu 1.) cylindrica, ihre oben beschriebene Parallelform als S. plicuta 2.) ulobosa und den der S. arritu näher stehenden Bastart als $S$. ambiruc künftighin zu bezeichnen.

Die S. plicata 2.) Mlobosa findet sich in Niederüsterreich in Gesellschaft ihrer beiden muthmasslichen Stammältern im Bereiche des böhm.-mährischen Gebirgsplateaus auf der höchsten Kuppe des Jauerlings (3000') und auf den „Neuntagwerkwiesen" bei Bergern $\left(1800^{\circ}\right)$; an beiden Standorten in zahlreichen Exemplaren.

46. F. Pegeves 2.) rosmarinifolia Koch Syn. 368. - Amenta subcuactanea, sessilia. orata et bis longiora quam latiora vel subrotunda aequaliter longa ac lata, intetiferce ilobosa. Squamae obovatae, obtusae. purpureu-nigricantes, pilosae. Glandula tori brevis, truncata, purpurea. Germen ex orata basi conicum, post anthesin elongato-conicum, sericeo-tomentosum, pedicellatum, pedicello glandulan tori bis - ter superante. Stylus brevisimus. Stigmata lineria. orata, emarginata rel bipartita, erecto - patula, purpurea vel flarencenti-purpurea. Stamina du, antheris ante anthesin purpureis, deinde luteis et post cunthesin nigricuntilus. filamentis liberis. Folia linearia, linearilanceolato wel oblongro-lanceolalu ter - decies longiora quam latiora, marine plememerte subdefleca, integra vel paucis denticulis instructa. in acumen rectum proilucta, adoleseentia supra glabra, subtus sericea, adulta supra obscure viridia, nilidela, glabra rel levissime sericeo-pubescentia, suluts arienteosericeu et nitida vel glabrata et glauca. Nerri secundarii ad marginem decurrentes utroque latere $8-12$, in payina inferiori et superimi sulelev ti. Stipulae lanceolatae. Ramuli annotini pubescentes, demum glabrati.

Am. o $6-16^{\mathrm{mm}} \mathrm{lg} .6-12 \mathrm{~mm}$ lt. Am. 9 है-12um lg.

Squam. 1-1.5 $\mathrm{mm} \lg$. Germ. 2-3, $\mathrm{mm} \lg$. Pedic. $1-2 \mathrm{~mm} \lg$. Stan. $3-6^{\mathrm{mm}} \mathrm{lg}$. Variat foliorum forma:

r. Iretifolies. Folia oblonga vel oblongo-lanccolata, bis - quinquies longiora quam latiora.

Fol. $24-60^{\mathrm{mm}} \lg .6-18^{\mathrm{mm}} \mathrm{lt}$.

*) Siehe Seite 268 . 
S. repens b. latifolia Neilr. Fl. v. N. Oest. p. 264. - Kov. Fl. exsicc. Vind. Nir. 1071. 1072. S. pratensis $\mathrm{H}$ ost Salix tb. 51 .

b. cacsecstefotec. Folia linearia rel lineari-lanceolata, quinquies

- decies longiora quam latiora.

Fol. $45-\not 36^{\mathrm{mm}} \mathrm{lg} .3-8^{\mathrm{mm}}$ It.

S. repens a. angustifolia Neilr. Fl. r. N. Oest. p. 26k. Ko r. Fl. exsic. Vind. Nir 1069. 1070. S. temuis Il ost Salix p. 14. tab. 47, 48. - S. pratensis Host Salix tab. 30. - S. angustifolia et rosmarinifolia Wulf. in Jacq. collect. 3. p. 48. (sec. specim. in Herbar. Wulf.) - S. rosmarinifolia Fries Herb. norm. Fasc. VI. - (Fries und Kocli halten ihre $S$. repens und $S$. rosmarinifolia mit den gleichnamigen Weiden Linnés [L. sp. 1417 u. 1488] für gleichbedeutend und ihre S. angustifolia identisch mit S. incubacea des Li nnéschen Herbars und Willdenow's, wälirend die S. incubacea L. sp. pl. 14k7 sich nach Fries auf $S$. plicata Fries beziehen soll. - Wir theilen hingegen Wimmer's Ansicht, dass L inné unter seiner $S$. repens wahrscheinlieh die $S$. rosmarinifolia und $S$. repens $\mathrm{Koch}$, Fries zusammenfasste und dass seine $S$. rosmarinifolia mit der Kocli'schen $S$. angustifolia identisch sei. Unzweifellaft darüber in's Reine zu kommen, ist wohl kaum zu erwarten, wenn man Fries bei S. repens [1. c. p. 66] sagen lört: „Hujus ut rulgatissimae formas cum. S. Lapponum fusca, incubacea et forte myrtilloide sine dubio commutavit Linné. - Wir glaubten darum am 2weckmässigsten zu verfahren, wenn wir oben zu S. rosmarinifolia nicht Linné sondern K och als Autor zitirten.)

Einer der niedlichsten Sträucher unserer Flora. Der Hauptstamm ist unterirdisch kricchend, mit reichlichen Turzelfasern besetzt und seine Zweige hroben sich bog*enförmig ron dem Boden empor. Der unterste Theil der cinjährigen Zweige ist mit einigen Laubknospen besetzt, nach aufwärts folgen damn 10-40 Bliithenknospen und am Gipfel der Zweige stehen dann wieder 2-3 laterale Laubkno-pen. Diese letzteren kommen aber in der Regel grar nicht zur Entwicklung, dorren vielmehr schon vor dem Frühling mit sammt der Spitze des Zweiges ab, und die oberste sich entfaltende Knospe ist daher gewöhnlich eine Blüthenknospe. - Vach dem Ausflegen der Samen stirbt dann auch jener Theil des Zweiges, welcher nit den Kätzchen besetzt war, ab. Nur der untere mit Laubknospen besetzte Theil bleibt grïnend, schmiegt sich dann der Erde an, bildet die Verlängerung des kriechenden Hauptstammes und aus seinen Laubknospen wachsen neue schlanke reichbeblätterte Ruthen empor, an welchen sich der eben erläutcrte Vorgang im nächsten Jahre wiederholt. - Viel seltener kommen die am Gipfel der einjährigen Zweige stehenden zwei oder drei lateralen Laubkno:pen zur Fntwicklung und da dieselben dicht gedräng't stehen, so entspringen dann anch die aus ihnen herrorsprossenden $z$ wei oder drei neuen Zweige fast in gleicher IÏ̈le rom Gipfel des zweijährigen Zweiges, der inzwischen wuit hinab nackt geworden ist und zahlreiche Narben von den abgefallenen Kätzihen zeirt. In diesem letzteren Falle erhebt sich s. repens manchmal bis zu zwei oder drei Schuh, in ersteren Falle hingegen bleibt sie niedriger und stellt guwïhnlich nur ein spannhohes Sträuchelehen dar, densen unterster Theil ein fast verkrïppeltes Aussehen zeigt, da die Stummeln der abredurten Zweige sich gewöhnlich noch Jahre lang erhalten, - Auf den Wienen, weldhe 
gemäht werden, erscheint sie durch die bei der Mahd erfolgende Verstïmmelung natürlich noch mehr verkrüppelt.

Die einjährigen Zweige sind gewöhnlich flaumig. Die zweijährigen Zweige jedoch sind kahl und hellbraun, ihre Rinde aber ist gewöhnlich glanzlos und wird schon im nächsten Jahre runzelig und grau. Die Blätter wechseln in Umriss, Grösse und Bekleidung sehr ab. In Beziehung auf den Umriss durchlaufen sie bei der oben beschriebenen S. repens 2. rosmarinifolia gerade so, wie bei ihrer in Niederösterreich bisher nicht aufgefundenen Parallelform S. repens 1. eylindrica (S. repens Koch. Syn. p. 567 [excl. var. $\delta . \varepsilon$.] Fries Nor. fl. suec. M. I. p. 64. Host Salix p. 16. t. 53.) eine ganze Stufenreihe ron der linealen bis zur breit-ellyptischen Form. Während aber bei S. repens 1. cyllindrica die ellyptische Form die rorherrschende ist, erscheinen die Blätter der S. repens 2. rosmarinifülia in ihrer typi:chen Form lineal ader lineal-lanzettlich. Die Blätter der $S$. repens 1 . cylind. sind in der gewöhnlichen typischen Form 2-3mal, in ihrer schmalblättrigen Tarietät 4-ömal so lang als breit, jene der $S$. repens 2. $r 0 s m$. in ihrer breitblättrigen Varietät 3-ömal, in der gewöhnlichen typischen Form 5-10mal so lang als breit. Die Blätter der S. repens 1. cyl. sind auch steifer, mehr lederig, am Rande umgebogen und ron einem nach abwärts gekrümmten Spitzchen kurz bespitzt, während jene der S. repens 2. rosm. sich in eine gerade Spitze verschmälern. Bei beiden Parallelformen treten die Fiedernerren unter spitzen $W^{\text {ink }}$ ln $\left(30-\$ 0^{\circ}\right)$ rom Mittelnerren ab und springen nur ganz wenig, und zwar an der unteren und oberen Blattseitc gleichmässig ror. Die Zahl der stärkeren, bis zum Rand rerlaufenden Fiedernerren schwankt bei S. repens 1. cyl. zwischen $6-8$, bei S. repens 2.rosm. zwischen 8 und 12. - Am häufigsten erscheinen die Blätter der S. repens 2. rosm. oberseits kahl oder nur mit spärlichen Härchen bestreut, unterseits ron langen, geraden, dem Mittelnerr parallel anliegenden Haaren seidig und silberglänzend. Diese Bekleidung tritt aber erst im ausgewachsenen Zustande deutlicher herror. Zur Zeit, wo die Blätter aus den Knospen treten, sind sie fast kahl und nur an einer auf Torfmooren bei Gross-Weissenbach am Plateau des Waldviertels rorkommenden Form erschienen sie schon in der ersten Jugend beiderseits seidig, und waren bei dieser dann auch im ausgewachsenen Zustande oberseits stärker behaart. So dicht bekleidete, beiderseits seidig-filzige und silberglänzende Blätter aber, wie sie die S. repens 1 . cylind. gewöhnlich an den Dünen der Nord- und Ostsee zeigt ( $S$. aryentea Sm.) finden sich an S. repens 2. rosm. niemals ror. Selten sind die ganz kahlen Spielarten der S. repens 2. rosmarinifolia. Sie scheinen nur das Erzeugniss eines sehr üppigen Bodens zu sein, uึnd gewöhnlich sind es die breitblättrigen Formen, welche beiderseits kahle Blätter besitzen. Gerade die breitblättrigen Formen der S. repens 1. cylindrica aber sind unterseits dicht seidig und es kann daher ron einer Verwechslung der breitblättrigen Spielarten der S. reprens 2. rosm. und S. repens 1. cylind. wohl keine Rede 
sein. - Viel leichter ist eine Verwechslung ihrer schmalblättrigen Varietäten, und oft dürfte es kaum möglich sein, aus den Blättern die eine oder andere zu erkennen. Sicheren Aufschluss zur Unterscheidung geben dann nur die Kätzchen. - Bei S. repens 2. rosmarinifolia sind die Kätzchen zur Zeit der vollen Blüthe sitzend, halbkugelig oder eiförmig, dichtblüthig und so klein, dass die schuppenförmigen, linealen Blättchen, welche die Basis umgeben, mit ihnen fast gleiche Länge haben oder wenigstens die halbe Länge der Kätzchenspindel erreichen. Bald aber nehmen die Kätzchen sehr an Umfang zu. Die zur Zeit der vollen Blüthe $2-3 \mathrm{mn}$ langen Fruchtknoten verlängern sich bis auf $6-7 \mathrm{~mm}$ und die früher nur $1 \mathrm{~mm}$ langen Stielchen zeigen jetzt eine Länge von $3 \mathrm{~mm}$. Dabei bleibt aber die Spindel des Kätzchens verhältnissmässig kurz $\left(6-10^{\mathrm{mm}}\right)$ und die fruchttragenden Kätzchen erscheinen daher fast kugelförmig. Hierin ist nun ganz vorzüglich ein Merkmal gegeben, um die S. repens 2. rosm. ron der S. repens 1. cyl. unterscheiden zu können, indem letztere zur Zeit der rollen Blüthe längliche Kätzchen besitzt, die zum wenigsten zweimal so lang als breit sind, die die schuppenförmigen Blättchen an der Basis um mehr als das Doppelte überragen, zur Zeit der Fruchtreife zilindrisch werden und sich bis zu $1 \ddot{-}-22^{m m}$ verlängern. - Im Baue der einzelnen Blüthen besteht jedoch zwischen beiden Formen nicht der geringste Unterschied.

Vergleicht man die breitblättrige S. repens. 1. cyl. mit elliptischen am Rande umgerollten und zurückgekrümmt bespitzten, beiderseits seidigen Blättern und zilindrischen Fruchtkätzchen ron den Torfmooren der Alpen oder den Dünen der Nord- und Ostsee mit unserer S. repens 2.rosm., so ist man allerdings geneigt, beide fïr spezifisch verschiedene Teidenarten zu halten und die schmalblättrigen Formen der S. repens 1. cul. als Bastarte aus diesen zwei Stanmarten anzusehen. - Da aber, wie erwähnt, im Bau der einzelnen Blüthen bei der einen wie der andern kein Unterschied besteht, so scheint eine Trennung in zwei Arten kaum gerechtfertigt und es ist wahrscheinlich, dass S. repens 1. cyl. und S. repens 2. rosm. Parallelformen eines und desselben Stammes darstellen, obschon es bei den riclen zweifelhaften Angaben über das Vorkommen dieser zwei vielfach konfundirten Weiden, so wie bei den mangelhaften Daten über die Verhältnisse der Standorte nicht möglich ist, mit einiger Wahrscheinlichkeit den Faktor anzugeben, welcher die Dirergenz beider Formen beding't.

Von Grisebach (Veg. Lin. d. n. ö. D. p. 72.) wird der S. rosmarinifolia eine südliche Vegetationslinie zugeschrieben, die ron England her durch das nordwestliche Deutschland unterm $\ddot{3} 20$ verläuft und sich ostwärts nach Oesterreich fortsetzt. - Die S. rosmarinifolia Koch's, so wie die S. rosmarinifolia Fries's des südlichen Schwedens ist aber naeh OriginalExemplaren mit der oben beschriebenen S. repens. 2. rosincrinifolia der Donautiefländer, so wie mit der südlich der Alpen an der venetianischen Ǩ̈̈ste rorkommenden gleichnamigen $W^{2}$ eide identisch. und wenn wir alle dic- 
jenigen Standorte, die sich nach vorliegenden Exemplaren, oder nach zurerlïssigen neueren Angaben auf S.rosmarinifolia bezichen, zusammenfassen, so ergibt sich eine riel weiter nach Süden gerïckte Veg.-Linie, welche aus dem siidlichen Frankreich nach Tenedig. dann an die Lfer der Sare, in das Temeser Banat und durch das südliche Siebenbïrgen in das Gebiet des Dniepers (Nicolajew, nach Exempl. im Wien. Mus.) nach Bokhara (Exempl. ron Lehman, ron Bunge als ,S. repens rar." bezeichnet im Wien. Mus.) hinzieht. Nördlich ron dieser Linie ist $S$. repens 2. rosmarinifolia in den Donautiefländern eine häufige, und sowohl für die Flora der torfigen Sïmpfe, so wie auch des fuchten Sandbodens charakteristische Teide. Sie dringt jedoch ron dem Elachlande weder in die Thäler der Alpen, noch der Karpathen ein, und nur ein paar rereinzelte Standorte sind bisher auf Torfmooren im alpinen Gebiete angegeben; desto häufiger erscheint sie auf dem Plateau des bühmisch-mährischen Gebirges. Bis zu den höchsten Kuppen zu $30000^{\prime}$ findet sie sich dort als charakteristischer Bestandtheil der Moorwiesen und bildet auch dort mit $S$. aurita den früher beschriebenen Blendling S. plicata 2. globosa. - In dem niederösterreichischen Antheil des böhmisch-mährischen Gebirgsplateaus findet sie sich insbesonders bei GrossTYeissenbach, Kirchberg am Walde, Gföhl, Hartenstein, am Jauerling, im Isperthale und über Gansbach und Bergern bis an den Südrand des Gebirges nach Viehhofen bei St. Pölten. - In dem Flachlande des Wiener Beckens ist sie insbesonders im Marchfelde, dann in der südüstlichen Niederung ron Wien und ron dort einwärts in die niederen Thäler des Wienerwaldes (Kaltenleutgeben) rerbreitet. - In dem alpinen Gebiete Niederösterreichs ist sie bisher nicht aufgefunden.

Die S. repens 1. cylindirica kommt in Niederösterreich, so wie auch in den südöstlich an Niederösterreich sich anschliessenden Gebieten (ungar. Flachland, Banat, Siebenbürgen, Serbien, Südrussland *) nicht ror, doch findet sie sich in den nördlich und westlich angrenzenden Bezirken in den ungarischen nördlichen Karpathen, in Bühmen und Mähren, so wie auf Torfmooren in Südbaiern, Tyrol, Salzburg und Steiermark. - Sie scheint mit S. myrtilloides fast gleiche Terbreitung zu haben und findet sich wie diese auf den Torfmooren der Alpen und Karpathen, in der baltischen Niederung und nördlich bis Lappland.

S. repens 2. rosm. erreicht hingegen schon viel frïher ihre nördliche Yegetationslinie, die rom mittleren Schweden und den Allandsinseln nach Finnland, Petersburg und Moskau hinzieht.

* In Sertum Fl. trans. won Schur wird sie zwar neben S. rosmarinifolia aufrefiilırt. Die unter dem Namen S. repiens im Herb. des Wiener bot. Hofkabinetes befiddichen Sch urischen Eexemplare gelïren jedoch zu S. repens 2.j rosmarinifolia. Ebenso gehüren alle aus Suidrusslaul dort liegrenden Exemflare zu S. rosmarinifolia und Claus's Angabe der $S$. repens in her kaspischen Steppe dürte sich gleichfalls auf $S$, rosmarinifolia bezielien. 
Die S. myrtilloides, welche sich nebst mehreren muthmasslich aus ihr herrorgegangenen Blendlingsarten an S. repens anschliesst, wurde in Niederösterreich bisher nicht aufgefunden.

\section{Sect. XIV. Purpureae Ko ch. Frutices rel arbores minores trunco} erecto, ramis rectis gracilibus et tenacibus. Folia obrerse lancenlata, supra medium dilatala. Amenta staminigera et pistilligera cylindrica. Stamina duo, antheris anle anthesin purpureis, sub anthesi luteis, serius nigricantibus, filamentis totis rel in rariis distantiis comnalis. Germina orata vel oraloconica, sessilia rel breviter pedicellata, pedicello glandulam tori subaequante. Stylus brevissimus rel mullus. Stigmala brevia ovata.

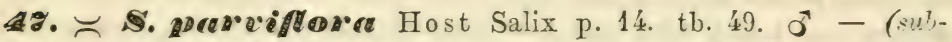
purpureo-repens). - Amenta praecocia, sessilia, staminigera bieviter culindrica, recta, bis lonyiora quam latiora. Squamae oblongae, obtusae, supra medium purpureo-nigricantes, villosae. Glandula tori brevissima, truncata, subquadrata. Stamina duo, antheris ante anthesin purpureis, sub anthesi luteis et serius nigricantibus. Folia lineari-lanceolata, infra medium integra et angustata, supra medium serrata et plerumque dilatata, breriter acuta, adolescentia sericea, adulta supra gla'srescentia et vitidula, subtus subsericea, demum glabruta. glauca, laerigata. Nervi secundarii ad marginem decurrentes utroque latere $8-12$, obliterati, in foliis exsiccatis in pagina inferiori et superiori subelevati. Ramuli annotini pubescentes.

Am. ठ 14-20

Squam. $1.5^{\mathrm{mm}} \mathrm{lg}$. Stam. $4-\mathrm{g}^{\mathrm{mm}} \mathrm{lg}$.

Fol. $36-60^{\mathrm{mm}}$ lg. $6-10^{\mathrm{mm}} \mathrm{lt}$.

S. parviflora Host Salix ơ tb. 49 p. 1 ; staminibus basi connatise et p. 15. „Folia primo sericen villo tecta, dein glabra, facie saturate viridia, dorso pallida, pauca apicem versus denticulata . Stamina duo inferne coalita ${ }^{\star}$. Auch dıe auf Tr. 49 Fig. 3 dargestellte Blüthe stimmt vollkommen überein. - S. purpureo-repens Nie ilr. Fl. v. N. Oest. p. 2ั\%. Die von Wimmer im Herb. Salic. Fasc. II. Nr. 18 ausgegebene männliche $S$. purpureorepens ron 0 els in Schlesien ist ron der hier beschriebenen Weide durch kahle einjährige Zweige, länğere Kälzchen, und durch die bis gegen die Antheren hinauf rerwachsenen Staubfaden verschieden und stelit jedenfalls der $S$. purpurea näher als die $S$. parviflora $\mathrm{H}$ o st.

Kleiner Strauch mit aufrechtem Stamme und schlanken dïnnen Acsten, der durch den grauflaumigen Ueberzug der einjährigen Zweige, die kurzen geraden Kätzchen und die seidige Bekleidung der Blätter mit s. inens verwandt erscheint, anderscits durch die an der Basis oder bis zum unteren Drittel verwachsenen Staubfäden, die im vordersten Drittel gewöhnlich breitesten Blätter und durch seine Wachsthunsweise sich an s purpureu anschliesst. - Blüht etwas früher als S. repens 2. rosmarinifolia. 
Wurde von Neilreich im Marchfelde aufgefunden, wo auch die beiden muthmasslichen Stammältern S. repens 2.) rosmarinifolia und S. purpurea häufig rorkommen.

48. S. nowspeener L. sp. 14.2. - Amenta praecocia, sessilia, cylindrica, densiflora, plerumque arcuata, staminigera ter et semissi - quater, pistilligera quater - octies longiora quam latiora. Squamae oboratae, rotundatae, obtusae, supra medium atratae, pilosae. Glandula tori brevis, oblonga, truncata, basin germinis superans. Germen sessile, ovatum, sericeo-tomentosum. Stylus nullus vel brevissimus. Stigmata brevissima, ovata vel subrotunda, lutea vel purpurea. Stamina duo, filamentis usque ad apicem connatis, antheris ante anthesin purpureis, sub anthesi luteis et serius nigricantibus. Folia obverse lanceolata, quinquies - octies longiora quam latiora, infra medium angustata et integra, supra medium dilatata et serrata, breviter acuminata, adolescentia villo abstergendo, rubiginoso tecta et sacpissime subsericea, adulta glaberrima, supra viridissima et nitidula, subtus glauca, opaca, laevigata. Nervus medius crassus, flarus vel ferrugineus. Nervi secundarii ad marginem decurrentes utroque latere 22-30, obliterati, in pagina superiori foliorum exsiccatorum tandem subelevati. Ramuli annotini glaberrimi, cortice nitido tecti.

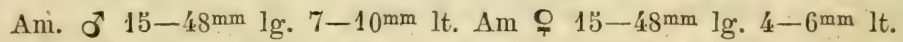

Squam $1 \mathrm{~mm} \mathrm{lg}$. Germ. 1.5 $\mathrm{mm} \mathrm{lg}$. Stam. $3-4^{\mathrm{mm}} \mathrm{lg}$.

S. purpurea Host. Salix tab. 40 u. 41. Koch. Syn. p. 560, Fries Herb. norm. Fasc. II. Nr. 56. W imm. Flora 1819 p. 33, Herb. Salic. Fasc. V. Nr. 52. Kor. Fl. exsicc. Vind. Nr. T76. Neilr. Fl. v. N. Oest. p. 256. - S. mutabilis Host Salix tab. 42 u. 43. S. carniolica Host Salix $\mathbf{O}$ tb. 45. - S. oppositifolia Host. Salix tb. 39, (S.oppositifolia Host $\sigma^{7}$, welche nach der Abbildung tb. 38 getrennte Antheren und unterseits blassgrüne Blätter besitzt, ebenso S. carniolica $\widehat{O}^{\top}$, welche Host nfilamento unico apice bifido, laciniis antheriferis « beschreibt, im Gegensatze zu dieser Beschreibung aber tb. 4 ' Fig. 3 mit Staubfiden, die der ganzen Länge nach rerwachsen sind, abbildét, sind $\mathrm{z}$ weifelhafte Formen, die entweder zu S. Forbyana !oder zu der Seite 27ł zu erwälnenden S. purp. var. monadelpha gehören.)

Variat: latiora.

e. Eetifoece. Folia oborato-lanceolata, quinquies longiora quam

Fol. $50-85^{\mathrm{mm}} \mathrm{lg} \cdot 12-22 \mathrm{~mm}$. It.

S. purp. $\beta$. Lambertiana Koch Syn. p. 560 . - S. purp. var. d. WVimm. Flora 1819 p. 33. S. Helix T a usch. pl. sel. ठ̋' et fol.

E. cusgestifotere. Folia lineari-lanceolata, octies longiora quam latiora.

Fol. $50-110^{\mathrm{mm}}$ lg. $6-1 \mathrm{x}^{\mathrm{mm}} \mathrm{lt}$.

S. Helix II ost Salix p. 10 tb. 36. u. 37. - S. purpurea $\gamma$. Helix K och Syn. p. 560. excl. Syn. L. (Von Koch und den meisten Autoren wurde S. Helix L. auf die sclimalblätrige Form der S. purpurca bezogen. Smith, welcher in der Lage war das Linnésche Herbarium zu vergleichen, beschreibt nümlich die S. Helix als monandra und auch die Ab- 
bildung in S mith English Botany Vol. XIX tb. 13ł3 zeigt die Staubfäden rollständig miteinander verwachsen und das Blatt vom Zuschnitte der $S$. purpurea. Der weiblichen Pllanze aber schreibt Smith einen verlängerten Griffel zu und die auf der zitirten Tafel abgebildete weibliche Blüthe scheint des deutlichen Griffels wegen der S. rubra anzugehüren. Wahrscheinlich hat daher Smith. Stempelblüthen der $S$. rubra mit nicht dazu gehörigen Staubblüthen und Blättern der $S$. purpurea unter seiner $S$. Helix beschrieben. Wenn aber Smith auch im Linnéschen Herbarium vielleicht Stempelblüthen der $S$. rubra und Staubblüthen der S. purpurea zusammengewürfelt als $S$. Helix vorgefunden haben sollte, so steht doch sehr zu bezweifeln, dass Linné diese $z$ mei Weiden auch nicht richtig geschieden habe und dass er, wie Wimmer sehr richtig bemerkt, eine so häufig vorkommende Form wie S. rubra nicht gekannt und anderseits die so scharf characterisirte S. purpurea mit zwei Namen sollte belegt haben. - Wir sind daher mit W imm. der Ansicht, dass sich der Name S. Helix L. auf einen der Bastarte ans $S$. viminalis mit $S$. purpurea und zmar wahrscheinlich auf den häufigsten, nämlich $S$. rubra beziehe. [Veryl. auch hierüber Seringe Saul. d. l. Suisse p. 6 u. 7 und Wimmer Flora 1819 p. 52.]) - S. purpurea rar. c. Wimm. Flora 1819. p. 33.

Die S. purpurea erscheint als buschiger Strauch, der sich manchmal bis zu drei Klaftern erhebt, aber niemals einen bedeutenden Stammumfang erreicht und gewöhnlich rom Grunde aus in zahlrejche Aeste aufgelïst erscheint. Die Zweige sind schlank, biegsam, zäh und mit zahlreichen länglichen, an beiden Seiten gekielten Knospen besetzt, im ersten und zwciten Jahre mit heller, glatter, glänzender, entweder gelblich-grïner oder roth überlaufener Rinde überzog*en, später graugrün und glanzlos. Die abogeschälte Rinde erscheint an der inneren Fläche zitronengelb. Der aus der obersten lateralen Laubknospe herkommende Spross rerlängert sich weit mehr, als jene, welche aus den nach abwärts folgenden Laubknospen sich entwickeln und bildet die gerade, schlanke Fortsetzung des rorjährigen Zweiges, aus dem er herrorgegangen. Die Blätter sind zur Zeit, wenn sie aus den Knospen brechen, entlang dem Mittelnerren regelmäsig mit schmutzigem, meistens rostfarbigem, leicht abwischbarem Filze bedeckt, der schon zeitlich schwindet; riel seltener sind sic etwas seidig behaart (rar. eericea Sering, Saul. d. 1. Suisse. p. 8 et Nr. $32 \mathrm{Koch}$ Syn. p. 56, Wimm. Fl. 1849. p. 33.) und bisher haben wir einen einzigen zu dieser letzteren Form gehörigen Strauch am Donauufer bei Mautern beobachtet. (Verh. d. z. b. V. I. p. 32). Die ausgewachsenen Blätter sind jedoch immer rollständig kahl, oberseits dunkelgrün, etwas glänzend, glatt, und nur im getrockneten Zustande ron feinen, etwas erhabenen Jerrchen geadert, unterseits bläulich, glatt. ron dem rorspringenden gelben Mittelnerr durchzogen. - Formen nit gegenständigen Blättern kommen nicht selten vor und wurden ron IIost als S. oppositifolia $l$. c. beschrieben. - Die dichtblüthigen, schlanken, zilindrischen Kätzchen sind beim Herausbrechen in einen weissen Pelz einguhillt. durch welchen jedoch die schwärzlich-purpurnen, sich noch deckenden Kitzchenschuppen als schwarzer Kern durchschimmern. Seltener ist die Buharung der Schuppen sehr spärlich und die Kätzchen kommen dann fast nackt aus den Knospen herror. - Die Staubkätzchen sind zur Zeit der rollen Blüthe immer bugenfürmig abwärts gekrïmmt. Die Staubfïden stehen zur Zeit, wo sie 
st:iuben, senkrecht auf der Kützchenspindel und die Schuppen sind nach der Blüthe regelmässig zurückg'eschlagen. Die Staubfäden sind der ganzen Länge nach mit einander verwachsen. Sehr selten finden sich androgynische Kätzchen, an deren Staubblïthen die Staubfäden nur theilweise rerwachsen erscheinen. (S. mirabilis Host. Salix p. 13 tb. 46 - S. purp. var. monadelpha Koch u. Neilr.) Diese sehen dann der S. Forbyana ähnlich, unterscheiden sich aber durch die unterseits seegrünen Bläiter, den fehlenden Griffel und die knopffürmigen, sitzenden Narben. - Die Fruchtknoten sind unter allen Weiden bei S. purpurea am kleinsten, und da sie nicht gestielt sind, ist natiirlich auch der Durchmesser der Fruchtkätzchen unter allen Weiden bei der S.purpurea am geringsten. Zur Zeit der rollen Blüthe erscheinen die Fruchtknoten eiförmig, und ihre sitzenden gelben, seltener fleischrothen Narben sind rundlich, knopfförmig. Die zum Aufspringen reifen Kapseln sind eiörmig, etwas zusammengedrückt und nach dem Aufspringen sind ihre Klappen nur wenig nach auswärts gebogen.

Die S. purpurea ist in Europa ron der Mittelmeerzone zu einer nordüstlichen Tegetationslinie rerbreitet, die ron Island her, durch das mittlere Schweden über Petersburg und Moskau an die untere Wolga herabzieht. In Asien wird sie im altaischen und baikalischen Sibirien angegeben und findet sich ferner im mittleren und östlichen Nordamerika und in Nordafrika. Thre obere Grenze fällt in den baierischen Alpen auf $3376^{\circ}$, in den niederö.terreichischen Alpen auf $3100^{\prime}$, in den siebenbürgischen Karpathen auf $2 \mathbf{2} 00^{\prime}$. Unter allen Weiden Niederösterreichs ist $S$. purpurec die häufigste und bildet namentlich in den Donau-Auen streckenweise reine Buschwälder. Sie ist dort der wichtigste Bestandtheil der ersten, auf den Schotterbänken ich ansiedelnden Weidengencration, und wie ron $R$ eissek nachgewiesen wurde, ron grösster Wichtigkeit für die Geschichte der Donauinseln, indem die grösstentheils aus der Puıpurweide bestehenden Anfliige den bei Hochwässern mitgcführten Sand auffangen und zur Ablagerung einer 6-8 Schuh hohen Sandlage Veranlassung geben. Der so über den Schotter aufgeschichtete Sand, in welchem das Buschwerk der S. purpurea oft bis zur Hälfte begraben erscheint, wird dann das Substrat für die später auftretenden Waldgencrationen. Wird die Purpurweide ron hochstämmigen Bäumen überwachsen, so stirbt sie wie die meisten anderen niederen Buschweiden ab. - In prachtroller Entwicklung findet sie sich längs dem Unterlaufe der alpincen Zufliisse der Donau, wo sie auf dem schotterigen Lferlande mit S. incana fast undurchdringliche Buschwälder bildet und dort selbst für den landschaftlichen Charakter Bedeutung gewinnt. - Noch weit einwärts in den Alpenthälern, in welche die Lfer-Chloriteen: S. fragilis, S. alba und S. amyidalina nicht mehr hinansteigen, bildet die S. purpurea nit S. incana, S. nigiricans und S. grandifolia das Ufergebüsch der rauschenden Bäche; findet sich dort auch vereinzelt an quelligen Stellen auf Felswänden (Lassingsfall) und im verkrüppelten Zustande auf Torfboden der 
Hochmoore (Mitterbach) vor. - Bis zu $2800^{\circ}$ ist sie noch ganz allgemein verbreitet. Ton da an vereinzelnen sich aber ihre Standorte und die höclısten Punkte, wo S. purpurea noch rorkommt, finden sich, wie früher bemerkt, bei 3100 Fuss. - Im böhmisch-mährischen Gebirge wird sie noch auf den Höhen des Plateaus, so z. B. um Moidrams bei $2300^{\prime}$ angetroffen. - Sie ist auf kalkreichem Substrate ebensowohl, wie auf kalklosen Unterlagen aufgefunden worden.

\section{Ch a $\mathbf{m}$ it e a *) n. g. Zwergweide.}

Flores dioici, amentacei. Amentibracteae indirisae, unicolores rosaceae. Torus in urceolum laciniatum tumens. Stamina duo. Filamenta libera. Germen sessile, diphyllum, uniloculare. Gemmulae prope basin carpophyllorum nerro adnatae, anatropae. Stylus brevissimus. Stigmata duo, biloba. Capsula unilocularis, bivaltis, valvis post dehiscentiam extrorsum arcuatis, basi medio seminiferis. Semina in utraque valta 3-5, erecta, oblongo-linearia, funiculo brerissimo, crasso pedicellata et in comam lanuginosam, ex apice funiculi orientem intoluta. Albumen nullum. Embryo orthotropus. Radicula infera. Fruticuli alpini, foliis alternis, mediocriter petiolatis, nervigeris.

Die S. reticulata $L$. bietet eine solche Fülle ron auffallenden, eig'enthümlichen Merkmalen dar, dass sich die Autoren fast durchgehends mit der Angabe einiger weniger der hervorragend en Kennzeichen begnügten. - L in né, Smith, Allioni, Wahlenberg, Seringe, Jacquin und die Mehrzahl der älteren Autoren, welche S. reticulata beschrieben haben, berühren nirgends die so merkwürdige Form des Torus. - Koch spricht in seiner Comm. d. salic. von einem "nectarium basin capsulae superans" und dieser Passus ist in seine Synopsis, so wie in die meisten Floren nach ihm übergegangen. - Die Abbildung ron Host zeigt wohl an Fig. 3 u. $\ddot{3}$ ganz gut die der Kätzchenspindel zugewandte Seite der einzelnen Blüthen, doch spricht auch $\mathrm{H}$ ost nur von einem "Nectarium bi-aut tripartitum" und es geht daraus hervor, dass er sich mit der oberflächlichen Ansicht einer ron dem Kätzchen losgetrennten Blüthe, bei welcher er nur zwei oder drei Zipfel des ringsum gelappten Torus wahrnahm, begnïgte, ohne den Bau des Blïthenbodens weiter zu verfolgen. - Dass auch an den Staubblïthen (bei welchen

*) Deriv. $\alpha$ $\chi \alpha \mu \alpha i$ et $i \tau \dot{\varepsilon} \alpha$. 
man an frischen Blïthen, olne die Staulfüden zu entfernen, den die Inscrtionsstelle der Staubgefässe rings umgebenden, zerschlitzten, fleischigen Becher wahrnimmt) die charakteristische Torusbildung den Autoren nicht aufgefallen war, lässt sich nur dadurch crklären, dass die als Salix von Alters her überkommene Pflanze noch eine Menge anderer, schon beim ersten Anblicke in die Augen springender, eigenthümlicher Merkmale darbot, und daher die Angabe einiger weniger derselben schon hinreichte, um sie ron den andern Arten, mit denen sie durch $\mathrm{Koch}$ und $\mathrm{Fries}$ in die so unnatïliche Gruppe: Glaciales zusammengewürfelt worden war, zu unterscheiden, und daher ein Eingehen auf Merkmale, die erst bei näherer Zergliederung wahrnehmbar werden, überflüssig schien.

Nach unserem Dafürhalten ist Chamitea ron Salix eben so gut zu trennen wie ron Populus, und die nachstehende Tabelle möge die wesentlichsten Merkmale der drei Gattungen der Salicineen vorführen :

\section{Salix. | Chamitea.}

Folia penninerria, breviter Folia nervigera, mediocri- Folia nervigera vel pennivel brevissime petiolata. ter vel longe petiolata.

Squamae amenti luteo-Squamae amenti rosaceae Squamae amenti luteorirides unicolores, rel unicolores, integerrimae. versus apicem coloratae: rubiginosae, purpureae et atratae, integerrimae.

Torus in glandulam uni-Torus in urceolum laci-Torus in urceolum intecam internam vel in niatum tumens. glandulas duo: alteram externam, alteram internam tumens. nervia, mediocriter vel longe petiolata. virides, rubiginosae vel rufae, crenatae vel digitato-laciniatae.

grum, oblique truncatum tumens.

Die Rotte der Purpurweiden und Moorweiden betrachten wir aus den oben Seite 43 erörtertem Grunde als die Grenzglieder der Salicineen. Sie besitzen ebenso wie die Rotten der Abtheilungen: Microstulae und Macrostylae an den Staub- und Fruchtblüthen nur eine innere, drüsenfürmige Verlängerung des Torus. Bei den Weidenrotten: Retusae, Amygdalinae und Albae findet sich an den Fruchtblïthen noch dasselbe Verhältniss, die Staubblüthen zeigen aber schon eine zweite, kleine, äussere Drüse, und bei der Rotte: Fragiles haben sowohl Frucht-, wie Staubblüthen eine innere und äussere Drüse des Torus aufzuweisen. - Bei der Gattung Chamitea entwickelt sich der Torus zu einem die Insertionsstelle des Fruchtknotens oder der Staubgefässe rings umwachsenden, kurzen, gelappten Becher und bei 
der Gattung Populus stellt er endlich eine abgestutzte, nicht zerschnittenc, becherförmige Verlängerung dar.

1. CF. Petecelete. - Anenta serotina, in ramulo tri - quadrifoliato, gemmifero, superne nudo, longissime pedunculata, recta, pistilligera densiflora, staminigera laxiora, bis - quater longiora quam latiora. Squamac unicolores rosaceae, rotundatae, cxtus subglabrae, intus breviter villosae. Torus in urceolum laciniatum tumens, laciniis basin germinis superantibus. Germen sessile, oratum, cano-tomentosum. Stylus brevissimus. Stigmata divergentia, patula, biloba, purpurea. Stamina duo, antheris ante anthesin purpureis, serius nigricantıbus, filamentis liberis, rubescentibus, in basi pilosis. Valrae capsulae purpurascentes, post dehiscentiam extrorsum arcuatae. Folia coriacea, nerrigera, mediocriter vel longe petiolata, elliptica rel orbiculata, obtusa, in basi rotundata rel subcordata, margine deflexa, adolescentia pilis longis sericeis restita, adulta glaberrima, supra obscure viridia, subtus albido-glauca. Nerri $5-7$ in pagina inferiori prominentes, plerumque sicut petiolus rubescentes et cum renis reticulum elegantissimum constituentes, in pagina superiori lineis impressis significati, quare folium rugulosum. Ramuli castaneo-rufescentes, glaberrimi.

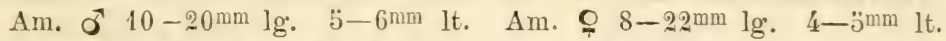
Squam. $1 \mathrm{~mm}$ lg. Germ. 1-1..̈mm lg: Stam. $2-3^{\mathrm{mm}} \mathrm{lg}$.

Fol. $12-46 \mathrm{~mm} \lg .10-32 \mathrm{~mm}$ lt.

S. reticulata L. sp. 146, Host Salix p. 33. tab. 103. Koch Syn. 570. Fries Nov. fl. suec. M. I. p. 73. Herb. norm. Fasc. IX. Nr. 62. W imm. Herb. Sal., Nr. 8 et 93, Neilr. Fl. v. N. Oest. p. 266.

Zierlicher Strauch mit sparrigen, fast rechtwinklig sich abzweigenden Aestchen und knorrigem, niederliegendem Stamme, der als grüssten Durehmesser 1 Centim. zeigt und dann 18-20 Jahresringe aufweist. Die Rinde der 1-3jälhrigen Aestchen ist kastanienbraun, glänzend und kahl, im 4. Jahre wird sie jedoch runzelig, matt und graubraun. Die zweijährigen Aestchen entwickeln an geeigneten Stellen reichliche Adrentirwuzeln. Die Knospen sind glänzend gelb, länglich eifö:mig und verhältnissmässig sehr gross $\left(4-8^{\text {nm }}\right.$ lg. $3-4^{\mathrm{mm}}$ 1t.). Die Knospendeckicn bleiben manchmal bis zur Blüthezeit an der Basis des herrorgesprossten Aestchens haften, so dass sie die Sticle der unteren Blätter fast scheidig umfassen. Die Blattstiele sind rinnig, an der Basis etwas verbreitert, purpurioth überlaufen und entweder halb so lang als der Längendurchmesser des Blattes, oder bei runder Blattform fast gleichlang und daher die Blätter entweder mittelmäsig oder lang gestielt, durch welches Merkmal Chamitea ein ron dem Weidentypus ganz und gar abweichendes Aussehen erhält, da auch die kleinen Alpenweiden (S. retusa, herbacea, polaris) sehr kurzgestielte Blätter besitzen. - Nur an sehr üppigen Sprossen finden sich an der Stelle der zwei Nebenblätter zwei kleine, purpurrothe Drïsen. - Die Blätter wechseln in ihrem Zuschnitt rom 
länglich elliptischen bis zuin kreisrunden. Ihr äusserster Rand ist umge_ bogen und bei der in Niederösterreich vorkommenden und auch anderwärts auf Kalkboden wurzelnden Form drüsenlos und ungezähnt. Auf Schieferunterlage zeigt jedoch der Rand gewöhnlich kleine, drüsige Ansätze, die namentlich gegen die Basis zu, deutlich wahrnehmbar sind. Es wiederholt sich demnach hier das bei anderen Alpenweiden beobachtete, Seite 23 besprochene Verhalten und es zerfällt auch Chamitea reticulata in eine Kalkund Schiefer-Parallelform, ' von welchen sich die erstere:

1. isetegrifolia durch rollkommen ganzrandige, zeitlich kahl werdende Blätter, schwächer behaarte Kätzrhenschuppen und frühzeitig abfallende Knospendecken auszeichnet, während

2. vestita (Pursh Fl. Amer. septentr. II. p. 610.) sich durch die an der Basis mit Drüschen besetzten, noch zur $Z$ eit der vollen Blïthe dicht seidig zottigen Blätter, dichter bekleidete Kätzchenschuppen und die stehenbleibenden, die Basis der Blätter scheidig umfassenden, grossen Knospendecken unterscheidet.

Letztere ist in Niederösterreich nicht aufgefunden. Aus den Centralalpen liegen uns jedoch Exemplare derselben ror, welche mit Lappländischen vollkommen übereinstimmen und ron Sauter wurde diese Form schon in der Flora 18:9, p. 662, als von Mielichhofer in den SalzburgerAlpen gefunden, angegeben.

Die Blätter beider Parallelformen sind benervt. Die zwei oder drei unterhalb der Mitte des Blattes unter Winkeln ron $30-40^{\circ}$ entspringenden Seitennerrenpaare sind nämlich verlängert, riel dicker als die noch weiter iiber der Mitte aus dem Mittelnerv herrorkommenden, schwachen Nervchen, und kommen der oberen Hälfte des Mittelnerrs an Stärke gleich. Von den Weiden hat nur $S$. herbacea bei den rundblättrigen Formen manchmal eine ähnliche Nerratur, alle anderen Weidenarten aber sind fiedernervig. Desto häufiger erscheirien benerrte Blätter bei den Pappeln, mit deren Blättern die Blätter ron Chamitea auch durch die reilängerten Stiele übereinkommen. Die $\ddot{3}$ oder 7 fast fächerförmig die Blattfläche durchzichenden Hauptnerven sind durch zahlreiche, kräftige Anastomosen zu einem grossmaschigen, meist rosaroth oder purpurn gefärbten Netze verbunden, das sich aus der weisslichen Grundfarbe der unteren Seite höchst zierlich heraushebt*). An der oberen, dunkelgrïnen, fast glanzlosen Blattseite ist das Nerrennetz durch

*j Seringe macht auf die sehr eigeuthümliche Tervatur mit den Worten aufmerksam: „face infér. d'un blanc gris, relevée de nervures rougeâtres très saillantes, longitudinales, presquue comme dans lez feuilles des monocotylédonnées. - Saules de la Suisse p. æฌ. 
rertiefte Linien angedeutet, und daher das Blatt runzelig. In der Jugend ist der Blattstiel so wie die untere Blattläche mit langen, weichen, seidigglänzenden Haaren bedeckt. Zur Zeit der Blüthe aber sind die Blätter bei der Var. 1. integrifolia vollkommen kahl, - bei der Parallelform Tar. 2. vestita hingegen bleibt die Behaarung bis zur Fruchtreife. - Im Verwelken werden die Blätter braun. - Von den Knospen in den Achseln der 3-4 Blätter eines Sprosses kommen selten mehr als zwei, gewöhnlich nur eine (nämlich die oberste laterale) zur weiteren Entwicklung. Da die 3 oder 4 Blätter ziemlich gedrängt an der unteren Hälfte des Sprosses sitzen, dessen Abschluss das Kätzchen bildet, die obere Hälfte aber nackt ist, so erscheint das Kätzchen lang gestielt. - - Die Staubkätzchen, so wie die Fruchtkützchen sind schmal, walzlich, 20-80blüthig, ihre Blüthen sind gewöhnlich in 6 Zeilen angeordnet und stehen bei den Staubkätzchen etwas lockerer, bei den Fruchtkätzchen aber immer dicht und geschlossen. Die rosafarbigen Kätzchenschuppen sind fast kreisrund, ganzrandig, an der äusseren Seite kahl, an der inneren Seite aber immer kurzhaarig oder dicht zottig. Erwähnenswerth ist hiebei, dass, wie schon Seringe (a. a. O. S. 28.) bemerkt, die Schuppen, welche die Staubblüthen stützen, immer riel stärker zottig sind als jene der Stempelblüthen. - Der Torus bildet einen becherförmigen Kranz gelber, fleischiger, über die Basis des Fruchtknotens hinausreichender Lappen. Die Staubfäden sind röthlich, an der unteren Hälfte gewimpert, die Antheren rundlich, vor und während dem Blühen purpurroth, nach dem Abblühen schwarz. - Der sitzende oder sehr kurzgestielte Fruchtknoten ist eifürmig, stumpf, ron aufrecht abstehenden Härchen weissfilzig, glanzlos. Der sehr kurze Griffel theilt sich in zwei bogenförmig auseinanderlaufende, abstehende, zweispaltige, purpurrothe Narben. Die Kapsel, die gewöhnlich purpurn überlaufen erscheint, ist eifürmig $3 \mathrm{~mm}$ lang. Ihre Klappen sind nach dem Aufspringen nur wenig sichelförmig auswärtsgekrümmt. An dem Mittelnerr jeder Klappe sitzen nahe gegen den Grund zu, 3-ö lincale $1^{\mathrm{mm}}$ lange Samen, die von dem fast dreimal so langen Haarschopf umhüllt sind.

Die Zwergweide ist fast durch alle Hochgebirge der nördlichen Halbkugel, so wie auch durch die arktische Zone der alten und neuen Welt rerbreitet, findet sich noch nürdlich rom Polarkreise (Grönland, Lappland) und erreicht ihre nördliche Grenze erst auf Port Bowen siidwestlich von der Melville-Insel.

In Europa findet sie sich auf den Hochgebirgen der Mittelmeerzone, dann in den Alpen, Karpathen, in den schottischen und skandinarischen Hochgebirgen bis Island und Lappland. Sie fehlt in den Sudeten.

Ihre untere Grenze fällt in Schottland auf $1900^{\prime}$, in den bairischen Alp?n auf $52: 50^{\prime}$, in den niederösterreichischen Alpen auf $4: 30$. (In den Centralalpen scheint ihre untere Grenze tiefer zu liegen. Zahlbruckner gibt dieselbe dort auf $4000^{\prime}$, Unger auf $4600^{\circ}$ an.) - Thre obere Grenze wird in den französsschen Alpen von De-Candolle auf $8000^{\circ}$ angegebeu, in 
Baiern fällt sie nach Sendtner auf $7000^{\prime}$, in den niederösterreichischen Alpen findet sich $C h$. reticulata bis auf die hüchsten Kuppen der Kalkalpen der Raxalpe des Schneeberges und Oetschers zu 6̈366. Doch ist diese Iühe nicht als ihre obere Grenze anzusehen, da sie auf den benachbarten, höheren Kalkalpen Steiermarks auf den IIühen des Hochschwabes noch bei $7000^{\prime}$ angetroflen wird. Sie bildet in der nürdlichen Kalkalpenkette einen wesentlichen Bestandtheil jener Pflanzenformation, die bei S. retusa bereits ihre Erwähnung gefunden.

\section{I n d e $x$.}

\section{Chamitea}

reticulata 133.

\section{Sntix}

acuminata Hoffm. 93.

acuminata Koch 91, 93.

acuminata Smith 93, $9 \ddot{3}$.

alba L. 6 .

alopecuroides Tausch 68 .

alpestris Host 84 .

ambigua Ehrh. 143, 144.

amygdalina Koch 70.

amygdalina L. 70.

amygdalino-fragilis Neilr. 68. amygdalina-fragilis Wimm. 68 . angustifolia Fries 96 .

angustifolia Tulf. 145.

arbuscula L. 84.

argentea Sm. 146.

attenuata 124.

aurita Host 117.

aurita L. 131.

aurita-repens Wirum. 143.

auritoides 133 .

austriaca Host 137.

bicolor Ehrh. 84, 86.

bijida Tulf. 103.

Blyttii 88.

cacsia Vill. 83.

\section{Salix}

Canthiana 96.

capraeformis Wimm. 95.

Caprea L. 125.

Caprea-cinerea Wimm. 128.

Caprea-dasyclados Wimm. 93.

carniolica Host 130.

cinerea Host 110.

cinerea L. 128.

cinerea Willd. 110.

cinerea-aurita Wimm. 131.

cinerea-incana Wimm. Flora 1848 . 101.

concolor Host 98, 100.

coruscans Host 84, 113.

cuspidata Schultz 59.

daphnoides Vill. 109.

dasyclados Wimm. 93, 94.

dasyclados-riminalis Wimm. 94.

discolor Host 140.

elaeagnifolia Tausch 97.

excelsa Tausch 62 .

excelsior. Host 63.

Fenzliana 73.

flarescens Host 84.

Forbyana Sm. 99.

fragilior Host 62 .

fragilis Host 60 .

fragilis L. 62 . 


\section{G117x}

fragilis Fries $6 \ddot{3}$.

fragilis-alba Wimm. 6 .

fragilissima Host 62.

fragilis-triandra Wimm. 68.

Friesii 61.

glabra Scop. 113.

g'lauca L. 88.

glaucescens Host 117.

grandifolia Ser. 120,

hastata L. 119.

hastata-silesiaca Wimm. 120.

heliciflora Tausch 100.

Helix Host 130.

Helix L. 98, 150.

Helix Tausch 150.

helvetica Vill. 88.

herbacea L. 79.

heterophylla Host 132.

hippophaëfolia Thuillier 90.

Hoffmanniana Tausch 98.

holosericea Seringe 101.

Hostii 91:

Jacquiniana Host 81.

incana Schrank 104.

incana-Caprea Wimm. 101.

incana-cinerea Wimm. Flora 1849. 102.

incana-daphnoides Wimm. 108.

incano-purpurea Neilr. 104.

incana-purpurea Wimm. 104.

incubacea L. 14 .

intermedia Host 102.

Kanderiana Seringe 101.

Kitaibeliana Milld. 76.

Kovátsii 68.

lanceolata Fries 93, 95.

lanceolata Seringe 101.

Lapponum L. 88.

ligustrina Host 71 .

longifolia Host 91, 93.

lutescens 131.

macrophylla 12:3.

\section{Srtix}

Mautemensis 139.

menthaefolia Host 117.

mirabilis Host 132 .

mollissima Ehrh. 90.

monandra Host 120.

mutabilis Host 150.

Myrsinites L. 81.

myrtilloides L. 149.

Neilreichii 136.

Neisseana 9ö.

nigricans. Sm. 116.

nitens Gr. et Godr. 9̋̈.

oleifolia Host 140.

oppositifolia Host 130.

orata Host 117.

palustris Host 64 .

parietariaefolia Host 117.

parviflora Host 149.

pentandra L. 0 7.

pentandra-fragilis Wimm. 59. phylicifolia Koch coimm. 116.

phylicifolia L. 84, 116.

plicata Fries 142.

Pokornyi 59.

polaris Wahlbg. 83.

polymorpha Host 128, 129.

Pontederae Vill. 137.

Pontederana Bertol. 137.

Pontederana Schleicher 138.

praecox Willd. 110.

pratensis Host 14', 143.

prunifolia Host 117.

pulchella Host 84.

purpurea L. 150.

purpurea-aurita Winm. $13 \ddot{.}$

purpurea-Caprea Wimm. 140.

purpurea-cinerea Wimm. 136.

purpurea-grandifolia Wimm. 138.

purpurea-nigricans Wimm. 141.

purpureo-repens Neilr. 149.

purpurea-repens $\Pi$ imm. 149.

purpurea-riminalis Wimm. 98. 


\section{Sritix}

pyrenaica Fries 88.

pyrenaica Gouan. 88.

Reichardtii 127.

repens L. 145.

reticulata L. 153.

retusa L. 74.

riparia Willd. 105.

rivalis Host 117.

rosmarinifolia Koch $\mathbf{1 4 4 .}$

rosmarinifolia L. 96, 145.

rosmarinifolia Wulf. 145.

rubra Huds. 98.

Russeliana Sm. 6 . .

semperflorens Host 72.

sericans Tausch 92.

Seringiana Gaud. 100.

serpyllifolia Scop. 76.

silesiaca Willd. 123.

sordida 135.

speciosa Host 68.

spectabilis Host 70, 73.

stipularis Sm. 91, 95.

subalpina 103.

subglabra 115.

\section{Sritix}

subtriandra Neilr. 67.

tenuis Host 145.

tetandra L. 59.

triandra L. 71.

undulata Ehrh. 90 .

Vundensis Forbes 141.

varia Host 72.

renusta Host 72.

vestita Pursh 156.

viminalis L. 89.

viminalis-Caprea Wimm. 92, 93. viminalis-cinerea Wimm. 95, 96.

viminalis-dasyclados Wimm. 95. viminalis-purpurea Wimm. 100. viminalis-repens Wimm. 97. viridis Fries 64. vitellina Host 66 . Vratislaviana 92, 94.

Waldsteiniana Willd. 84.

Weigeliana Willd. 86.

Wimmeri Kerner 108.

Wulfeniana Host 113.

Zedlitziana 95 .

\section{Corrigenda.}

Seite 3 Zeile 2 statt Salicis: "Salices"

\begin{tabular}{|c|c|c|c|}
\hline 62 & 22 & $"$ & fragilis: "fragilior" \\
\hline 63 & 24 & $\eta$ & gestielte : „länger gestielte" \\
\hline 80 & 32 & $\eta$ & Jaquin: "Jacquin" \\
\hline 81 & $\because \cdot 13$ & $"$ & Jaquiniana: "Jacquiniana" \\
\hline 88 & m. 12 & $"$ & pyrenica: "pyrenaica" \\
\hline 117 & 1 & $"$ & variabilis salix: "variabilis frute ${ }^{6}$ \\
\hline 136 & 3 & $\pi$ & ter: "bis". \\
\hline
\end{tabular}






\section{New York Botanical Garden Library}

QL $72.53 \mathrm{~K} 4$

Kerner, Anton Josep/Niederosterreichisch gen 1

35185000612943 
